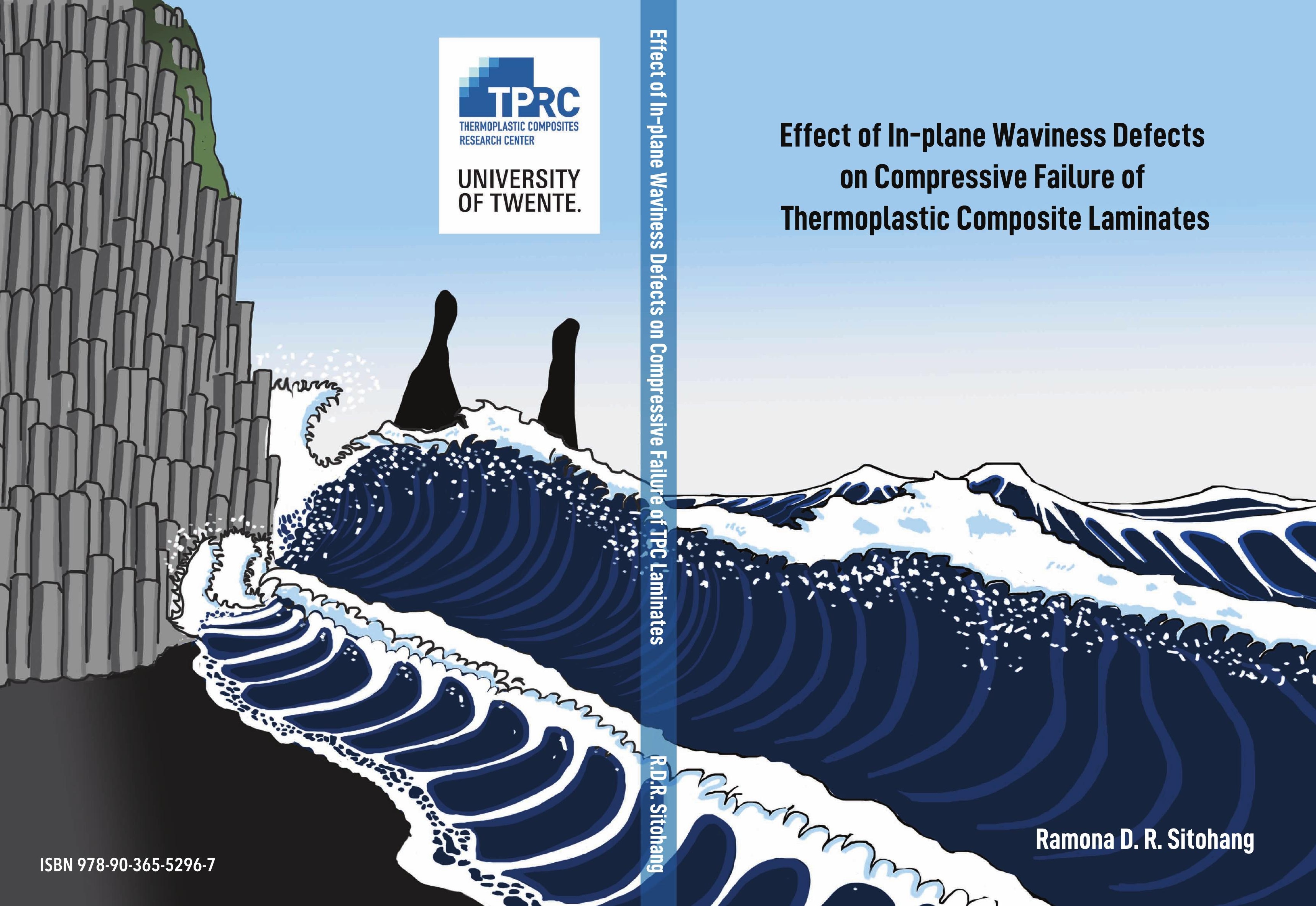




\section{EFFECT OF IN-PLANE WAVINESS DEFECTS ON COMPRESSIVE FAILURE OF THERMOPLASTIC COMPOSITE LAMINATES}

Ramona D. R. Sitohang 



\title{
EFFECT OF IN-PLANE WAVINESS DEFECTS ON COMPRESSIVE FAILURE OF THERMOPLASTIC COMPOSITE LAMINATES
}

\author{
PROEFSCHRIFT
}

ter verkrijging van

de graad van doctor aan de Universiteit Twente, op gezag van de rector magnificus, prof. dr. ir. A. Veldkamp,

volgens besluit van het College voor Promoties in het openbaar te verdedigen

op donderdag 27 januari 2022 om 14:45 uur

door

Ramona Delphine Romian Sitohang

geboren op 12 februari 1990

in Bandung, Indonesië 
Dit proefschrift is goedgekeurd door:

Promotor

prof. dr. ir. R. Akkerman

Co-promotor

dr. ir. L. L. Warnet

Cover design: artwork by Primuda Immanuel Sitohang

Printed by: Gildeprint, Enschede, The Netherlands

ISBN: 978-90-365-5296-7

DOI: $10.3990 / 1.9789036552967$

The illustration on the cover shows waves crashing against the basalt columns wall at Reynisfjara black sand beach in Iceland. The basalt stone columns resemble the terraces of microbuckled fibers shown in the scanning electron micrograph in Chapter 3.

(c) 2022 Ramona Delphine Romian Sitohang, The Netherlands. All rights reserved. No parts of this thesis may be reproduced, stored in a retrieval system or transmitted in any form or by any means without permission of the author. Alle rechten voorbehouden. Niets uit deze uitgave mag worden vermenigvuldigd, in enige vorm of op enige wijze, zonder voorafgaande schriftelijke toestemming van de auteur. 


\section{PROMOTIECOMMISSIE:}

Voorzitter / secretaris:

Promotor:

Co-promotor:

Leden: prof. dr. ir. H. F. J. M. Koopman

prof. dr. ir. R. Akkerman

dr. ir. L. L. Warnet

prof. dr. C. Bisagni

prof. dr. I. M. Gitman

prof. dr. ing. S. Thiede

prof. dr. ir. L. J. Sluys

This research was financially supported by the Topsector HTSM, the ThermoPlastic composite Research Center (TPRC), and the University of Twente, within the Connecting Industries framework. 



\section{Summary}

Defect-free manufacturing of parts and structures based on advanced materials can be challenging. Thermoplastic composites form no exception. In particular, processinduced in-plane fiber waviness is worrisome as it is often difficult to prevent, while it may have a detrimental effect on the mechanical performance. Often in practice, the part is rejected when the effect of the defect is unknown. A proper understanding and quantification of the effect of in-plane waviness on the mechanical performance are therefore required. Earlier studies, mainly on unidirectional composites, showed that the compressive strength is especially sensitive to waviness. To confirm whether this translates to multidirectional thermoplastic composites, this thesis investigates the effect of in-plane waviness on the compressive failure of quasi-isotropic laminates.

The objectives of this work are $i$. to develop a methodology to measure the effects of waviness on the mechanical performance, $i i$. to identify the mechanisms leading to failure, and iii. to quantify the effect of in-plane fiber waviness on the laminate's compressive strength. Reverse forming and press consolidation were used to manufacture well-defined test coupons, having waviness with a wide range of severities that reflect those seen in manufacturing. Uniaxial compression and bending tests were used to study the compressive damage development and to quantify the strength.

Localized in-plane waviness in the plies that are oriented in the loading direction can have a pronounced adverse effect on compressive strength due to early damage initiation which is governed by kinking failure. Two parameters, namely the maximum waviness angle and number of wavy plies in the loading direction, play an important role in the compressive damage development and strength. It was experimentally demonstrated that the compressive strength initially decreases with increasing maximum waviness angle and tends to level off for angles larger than $20^{\circ}$. Increasing the number of wavy plies in the loading direction has a similar degrading effect on the strength. The reduction is linearly proportional to the fraction of wavy axial plies, which means that the intact axial plies govern the ultimate strength. Between the two waviness parameters, the latter is the most influential on the ultimate strength. Lastly, the implication on the design of aircraft structures was evaluated by comparing the results from this work with the reference open-hole compressive strength retention. This work shows that, for the material system and the severity studied, the existing design value derived from open-hole compressive strength can accommodate the reduction due to waviness. 



\section{Samenvatting}

Defect-vrije productie van onderdelen en constructies op basis van geavanceerde materialen kan een uitdaging zijn. Thermoplastische composieten vormen daarop geen uitzondering. Met name procesgeïnduceerde vezelgolvingen in het vlak zijn zorgwekkend omdat deze vaak moeilijk te voorkomen zijn, terwijl ze wel een nadelig effect kunnen hebben op de mechanische eigenschappen. Wanneer het effect van deze defecten onduidelijk is, zal het eindproduct niet in gebruik worden genomen. Een goed begrip en kwantificering van de mate van vezelgolving in het vlak, en het effect op de mechanische eigenschappen van het eindproduct, is daarom vereist. Eerdere studies, voornamelijk op unidirectionele composieten, laten zien dat in het bijzonder de sterkte onder compressiebelasting gevoelig is voor de aanwezigheid van vezelgolvingen. Hoe deze gevoeligheid zich vertaalt naar multi-directionele thermoplastische composiet laminaten is onderwerp van dit proefschrift.

De doelstelling van dit proefschrift is drieledig en omvat $i$. het ontwikkelen van een meetmethodologie voor vezelgolvingen en het effect daarvan op de sterkte, $i$. het identificeren van de mechanismen welke leiden tot falen, en iii. het kwantificeren van de invloed van vezelgolvingen op de compressiesterkte van laminaten van thermoplastisch composiet. Proefstukken zijn gefabriceerd middels persconsolideren en het terugvouwen van reeds geperste laminaten. Hierdoor was het mogelijk om een brede variëteit aan procesrelevante vezelgolvingen te creëren. Uniaxiale compressieen buigtesten zijn gebruikt om de schadeinitiatie en -progressie te bestuderen en de sterkte te kwantificeren.

Lokale vezelgolving in lagen welke geörienteerd zijn in de belastingsrichting kunnen een uitgesproken negatief effect hebben op de compressiesterkte. Het onderliggende knikfalen zorgt voor een vroege initiatie van schade. Twee parameters, te weten de maximale afwijking ten opzichte van de gewenste vezeloriëntatie en het aantal aangetaste lagen waarvan de vezels in de belastingsrichting liggen, spelen een belangrijke rol in de ontwikkeling van schade onder drukbelasting en de bijbehorende afname van de sterkte. De druksterkte neemt intieel snel af met toenemende vezelorientatieafwijking en bereikt een plateauwaarde voor afwijkingen groter dan $20^{\circ}$. Het vergroten van het aantal aangetaste lagen waarvan de vezels in de belastingsrichting liggen heeft een vergelijkbaar verslechterend effect op de sterkte. De sterktereductie schaalt lineair met de ratio van lagen met golvende vezels ten opzichte van het totaal aantal lagen, hetgeen suggereert dat het aantal intacte lagen de uiteindelijke sterkte bepaalt. Van de genoemde twee parameters, heeft het aantal defecte lagen heeft 
de grootste invloed op de uiteindelijke sterkte van het laminaat. Ten slotte zijn de bevindingen in breder perspectief geplaatst door de gevonden sterktes te vergelijken met de zogenaamde open-hole compressiesterkte, die vaak gebruikt wordt als ontwerpcriterium. Hieruit blijkt dat, voor het bestudeerde materiaalsysteem en de onderzochte defectgrootte, het huidige ontwerpcriterium toereikend is om het negatieve effect van vezelgolving mee te nemen. 


\section{Nomenclature}

The symbols used in this thesis are classified into a Roman or a Greek symbol group. Although some symbols can represent multiple quantities, its intended meaning follows from the textual context.

\section{Roman symbols}

$\begin{array}{ll}A & \text { amplitude } \\ b & \text { specimen width } \\ d_{11} & \text { element of laminate bending compliance matrix } \\ E_{11}, E_{22}, E_{33} & \text { elastic modulus in the principal directions of lamina } \\ E_{f} & \text { flexural secant modulus } \\ f_{s} & \text { sampling frequency } \\ F_{12} & \text { Tsai-Wu interaction coefficient } \\ G_{12}, G_{13}, G_{23} & \text { shear modulus of lamina } \\ \mathrm{h} & \text { V-bend height } \\ h & \text { specimen thickness } \\ L & \text { support span length } \\ L_{\mathrm{W}} & \text { distance between the outermost edges of a wavy region } \\ M_{x} & \text { bending moment per unit width } \\ m & \text { slope of the secant of the force-deflection curve } \\ N & \text { number of blocks } \\ n & \text { number of tested specimens } \\ P & \text { force } \\ Q_{11} & \text { element of the lamina stiffness matrix } \\ R_{\text {inner }} & \text { inner radius } \\ S_{1} & \text { top arc path length } \\ S_{2} & \text { bottom arc path length } \\ S_{c 1} & \text { compressive strength in the fiber direction } \\ S_{c 2} & \text { compressive strength in the transverse direction } \\ S_{t 1} & \text { tensile strength in the fiber direction } \\ S_{t 2} & \text { tensile strength in the transverse direction } \\ S_{s 12} & \text { lamina in-plane shear strength } \\ x_{\mathrm{a}} & \text { horizontal coordinate of fiber segment at point a }\end{array}$

$[\mathrm{m}]$
$[\mathrm{m}]$
$\left[1 / \mathrm{m}^{3} \cdot \mathrm{Pa}\right]$
$[\mathrm{Pa}]$
$[\mathrm{Pa}]$
$[1 / \mathrm{m}]$
$[-]$
$[\mathrm{Pa}]$
$[\mathrm{m}]$
$[\mathrm{m}]$
$[\mathrm{m}]$
$[\mathrm{m}]$
$[\mathrm{N} \cdot \mathrm{m} / \mathrm{m}]$
$[\mathrm{N} / \mathrm{m}]$
$[-]$
$[-]$
$[\mathrm{N}]$
$[\mathrm{Pa}]$
$[\mathrm{m}]$
$[\mathrm{m}]$
$[\mathrm{m}]$
$[\mathrm{Pa}]$
$[\mathrm{Pa}]$
$[\mathrm{Pa}]$
$[\mathrm{Pa}]$
$[\mathrm{Pa}]$
$[\mathrm{pixel}]$




$\begin{array}{llr}x_{\mathrm{b}} & \text { horizontal coordinate of fiber segment at point } \mathrm{b} & \text { [pixel] } \\ y_{\mathrm{a}} & \text { vertical coordinate of fiber segment at point a } & \text { [pixel] } \\ y_{\mathrm{b}} & \text { vertical coordinate of fiber segment at point } \mathrm{b} & \text { [pixel] } \\ x, y & \text { in-plane coordinate } & \text { [m] } \\ z & \text { out-of-plane coordinate } & \text { [m] }\end{array}$

\section{Greek symbols}

$\epsilon_{x} \quad$ longitudinal strain

$[-]$

$\kappa_{x} \quad$ curvature along the $x$-axis

$[1 / \mathrm{m}]$

$\lambda \quad$ wavelength

$[\mathrm{m}]$

$v_{12}, v_{13}, v_{23}$ Poisson's ratio of lamina

$[-]$

$\sigma_{c} \quad$ apparent compressive strength of a rotated ply

$[\mathrm{Pa}]$

$\sigma_{11} \quad$ longitudinal stress in the principal material coordinate system

$[\mathrm{Pa}]$

$\sigma_{22} \quad$ transverse stress in the principal material coordinate system

$[\mathrm{Pa}]$

$\theta \quad$ fiber orientation angle

$\theta_{\max } \quad$ maximum waviness angle

$\tau_{12}$ in-plane shear stress in the principal material coordinate [Pa] system

\section{Abbreviations}

$\begin{array}{ll}\text { 2D } & \text { two dimensional } \\ \text { 3D } & \text { three dimensional } \\ \text { 3PB } & \text { three-point bending } \\ \text { 4PB } & \text { four-point bending } \\ \text { AE } & \text { acoustic emission } \\ \text { CS } & \text { coordinate system } \\ \text { CT } & \text { computed tomography } \\ \text { CLC } & \text { combined loading compression } \\ \text { CLT } & \text { classical laminate theory } \\ \text { CNC } & \text { computer numerical control } \\ \text { C/PEEK } & \text { carbon fiber / Polyether ether ketone } \\ \text { C/PPS } & \text { carbon fiber / Poly(phenylene sulphide) } \\ \text { CFRP } & \text { carbon fiber reinforced plastic } \\ \text { DIC } & \text { digital image correlation } \\ \text { ELB } & \text { end-loaded bending } \\ \text { FE } & \text { finite element } \\ \text { FI } & \text { failure index } \\ \text { FEA } & \text { finite element analysis }\end{array}$


HSC high-speed camera

HRMA high resolution misalignment analysis

MD multidirectional

$\mathrm{OHC}$ open-hole compressive

PC press consolidation

PEEK poly(ether ether ketone)

$\mathrm{RF} \quad$ reverse forming

ROI region of interest

RVE representative volume element

SD standard deviation

SEM scanning electron microscope

TPC thermoplastic composite

TPRC thermoplastic composites research center

TSC thermoset composite

UD unidirectional

UNC unnotched compressive

QI quasi-isotropic 



\section{Contents}

Summary i

Samenvatting $\quad$ ii

$\begin{array}{ll}\text { Nomenclature } & \mathbf{v}\end{array}$

1 Introduction $\quad 1$

1.1 Background and motivation . . . . . . . . . . . . . . 1

1.2 Waviness defects in thermoplastic composites . . . . . . . . . . 2

1.3 Effect of waviness on mechanical properties . . . . . . . . . . . 3

1.4 Objectives and scope . . . . . . . . . . . . . . . . 6

1.5 Outline and approach $\ldots \ldots \ldots \ldots \ldots$

2 Reverse forming method to reproduce waviness in test coupons 13

2.1 Introduction . . . . . . . . . . . . . . . . . . . . 14

2.2 Experimental methods . . . . . . . . . . . . . . 17

2.2 .1 Materials . . . . . . . . . . . . . . . 18

2.2 .2 Press consolidation . . . . . . . . . . . . . . . 18

2.2 .3 Stamp forming ...................... 18

2.3 Assessment methods . . . . . . . . . . . . . . . . . . . 20

2.3.1 Characterization methods . . . . . . . . . . . . . . . 21

2.3.2 Waviness parameters measurement from surface micrography . 22

2.4 Results ........................ 25

2.5 Discussion . . . . . . . . . . . . . . . . . 30

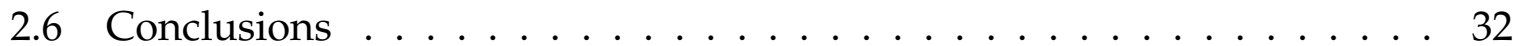

3 Effect of waviness on compressive properties of laminates 37

3.1 Introduction . . . . . . . . . . . . . . . . . . . 38

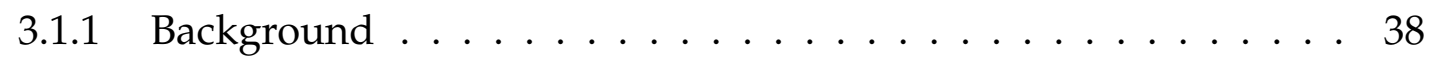

3.1 .2 Literature review . . . . . . . . . . . . . . . 39

3.1.3 Objectives and approaches ................ 40 
3.2 Experimental procedure . . . . . . . . . . . . . . . . . 41

3.2.1 Material and specimens . . . . . . . . . . . . . 41

3.2.2 Measurement of in-plane waviness severity . . . . . . . . . . . . . 42

3.2.3 Compression tests . . . . . . . . . . . . . . . 43

3.3 Results and discussion . . . . . . . . . . . . . . . . 44

3.3.1 Measured waviness parameters . . . . . . . . . . . . . . . . 44

3.3.2 Effect of fiber waviness on stiffness . . . . . . . . . . . . . 45

3.3.3 Damage development . . . . . . . . . . . . . 46

3.3.4 Effect of fiber waviness on strength . . . . . . . . . . 52

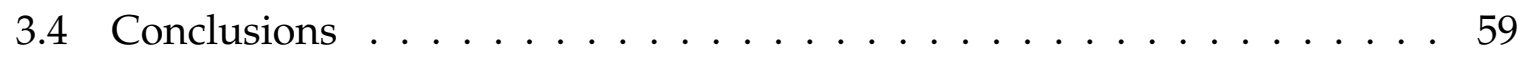

4 Relation between waviness severity and first ply failure 63

4.1 Introduction . . . . . . . . . . . . . . . . . 64

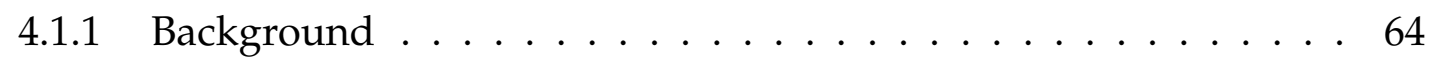

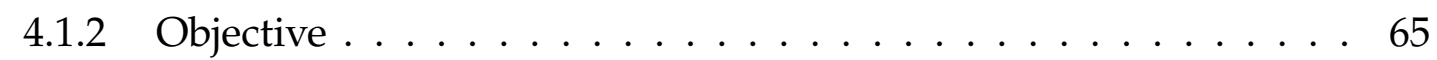

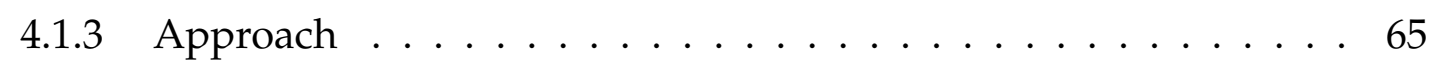

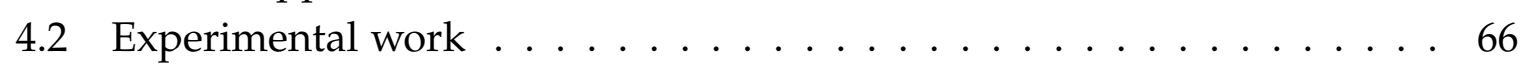

4.2.1 Material and specimens . . . . . . . . . . . . 66

4.2.2 Characterization of waviness parameters . . . . . . . . . 68

4.2.3 Mechanical testing procedure . . . . . . . . . . . . 70

4.3 Results and discussion . . . . . . . . . . . . . . . . 73

4.3.1 Waviness characterization results. . . . . . . . . . . 74

4.3.2 Bending test results of baseline samples . . . . . . . . . . 76

4.3.3 Bending test results of samples with waviness . . . . . . . . . 79

4.3.4 The relation between waviness parameters, stress at first failure, and failure mechanisms . . . . . . . . . . . 81

4.4 Conclusions . . . . . . . . . . . . . . . . . 86

5 Influence of waviness severity on compressive failure: a theoretical analysis 91

5.1 Introduction . . . . . . . . . . . . . . . . . . . . 92

5.2 Finite element model description . . . . . . . . . . . . . . . . 93

5.3 FE analysis results and discussion . . . . . . . . . . . . 97

5.3.1 Local stress state in the wavy ply . . . . . . . . . . . . 97

5.3 .2 Failure analysis . . . . . . . . . . . . . . . . 100

5.4 Analytical model description . . . . . . . . . . . . . . . . . 103

5.4 .1 First ply failure . . . . . . . . . . . . . . . . 104

5.4 .2 Ultimate failure . . . . . . . . . . . . . . . . 104

5.5 Analytical modeling results and discussion . . . . . . . . . . . 106 
5.5.1 Local stress state of the rotated wavy ply . . . . . . . . . . . 106

5.5 .2 First-ply failure stress . . . . . . . . . . . . . . . . . 107

5.5 .3 Ultimate strength . . . . . . . . . . . . . . . . . 108

5.6 Conclusions . . . . . . . . . . . . . . . . . . . . 110

5.A Mesh refinement analysis . . . . . . . . . . . . . . 113

6 Discussion $\quad 115$

6.1 Defect assessment . . . . . . . . . . . . . . . . . . . . 115

6.2 Waviness effects measurement methodology . . . . . . . . . . . 117

6.2.1 Severity characterization . . . . . . . . . . . . . . 117

6.2.2 Method to reproduce representative test coupons . . . . . . . . . 118

6.2 .3 Mechanical testing . . . . . . . . . . . . . . . . . 118

6.2 .4 Modeling approach . . . . . . . . . . . . . . . . . . . 119

6.3 Effect of waviness on compressive failure . . . . . . . . . . . . . 120

6.3 .1 On the damage development . . . . . . . . . . . . . 120

6.3.2 On the compressive strength . . . . . . . . . . . . . 123

6.4 The implication on design of aircraft structures . . . . . . . . . . . . 124

6.5 Concluding remarks . . . . . . . . . . . . . . . 126

7 Conclusions and recommendations 131

7.1 Conclusions . . . . . . . . . . . . . . . . . . . 131

7.2 Recommendations . . . . . . . . . . . . . . 133

$\begin{array}{ll}\text { Acknowledgments } & 135\end{array}$

$\begin{array}{ll}\text { Publications } & 139\end{array}$ 



\section{ChAPTER 1}

\section{Introduction}

\subsection{Background and motivation}

The aerospace industry is continuously seeking to reduce the fuel consumption of aircraft in an effort to reduce their costs and their environmental impact. The development of lightweight aircraft design is one of the key ways which can help in reducing fuel consumption. Composite materials are most suitable for this purpose since they have high specific stiffness and strength which is beneficial for reducing the weight of aircraft structures. As a result, the application of composite materials has been increasing over the last decades. Currently, these materials make up half of the weight of the recent aircraft such as the Boeing 787 Dreamliner [1] and Airbus 350 XWB [2]. Most of these materials are thermoset composites.

Cost reduction is an important driver for technology development. Thermoplastic composite (TPC) material is particularly attractive in this aspect. A thermoplastic matrix is melt-processable and therefore allowing it to be melted, shaped and solidified within a short time period. This characteristic enables short process cycles and the possibility of automation and fusion bonding leading to overall cost-effective processing of TPC [3]. Moreover, TPC offers improved toughness and recyclability compared to thermoset-based composites [4]. These benefits have stimulated the increasing interest in the use of TPCs over their thermoset counterparts for aircraft structures. Initially, woven fabric reinforced thermoplastic composites were used in press forming processes to manufacture small parts, such as clips and brackets as used in large numbers in for example the Airbus A350 XWB aircraft [5]. In the more recent years, the increasing availability of UD carbon fiber reinforced tape materials has made TPC being considered for large structures such as fuselage sections [6, 7] or engine pylons [8].

As with any other manufacturing process of advanced materials, TPCs manufacturing is also prone to defect formation. The mechanical properties of composite materials can be adversely affected by the presence of process-induced defects. A well-known defect from the stamp forming process is waviness. This type of defect 
may be induced when a blank is formed into a complex doubly curved shell. If the occurrence of defects can be predicted in the design stage and the effects of those defects are known beforehand, a certain level of defects may potentially be tolerable in a composite part. This way, the process can be more robust and have a larger processing window while still achieving the desired mechanical properties within the permissible margin of safety. If unexpected defects occur, further evaluation is required to determine if the defects remain allowed, need repair, or be rejected, all of which incur extra costs. Another possible implication is a high safety factor in design which then leads to an increase of the structural weight. Often in industrial practice, in case the effects of a given defect are unknown, the defective part will be rejected due to the uncertainty and the possible risk arising from the performance being below the expectation. All of these can be minimized if the effects of defects on mechanical properties are understood and can be quantified. The knowledge and database generated can eventually be used as the basis to define the accept/repair/reject criteria for a defect.

\subsection{Waviness defects in thermoplastic composites}

Manufacturing of thermoplastic composites may induce defects such as waviness. It is described as "undesirable curviness of some fibers/plies in an area where all fiber/plies should be aligned" [9]. Various terms are used in the literature to describe this defect: fiber misalignment, wrinkle, in-plane waviness, out-of-plane waviness, folding, marcel and undulation [9-12]. All these terms essentially describe some type of fiber distortion or imperfection of the fiber straightness often at different scales. Waviness can be broadly differentiated into two types: in-plane and out-of-plane waviness. Related research on the formation of fiber waviness during TPC laminate consolidation performed parallel within the research program at the ThermoPlastic composites Research Center (TPRC) has identified the root cause of waviness formation. Axial compressive stress on the fiber is the cause of waviness formation during the consolidation of flat carbon fiber reinforced polyetherether-ketone (C/PEEK) laminates under vacuum bag only conditions [13]. The fibers in the plies can buckle when the critical buckling stress is reached and the transverse stabilization around the fiber is unable to sufficiently support the fiber [13]. The buckled fibers can manifest into primarily in-plane or out-of-plane waviness, depending on the constraints from the tooling. In-plane waviness defects can be found locally in a stamp-formed part (Figure 1.1), particularly when matched metal tooling is used during processing. The rigid tooling can restrict the fibers to buckle out-of-plane extrinsically (protruding out of the surface) such that the laminate is still flat and within typical thickness tolerance. Occasionally, in-plane waviness can even be found in a simple flat laminate consolidated by using a press or an autoclave [14]. 


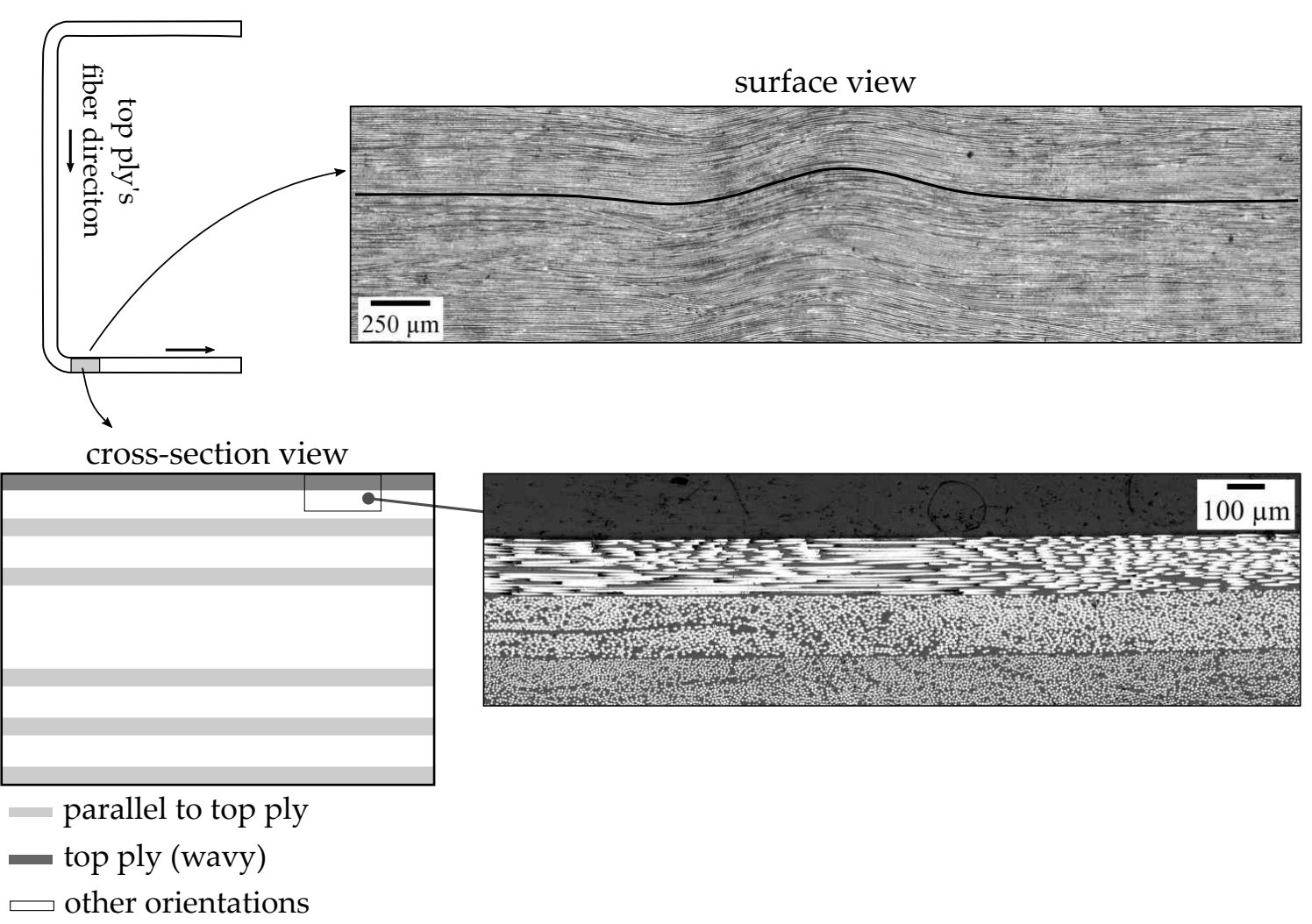

Figure 1.1 In-plane fiber waviness defects in a C-shaped stamp-formed multidirectional TPC part.

An example of the in-plane fiber waviness defects that can be realistically expected from manufacturing is shown in Figure 1.1. It shows surface and cross-sectional micrographs of waviness found in a C-shaped stamp-formed TPC part. The crosssectional micrographs were taken from the section parallel to the fiber orientation of the top ply. The schematic in Figure 1.1 shows that in-plane waviness in the part was present in the top surface ply. Characterization of the typical waviness defects originating from the manufacturing process of thermoplastic composites indicates that the waviness is in most cases visible on the surface of the TPC laminates. After processing, the laminates have distinct regions which appeared on the surface as patches of wavy fibers. These patches are limited to an area much smaller than the size of the laminate. In some cases, the waviness can extend to several plies underneath with the most severe waviness typically observed in the surface ply. The extent of waviness through the thickness depends on many variables such as the processing technique and parameters, the geometry, and also the layup.

\subsection{Effect of waviness on mechanical properties}

Various experimental studies on the effects of waviness defects on the mechanical properties of composites have been reported in the past years, with most studies 
Table 1.1 Overview of the available literature on the effects of waviness on various mechanical properties in thermoset (TSC) and thermoplastic (TPC) composite materials with unidirectional (UD) and multidirectional (MD) layup. A minus (-) sign indicates that no literature was found. The waviness studied was in the ply oriented in loading direction unless explicitly mentioned otherwise.

\begin{tabular}{cccccc}
\hline & & Tensile & Compressive & Bending & Fatigue \\
\hline & $\mathrm{UD}$ & {$[16-22]$} & {$[16-18,23-28]$} & {$[29]$} & {$[30,31]$} \\
$\mathrm{TSC}$ & $\mathrm{MD}^{1}$ & {$[32,33]$} & {$[11,21,34]$} & - & {$[35]$} \\
& $\mathrm{MD}^{2}$ & - & {$[36,37]$} & - & - \\
& $\mathrm{MD}^{3}$ & - & {$[38,39]$} & - & {$[38,39]$} \\
& $\mathrm{MD}^{4}$ & off-axis $\left(45^{\circ}\right)[17]$ & off-axis $\left(45^{\circ}\right)[17]$ & - & - \\
\hline \multirow{2}{*}{$\mathrm{TPC}$} & $\mathrm{UD}^{1}$ & {$[40]$} & {$[10,41,42]$} & {$[43]$} & - \\
& $\mathrm{MD}^{1}$ & - & - & - & - \\
& $\mathrm{MD}^{2}$ & - & {$[44]$} & - & {$[45]$} \\
\hline
\end{tabular}

${ }^{1} 0^{\circ}, \pm 45^{\circ}, 90^{\circ}$ family

${ }^{2}$ cross-ply $\left(0^{\circ}, 90^{\circ}\right.$ orientations $)$

${ }^{3} 0^{\circ}, \pm 45^{\circ}$ orientations

$4 \pm 45^{\circ}$ orientations

evaluating the defects in thermoset composite (TSC) material. A detailed overview of this topic is available in Ref. [15]. Table 1.1 shows an overview of existing studies in the literature. Most of these investigated the effects in unidirectional (UD) composites since this is the basic building block of laminates. The mechanical properties that have been studied are tensile, compression, bending, and fatigue properties. The effect on impact properties has also been studied, although it received very little attention in the literature [16]. Moreover, the most commonly studied type of waviness defect is out-of-plane waviness. There are fewer studies on in-plane waviness defects. The studies in Table 1.1 showed that increasing severity of waviness in the ply oriented in loading direction causes a reduction in mechanical properties, whereas little to no adverse effect was found from the studies on in-plane waviness in the off-axis plies [17].

For aircraft structures, the compressive strength is often a limiting design factor of composites material. One of the reasons is that it is usually often significantly lower than the tensile strength. Moreover, earlier studies showed that compressive strength is especially sensitive to fiber waviness. In UD composites, waviness can act as a trigger for early kinking failure which then leads to catastrophic failure when the structure is loaded under compression [10, 24, 28, 30, 46, 47]. Kinking is caused by localized shear deformation of the matrix precipitated by pre-existing fiber misalignment $[46,48]$. Yielding of the matrix initiated fibers rotation forming a band of kinked fibers and may eventually lead to fiber breakage due to local bending of fibers [24,49]. Therefore, this failure mechanism limits the composites compressive strength. For this reason, it is important to evaluate the influence of waviness severity 
on compressive strength.

Some of the important findings from earlier studies on the effect of waviness on compressive properties are discussed next. The literature overview presented here concerns both the in-plane and out-of-plane waviness unless explicitly mentioned otherwise. Several researchers have studied the influence of various types of waviness defects which developed from manufacturing and their effect on compressive properties of UD composites, with particular attention on the compressive strength. Generally, an increase in the magnitude of the waviness severity is accompanied by a reduction in longitudinal compressive strength [10, 18, 23-26, 28, 41, 42]. Similarly, the compressive failure strain is also reduced due to in-plane waviness that is limited to the laminate's surface [27]. Data available in the literature concerning compressive stiffness of UD composites show that it is also adversely affected by waviness but to a lesser extent than the reduction in compressive strength $[16,28]$.

As summarized in Table 1.1, the influence of waviness on the mechanical properties of multidirectional (MD) composites has not yet received as much attention as the UD composites. The focus on MD composites is particularly relevant for the industrial application of TPC products. Few of those studies in the literature concern the effects on compressive properties of MD composites. The compressive strength of MD composites with various stacking sequences, which consist of the $0^{\circ}, \pm 45^{\circ}$, and $90^{\circ}$ family, are adversely affected by the presence of waviness in the ply oriented in loading direction [11, 21, 34, 36-38,44]. Generally, an increase of waviness severity in the ply oriented in loading direction decreases the compressive strength. In some cases, depending on the waviness severity, the compressive modulus of QI laminate can also be decreased due to out-of-plane waviness in the $0^{\circ}$ plies, although again to a lesser extent than the reduction in strength [21]. Compression tests of $\pm 45^{\circ}$ laminates with in-plane waviness showed similar, if not higher, compressive strength than the control specimens [17]. Those results indicate that the compressive strength of off-axis plies is relatively insensitive to in-plane waviness.

In principle, as mentioned earlier in section 1.2, waviness can be differentiated into in-plane and out-of-plane waviness. In a study on UD composites with artificially induced in-plane and out-of-plane waviness with similar levels of severity, it was found that the specimens with large out-of-plane waviness failed by delamination when loaded under compression [16]. Such failure mode was not observed in the UD specimens with in-plane waviness [16]. Although the decreasing trend in compressive strength with increasing severity is generally similar for both types of waviness, the failure mechanism and hence the magnitude of strength reduction may differ.

As highlighted in the literature overview presented earlier, despite the improvement over the past years in the understanding of the effect of waviness in UD composites, the studies on the influence for MD composites are still lacking, especially concerning TPC materials with in-plane waviness defects. Besides, the failure process in MD 
composites is more complex than in UD composites. This is due to the interaction between plies with different orientations which may activate the interlaminar (delamination) failure mode. Earlier studies on MD composites having waviness indicate that there are multiple possible failure modes that govern the compressive failure initiation of a laminate. These possible failure modes include fiber kinking of the wavy ply oriented in the loading direction and delamination; and the occurrence and its sequence depend on the type of material, the stacking sequence, and the waviness type and severity [11, 34, 38, 50]. Most of those past studies have investigated the compressive failure mechanism of TSCs. For TPCs, the inherent toughness of thermoplastics may affect the occurrence of these failure modes, but very little effort has been spent on these materials. Table 1.1 shows that so far there is only one study on out-of-plane waviness in cross-ply TPC laminates and its effect on compressive strength [44]. To the best knowledge of the author, no study on in-plane waviness defects in MD TPC laminates can be found in the open scientific literature. This may be partly due to the difficulties in obtaining the representative defects in specimens for mechanical testing. Moreover, the range of in-plane waviness severity expected from TPC manufacturing has not yet been identified.

\subsection{Objectives and scope}

A proper understanding and quantification of the influence on the mechanical properties are required in order to define more efficient acceptability limits of in-plane fiber waviness defects. In particular, the influence on the compressive properties of laminates is of interest for aircraft structure applications. Therefore, the objectives of this thesis are to:

1. develop a methodology to measure the effects of waviness on the mechanical performance, with a focus on the technique to manufacture test coupons with realistic in-plane fiber waviness, and on the mechanical test methodologies,

2. identify the mechanisms leading to failure in order to analyze the role of waviness defects in determining the laminate compressive strength,

3. quantify the effect of waviness defects on the compressive strength of TPC laminates.

The current work aims to achieve its objectives mainly through experiments supported by modeling.

This work focuses on in-plane fiber waviness defects that can be realistically expected from the manufacturing process whose characteristics were described in section 1.2. Waviness defects in TPC laminates occur locally and are limited to a region much smaller than the size of the laminate. The waviness is, in most cases, visible on the surface. In some cases, it can extend to several plies deep. This thesis investigates 
the influence of waviness on compressive properties at the laminate coupon level in a quasi-static condition. Quasi-isotropic laminates made of C/PEEK UD tapes were selected as the study material since this material system and layup is frequently used for aerospace applications. The defects were produced to be in the ply oriented parallel to the loading direction. The influence of waviness on the compressive strength is expected to be maximum at this condition. The waviness in this work is only limited to the laminate surface.

\subsection{Outline and approach}

This thesis comprises four main chapters which are linked to each other according to the schematic presented in Figure 1.2. These chapters are reproduced from research papers. This format allows the readers to study the chapter independently as the chapters are self-contained. However, as a consequence, some of the essential details are repeated in every chapter. The author apologizes for any inconvenience that may be caused by the repetition.

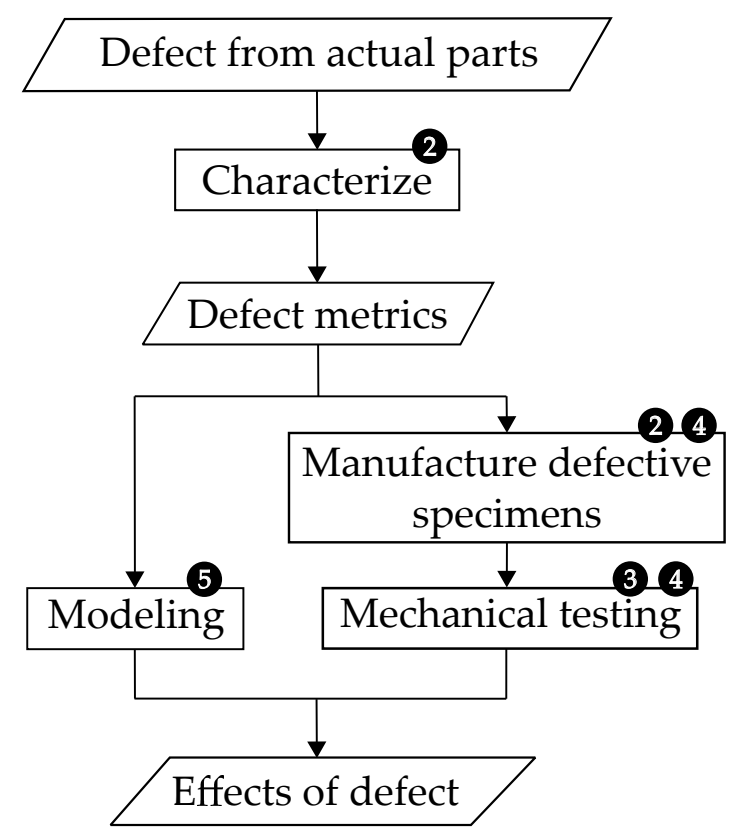

Figure 1.2 Outline of the approach of this thesis showing the chapters which elaborate the specific subjects.

Chapter 2 presents a reverse forming method to produce test coupons with inplane waviness defects in a controlled manner suitable for typical mechanical test coupons. This experimental method can facilitate the measurement of the influence of waviness on mechanical properties. The induced waviness defects were made such that they closely resemble the typical in-plane waviness defects observed from 
TPC manufacturing. In order to quantify the defect severity, a characterization method of the defect metrics, which are represented as the waviness parameters, is described in this chapter and used to measure characteristics of in-plane waviness found from several examples of industrial parts. The characterization and test coupon manufacturing methods are used throughout the thesis.

Chapter 3 focuses on the influence of the waviness on the compressive properties of QI C/PEEK laminates. To this end, uniaxial compression tests were performed using the standard combined loading compression (CLC) test method. The CLC tests were combined with high-speed camera monitoring to study the damage development. Furthermore, a finite element (FE) model was developed and used to investigate the stress state in the wavy region to assess the compressive failure mechanisms.

Chapter 4 elaborates on the initiation of failure in the wavy ply in more detail by using bending test methods as these allow for more gradual damage progression compared to the uniaxial compression test method. In order to obtain a wider range of waviness severity than that achieved solely from the experimental work in Chapter 2, an additional method using a press consolidation process is introduced to manufacture test coupons with lower severity waviness. In this chapter, the ply compressive stress at which the first failure occurs is measured by using the endloaded and four-point bending test methods.

Chapter 5 presents a theoretical analysis of the influence of waviness on the compressive failure of laminate by means of a FE model and an analytical model. A parametric study by using the FE model was performed to investigate the influence of maximum waviness angle on the stress state and failure of the wavy ply to confirm the failure behavior observed in the experiments. Moreover, an analytical approach, employing the classical laminate theory (CLT), is presented in this chapter as a tool for quick and simple analysis of the effect of waviness on compressive strength. This tool provides a first approximation of the first failure stress and the ultimate strength of laminates with waviness, helpful for industrial application of the gained knowledge.

The complete work is put into a broader perspective in Chapter 6. A potential defect assessment approach and the methodology specific for waviness effect characterization which was developed in this work are reviewed in this chapter. The influence of waviness defects on the compressive failure of laminates and their implication on the design of aircraft structures are also elaborated in this chapter based on the results from Chapters 3-5. Finally, Chapter 7 presents the main conclusions and provides the recommendations for further research. 


\section{References}

[1] Boeing 787 from the ground up, 2006. URL https:/www.boeing.com/commercial/aeromagazine/articles/qtr_4_06/

AERO_Q406_article4.pdf, Retrieved on 30 Jun. 2021.

[2] A350 family aircraft. URL https://www.airbus.com/aircraft/passengeraircraft/a350xwb-family.html, Retrieved on 30 Jun. 2021.

[3] A. R. Offringa. Thermoplastic composites-rapid processing applications. Composites Part A: Applied Science and Manufacturing, 27(4):329-336, 1996. 4th International Conference on Automated Composites.

[4] A. Offringa. New thermoplastic composite design concepts and their automated manufacture. JEC Composites Magazine 58, 2010.

[5] S. Black. Thermoplastic composites "clip" time, labor on small but crucial parts, 2015. URL https://www.compositesworld.com/articles/thermoplastic-compositesclip-time-labor-on-small-but-crucial-parts, Retrieved on 13 Jul. 2021.

[6] H. Mason. Moving forward on the Multifunctional Fuselage Demonstrator (MFFD), 2020. URL https://www.compositesworld.com/articles/moving-forward-onthe-multifunctional-fuselage-demonstrator-mffd-, Retrieved on 24 Sept. 2021.

[7] W. M. van den Brink, W. J. Vankan, J. C. de Kruijk, S. L. Veldman, and R. Herrmann. Multifunctional fuselage demonstrator: thermoplastic composite skin manufacturing developments. Report NLR-TP-2020-484. 2021.

[8] G. Gardiner. Thermoplastic composite demonstrators - EU roadmap for future airframes, Composites World, 2018. URL https://www.compositesworld.com/articles/thermoplastic-composite-demonstratorseu-roadmap-for-future-airframes-, Retrieved on 24 Sept. 2021.

[9] R. Elhajjar, P.N. Grant, and C. Ashforth. Composite Structures: Effects of Defects. Wiley, 2018.

[10] P. J. Joyce and T. J. Moon. Compression Strength Reduction in Composites with inPlane Fiber Waviness, pages 76-96. ASTM International, West Conshohocken, PA, 1998.

[11] B. Khan, K. D. Potter, and M. R. Wisnom. Simulation of process induced defects in resin transfer moulded woven carbon fibre laminates and their effect on mechanical behaviour. In The 8th International Conference on Flow Processes in Composite Materials (FPCM8), 2006.

[12] K. Potter, B. Khan, M. Wisnom, T. Bell, and J. Stevens. Variability, fibre waviness and misalignment in the determination of the properties of composite materials and structures. Composites Part A: Applied Science and Manufacturing, 39(9):13431354, 2008.

[13] E. T. M. Krämer. The formation of fiber waviness during thermoplastic composite laminate consolidation. Ph.D. Thesis, University of Twente, 2021.

[14] E. T. M. Krämer, W. J. B. Grouve, S. Koussios, L. L. Warnet, and R. Akkerman. Real-time observation of waviness formation during C/PEEK consolidation. 
Composites Part A: Applied Science and Manufacturing, 133:105872, 2020.

[15] P. Kulkarni, K. D. Mali, and S. Singh. An overview of the formation of fibre waviness and its effect on the mechanical performance of fibre reinforced polymer composites. Composites Part A: Applied Science and Manufacturing, 137:106013, 2020.

[16] C. Wu, Y. Gu, L. Luo, P. Xu, S. Wang, M. Li, and Z. Zhang. Influences of inplane and out-of-plane fiber waviness on mechanical properties of carbon fiber composite laminate. Journal of Reinforced Plastics and Composites, 37(13):877-891, 2018.

[17] J. W. Nelson, T. W. Riddle, and D. S. Cairns. Effects of defects in composite wind turbine blades - part 1: Characterization and mechanical testing. Wind Energ. Sci., 2(2):641-652, 2017.

[18] T. W. Riddle, J. W. Nelson, D. S. Cairns, and J. E. Workman. Effects of Defects : Part A - Development of a Protocol for Defect Risk Management \& Improved Reliability of Composite Structures. 53nd AIAA/ASME/ASCE/AHS/ASC Structures, Structural Dynamics and Materials Conference, 2012.

[19] L. D. Bloom, J. Wang, and K. D. Potter. Damage progression and defect sensitivity: An experimental study of representative wrinkles in tension. Composites Part B: Engineering, 45(1):449-458, 2013.

[20] J. Galos. Novel method of producing in-plane fibre waviness defects in composite test coupons. Composites Communications, 17:1-4, 2020.

[21] M. Thor, U. Mandel, M. Nagler, F. Maier, J. Tauchner, M. G. R. Sause, and R. M. Hinterhölzl. Numerical and experimental investigation of out-of-plane fiber waviness on the mechanical properties of composite materials. International Journal of Material Forming, 14(1):19-37, 2021.

[22] C. Zhao, J. Xiao, Y. Li, Q. Chu, T. Xu, and B. Wang. An experimental study of the influence of in-plane fiber waviness on unidirectional laminates tensile properties. Applied Composite Materials, pages 1-17, 2017.

[23] P. Davidson and A. M. Waas. The effects of defects on the compressive response of thick carbon composites: An experimental and computational study. Composite Structures, 176:582-596, 2017.

[24] P. Y. Mechin, V. Keryvin, J. C. Grandidier, and D. Glehen. An experimental protocol to measure the parameters affecting the compressive strength of CFRP with a fibre micro-buckling failure criterion. Composite Structures, 211:154-162, 2019.

[25] H. M. Hsiao and I. M. Daniel. Effect of fiber waviness on stiffness and strength reduction of unidirectional composites under compressive loading. Composites science and technology, 56(5):581-593, 1996.

[26] S. N. Nair. Effect of in-plane fiber waviness on the failure of fiber reinforced polymer composites. Ph.D. Thesis, Nanyang Technological University, 2018.

[27] M. R. Wisnom and J. W. Atkinson. Fibre waviness generation and measurement and its effect on compressive strength. Journal of Reinforced Plastics and 
Composites, 19(2):96-110, 2000.

[28] D. Wilhelmsson, R. Gutkin, F. Edgren, and L. E. Asp. An experimental study of fibre waviness and its effects on compressive properties of unidirectional NCF composites. Composites Part A: Applied Science and Manufacturing, 107:665-674, 2018.

[29] B. D. Allison and J. L. Evans. Effect of fiber waviness on the bending behavior of s-glassepoxy composites. Materials E Design (1980-2015), 36:316-322, 2012.

[30] M. R. Piggott. The effect of fibre waviness on the mechanical properties of unidirectional fibre composites: a review. Composites science and technology, 53(2):201-205, 1995.

[31] S. Hörrmann, A. Adumitroaie, C. Viechtbauer, and M. Schagerl. The effect of fiber waviness on the fatigue life of cfrp materials. International Journal of Fatigue, 90:139-147, 2016.

[32] R. F. El-Hajjar and D. R. Petersen. Gaussian function characterization of unnotched tension behavior in a carbon/epoxy composite containing localized fiber waviness. Composite Structures, 93(9):2400-2408, 2011.

[33] S. Mukhopadhyay, M. I. Jones, and S. R. Hallett. Tensile failure of laminates containing an embedded wrinkle; numerical and experimental study. Composites Part A: Applied Science and Manufacturing, 77:219-228, 2015.

[34] S. Mukhopadhyay, M. I. Jones, and S. R. Hallett. Compressive failure of laminates containing an embedded wrinkle; experimental and numerical study. Composites Part A: Applied Science and Manufacturing, 73:132-142, 2015.

[35] S. Mukhopadhyay, O. J. Nixon-Pearson, and S. R. Hallett. An experimental and numerical study on fatigue damage development in laminates containing embedded wrinkle defects. International Journal of Fatigue, 107:1-12, 2018.

[36] D. O. Adams and S. J. Bell. Compression strength reductions in composite laminates due to multiple-layer waviness. Composites Science and Technology, 53(2):207-212, 1995.

[37] A. Caiazzo, M. Orlet, H. McShane, L. Strait, and C. Rachau. The effects of marcel defects on composite structural properties, volume 1383 of American Society for Testing and Materials Special Technical Publication, pages 158-187. American Society Testing and Materials, W Conshohocken, 2001.

[38] J. F. Mandell, D. D. Samborsky, and L. Wang. Effects of fiber waviness on composites for wind turbine blades. In 48th International SAMPE symposium, volume 48, 2003.

[39] L. Wang. Effects of in-plane fiber waviness on the static and fatigue strength of fiberglass. MSc thesis, Montana State University-Bozeman, College of Engineering, 2001.

[40] H. Diao, P. Robinson, M. R. Wisnom, and A. Bismarck. Unidirectional carbon fibre reinforced polyamide-12 composites with enhanced strain to tensile failure by introducing fibre waviness. Composites Part A: Applied Science and Manufacturing, 87:186-193, 2016. 
[41] A. M. Mrse and M. R. Piggott. Compressive properties of unidirectional carbon fibre laminates: Ii. the effects of unintentional and intentional fibre misalignments. Composites Science and Technology, 46(3):219-227, 1993.

[42] A. L. Highsmith, J. J. Davis, and K. L. E. Helms. The influence of fiber waviness on the compressive behavior of unidirectional continuous fiber composites. ASTM International, 1992.

[43] T. Yokozeki, K. Akakabe, T. Aoki, and A. Kobiki. Effects of process-induced fiber bundle waviness on the mechanical properties of carbon fiber reinforced thermoplastic composites. In ECCM 2016 - Proceeding of the 17th European Conference on Composite Materials, 2016.

[44] D. O. Adams and M. W. Hyer. Effects of layer waviness on the compression strength of thermoplastic composite laminates. Journal of Reinforced Plastics and Composites, 12(4):414-429, 1993.

[45] D. O. Adams and M. W. Hyert. Effects of layer waviness on the compression fatigue performance of thermoplastic composite laminates. International Journal of Fatigue, 16(6):385-391, 1994.

[46] B. Budiansky and N. A. Fleck. Compressive failure of fibre composites. Journal of the Mechanics and Physics of Solids, 41(1):183-211, 1993.

[47] S. N. Nair, A. Dasari, C. Y. Yue, and S. Narasimalu. Failure behavior of unidirectional composites under compression loading: Effect of fiber waviness. Materials (Basel, Switzerland), 10(8):909, 2017.

[48] I. M. Daniel, H. Hsiao, and S. Wooh. Failure mechanisms in thick composites under compressive loading. Composites Part B: Engineering, 27(6):543-552, 1996.

[49] Q. Sun, H. Guo, G. Zhou, Z. Meng, Z. Chen, H. Kang, S. Keten, and $X$. Su. Experimental and computational analysis of failure mechanisms in unidirectional carbon fiber reinforced polymer laminates under longitudinal compression loading. Composite Structures, 203:335-348, 2018.

[50] A. Shipsha, S. Hallström, and M. Burman. Effect of stacking sequence and bundle waviness in quasi-isotropic NCF composites subjected to compression. Composites Part B: Engineering, 178:107423, 2019. 


\title{
CHAPTER 2
}

\section{Reverse forming method to reproduce in-plane fiber waviness defects in test coupons*}

\begin{abstract}
In-plane fiber waviness is one of the defects that can occur from the stamp-forming process of thermoplastic composite (TPC) parts. The influence of this defect on the mechanical performance of multidirectional composites is not yet fully understood. The main challenge in determining the influence on mechanical properties lies in reproducing the waviness in test coupons that can subsequently be subjected to testing. This chapter describes an experimental approach to reproduce representative in-plane waviness defects, specific for TPC, by reverse-forming of V-shape parts of various bend angles and inner radii. Characterization results show that this method enables the manufacturing of localized in-plane waviness in flat 24-ply quasiisotropic $\mathrm{C} / \mathrm{PEEK}$ composites with no voids. Furthermore, laminates having varying levels of maximum waviness angle $\left(\theta_{\max }\right)$, between $14^{\circ}$ to $64^{\circ}$, were successfully produced in this work. By comparing the $\theta_{\max }$ value with the examples of industrial stamp-formed parts, it can be concluded that the developed coupon manufacturing method can reproduce waviness from TPC part production reasonably well. Finally, all of the produced laminates have defective region lengths smaller than $20 \mathrm{~mm}$, localized within a predefined location which makes them well suited for standard compression test coupons.
\end{abstract}

\footnotetext{
${ }^{*}$ Reproduced from Sitohang, R. D. R., Grouve, W. J. B., Warnet, L. L., Koussios, S., Akkerman, R., An experimental approach to reproduce in-plane fiber waviness in thermoplastic composites test coupons using a reverse forming method. Journal of Composite Materials, July 2021. https://doi.org/10.1177/00219983211026734
} 


\subsection{Introduction}

Thermoplastic composites (TPCs) are increasingly applied by the aerospace industry due to their high stiffness and strength to weight ratio, recyclability, and potential for rapid high-volume manufacturing. One manufacturing technique that is ideally suited for large volume production of TPCs is the stamp forming process. The three main deformation mechanisms occurring in the forming process of composites are the intra-ply shearing, out-of-plane bending and inter-ply slippage [1]. Defects, such as in-plane fiber waviness (see Figure 3.1), may occur when the necessary deformation mechanism to allow the material to conform to the desired shape is inhibited. Parts with such defects are designed with a high safety factor or even rejected due to the uncertainty, as the waviness influence on the mechanical performance of multidirectional composites is not yet fully understood. Earlier studies on the lamina level (unidirectional) indicate that the presence of fiber waviness can cause a significant reduction in the compressive strength due to early kinking failure [2-6]. The compressive strength is often a limiting design factor of composite materials for aircraft structures, as this is typically much lower than the tensile strength [2]. For (multidirectional) laminates, there is no single dominant failure mode that is applicable for all types of laminates. Possible dominant failure modes that have been reported in the literature for thermoset-based laminates are fiber kinking and delamination [7-10]. The occurrence of the failure mode seems to be dependent on the severity of waviness [7] and the stacking sequence [10]. The mechanisms leading to failure have not yet been identified particularly for thermoplastic composite laminates. The inherent toughness of thermoplastics may affect the occurrence of the dominant failure mode. Thus, to be able to apply optimum design procedures for TPC parts, a proper understanding of the failure mechanisms and quantitative data of the compressive strength is essential. Both these factors entail an experimental study with waviness that is representative of the typical defects found from the production of TPC parts.

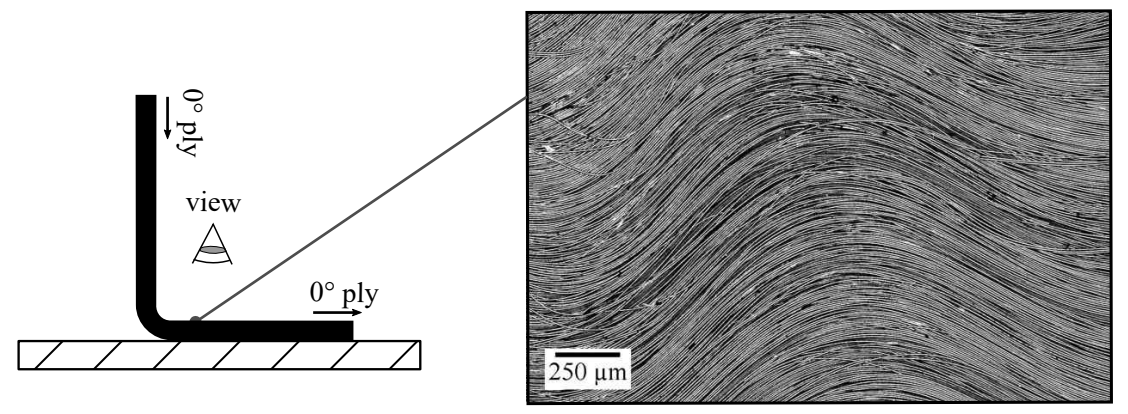

Figure 2.1 In-plane waviness defects observed in the concave side of a stamp-formed L-shaped part.

The waviness defects in thermoplastic composite parts are typically visible on the laminate surface (see Figure 3.1). Upon further investigation by the author, it was 
found that the in-plane waviness can extend to several plies underneath the surface plies, depending on the processing technique and parameters, the geometry, and also the layup. Some examples of the stamp forming processing parameters that may affect the extent of waviness are blank tensioning, forming speed, pressure and temperature. Particularly for curved parts manufactured by stamp forming, the waviness defects are typically only found on the concave side of the part, due to the compressive forces caused by the forming of the laminate [11]. Our measurements from several examples of stamp-formed TPC parts have shown that the typical waviness defects found in such parts have a wavelength in the order of magnitude less than $10 \mathrm{~mm}$. An example of the waviness at the corner section of a generic L-shaped profile typically found in a stiffener is presented in Figure 3.1. Interpreting the mechanical test results from such parts, however, is rather difficult in practice due to the complex stress distribution in the curved section. For this reason, a method to reproduce fiber waviness in generic flat test specimens for standard coupon mechanical testing is necessary.

There are several coupon manufacturing methods reported in the literature considering the technique to reproduce in-plane fiber waviness in unidirectional (UD) prepreg material. An example of the method for thermoset UD prepreg materials is by first forming the individual prepreg on a cylindrical rod while simultaneously heating the region that will be deformed locally with a hot air gun, and then manually shaping the material to generate in-plane waviness $[12,13]$. The same method has also been used by other authors for stacks of thermoset UD prepregs by first laying them on a curved geometry, and then subsequently flattening them before the full curing cycle was completed [14-16]. Alternatively, a compressive strain can be induced directly in the composite material by clamping thermoset UD prepreg slit tapes between prestretched silicone rubber sheets, which will then induce compressive strain along with the disappearance of tensile deformation of the elastomer [17]. The authors, however, have not yet applied this technique for a laminate. If this method was to be applied for thermoplastic composites, it is yet unknown whether the induced small wavy patches will still be present after the subsequent consolidation process of the whole stack of prepregs.

None of the previously mentioned techniques for reproducing in-plane waviness have been applied to multidirectional TPC laminates. Aerospace-grade thermoplastic UD tapes based on polyether-ether-ketone (PEEK) matrix are used in this work. Below the melting temperature, the semicrystalline thermoplastic polymer is in its solidstate, and therefore it is impossible to manipulate the prepreg tape to conform to the shape of a curved tool without breaking the fibers. Moreover, as observed from our scoping experiments, a manual shearing approach by locally heating up the tape produced waviness with a relatively large wavelength, i.e. in the order of $25 \mathrm{~mm}$. As described previously, the typical waviness induced in TPCs by the stamp forming process is much smaller than this wavelength, in the order of 
magnitude less than $10 \mathrm{~mm}$. Smaller localized waviness, as in the typical case of TPC parts, may have a less adverse influence on the compressive properties. To confirm whether this is true, further experimental study on the representative waviness is required. This review of the literature highlights that one of the main challenges in determining the mechanical properties of composites having waviness defects lies in obtaining the waviness in standard mechanical test coupons that is representative of the defects found in industrial TPC parts. Therefore, this chapter introduces a test coupon manufacturing method, which is suited for TPC materials, to facilitate that investigation. It may ultimately contribute to expanding the database of the effect of waviness and defining the allowance limit. This work aims to experimentally assess the applicability of a reverse forming method to manufacture flat test coupons having in-plane waviness based on the following requirements:

1. Produce flat laminates with good consolidation quality.

2. Produce wavy test coupons with a wide range of maximum waviness angle values, representative of typical defects from industrial practice.

3. Produce wavy test coupons that are suited for a standard compression test, i.e. with the waviness region being localized in a predefined area.

The majority of past studies have characterized waviness severity by using the maximum misalignment angle [3, 4, 6, 9, 18-20], which has been suggested to be the most critical measure as it has the most significant influence on the compressive strength $[18,19]$. Most characterization methods to measure this parameter are based on microscopy analysis which is often coupled with image analysis algorithms to automatically detect the fibers and measure the angles [21-24]. Considering the second requirement, the maximum angle is chosen as the parameter to represent the severity of the waviness produced. A variation in the maximum waviness angle is necessary to establish the correlation between the severity and the measured compressive properties. Furthermore, considering the third requirement, the wavy regions within the produced test coupon have to fit the unsupported gage length of 20 $\mathrm{mm}$ as described in the standard combined load compression (CLC) test method [25]. Finally, quasi-isotropic (QI) laminates are chosen as a case study for multidirectional composites, since such layup is one of the most common for aircraft structures.

This chapter first presents a reverse forming method used to obtain in-plane waviness in flat laminates. This method is based on the same principle from one of the techniques mentioned earlier for thermoset composites, i.e. pre-forming into a curved geometry to create excess material in a certain region. The experimental method firstly involves stamp forming of a blank into a V-shape (single-curved) geometry, and then subsequently flattening it back by a second forming step to induce the waviness. Furthermore, the QI stacking sequence was varied to assess the number of inner plies that were affected by the compressive forces caused by the forming of the laminate. For this reason, the position of the plies that are oriented in the 
bending direction of the laminate was varied by altering the ply grouping within the stack. The formed laminates were characterized using a microscope to evaluate the voids, the number of wavy plies, the maximum waviness angle, and the defective region length in order to assess whether the proposed reverse forming method meets the aforementioned requirements. The maximum waviness angle obtained using the reverse forming method was then compared with the measured parameters from several examples of industrial parts to objectively assess how the produced waviness samples reflect the typical defect characteristics.

\subsection{Experimental methods}

The manufacturing process steps to obtain in-plane waviness in flat laminates are illustrated in Figure 2.2. The main principle of the proposed manufacturing method lies in a local pre-forming of the blank into a curved geometry with a small radius to create excess material in the corner region. The steps include: $i$ ) a press consolidation step to manufacture a quasi-isotropic blank, ii) a stamp forming process to produce a V-shape part (the first stamp forming step in Figure 2.2), and iii) a flat forming process to induce the waviness (the second stamp forming step in Figure 2.2). The process parameters are described in more detail in the following sections.

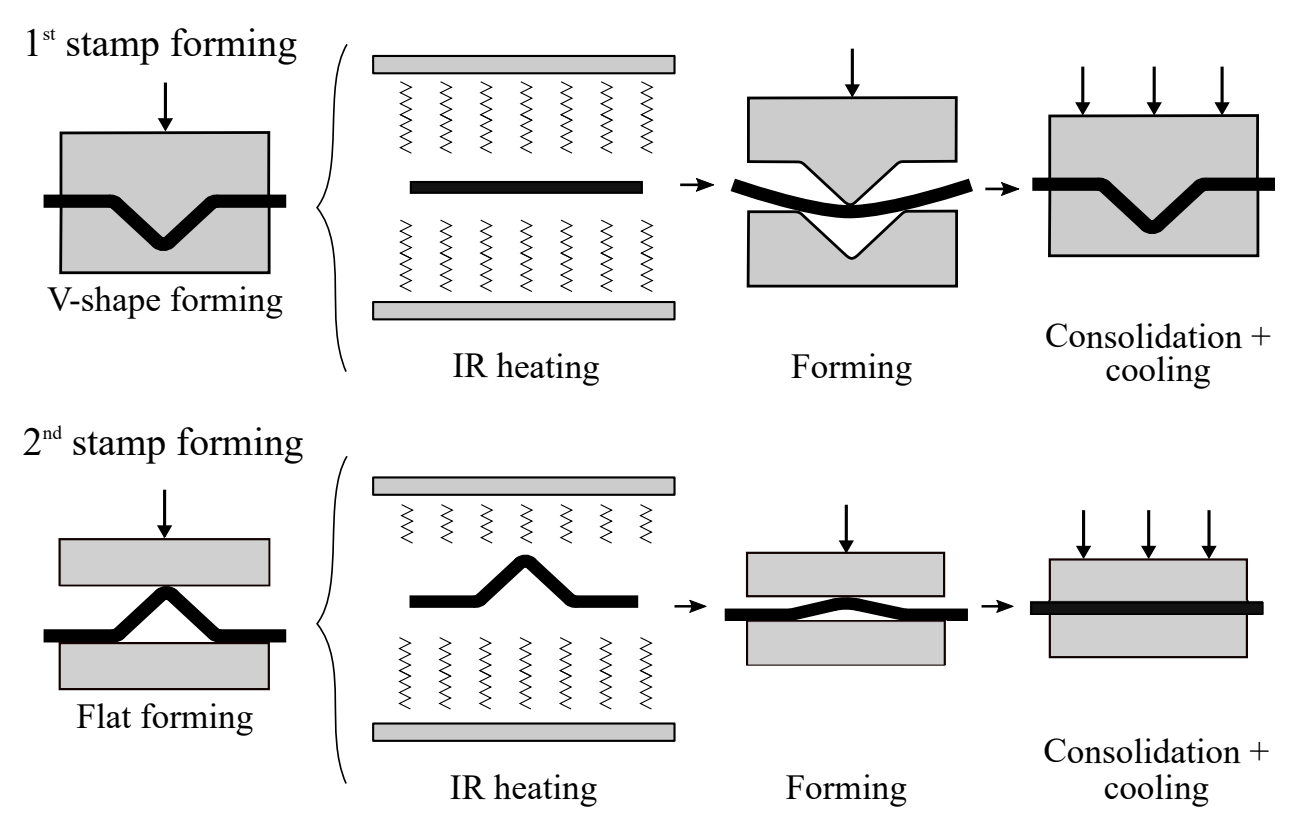

Figure 2.2 Reverse forming process steps to form in-plane waviness defects in a flat laminate. 


\subsubsection{Materials}

Quasi-isotropic (QI) laminates with various stacking sequences, i.e. [0/45/90/-45] 3 s, $\left[0_{2} / 45_{2} / 90_{2} /-45_{2} / 0 / 45 / 90 /-45\right]_{s}$, and $\left[0_{3} / 45_{3} / 90_{3} /-45_{3}\right]_{s}$ (Table 2.1), were prepared from unidirectional (UD) carbon/PEEK tapes, known as Cetex ${ }^{\circledR}$ TC1200 from Toray Advanced Composites. The prepreg tape contains AS4 fibers with a fiber volume fraction of 59\% [26]. A total of 24 plies were used to produce laminates with a nominal thickness of $3.4 \mathrm{~mm}$. The three different QI layups were chosen such that the laminate thickness and the number of plies in each orientation, hence the axial stiffness, remained the same for all samples.

\subsubsection{Press consolidation}

Laminates with the size of $300 \mathrm{~mm} \times 300 \mathrm{~mm}$ were laid up from 12" wide tapes. The laminates were placed between $1 \mathrm{~mm}$ thick stainless steel caul sheets, coated with Marbocote 227CEE release agent, in a picture frame mold. They were consolidated in a Pinette P.E.I. press under 20 bar pressure with 20 minutes dwell time at $385^{\circ} \mathrm{C}$, and a cooling rate of $5^{\circ} \mathrm{C} / \mathrm{min}$. After press consolidation, the laminates were cut using a water-cooled diamond-coated saw into two blanks of $300 \mathrm{~mm} \times 150 \mathrm{~mm}$ size for the subsequent stamp forming processes. The blanks were manufactured in such a way that a minimum of five standard mechanical test coupons, e.g. a nominal size of $147 \mathrm{~mm}$ long and $12 \mathrm{~mm}$ wide (according to ASTM D6641 for the standard CLC test method [25] could be obtained from a single plate.

\subsubsection{Stamp forming}

The V-shape tooling, coated with Marbocote 227CEE release agent, was used for the first stamp forming step. This step produced composites with the geometry as shown in Figure 2.3. The following three positive toolings, with various combinations of bend angles (shown as $\theta$ in Figure 2.3) and inner radius $\left(R_{\text {inner }}\right)$, were used to produce the V-shape parts:

- $90^{\circ}$-bend with $6.4 \mathrm{~mm}$ inner radius

- $105^{\circ}$-bend with $8 \mathrm{~mm}$ inner radius

- $120^{\circ}$-bend with $10 \mathrm{~mm}$ inner radius

The $90^{\circ}$-bend tooling was made of steel, while the $105^{\circ}$ and the $120^{\circ}$-bend toolings were made of aluminum. The $90^{\circ}$-bend angle is a common enclosed angle of a corner section. Two larger bend angles with an increment of $15^{\circ}$, i.e. $105^{\circ}$ and $120^{\circ}$, were also used in this study. These various combinations were used in order to vary the arc path lengths of the top and bottom layers at the corner section $\left(S_{1}\right.$ and $S_{2}$ in Figure 2.3), which was expected to affect the induced in-plane waviness severity. 
Matched metal negative toolings were produced accordingly to reach a nominal gap thickness of $3.4 \mathrm{~mm}$. These various combinations were chosen in order to vary the arc path lengths of the top and bottom layers at the corner section $\left(S_{1}\right.$ and $S_{2}$ in Figure 2.3), which was expected to affect the induced in-plane waviness severity. The sample code is defined by the bend angle and the layup used, as V(tool-angle)-(layup sample code), e.g. V90-QI1 for the sample with a single $0^{\circ}$ ply in the outermost side which was formed using the $90^{\circ}$-angle V-shape tooling (see Table 2.1).

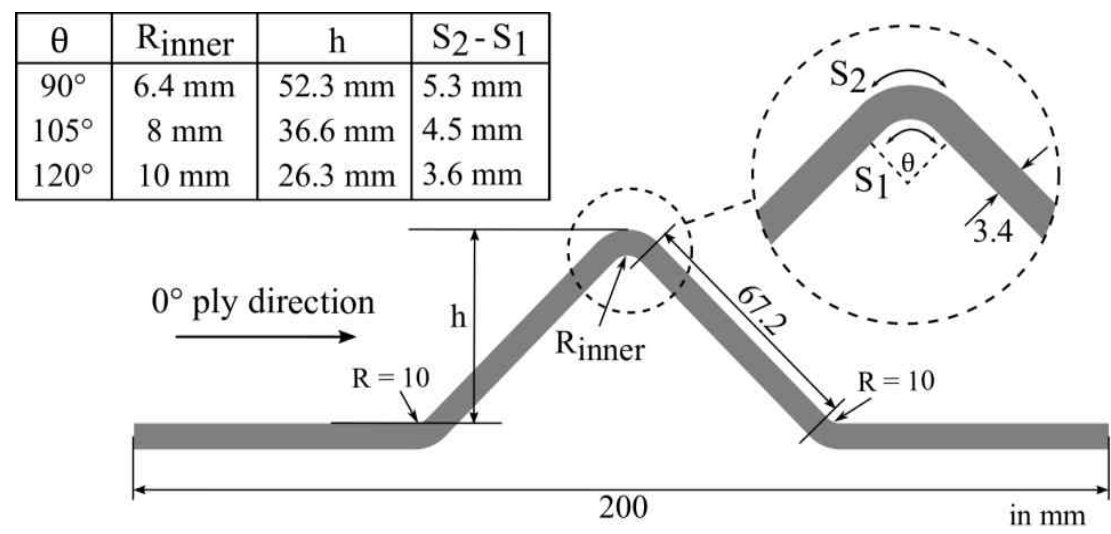

Figure 2.3 $\quad V$-shape geometry. The table shows the dimensions of the parts.

Table 2.1 Sample code and laminate layups

\begin{tabular}{ccc}
\hline Sample name & V-shape bend angle & Layup \\
\hline V90-QI1 & $90^{\circ}$ & {$[0 / 45 / 90 /-45]_{3 \mathrm{~s}}$} \\
V90-QI2 & $90^{\circ}$ & {$\left[0_{2} / 45_{2} / 90_{2} /-45_{2} / 0 / 45 / 90 /-45\right]_{\mathrm{s}}$} \\
V90-QI3 & $90^{\circ}$ & {$\left[0_{3} / 45_{3} / 90_{3} /-45_{3}\right]_{\mathrm{s}}$} \\
\hline V105-QI1 & $105^{\circ}$ & {$[0 / 45 / 90 /-45]_{3 \mathrm{~s}}$} \\
V105-QI2 & $105^{\circ}$ & {$\left[0_{2} / 45_{2} / 90_{2} /-45_{2} / 0 / 45 / 90 /-45\right]_{\mathrm{s}}$} \\
V105-QI3 & $105^{\circ}$ & {$\left[0_{3} / 45_{3} / 90_{3} /-45_{3}\right]_{\mathrm{s}}$} \\
\hline V120-QI1 & $120^{\circ}$ & {$[0 / 45 / 90 /-45]_{3 \mathrm{~s}}$} \\
V120-QI2 & $120^{\circ}$ & {$\left[0_{2} / 45_{2} / 90_{2} /-45_{2} / 0 / 45 / 90 /-45\right]_{\mathrm{s}}$} \\
V120-QI3 & $120^{\circ}$ & {$\left[0_{3} / 45_{3} / 90_{3} /-45_{3}\right]_{\mathrm{s}}$} \\
\hline
\end{tabular}

The prepared blanks were stamp formed into V-shape parts (see Figure 2.3) using a Pinette P.E.I. press equipped with an infrared (IR) oven and an automated shuttle transfer frame. Toggle clamps were used as the blank holder in the transport frame for this process. The blanks were heated using IR panels with a temperature of $465^{\circ} \mathrm{C}$ for 300 seconds, to reach a midplane temperature of $390^{\circ} \mathrm{C}$. The blanks were then rapidly transported towards the matched metal toolings. The forming was initiated by the downward movement of the male tool. The V-shape forming was completed by applying 40 bar consolidation pressure for 60 seconds while the laminate was cooled down to the tool temperature of $240^{\circ} \mathrm{C}$. 
After forming the blank into the V-shape geometry, a second press forming cycle was applied to unfold the V-shape part into a flat laminate. For this forming step, four springs at each corner of the V-shape part (see Figure 2.4), with a spring rate of $0.43 \mathrm{~N} / \mathrm{mm}$, were used to suspend the part in the transport frame. The V-shape part was reheated in the IR oven with the same settings as before. As shown in Figure 2.4, the corner section of the V-shape part was closer to the top IR panel (at approximately $10 \mathrm{~cm}$ distance) than the rest of the part. Therefore, this region melted first and immediately unfolded into a somewhat flat laminate due to the tension from the springs.
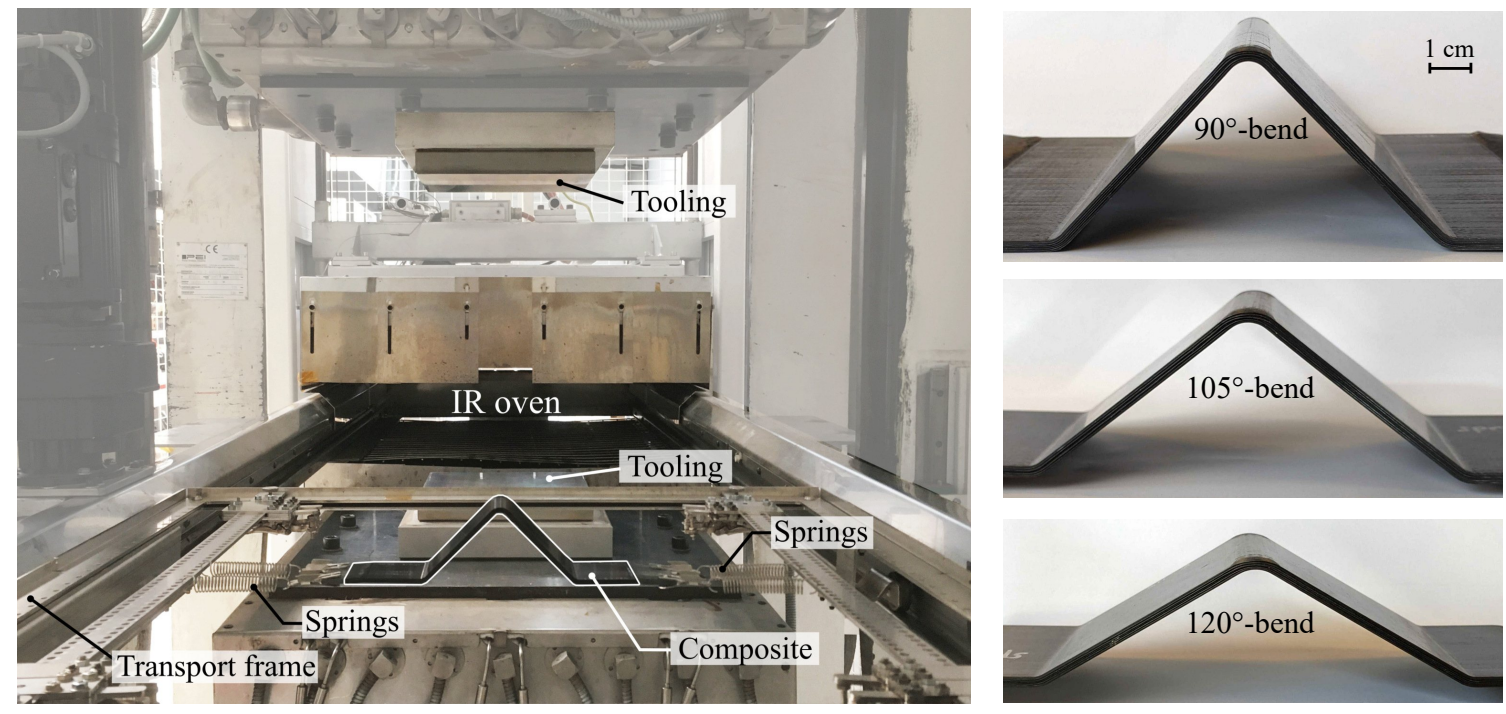

Figure 2.4 Formed V-shape part loaded into the transport frame prior to the flat forming process (left). Examples of the formed parts with three different geometries (right).

For the second forming step, a flat $250 \mathrm{~mm} \times 250 \mathrm{~mm}$ aluminum tooling coated with Marbocote 227CEE release agent was used in the same press as the first forming step. The flat forming was carried out by applying 100 bar consolidation pressure for 60 seconds, with the tooling temperature being kept at $240{ }^{\circ} \mathrm{C}$. The relatively high consolidation pressure was used to ensure void-free laminates. All of the formed laminates were subsequently assessed according to the methodology that is described in the following section.

\subsection{Assessment methods}

Two types of micrography analysis, i.e. on a cross-section ( $x-z$ plane view in Figure 2.5) and on the surface ( $x-y$ plane view), were performed in order to investigate the consolidation quality of the formed laminates, the number of wavy plies, and the wave parameters of the induced defects, i.e. maximum waviness angle $\left(\theta_{\max }\right)$ 
and defective region length. The methods to determine these parameters are further described in the following sections. Furthermore, X-ray micro-computed tomography (CT) analysis was carried out to evaluate the inner plies.

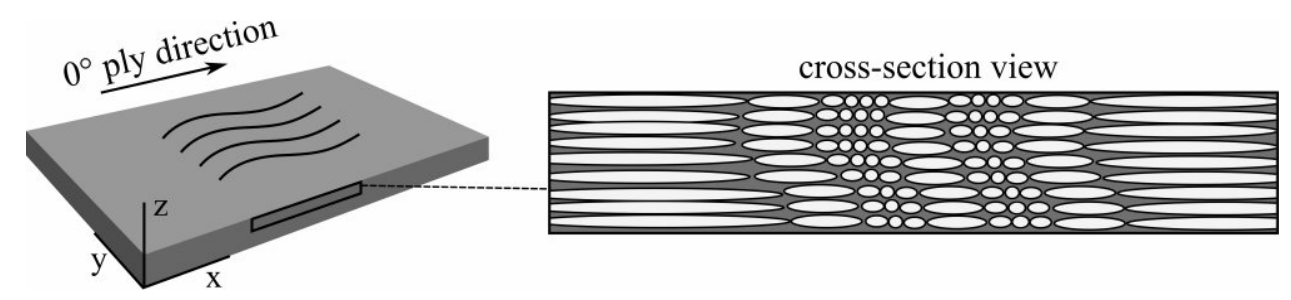

Figure 2.5 Schematic of the sections characterized for the assessment of the waviness. The right figure shows a portion of the cross-section of the wavy region in the top $0^{\circ}$ ply.

\subsubsection{Characterization methods}

\section{Cross-sectional microscopy}

Three specimens from each set of forming experiments were cut in the region of interest, embedded in epoxy, and then polished. The micrograph illustrated in Figure 2.5 was taken with a sectioning plane $(x-z)$ parallel to the main fiber direction in the surface ply by using a Keyence VHX-5000 digital microscope. Such a micrograph was taken to check for the presence of voids and determine the number of wavy plies. The cross-sectional shape of the fiber that is misaligned from the sectioning plane appears as an ellipse that has a small aspect ratio, i.e. major-axislength over minor-axis-length (see Figure 2.5). Therefore, the waviness region in the corresponding plies was identified by observing the shape of the fiber's cross-section.

\section{Surface microscopy}

Micrographs of the laminates were taken as-is from the wavy surface. Before the image acquisition, the surface was only prepared by applying a thin layer of sunflower oil on the sample's surface to enhance the visibility of the fiber patterns. The oil conceals the surface roughness of the laminate. In this way, less light is being scattered by the inherent roughness of the surface and more light is then directed through the objective lens, hence a clearer image can be observed. The effect is demonstrated in Figure 2.6. The surface micrographs were acquired using a Keyence VHX-5000 digital microscope with an objective lens magnification at 150x. The images were taken at a high resolution, i.e. at $1.5 \mu \mathrm{m}$ per pixel, in such a way that the individual fibers can be well distinguished. 


\section{X-ray micro-computed tomography}

X-ray tomography scans were performed using a Scanco vivaCT 40 on the specimen to observe the state of the waviness in the inner plies. 2D X-ray images of each ply were acquired with the resolution of $6 \mu \mathrm{m}$ pixel size and 23 slices through the thickness to visualize each ply within the laminate.

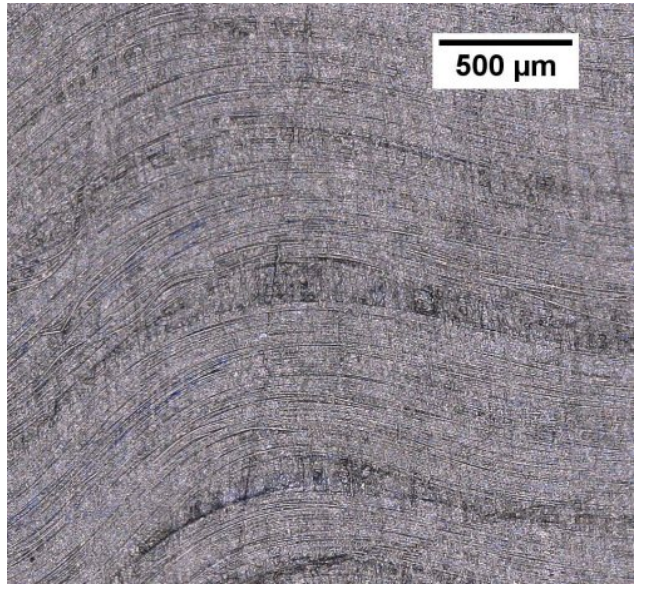

(a)

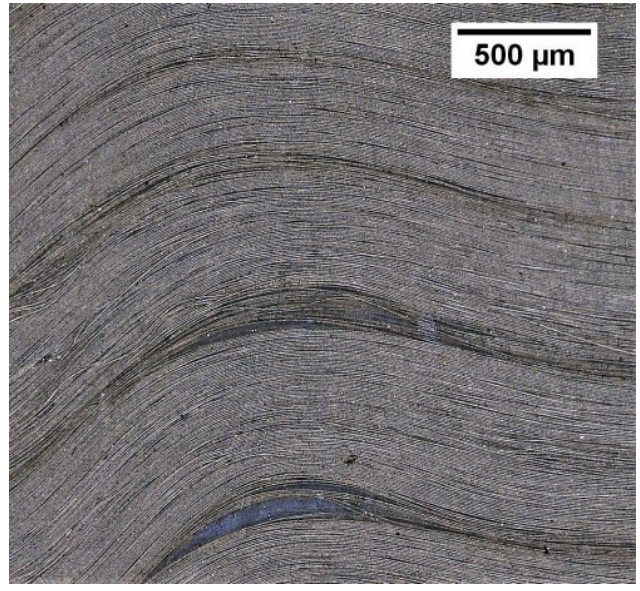

(b)

Figure 2.6 Surface micrographs of a laminate containing in-plane waviness: (a) as-is and (b) after the oil application.

\subsubsection{Waviness parameters measurement from surface microgra- phy}

For each formed laminate, five micrographs of $20 \mathrm{~mm} \times 12 \mathrm{~mm}$ were taken from the surface that displayed fiber waviness. The micrographs were taken at the center of the laminate, at the locations that were intended to be the unsupported gage section of the CLC test coupons. Furthermore, wavy regions found in industrial stamp-formed parts were evaluated as well to obtain reference values of the waviness severity found in actual parts. These parts were provided by a company that manufactures thermoplastic composite parts for aircraft. The examples were taken from aircraft primary structure ribs and aerodynamic surface stiffeners. The parts were made of quasi-isotropic laminates consisted of polyether-ketone-ketone (PEKK) matrix reinforced with standard modulus carbon fibers. Surface micrographs of 22.5 $\mathrm{mm} \times 22.5 \mathrm{~mm}$ were taken from the most severe wavy region of each part. The parts have an areal size of about $50 \mathrm{~cm} \times 15 \mathrm{~cm}$ with a nominal thickness of approximately $4 \mathrm{~mm}$. Following the agreement with the company, the detailed description of the parts cannot be disclosed in this thesis.

The fiber orientation was automatically measured by implementing the 'high resolution misalignment analysis' (HRMA) method developed by Wilhelmsson et 
al. [22] to the surface micrographs (see Figure 2.6), i.e. both from the formed laminates and the industrial stamp-formed parts. The micrograph of the specimen surface was taken with the nominal fiber orientation $\left(0^{\circ}\right)$ aligned to the longitudinal reference which was taken as the horizontal edge of the image. The image alignment procedure was done manually before performing the fiber orientation measurement. The HRMA method is fully automated, and in principle works by tracing the fiber segments individually within a small block from an image and measuring the fiber angles relative to a longitudinal reference. In the literature, there are other image analysis algorithms to automate fiber orientation measurement, i.e. the 'multiple field image analysis' method which determines the average fiber orientation by tracking light intensity variations [23], and the 'Fourier transform misalignment analysis' which uses Fourier transformation to compute the average fiber angle [24]. Both of these methods use a similar blockwise approach as the HRMA method, i.e. dividing the image into multiple small domains. However, in contrast to these two earlier methods, the HRMA method does not use a sophisticated algorithm as it only relies on tracing individual fibers from a binary image, hence a small computation time.
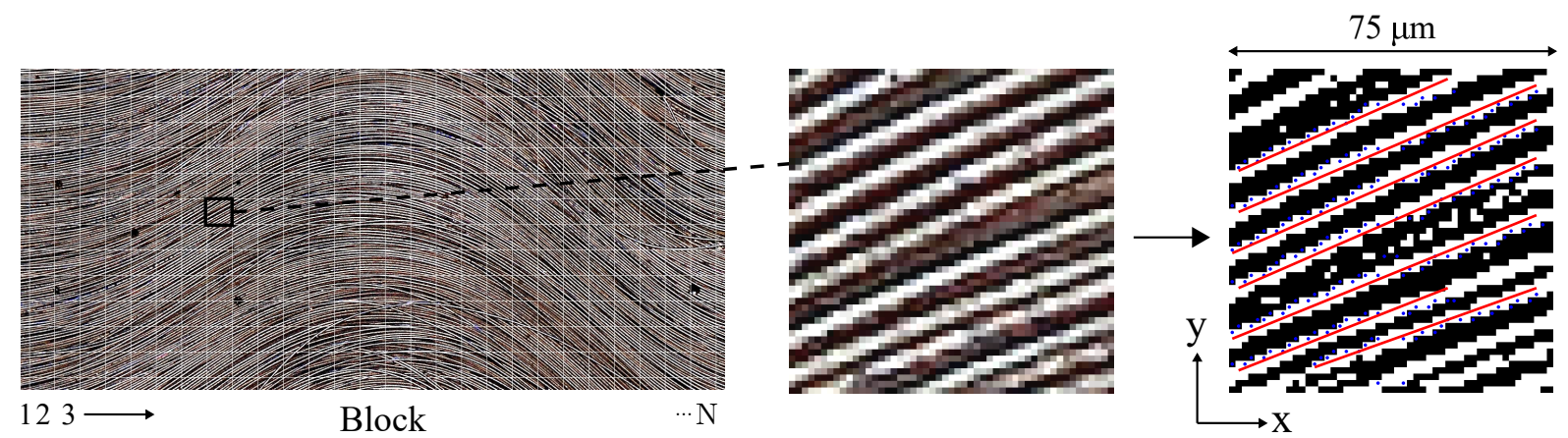

Figure 2.7 An example of traced fibers shown by the red lines in the black and white square image block (right) which was converted from the original micrograph with grids (left).

The image processing technique works by first dividing the micrograph into several square blocks. The size of each block determines the spatial resolution. A block size of $50 \times 50$ pixels $\left(75 \times 75 \mu^{2}\right)$ was used in this study. The image from each block is converted to a black and white binary image, with the white pixels representing the fibers, as shown in Figure 2.7. Fiber segments are traced in such a block based on continuity of the white pixels by moving one pixel step horizontally and then moving vertically up or vertically down, depending on the presence of the white pixels in a given direction. The ends of the fiber segments are marked if a black pixel is found, with the end points taken at the center of the fiber segments vertically. For an illustration of the traced fiber segments, red lines that pass the two end points of each fiber segment are shown in Figure 2.7. Interested readers are referred to the original paper for more detail of the algorithm [22]. Typically seven straight fiber segments were successfully measured for each block. Therefore, a total 
of approximately 300,000 measurements were performed on each micrograph. An example of the traced fiber segments in one square block is shown in Figure 2.7. The fiber angles $(\theta)$ are calculated based on the coordinates of each fiber segment's end points according to:

$$
\theta=\tan ^{-1}\left(\frac{y_{\mathrm{b}}-y_{\mathrm{a}}}{x_{\mathrm{b}}-x_{\mathrm{a}}}\right)
$$

where $a$ and $b$ are the labels for the ends of the fiber segments, while $x$ and $y$ represent the horizontal and vertical coordinates of the points, respectively. The angular orientation of each individual block here was calculated as the mean angle of the fiber segments in each block. The output of the HRMA method is the fiber angle as a function of position across the entire micrograph which was represented as a contour map of the fiber angles.

The maximum waviness angle is defined in this chapter as the absolute maximum value of the measured fiber angle from a given micrograph of a test specimen. The term waviness angle is used as it is considered more appropriate to represent the deviation of fiber angle in the waviness region, instead of the term misalignment which may imply that the fibers are misoriented but may still be straight fibers.

The surface micrographs of the test coupons contain in most cases one or two wavy regions as illustrated in Figure 2.8. The defective region length, indicated as $L_{\mathrm{W}}$ in Figure 2.8, was measured manually from the corresponding micrograph. $L_{\mathrm{w}}$ is defined as the distance between the outermost edges of the wavy regions within a test coupon, along the nominal fiber direction of the wavy ply.

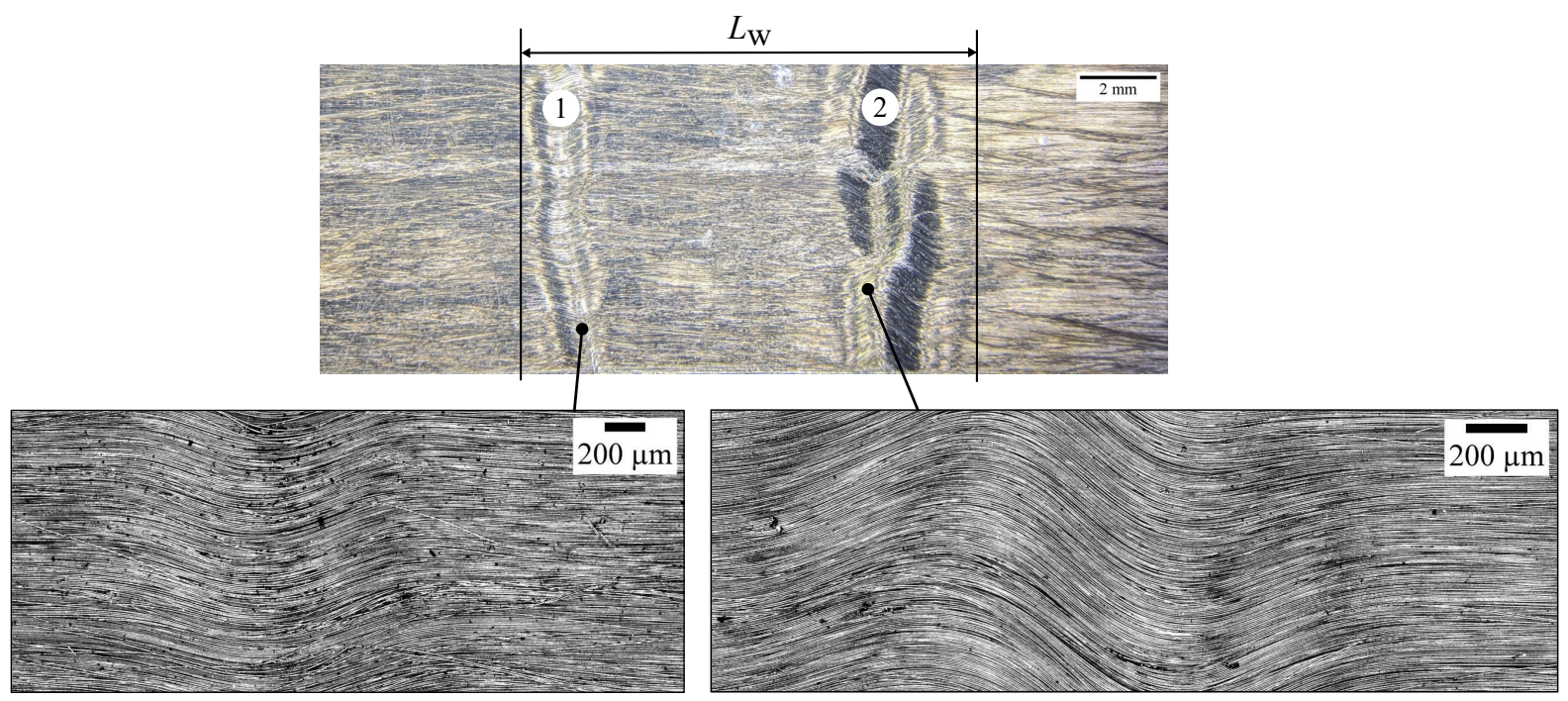

Figure 2.8 An example of two wavy regions in a test coupon. $L_{w}$ indicates the defective region length. Wavy region 1 has a smaller maximum waviness angle than wavy region 2. 


\subsection{Results}

The first stamp forming step produced V-shape parts with waviness localized on the concave surface of the three corner sections shown earlier in Figure 2.3. However, after the second stamp forming step, this initial waviness was no longer observed on the same surface. The fibers at these positions appeared to be straightened back during the flattening of the $\mathrm{V}$-shape parts. Instead, all of the laminates, after flat forming, had pronounced waviness visible on the surface that was on the convex side, in the middle V-shape corner section. The other two corner sections showed slight waviness after flattening, which appeared to be similar to the pre-existing random fiber misalignment which is sometimes found on the surface of flat laminates produced by press consolidation.

The representative cross-sectional micrographs in Figure 2.9 illustrate the result of forming experiments for the QI1 and QI2 laminates. These micrographs were taken from the section parallel to the $0^{\circ}$ ply fiber orientation. All laminates from the forming experiments, from all three different V-shape geometries (V90, V105, and V120), have similar cross-sections. They all show that the laminates have good consolidation quality indicated by the absence of voids. The forming experiments of the QI1 and QI2 samples produced laminates with localized in-plane waviness visible on the top side of the micrographs, where the fibers in the wavy region within the $0^{\circ}$ plies appeared as ellipses with a small aspect ratio.
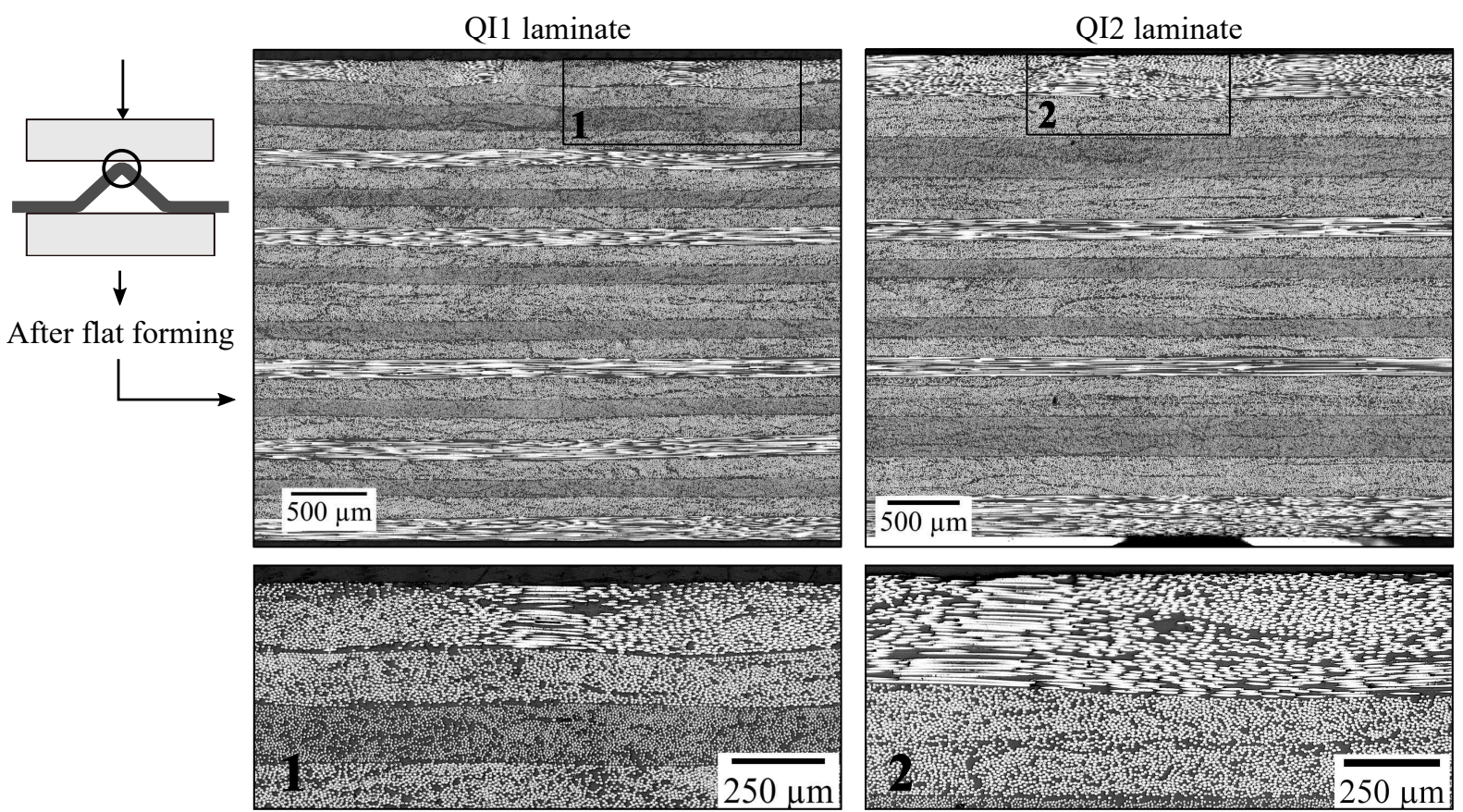

Figure 2.9 Representative cross-sectional micrographs of the reverse-formed QI1 and QI2 laminates, taken from the location which was initially the middle corner section of the V-shape part. 
For the QI1 samples, only a single outermost $0^{\circ}$ ply from the convex side of the middle corner section appeared to show waviness, as can be observed from the fiber cross-sectional shapes in the micrograph shown in Figure 2.9. An X-ray CT scanning of the QI1 laminate was also performed to check for waviness in the inner plies. The result presented in Figure 2.10 confirms that the in-plane waviness was only formed in the first $0^{\circ}$ ply. For the QI2 samples, both outermost $0^{\circ}$ plies from the convex side, as observed in Figure 2.9, have in-plane waviness defects. The fiber crosssectional shapes of the second $0^{\circ}$ ply from the top of Figure 2.9 have a larger aspect ratio than that of the surface. This means that the fibers are becoming more aligned with the nominal fiber orientation of the ply in conjunction with the increase of the depth. For this reason, measurement of the fiber orientation through the thickness was not performed, as the most severe waviness induced by the reverse forming was on the surface ply. Furthermore, these results show that the waviness was induced in the outermost ply that is oriented in the bending direction of the laminate during forming.
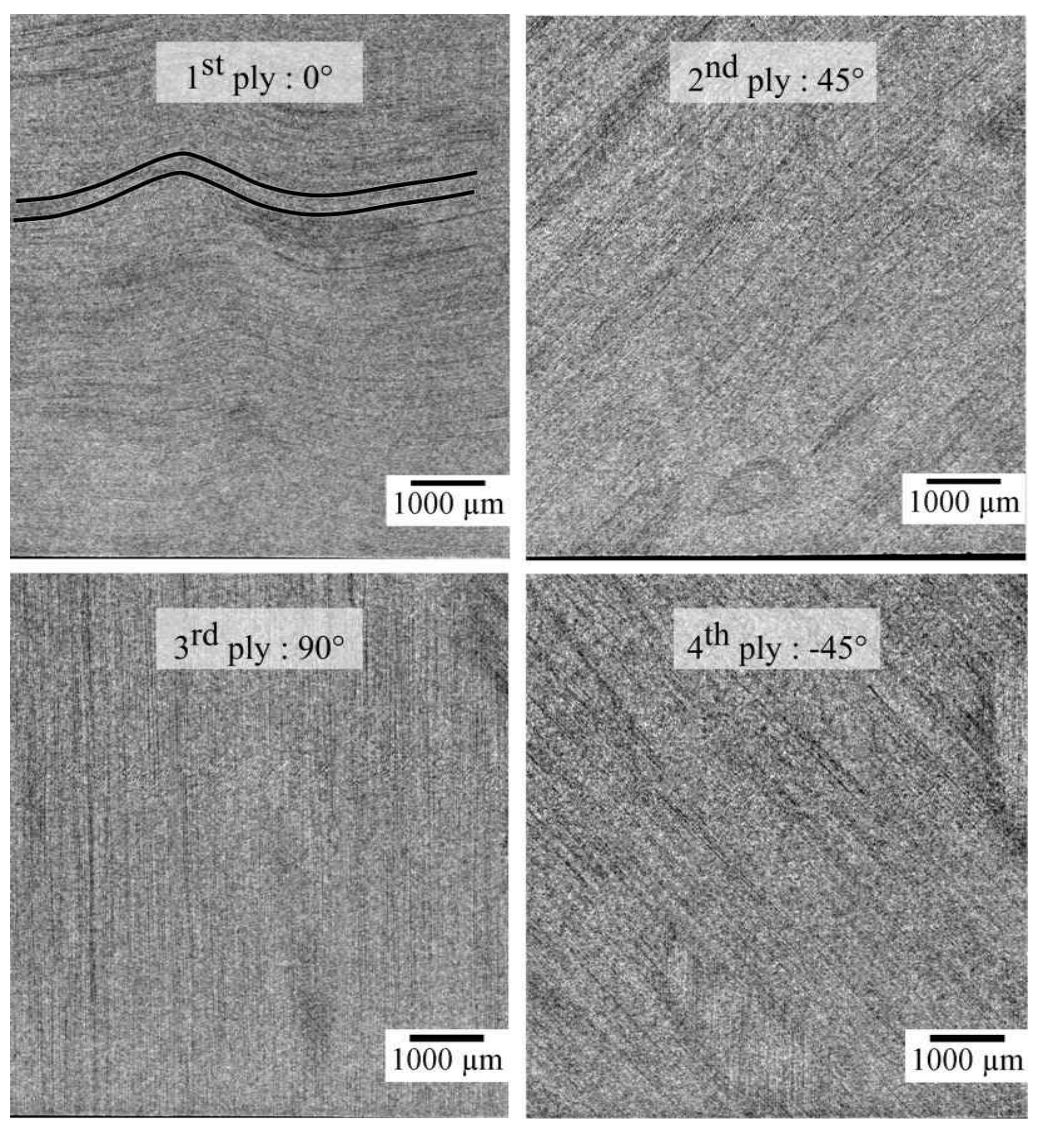

Figure 2.10 X-ray microCT scan result of the V90-QI1 specimen showing the four topmost plies with in-plane waviness only visible in the first $0^{\circ}$ ply. Some wavy fibers in the $0^{\circ}$ ply are highlighted for illustration purpose.

The representative cross-sectional micrographs from the QI3 laminates formed using 
the three different V-shape toolings (see Table 2.1), are shown in Figure 2.11. These micrographs were also taken at the region with waviness in a similar way as the micrograph in Figure 2.9. Also here, the micrographs indicate that the QI3 laminates have good consolidation quality. Similar to the QI2 laminates, only the outermost $0^{\circ}$ plies from the convex side of the middle V-shape corner section showed waviness. However, not all forming experiments produced wavy fibers over the full thickness of the outermost $0^{\circ}$ plies. Only the reverse forming experiments with the $90^{\circ}$-bend angle produced laminates having wavy fibers over the full thickness of the entire top three $0^{\circ}$ plies, as indicated by the arrow in Figure 2.11a. Conversely, Figure 2.11b and $c$ indicate that the forming experiments using the V-bend angles of $105^{\circ}$ and $120^{\circ}$ yielded partial waviness through the thickness of the top $0^{\circ}$ plies. There are several fibers, albeit a very small fraction, in the innermost part of the third $0^{\circ}$ plies that are not wavy. Moreover, Figure 2.11 shows that the ply at the wavy region appeared to be thicker than the region adjacent to it, although the overall laminate had a constant thickness.

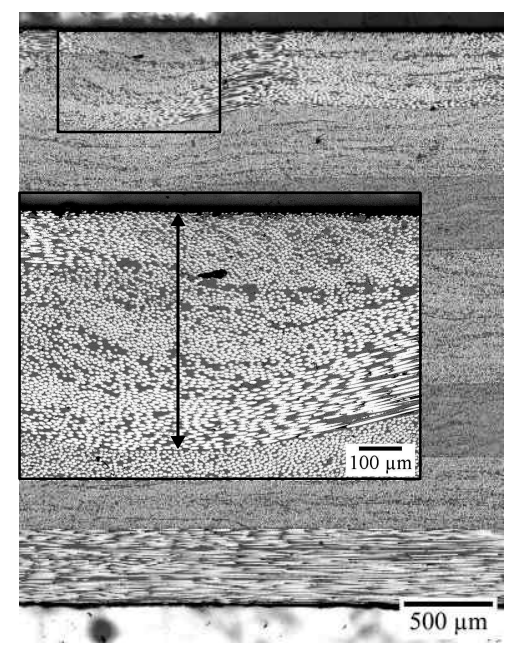

(a)

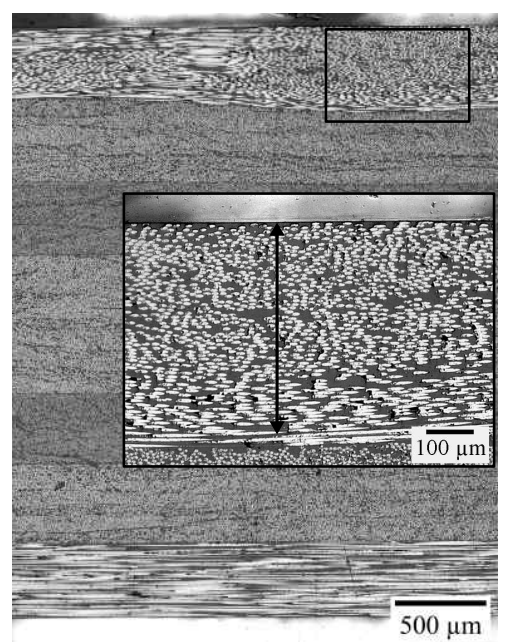

(b)

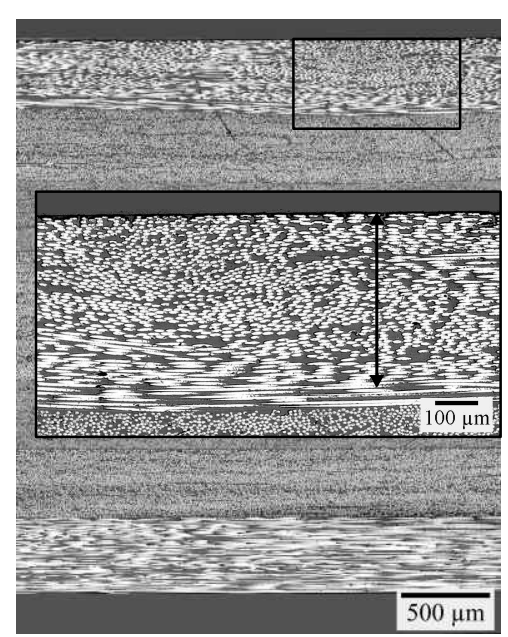

(c)

Figure 2.11 Representative cross-sectional micrographs of the QI3 laminates taken from the region with waviness: (a) V90-QI3, (b) V105-QI3, and (c) V120-QI3 laminates. These micrographs were extracted from the laminates at the section where the middle corners of the V-shape parts were initially located. The arrows indicate the portions of the $0^{\circ}$ plies that show inplane waviness.

Representative micrographs from both the top and bottom surfaces of the produced QI1 laminate are shown in Figure 2.12. All laminates (as listed in Table 2.1) have a similar surface appearance, hence only one example is presented here. No fiber breakage was observed in the wavy region after reverse forming. As can be seen from the contour maps of the fiber angle in Figure 2.12, the waviness was only observed on the top surface at the location which was initially the middle V-shape corner section. The formed laminates have one to three wavy regions within the region of interest, 
i.e. the $20 \mathrm{~mm}$ gage length. As presented earlier in Figure 3.4, the majority of the laminates have two wavy regions. The induced waviness appeared as a continuous wavy region extending throughout the entire width of the laminate.
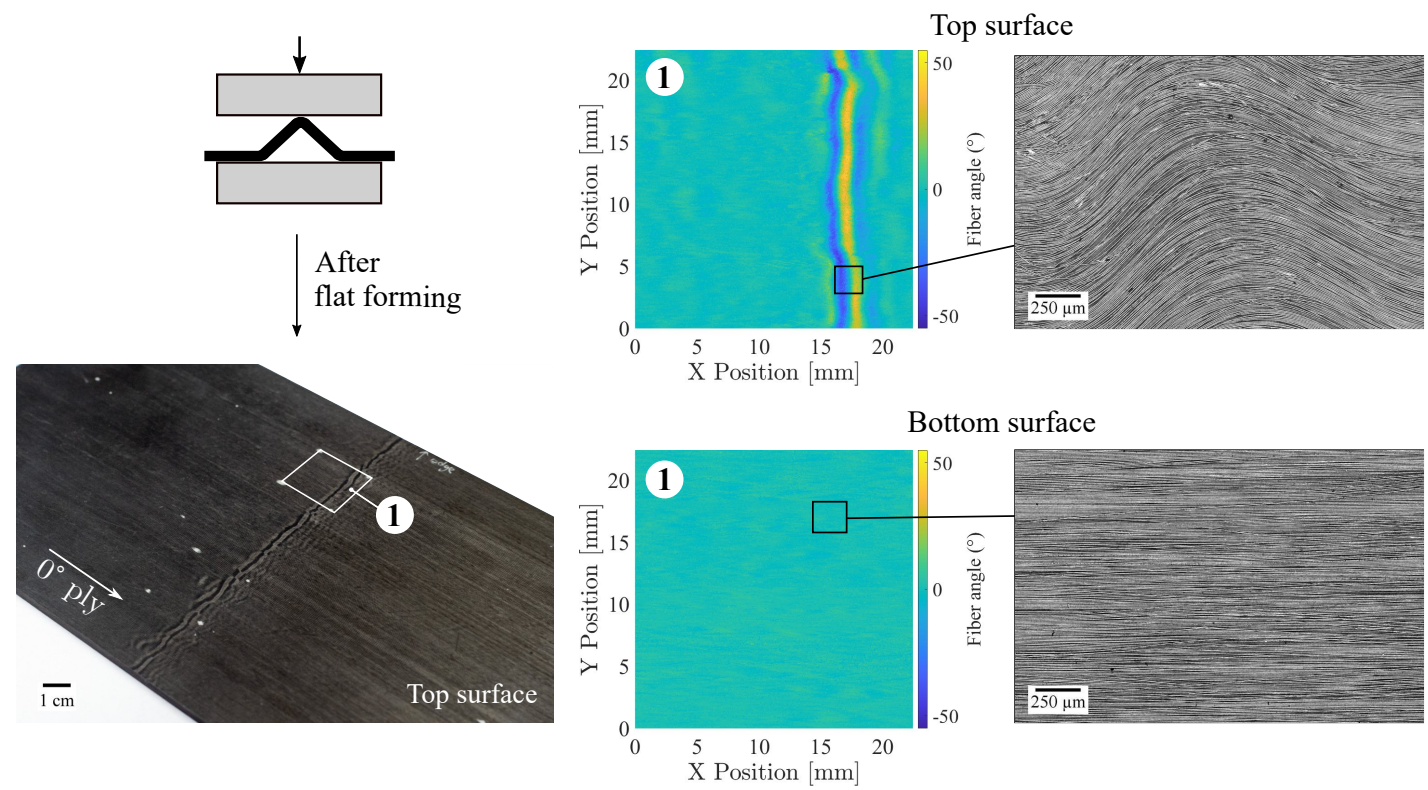

Figure 2.12 Reverse forming result of the QI1 laminate. In-plane waviness is visible only from the location which was initially the convex side of the middle V-shape corner section. The white square shown on the left picture indicates the fiber angle measurement area. The contour maps visualize the spatial distribution of fiber angles measured from the surface micrographs as taken from both the top and bottom surfaces within the white square.

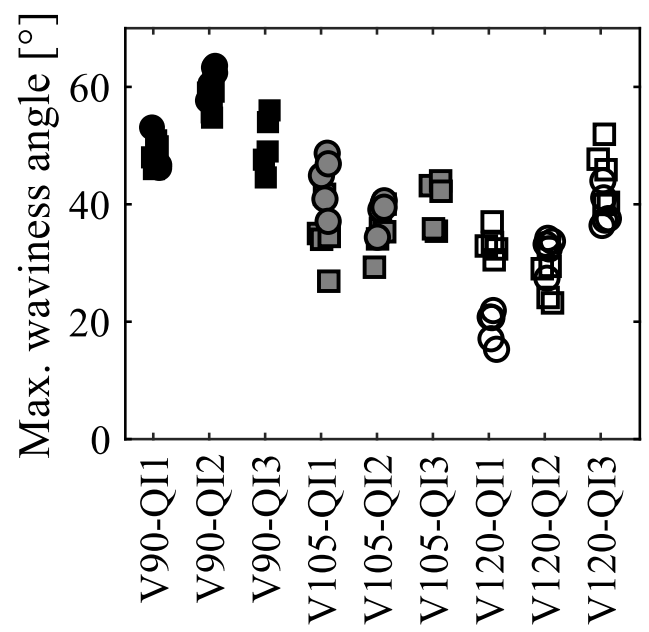

Figure 2.13 Maximum waviness angle $\left(\theta_{\max }\right)$ of the laminates formed using various $V$-shape geometries. Each symbol represents the result from one laminate, and each data point represents the measurement result from a single surface micrograph of the test coupon. Five measurements were performed for each laminate to evaluate the variation within a laminate. 
The characterization results from the surface micrographs, such as the one illustrated in Figure 2.12, for all reverse forming experiments are shown in Figure 2.13. The measured maximum waviness angle $\left(\theta_{\max }\right)$ in Figure 2.13 shows a decreasing trend with an increasing $\mathrm{V}$-shape bend angle and inner radius, although the relation is not as obvious for the larger bending angles, while there is no clear trend observed for $\theta_{\max }$ with the layup. The variation of $\theta_{\max }$ within a single laminate was found to be small, with the largest standard deviation of $5^{\circ}$ from all forming experiments. Furthermore, the formed laminates had defective region lengths $\left(L_{\mathrm{W}}\right)$ in the range between $3-18 \mathrm{~mm}$. The smallest length of about $3 \mathrm{~mm}$ was from the V90-QI1 laminates. These V90-QI1 laminates only had a single wavy region.

Reverse forming experiment

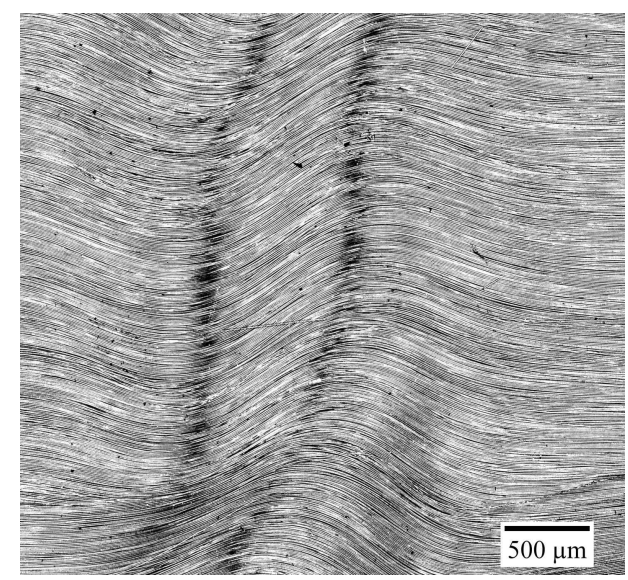

Example from an industrial part

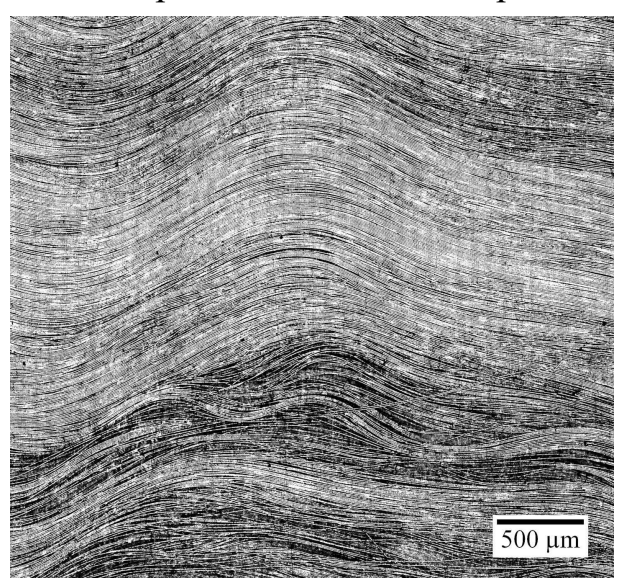

Figure 2.14 Sections of the typical waviness found on the surface of a reverse-formed laminate and from a stamp-formed industrial part.

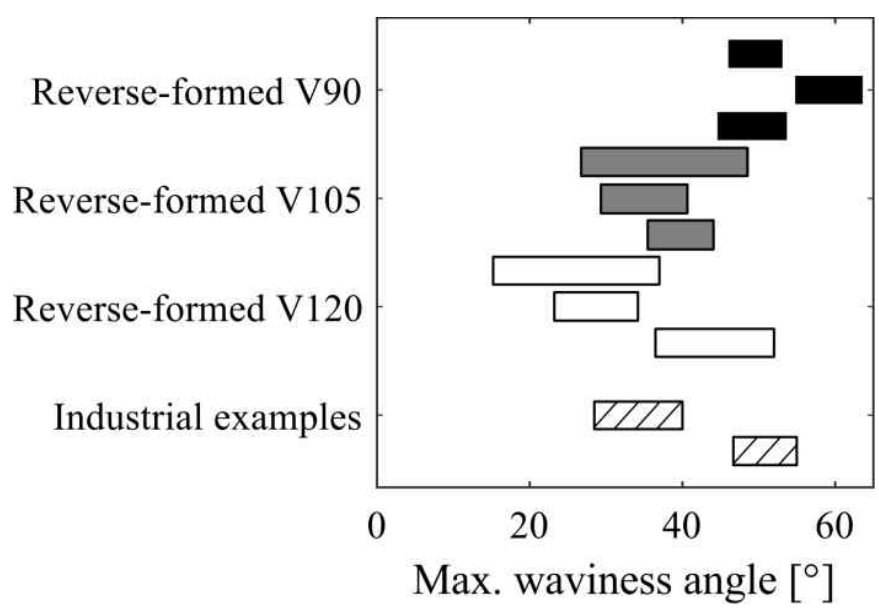

Figure 2.15 Comparison between the range of maximum waviness angle $\left(\theta_{\max }\right)$ obtained from the laminates manufactured by using the reverse forming method and the examples of industrial composites parts. 
All of the industrial parts evaluated in this work have multiple wavy patches scattered on the concave surface. An example of the fiber waviness found in an industrial stamp-formed part is shown on the right side of Figure 2.14. The waviness reproduced in this work (see the left figure in Figure 2.14) clearly mimics the appearance of waviness from the industrial example. The comparison of $\theta_{\max }$ from the reverse-formed laminates and the industrial parts is shown in Figure 2.15. The largest $\theta_{\max }$ from the industrial examples was up to $55^{\circ}$, which is comparable to the reverse-formed V90 laminates which represent the upper end of $\theta_{\max }$ from the forming experiments.

\subsection{Discussion}

The developed coupon manufacturing method makes use of stamp forming and thus employs the same conditions under which waviness is formed during this process in industrial practice. It is worth mentioning that the laminates have been exposed to two thermal cycles which represent the stamp forming process. A separate study on the thermal stability of the same material, however, has shown that no significant change in the degree of crystallinity was found even with a much longer exposure time of up to 20 minutes in the IR oven with the temperature set at $470^{\circ} \mathrm{C}$ [27]. This indicates that there is no significant degradation, even in a much more severe condition.

The first stamp forming step to manufacture the V-shape part already induced waviness in the inner radius. Similarly to that, the waviness from the industrial stamp-formed parts was also only observed on the concave surface. It is known that bending of a laminate with different fiber orientations is dominated by inter-ply slip to accommodate the path length difference of each ply around the bend [11]. During forming of a radius, if the inter-ply slippage is inhibited by inter-ply friction or constrained boundary conditions, axial compressive stresses are built up in the plies. The fibers in the plies at the inner radius can buckle when the critical buckling stress is reached. After the second stamp forming step, the waviness was only visible on one surface, as shown in Figure 2.12. The wavy region in the reverse-formed laminate was localized in the middle of the laminate where the convex side of the middle V-shape corner section was initially located. As mentioned earlier, bending of a blank requires inter-ply slip. As a result of this deformation, the plies at the inner radius have slipped with respect to the plies at the outer radius. During heating in the IR oven, when the matrix has melted, the V-shape part was already unfolded into a somewhat flat laminate due to the tension from the springs. In this stage, the excess ply length manifested mainly in the middle outer radius of the V-shape part. After the application of pressure during the second stamp forming step, waviness was formed at such a region with excessive material. Similar to the wrinkle formation 
mechanism over a radius, the excess material, in this case, has to be accommodated through buckling of the fibers in the form of in-plane waviness [28-30].

As previously observed from the cross-sectional micrographs, the reverse forming method appears to satisfy the first requirement, i.e. the technique is able to produce laminates with good consolidation quality. Furthermore, the X-Ray microCT scan and the micrographic analysis of the cross-section confirmed that the wavy plies were induced only in the outermost $0^{\circ}$ plies that are oriented in the bending direction of the laminate during forming. Up to three $0^{\circ}$ plies, which were stacked directly on top of each other, were found to be wavy. The extent of the waviness through the thickness of a ply was found to be consistent for all of the QI1 and QI2 samples, irrespective of the bend angles used during the forming experiments. However, for the QI3 samples, there were slight variations in the thickness of the wavy region within the third innermost $0^{\circ}$ ply (see Figure 2.11). This may be explained by the variation of compressive force through the thickness that was induced during the reverse forming process.

The characterization results showed that a wide range of maximum waviness angles between $14^{\circ}$ to $64^{\circ}$ was obtained from the forming experiments. As expected, the larger the bend angle and inner radius of the V-shape, the smaller the waviness severity (in terms of $\theta_{\max }$ ). This is primarily due to the smaller path difference between the top and bottom layers, which yields less excess material at the corner section, hence less severe waviness. This means that the variation in the formed waviness, in terms of $\theta_{\max }$, can be controlled significantly by varying the V-shape geometry.

The applicability of the reverse forming method to mimic the typical waviness defects observed from TPC part production is evaluated by comparing the $\theta_{\max }$ of the produced laminates with the examples from several industrial composite parts described earlier. It was found that the reverse-formed laminates cover a broader spectrum than the industrial examples at both ends of $\theta_{\max }$ value. Therefore, considering the second requirement, it can be concluded that the method proposed in this chapter can produce specimens with a wide range of maximum waviness angles that are representative of typical defect characteristics from industrial practice.

Finally, considering the last requirement of the coupon manufacturing method, the localized waviness in the laminates produced in this work are well suited for extracting standard mechanical test coupons. The defective region lengths in all of the produced laminates are smaller than the $20 \mathrm{~mm}$ requirement which conforms to the required length for the unsupported gage section of standard CLC test coupon [25]. As an example, Figure 4.5 illustrates the layout of the laminate after trimming. Five CLC test coupons according to the dimensions in ASTM D6641 [25] can be cut out from the laminate in such a way that the wavy region can be isolated within the unsupported gage length of $20 \mathrm{~mm}$. Although this work has only reproduced waviness in compression test coupons, the same manufacturing 
method can be used to fabricate test coupons meant for other types of standard mechanical testing typically performed for material qualification. This is possible since the laminate manufactured using the reverse forming method is in principle a generic flat laminate.

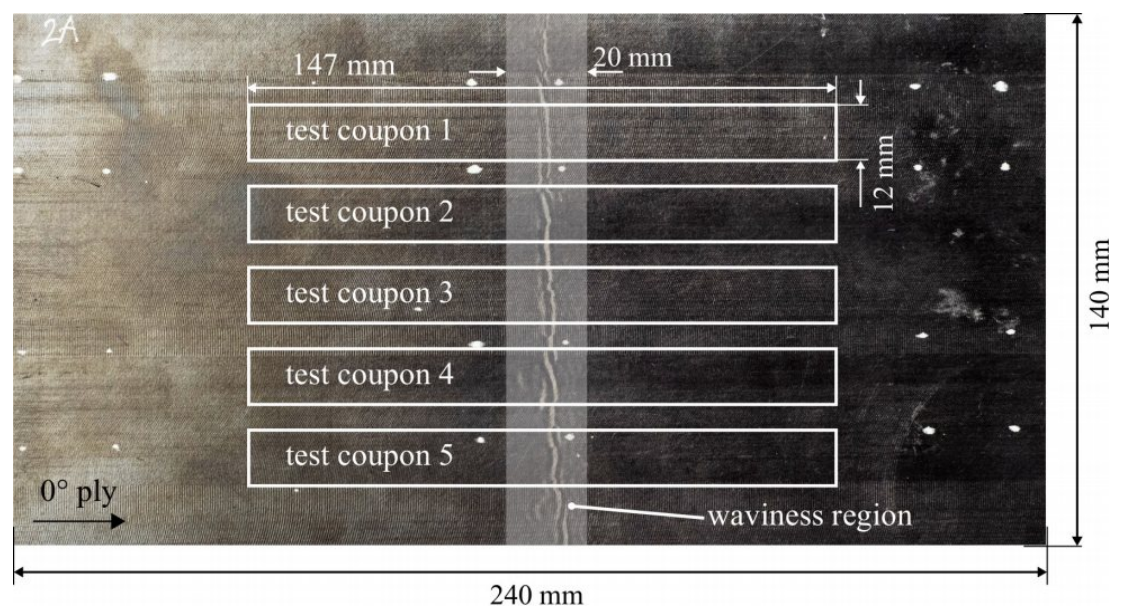

Figure 2.16 Layout of the laminate with the reproduced waviness and test coupons for standard compression test following the CLC test method according to ASTM D6641.

\subsection{Conclusions}

A test coupon manufacturing method based on a so-called 'reverse forming' process has been described in this chapter. This method works by unfolding a V-shape part using a stamp forming process and therefore directly mimics the mechanisms by which waviness is formed during this process in industrial practice. With this manufacturing method, the intended wavy plies have to be oriented in the bending direction of the laminate during forming. Several combinations of bending angles and inner radii of the $\mathrm{V}$-shape geometry were evaluated in this work to control the waviness severity.

The experimental results showed that all of the formed 24-ply QI laminates have no voids. Analysis of the surface micrographs showed that a wide range of maximum waviness angles $\left(\theta_{\max }\right)$, between $14^{\circ}$ to $64^{\circ}$, was successfully obtained in this work. The larger $\theta_{\max }$ was obtained from forming with the smaller V-shape bend angle and inner radius. By comparing the $\theta_{\max }$ value of the produced laminates and the examples of industrial stamp-formed composite parts, it can be concluded that the developed coupon manufacturing method can reliably reproduce the waviness from actual TPC part production. Furthermore, all of the produced laminates had defective region lengths smaller than $20 \mathrm{~mm}$. The waviness is small enough such that all of the wavy fibers can be contained within the unsupported gage section of a standard compression test coupon, which will be required for determining defect allowable 
limits. In summary, this work has demonstrated the applicability of the reverse forming method to reproduce test coupons with waviness which mimics the typical waviness defects characteristics from TPC production. This experimental technique can be used to facilitate future studies on the effect of waviness on the resulting mechanical properties and can contribute to expanding the database of the effect of waviness and defining the allowance limit. This method can be applied to reproduce waviness in test coupons meant for standard mechanical testing typically performed for material qualification.

\section{References}

[1] H. Alshahrani. Characterization and finite element modeling of coupled properties during polymer composites forming processes. Mechanics of Materials, 144:103370, 2020.

[2] B. Budiansky and N. A. Fleck. Compressive failure of fibre composites. Journal of the Mechanics and Physics of Solids, 41(1):183-211, 1993.

[3] M. R. Piggott. The effect of fibre waviness on the mechanical properties of unidirectional fibre composites: a review. Composites science and technology, 53(2):201-205, 1995.

[4] P. J. Joyce and T. J. Moon. Compression Strength Reduction in Composites with inPlane Fiber Waviness, pages 76-96. ASTM International, West Conshohocken, PA, 1998.

[5] S. N. Nair, A. Dasari, C. Y. Yue, and S. Narasimalu. Failure behavior of unidirectional composites under compression loading: Effect of fiber waviness. Materials (Basel, Switzerland), 10(8):909, 2017.

[6] D. Wilhelmsson, R. Gutkin, F. Edgren, and L. E. Asp. An experimental study of fibre waviness and its effects on compressive properties of unidirectional NCF composites. Composites Part A: Applied Science and Manufacturing, 107:665-674, 2018.

[7] S. Mukhopadhyay, M. I. Jones, and S. R. Hallett. Compressive failure of laminates containing an embedded wrinkle; experimental and numerical study. Composites Part A: Applied Science and Manufacturing, 73:132-142, 2015.

[8] B. Khan, K. D. Potter, and M. R. Wisnom. Simulation of process induced defects in resin transfer moulded woven carbon fibre laminates and their effect on mechanical behaviour. In The 8th International Conference on Flow Processes in Composite Materials (FPCM8), 2006.

[9] J. F. Mandell, D. D. Samborsky, and L. Wang. Effects of fiber waviness on composites for wind turbine blades. In 48th International SAMPE symposium, volume 48, 2003.

[10] A. Shipsha, S. Hallström, and M. Burman. Effect of stacking sequence and 
bundle waviness in quasi-isotropic NCF composites subjected to compression. Composites Part B: Engineering, 178:107423, 2019.

[11] U. Sachs. Friction and bending in thermoplastic composites forming processes. PhD Thesis. University of Twente, 2014.

[12] C. Wu, Y. Gu, L. Luo, P. Xu, S. Wang, M. Li, and Z. Zhang. Influences of inplane and out-of-plane fiber waviness on mechanical properties of carbon fiber composite laminate. Journal of Reinforced Plastics and Composites, 37(13):877-891, 2018.

[13] J. Galos. Novel method of producing in-plane fibre waviness defects in composite test coupons. Composites Communications, 17:1-4, 2020.

[14] M. R. Wisnom and J. W. Atkinson. Fibre waviness generation and measurement and its effect on compressive strength. Journal of Reinforced Plastics and Composites, 19(2):96-110, 2000.

[15] K. Engel, P. Horst, T. Hundt, C. Schmidt, and B. Denkena. Effect of manufacturing process induced fiber waviness on mechanical properties of composite structures by example of a prepreg forming process. In 16th European Conference on Composite Materials, ECCM 2014, 2014.

[16] W. J. R. Christian, F. A. Diazdelao, K. Atherton, and E. A. Patterson. An experimental study on the manufacture and characterization of in-plane fibrewaviness defects in composites. Royal Society Open Science, 5(5), 2018.

[17] C. Zhao, Jun Xiao, Yong Li, Qiyi Chu, Ting Xu, and Bendong Wang. An experimental study of the influence of in-plane fiber waviness on unidirectional laminates tensile properties. Applied Composite Materials, pages 1-17, 2017.

[18] N. Xie, R. A. Smith, S. Mukhopadhyay, and S. R. Hallett. A numerical study on the influence of composite wrinkle defect geometry on compressive strength. Materials E Design, 140:7-20, 2018.

[19] D. Wilhelmsson, R. Talreja, R. Gutkin, and L. Asp. Compressive strength assessment of fibre composites based on a defect severity model. Composites Science and Technology, 181:107685, 2019.

[20] T. W. Riddle, J. W. Nelson, D. S. Cairns, and J. E. Workman. Effects of Defects : Part A -Development of a Protocol for Defect Risk Management \& Improved Reliability of Composite Structures. 53nd AIAA/ASME/ASCE/AHS/ASC Structures, Structural Dynamics and Materials Conference, 2012.

[21] J. Wang, K. D. Potter, K. Hazra, and M. R. Wisnom. Experimental fabrication and characterization of out-of-plane fiber waviness in continuous fiber-reinforced composites. Journal of Composite Materials, 46(17):2041-2053, 2012.

[22] D. Wilhelmsson and L. Asp. A high resolution method for characterisation of fibre misalignment angles in composites. Composites Science and Technology, 165, 2018.

[23] C. J. Creighton, M. P. F. Sutcliffe, and T. W. Clyne. A multiple field image analysis procedure for characterisation of fibre alignment in composites. Composites Part A: Applied Science and Manufacturing, 32(2):221-229, 2001. 
[24] K. K. Kratmann, M. P. F. Sutcliffe, L. T. Lilleheden, R. Pyrz, and O. T. Thomsen. A novel image analysis procedure for measuring fibre misalignment in unidirectional fibre composites. Composites Science and Technology, 69(2):228238, 2009.

[25] ASTM. ASTM D6641 - Standard Test Method for Compressive Properties of Polymer Matrix Composite Materials Using a Combined Loading Compression (CLC) Test Fixture, 2001.

[26] Toray Advanced Composites. Cetex TC1200 PEEK - Technical Data Sheet, 2019.

[27] M. van der Werff. TPRC internal report September 2019: Thermal stability of PAEK composites. Report, TPRC, 2019.

[28] T. J. Dodwell, R. Butler, and G. W. Hunt. Out-of-plane ply wrinkling defects during consolidation over an external radius. Composites Science and Technology, 105:151-159, 2014.

[29] P. Hallander, M. Akermo, C. Mattei, M. Petersson, and T. Nyman. An experimental study of mechanisms behind wrinkle development during forming of composite laminates. Composites Part A: Applied Science and Manufacturing, 50:54-64, 2013.

[30] J. P.-H. Belnoue, O. J. Nixon-Pearson, A. J. Thompson, D. S. Ivanov, K. D. Potter, and S. R. Hallett. Consolidation-driven defect generation in thick composite parts. Journal of Manufacturing Science and Engineering, 140(7), 2018. 



\title{
CHAPTER 3
}

\section{Effect of in-plane fiber waviness on compressive properties of laminates*}

\begin{abstract}
The influence of in-plane fiber waviness defects on the compressive properties of quasi-isotropic (QI) carbon polyether-ether-ketone (C/PEEK) composites was investigated experimentally. Specimens with localized waviness were manufactured using a stamp forming process resulting into laminates featuring multiple wavy plies, i.e. from one to three wavy $0^{\circ}$ plies in a 24-ply QI composite and a range of maximum waviness angle between $23^{\circ}$ to $60^{\circ}$. No significant influence of the waviness was found on the coupon stiffness. Compression tests coupled with high-speed camera monitoring were performed to study the failure process. It was confirmed that the waviness defects act as a trigger for the initiation of damage, predominantly by the kinking mechanism, resulting into an early failure and significantly lower ultimate strength than the baseline when loading in $0^{\circ}$ direction. Furthermore, it was found that all specimens with waviness and with the same layup have a similar strength, indicating that the maximum waviness angle within the range studied in this work did not significantly influence the ultimate compressive strength. However, the presence of waviness in multiple plies clearly affected the strength. It was found that the ultimate compressive strength decreased proportionally to the percentage of plies oriented in the loading direction that is wavy.
\end{abstract}

${ }^{*}$ Reproduced from Sitohang, R.D.R., Grouve, W.J.B., Warnet, L.L., Akkerman, R., Effect of in-plane fiber waviness defects on the compressive properties of quasi-isotropic thermoplastic composites, Composite Structures 272 114166, 2021. https://doi.org/10.1016/j.compstruct.2021.114166 


\subsection{Introduction}

\subsubsection{Background}

Continuous fiber reinforced thermoplastic composites (TPCs) are increasingly used over recent decades. These materials are becoming more common, especially in the aerospace industry, as they are ideal for lightweight structure applications. This is mainly owing to their appealing mechanical properties and melt-processable nature which enable short processing times and allow parts to be welded. Manufacturing sometimes leads to defects in TPC parts, such as fiber waviness. As an example, Figure 3.1 shows in-plane waviness as created during a stamp forming process. Waviness can act as a trigger for micro-buckling failure, or kink band formation, which then leads to an early failure when the structure is loaded under compression [1-4]. There is a lack of quantitative data and predictive tools for the mechanical performance of parts having fiber waviness, particularly for multidirectional TPC materials. In industrial settings, this practically often leads to rejection of the manufactured part due to the uncertainty and possible risk associated with the waviness defects.

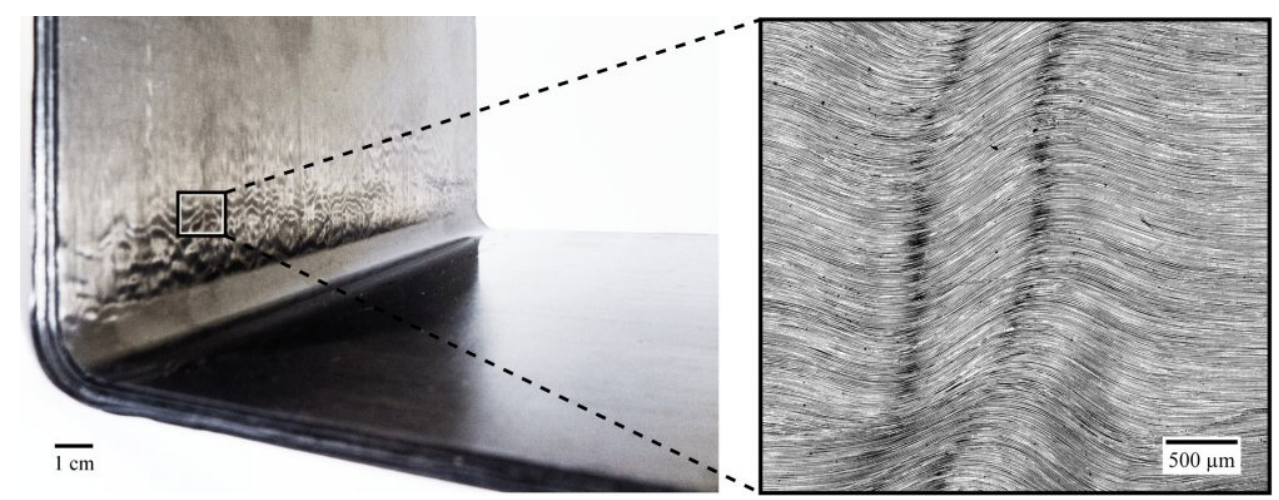

Figure 3.1 In-plane waviness defects in an L-shaped stamp-formed QI C/PEEK composites part

The waviness defects detected after manufacturing are typically visible on the surface of the laminate and can extend to several plies deep, depending on the processing technique and parameter, and the layup. For the stamp forming process of a curved part where rigid matched metal tools are used, the waviness is typically in the plane of the laminate and is found on the concave surface (Figure 3.1). The waviness defects are localized in the regions which have been subjected to compressive loads during processing and are only present in a few plies within the laminate. It has been demonstrated in a previous study that the waviness in stamp-formed TPC parts can be up to $55^{\circ}$ [5].

Reducing the scrap generated during processing due to induced fiber waviness requires a proper understanding of the effect of waviness on the mechanical behavior. 
Eventually, this may lead towards a proper definition of accept/reject criteria for these defects. In order to achieve this, it is first necessary to have an adequate understanding of the underlying failure mechanisms induced by the waviness defects. Arguably, the compressive properties are important for the structural application of composite materials. Hence, this study will focus on the effect of surface waviness defects on the compressive properties of quasi-isotropic (QI) TPCs.

\subsubsection{Literature review}

The influence of imperfections in fiber orientation, in the form of fiber waviness or wrinkles, on the composites' compressive properties has been studied by many researchers in the past. The majority of the previous research has investigated the effect of waviness in unidirectional (UD) composites on compressive failure [1-4, 613]. A study on out-of-plane waviness in UD showed that interlaminar shear failure (leading to delamination) was the dominant compressive failure mode [8]. However, the general consensus from the other studies is that it is the kink-band formation, initiated at the most severe misaligned fibers, that leads to the catastrophic failure in UD composites. [1-4, 6, 7, 9-12]. The kinking mechanism is known to be dominated by the initial fiber misalignment and plastic shear deformation of the matrix [7], which highlights the importance of experimentally measuring the fiber misalignment angle at the wavy region for predicting the compressive strength. Furthermore, the angle has been shown to be the most critical measure of waviness, in comparison with the defect area and the transverse defect extent ratio, as it has the most significant influence on the compressive strength [12]. A similar study on the effect of waviness on tensile strength also demonstrated that damage initiates at the maximum angle [14].

As opposed to the literature on UD composites, there are only very few studies on the influence of waviness on the compressive failure mechanisms and the mechanical performance of multidirectional (MD) composites. The failure process in MD composites is more complex than in UD composites, as the interaction between the plies may activate different failure mechanisms. In general, waviness in MD composites causes a reduction in the compressive strength [15-19]. These past studies have shown that the dominant failure mode which leads to catastrophic fracture in MD composites is either kinking failure or delamination. The dominant failure mode seems to be dependent on the waviness severity (the misalignment angle) [16] and the stacking sequence [19]. Furthermore, the previous studies have also investigated the influence of partial waviness in MD composites, i.e. where not all the plies are wavy $[15,17,18]$. These studies have evaluated the compressive strength of composites having waviness with the maximum waviness angle up to $30^{\circ}$. It is intuitive to expect that the partial waviness may have a less degrading effect on the compressive properties, as was also observed in UD composites [20]. The study on 
the MD composites indeed shows that the larger the number of wavy axial plies, the larger the reduction of compressive strength [15, 18].

\subsubsection{Objectives and approaches}

None of the studies in the literature has described the influence of waviness on the compressive properties of multidirectional (MD) composites having localized waviness with maximum waviness angle larger than $30^{\circ}$. This large waviness severity is relevant to the waviness found in stamp-formed TPCs, which can be up to $55^{\circ}$ or possibly larger. It is concluded from the literature review given previously that there is no single dominant failure mode that leads to the final compressive failure. The failure modes were found to change with the severity of waviness. Possible dominant failure modes that have been identified in the literature for MD thermoset composites with waviness are fiber kinking and delamination. The inherent toughness of thermoplastics may affect the occurrence on part of these failure modes in TPCs.

Given the above, this chapter aims to describe the damage development process in QI thermoplastic composites having waviness which was subjected to compression load, and to measure the compressive properties. For this purpose, specimens with in-plane waviness, similar to the ones observed in stamp-formed parts, were produced for compression testing. The influence of the waviness severity, which was represented as a maximum waviness angle and a number of wavy plies, was investigated in this chapter. The number of wavy plies was varied by changing the position of the $0^{\circ}$ plies within the 24-ply QI stack, essentially altering the ply grouping within the stack. The QI layup was chosen as a case study for multidirectional composites, since this layup is one of the most common stacking sequences for aircraft structures, considering that the structure is typically subjected to multiple loading orientations. A standard compression test was instrumented in such a way that the influence of localized waviness on the global behavior can be evaluated. The evolution of damage of the specimens during the compressive tests was investigated using a high-speed camera (HSC). Moreover, a finite element (FE) model was developed to investigate the stress state in the wavy region. Digital image correlation (DIC) experiments were performed to validate the strain fields from the FE model. Finally, the origin of the initiation of failure was discussed by considering the stress fields in the waviness region obtained using the FE analysis. 


\subsection{Experimental procedure}

\subsubsection{Material and specimens}

The composite material used is a carbon polyether-ether-ketone (PEEK) unidirectional (UD) tape, known as Cetex ${ }^{\circledR}$ TC1200 from Toray Advanced Composites. The prepreg tape is based on AS4 fibers and has a fiber volume fraction of 59\% [21]. The manufactured laminates consisted of 24 plies in a quasi-isotropic (QI) layup with various stacking sequences, i.e. $[0 / 45 / 90 /-45]_{3 s}(\mathrm{QI} 1),\left[0_{2} / 45_{2} / 90_{2} /-45_{2} / 0 / 45 / 90 /-\right.$ $45]_{\mathrm{s}}$ (QI2) and $\left[0_{3} / 45_{3} / 90_{3} /-45_{3}\right]_{\mathrm{s}}$ (QI3). The laminates with fiber waviness in this study were manufactured using a reverse forming method [5]. The manufacturing process consisted of a press consolidation step and was followed by the reverse forming process, i.e. two stamp forming steps. The processing parameters are described in more detail later. The previous work by the author of this thesis has indicated that this method was able to provide defects representative of the typical waviness parameters found from actual stamp-formed parts [5]. The ply grouping within the stack was varied, following the stacking sequences previously mentioned, to vary the amount of wavy $0^{\circ}$ plies. Using this method, the waviness was only formed in the outermost $0^{\circ}$ plies. The three QI layups were chosen such that the laminate thickness and the number of plies at each direction remained the same between the samples.

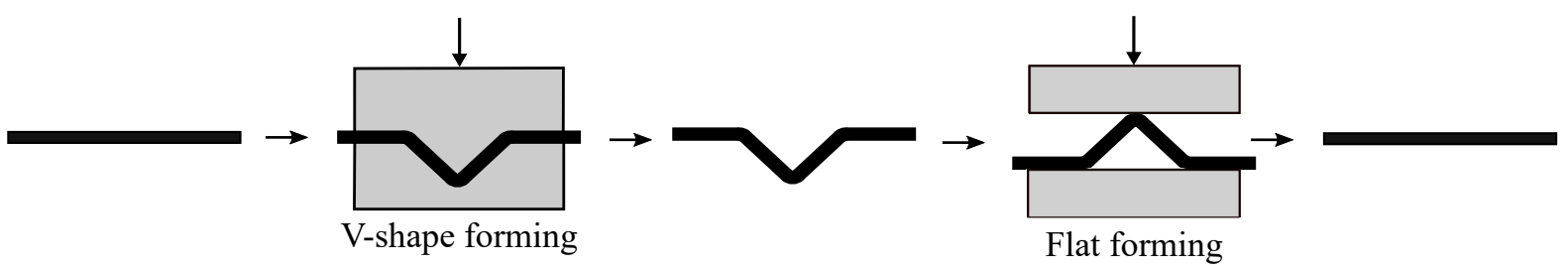

Figure 3.2 Reverse forming steps to form in-plane waviness defects in a flat laminate for compression test coupons.

Laminates with the size of $300 \mathrm{~mm} \times 300 \mathrm{~mm}$ were press-consolidated to be used as blanks in the subsequent stamp forming steps. The laminates were consolidated under 20 bar pressure with 20 minutes dwell time at $385^{\circ} \mathrm{C}$, and a cooling rate of $5^{\circ} \mathrm{C} / \mathrm{min}$. After the press consolidation, two $300 \mathrm{~mm} \times 150 \mathrm{~mm}$ blanks were cut from each laminate using a water-cooled diamond-coated saw. The reverse forming steps to obtain in-plane waviness in flat laminates are illustrated in Figure 3.2. Prior to the stamp forming process, the blanks were preheated at $465^{\circ} \mathrm{C}$ for 300 seconds in the IR oven to reach a midplane temperature of $390^{\circ} \mathrm{C}$. The V-shape forming was done by applying 40 bar consolidation pressure for 60 seconds while the laminate was cooled down to the tool temperature of $240^{\circ} \mathrm{C}$. Three V-shaped metal tools with different combinations of bend angles and inner radii were used in the first stamp-forming 
step in order to vary the waviness severity induced. The V-shape geometries used had a bend angle of $90^{\circ}, 105^{\circ}$, and $120^{\circ}$ with an inner radius of $6.4 \mathrm{~mm}, 8 \mathrm{~mm}$, and 10 $\mathrm{mm}$, respectively. Finally, the same processing parameters, except for the pressure, were used for the subsequent flat forming step. This second forming step was carried out by applying 100 bar consolidation pressure for 60 seconds to unfold the V-shape geometry into a flat laminate.

Laminates for baseline samples, as the non-defective reference, were stamp-formed without using the V-shape tool. Instead, these were manufactured using flat tooling by following the same two stamp forming process cycles as the reverse-formed parts. Therefore, these baseline laminates have the exact same pressure and thermal history as the laminates with waviness. A total of 12 laminates, i.e. 3 baseline and 9 with waviness, were manufactured. Compression test coupons were then cut from these laminates using a CNC milling machine. The specimens were produced with a nominal size of $12 \mathrm{~mm} \times 147 \mathrm{~mm} \times 3.4 \mathrm{~mm}$ (width $\times$ length $\times$ thickness) for testing with the Combined Loading Compression (CLC) test method. The length was chosen such that the whole wavy regions are within the $20 \mathrm{~mm}$ long unsupported gage section in the middle of the specimen, following the standard in ASTM D6641 [22]. Untapered end tabs made of woven glass fiber/polyetherimide (PEI) laminates with a $\left[( \pm 45)_{4}\right]_{s}$ layup were used for the baseline specimens. The tabs were bonded using a two-component epoxy adhesive, leaving an unsupported section of $20 \mathrm{~mm}$ in the middle of the specimen. The code for the samples with waviness is defined by the bend angle and the layup used, as V(tool-angle)-(layup), e.g. V90-QI1 for the sample with a single $0^{\circ}$ ply in the outermost side, i.e. with QI1 layup, which was formed using the $90^{\circ} \mathrm{V}$-bend tool.

\subsubsection{Measurement of in-plane waviness severity}

The waviness severity was measured following the methods as described in our previous work [5]. Surface micrographs were taken with a Keyence VHX-5000 digital microscope with a resolution of $1.5 \mu \mathrm{m}$ per pixel. Before the image acquisition, the surface was prepared by applying a thin layer of sunflower oil on the specimen's surface to enhance the visibility of the fibers. For each test coupon, a micrograph was taken from the surface that shows waviness at the gage section (20 mm long). The fibers were traced from the surface micrograph by using the High Resolution Misalignment Analysis (HRMA) method that was developed by Wilhemsson et al. [23]. A block size of 50 pixels $\times 50$ pixels was used in this study. From each block, 7 fiber segments were typically measured. Therefore, a total of approximately 300,000 fiber segments measurements were performed from the whole micrograph. The maximum waviness angle $\left(\theta_{\max }\right)$ was determined from these measurements. Furthermore, the number of wavy $0^{\circ}$ plies was also determined based on crosssectional micrographs taken from three locations from each laminate. The cross- 
sectional shape of the fiber that is misaligned from the sectioning plane appears as an ellipse that has a small aspect ratio, i.e. major-axis-length over minor-axis-length, indicating the presence of waviness in a given ply (an example is provided later in this chapter, see Figure 3.5).

\subsubsection{Compression tests}

The compression tests were performed according to the Combined Loading Compression (CLC) test method. The number of specimens tested is presented in Table 3.1, with a minimum of five specimens for each sample. Quasi-static tests were performed using an Instron universal testing machine equipped with a $100 \mathrm{kN}$ load cell. The loading direction was made parallel with the outermost ply $\left(0^{\circ}\right.$ ply) orientation, as the knock-down factor due to fiber waviness is expected to be maximum for this loading direction. All tests were performed at a constant displacement rate of $1.3 \mathrm{~mm} / \mathrm{min}$ based on ASTM D6641 [22], using a Wyoming CLC test fixture. The specimens were loaded until ultimate failure, i.e. until a $40 \%$ drop in load was detected, and the peak load was used to determine the ultimate compressive strength. The stress was calculated as the average compressive stress, i.e. load divided by cross-sectional area. The possible occurrence of undesired global buckling (instability) was checked by two strain gages with $6 \mathrm{~mm}$ grid length that were mounted on opposite faces in the gage section of a specimen.

\section{High speed camera setup}

The damage sequence of the specimen was monitored using a Photron Fastcam SA4 high-speed camera (HSC) during the test. For this reason, the specimen side was polished to enhance the visibility of the axial plies. The video was recorded at a frame rate of $100,000 \mathrm{fps}$. The camera was mounted in front of the test fixture viewing either the polished specimen side (configuration A) or the wavy surface using a mirror (configuration B) as illustrated in Figure 3.3. No strain gages were used during the test with configuration B to be able to monitor the wavy surface. During the test, snapshots were triggered manually at a noticeable damage event, i.e. at the moment that there was visible damage or at a noticeable load drop. The load levels corresponding to these damage events were then determined by manually inspecting the load drop from the load-displacement curve. Therefore, the load levels at the damage event associated with the initiation are only presented as a range. Furthermore, an end trigger input signal was coupled with the Instron end-of-test event such that the end of the video recording was synchronized with the load drop event. This way, the load level for each frame up to $3991 \mathrm{~ms}$ before the trigger signal could be traced back. 


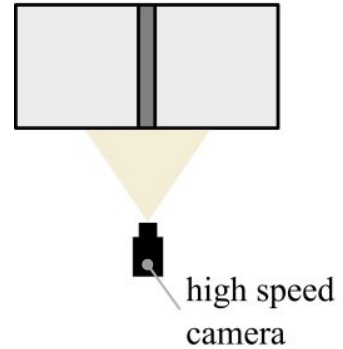

Top view
Configuration A

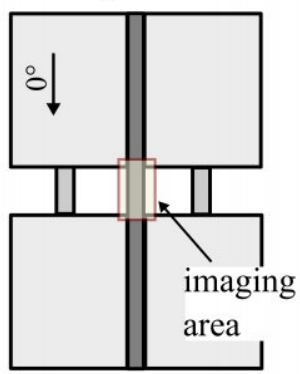

Front view
Configuration B

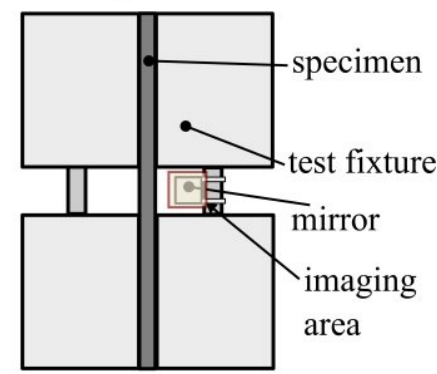

Front view

Figure 3.3 High-speed camera setup with configuration A viewing directly the specimen side and configuration $B$ facing the mirror to view the wavy surface.

\section{Fractography analysis}

The fractured surfaces from a few selected specimens were evaluated after testing in order to identify the failure modes. A Leica M125 microscope was used to obtain micrographs of the wavy surface. Moreover, micrographs of the fractured surface were also made with a JEOL JSM-7200F scanning electron microscope (SEM) to describe the fracture mechanisms.

\subsection{Results and discussion}

\subsubsection{Measured waviness parameters}

All test coupons have pronounced waviness visible only on one surface of the specimen and localized in the gage section. In all cases, the waviness extends over the full width of the test coupons. An example of the micrographs of a specimen having two wavy regions is shown in Figure 3.4. The majority of the specimens have such two wavy regions, and only the largest $\theta_{\max }$ (global) for each specimen is reported here, e.g. $\theta_{\max }$ of $40^{\circ}$ for the test coupon shown in Figure 3.4. The measured $\theta_{\max }$ from the surface micrographs of the samples with waviness are shown later in Table 3.1. The QI1 samples with waviness have $\theta_{\max }$ between $27^{\circ}$ to $54^{\circ}$. The range of $\theta_{\max }$ for the QI2 and QI3 samples with waviness was from $23^{\circ}$ to $60^{\circ}$ and from $35^{\circ}$ to $56^{\circ}$, respectively. Observing the scatter in Table 3.1, no obvious relation can be claimed between the maximum waviness angle and the (V-shape) bending angle, certainly for the larger bending angles.

As illustrated in Figure 3.5, the analysis of the cross-sectional micrographs, which were presented in the author's previous work on the reverse forming method [5], showed that in all cases, the wavy $0^{\circ}$ plies were located only at the outermost layers of the stack. It was found that all QI1 samples have a single wavy $0^{\circ}$ ply, while the 
QI2 and QI3 samples have waviness in the top (outermost) two and three $0^{\circ}$ plies, respectively. The fibers in the second and third top $0^{\circ}$ plies from the surface for the QI2 and QI3 samples appeared as ellipses with a larger aspect ratio than that of the surface [5]. Such fiber cross-sectional shape indicates that the waviness severity is decreasing with the increase of depth. As such, the fiber angles were only measured from the surface as the most severe waviness was on the surface ply.

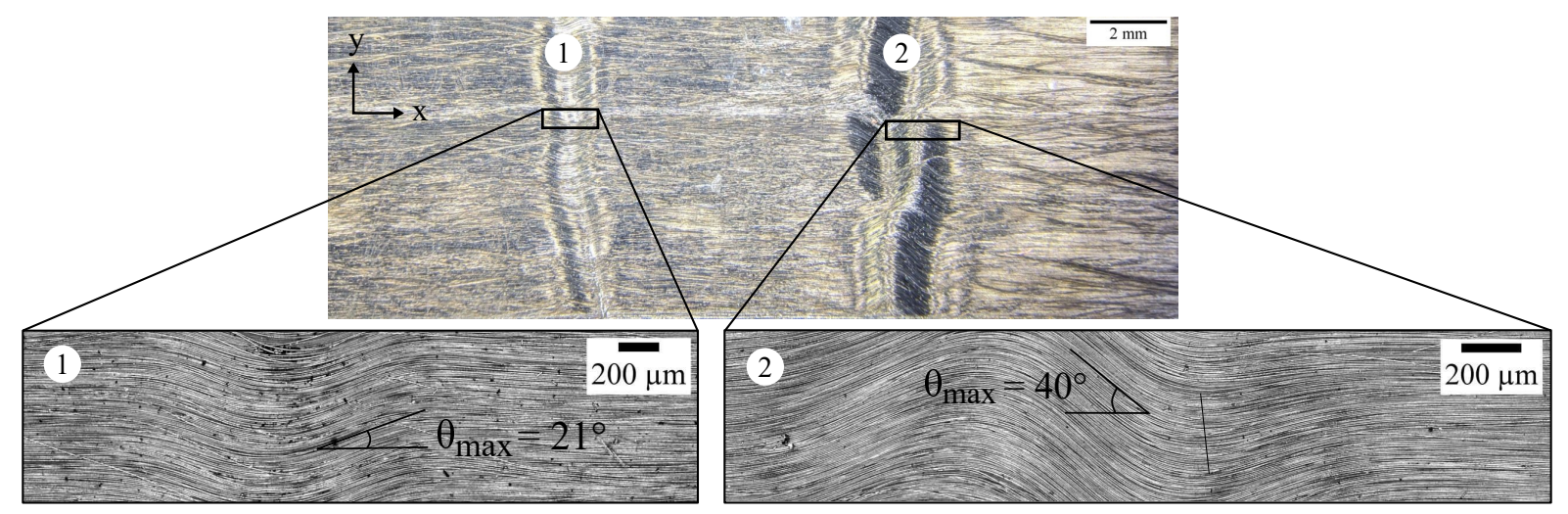

Figure 3.4 Surface micrographs of two wavy regions in a test specimen. The maximum waviness angle $\left(\theta_{\text {max }}\right)$ of each wavy region is shown in the bottom images.

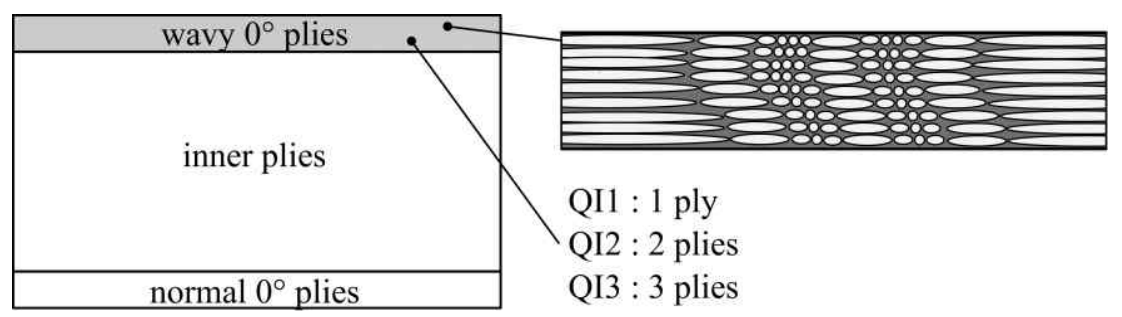

Figure 3.5 Schematic illustration of the QI1, QI2 and QI3 samples cross-sections. The right figure shows a portion of the cross-section from the wavy region in the top $0^{\circ}$ ply.

\subsubsection{Effect of fiber waviness on stiffness}

The results of the tests that were performed using the strain gages indicated that there was no global buckling in these tests. The compressive elastic modulus was evaluated from the average strain from the two strain gages mounted on opposing faces of each specimen, between the range of 1000 and $3000 \mu \varepsilon$ according to the standard [22]. The measured moduli from all samples are presented in Figure 3.6 and also summarized in Table 3.1. Please note that the number of specimens tested was not always equal for each sample, consequently, the error bars in Figure 3.6 were produced from different sample sizes. It appears that there is a slight reduction of the baseline stiffness due to the ply grouping. However, the difference is not significant. 


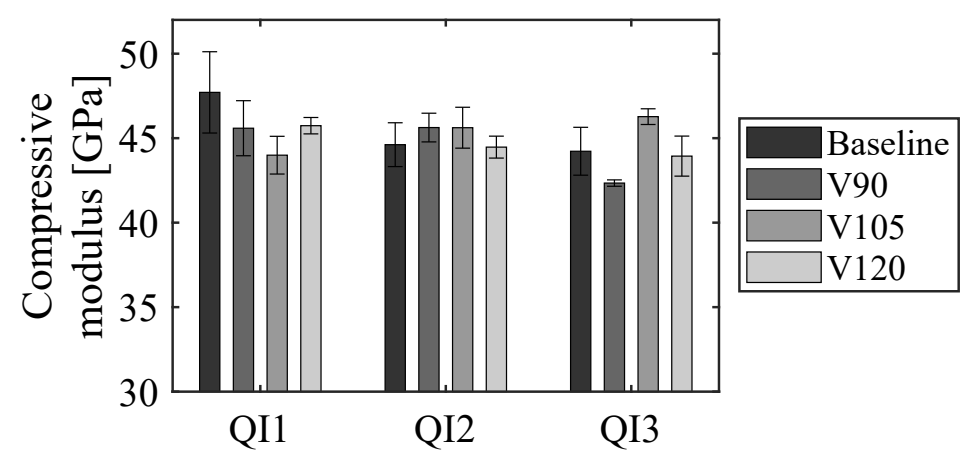

Figure 3.6 Compressive elastic modulus of QI samples. The standard deviation is indicated as the error bar.

All samples have a similar modulus, regardless of the presence or absence of waviness defects, with an overall mean of around $45 \mathrm{GPa}$. These results show that the presence of localized in-plane waviness within the cases in this study does not significantly affect the longitudinal stiffness of the QI composites. This is related to the fact that stiffness represents the global compressive response of the composite and therefore is not largely affected by such local defects.

\subsubsection{Damage development}

\section{Baseline samples}

The failure processes of all samples subjected to compression loading were examined based on the high-speed camera (HSC) footages. Note that, with the resolution of the images obtained from the setup used in this study, it was not possible to observe any damage occurring in the off-axis plies, e.g. to monitor matrix microcracks. Nevertheless, the high-speed camera can be used to monitor the occurrence of delamination or fracture in the $0^{\circ}$ plies that carry most of the load, which were the possible dominant failure modes as described in the introduction.

The typical images of the Baseline-QI1 ([0/45/90/-45 $\left.]_{3 \mathrm{~s}}\right)$ specimen side along with the load-displacement curve are presented in Figure 3.7. In this case, there was no noticeable discontinuity in the load-displacement curve prior to the signs of damage. The damage development leading to the final fracture, where a severe load drop was observed, occurred in a very short period of time (in the order of $30 \mu \mathrm{sec}$ ) at the peak load. The photograph of the baseline specimen in Figure 3.7 (indicated with 1) reveals the fracture of the outer $0^{\circ}$ ply in the gage section as the initial damage which eventually leads to the catastrophic fracture. The whole laminate began to bend due to the loss of support from the left side and followed by fiber fractures and multiple delaminations, leading to the final fracture. Seven out of eight Baseline-QI1 specimens showed very sudden failure where the propagation from the initial to the final fracture occurred within $80 \mu \mathrm{s}$. 


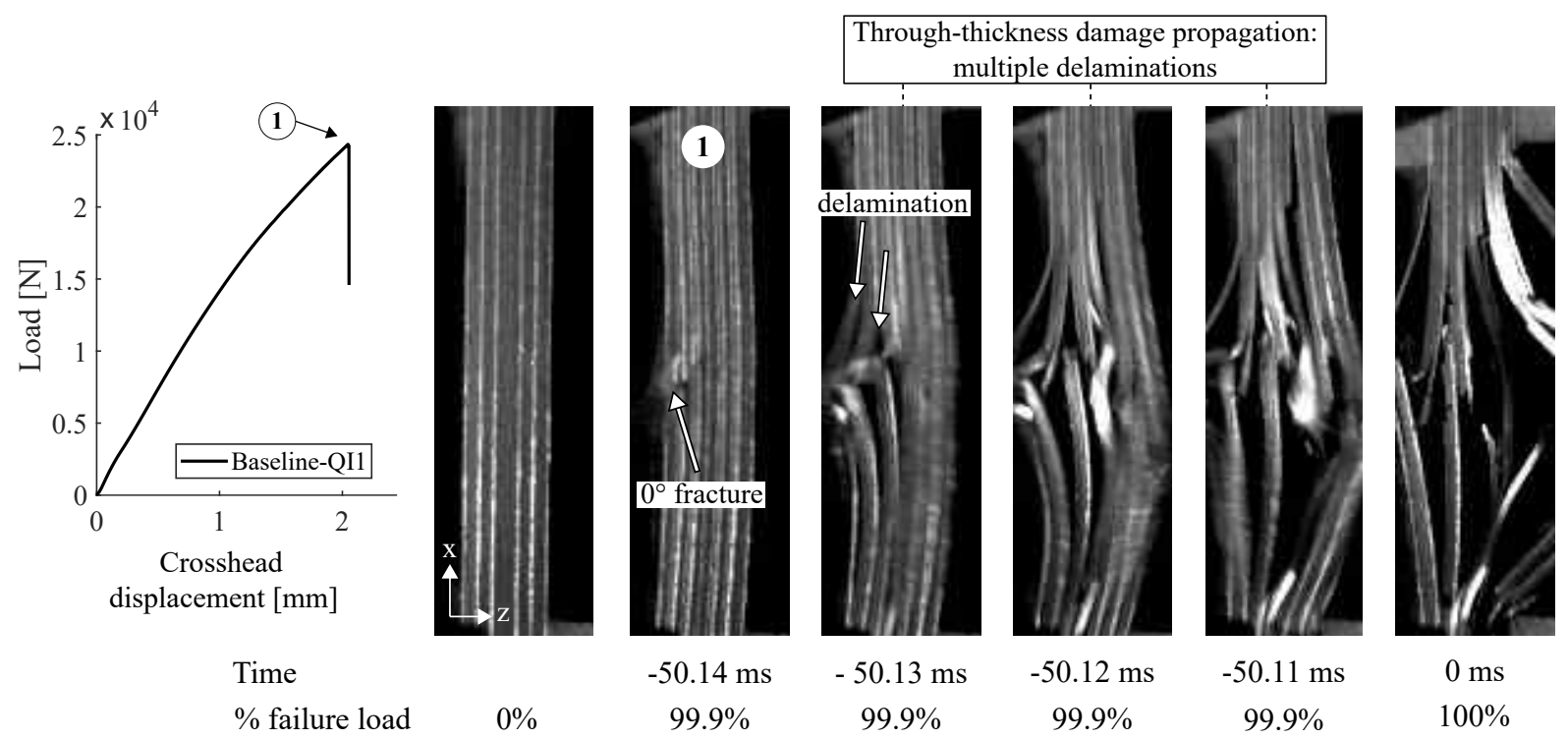

Figure 3.7 High-speed camera footages of the Baseline-QI1 test specimen side.

The fracture surface of the fibers in the outermost $0^{\circ}$ ply, where failure initiated, was observed using SEM after the test. Figure 3.8 shows that the fiber ends have two distinct areas, i.e. the surface area with a rough appearance indicates tensile failure and the area with a smoother surface indicates compression failure. This is characteristic for a microbuckled fiber, thus indicating kinking failure, which was also the expected failure mechanism for the axial ply in MD composites loaded under compression [24, 25]. It is known that the presence of fiber misalignment, even by only a small degree (in a range of $1^{\circ}$ to $2^{\circ}$ ), can already trigger the formation of kink bands [10].

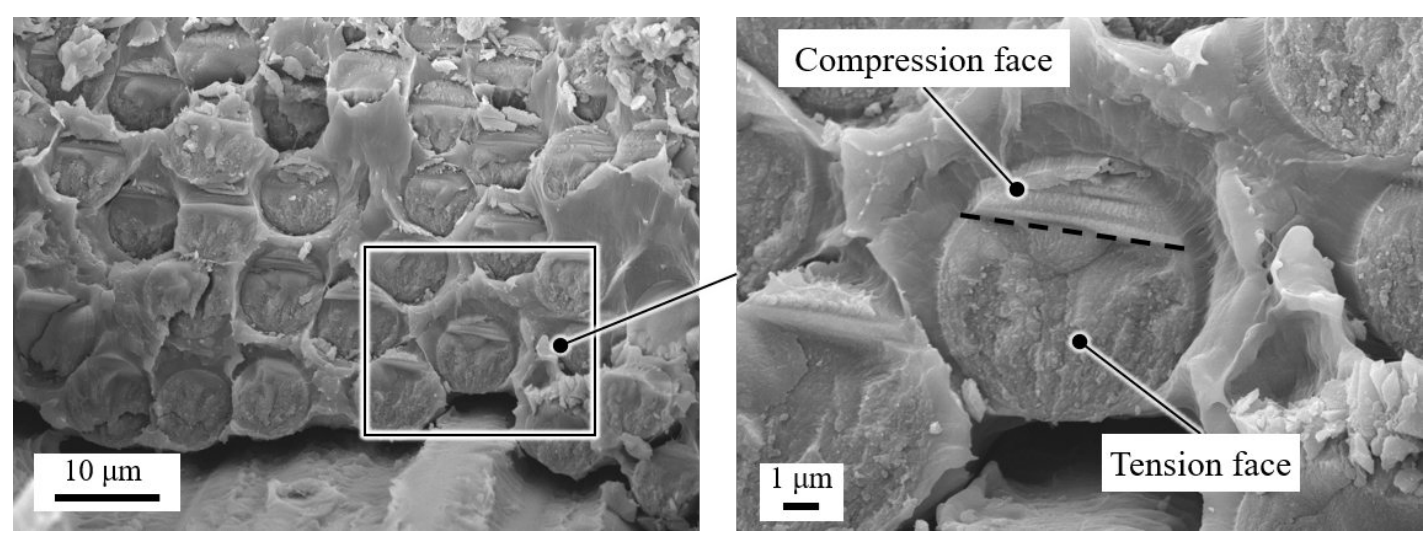

Figure 3.8 SEM images of Baseline-QI1 specimen showing microbuckled fibers in the outermost $0^{\circ}$ ply that showed the initial fracture.

The load-displacement curves and the HSC footages for the other baseline samples with the alternative layups (Baseline-QI2 with $\left[0_{2} / 45_{2} / 90_{2} /-45_{2} / 0 / 45 / 90 /-45\right]_{\mathrm{S}}$ 
layup and Baseline-QI3 with $\left[0_{3} / 45_{3} / 90_{3} /-45_{3}\right]_{s}$ layup) are similar to the Baseline-QI1 sample. For this reason, their behavior is not shown again here. The Baseline-QI2 and Baseline-QI3 samples appeared to also fail in a brittle manner where the propagation from the initial to the final fracture was very sudden. The sequence of damage development observed by the HSC was similar to that of the Baseline-QI1 sample, except that the entire outermost $0^{\circ}$ plies failed simultaneously. Clustering of plies with the same orientation is known to affect the damage development. Once a crack or $0^{\circ}$ fiber microbuckling initiates in one of these plies, the damage can propagate easily across the entire block [26].

\section{Samples with fiber waviness}

The typical damage sequence of a QI1 specimen with waviness is illustrated in Figure 3.9. The HSC images clearly show that the damage initiated at the righthand side outermost $0^{\circ}$ ply which was the wavy ply. This fracture event was accompanied by a minimal load drop. Local delamination between the failed outer $0^{\circ}$ ply and the ply underneath occurred soon afterward in the region where the initial fracture has occurred. At this point, the load still increased, and after some time, the second inner $0^{\circ}$ ply on the same side of the specimen (the side with wavy ply) also fractured. Subsequently, the next inner $0^{\circ}$ ply also failed, immediately leading to failure propagation through the thickness, ultimately leading to the total collapse of the specimen, where a large load drop was also observed.

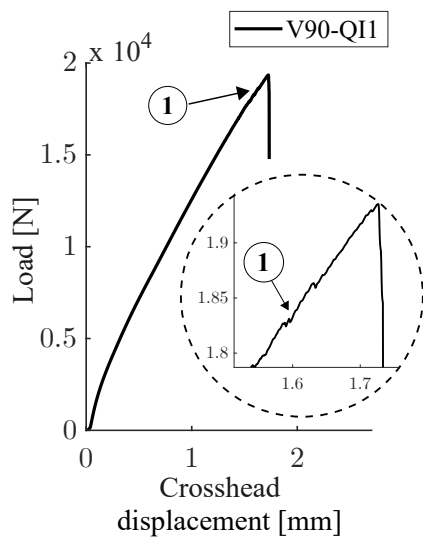

Time

$\%$ failure load

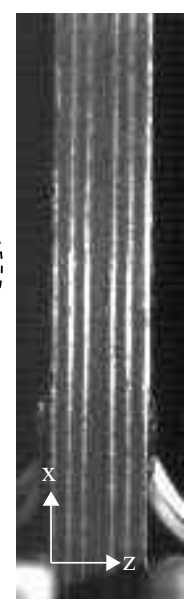

$0 \%$

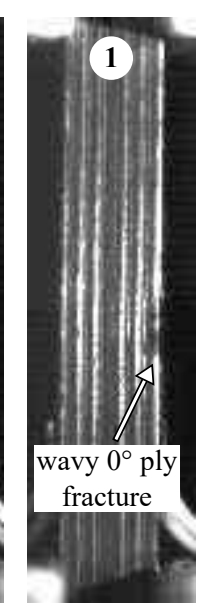

$<-3991 \mathrm{~ms}$ $94-97 \%$

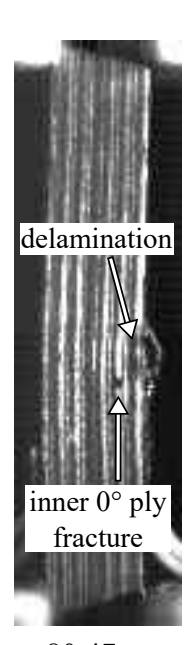

$-80.47 \mathrm{~ms}$ $99.9 \%$

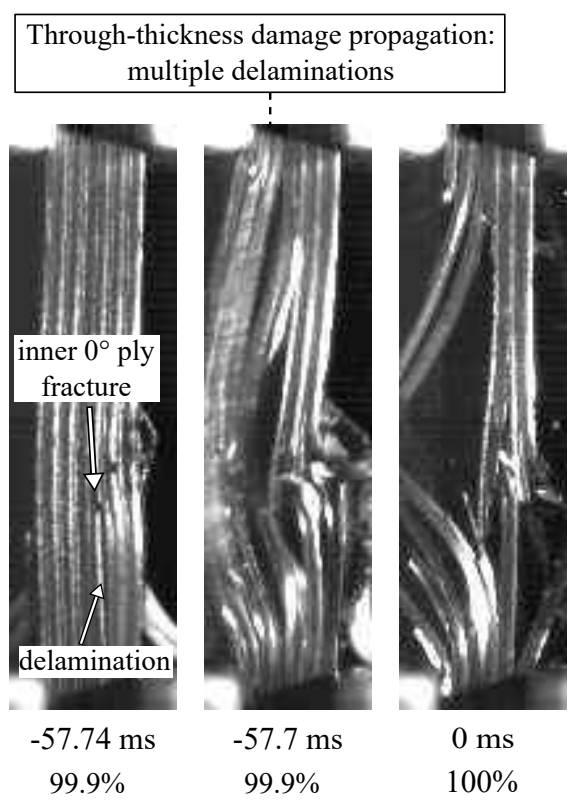

$99.9 \%$

Figure 3.9 High-speed camera footages of the side of the QI1 specimen with waviness.

The damage initiation occurred consistently in the wavy $0^{\circ}$ ply for all QI1 samples 
that have waviness (V90-QI1, V105-QI1, and V120-QI1). Since the wavy ply always fails earlier than the opposing outermost $0^{\circ}$ ply (the left side of the specimen in Figure 3.9), all the tested specimens showed a very noticeable preferred direction of bending, outward away from the wavy ply.

A few of the tests were performed by monitoring the wavy surface directly, using the HSC in configuration B (Figure 3.3), to better observe the damage initiation at the wavy region. Of these tests, some were interrupted at the point of the first observation of damage which was associated with an audible crack and a discontinuity in the load-displacement curve. An example of the first visible damage is shown in Figure 3.10. A minor load drop of about $0.1 \%$ was observed at this instant of damage. Post-mortem analysis of the fractured surface revealed the presence of kink bands in the wavy $0^{\circ}$ ply (Figure 3.10). The kink bands were found at the location of the waviness with the largest $\theta_{\max }$, i.e. $34^{\circ}$.

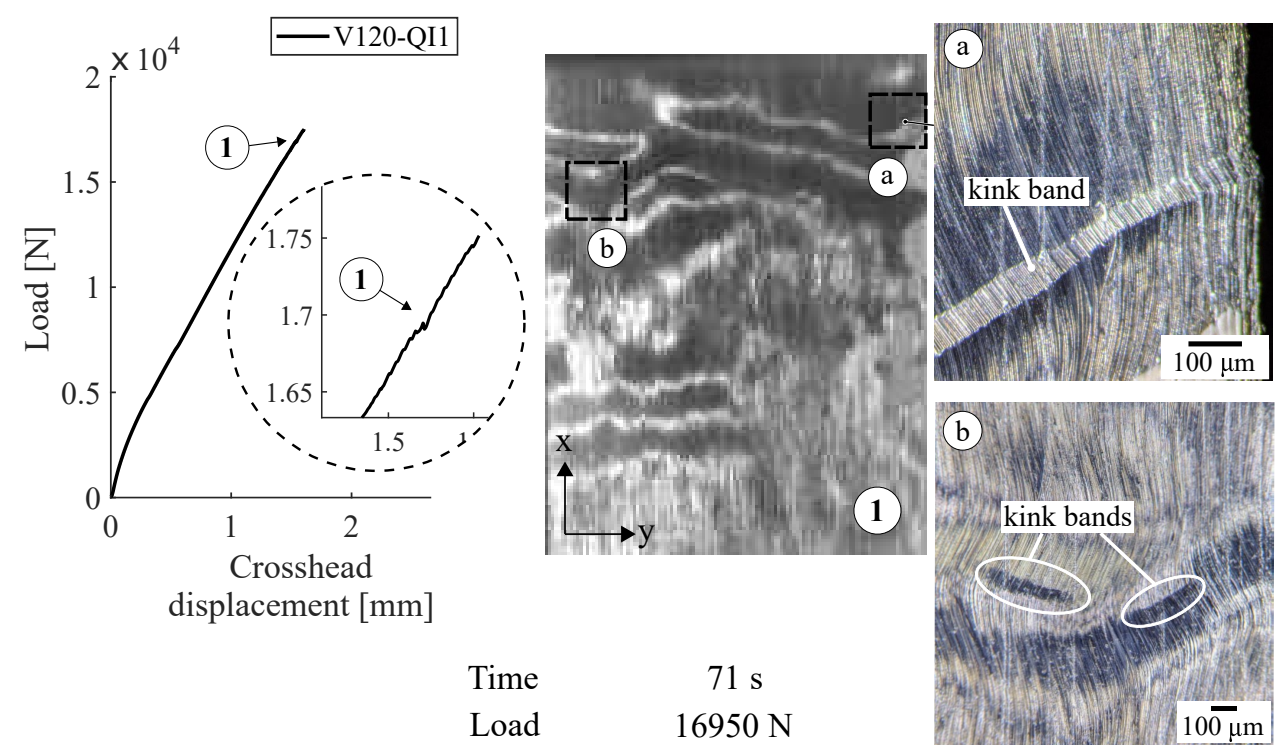

Figure 3.10 High-speed camera footages of the wavy surface from V120-QI1 specimen and surface micrographs showing kink bands at the waviness region with large maximum waviness angle.

Initial damage in the QI1 samples with waviness was observed at rather low load levels, i.e. as low as $82 \%$ of the peak load from the corresponding specimen. This means that the damage progression of the QI1 samples with waviness is more gradual compared to progression in the baseline sample. The time duration from the occurrence of the initial fracture to the final fracture was longer than that of the baseline sample, i.e. in most cases larger than 4 seconds.

Damage progression of the QI2 specimen with waviness, as shown in Figure 3.11, was similar to the QI1 samples with waviness. Here, also, damage initiated at the outermost wavy $0^{\circ}$ ply. This initial fracture location was consistently observed in 
all QI2 samples with waviness (V90-QI2, V105-QI2, and V120-QI2), independently of the waviness severity. In the particular case shown in Figure 3.11, there were two fracture locations (indicated with 1 and 2) within the wavy plies due to the presence of two regions of waviness having similar $\theta_{\max }$. SEM images in Figure 3.12a, taken from the same specimen as the one from Figure 3.11, show terraces that consist of microbuckled fibers which have failed at equal lengths which is a typical fracture morphology of fiber kinking [24]. This fracture event (indicated with 1) was also accompanied by a load drop, which was found to be slightly larger, hence more noticeable than in the QI1 samples with waviness. This is understandable since there are more wavy plies, in this case two, that were fractured at the same time. Again, similarly to the QI1 samples with waviness, the load was still increasing after the initiation of fracture in the wavy plies. After some time, the next inner $0^{\circ}$ ply on the same side of the specimen (the side with wavy ply) also fractured, immediately triggering the failure of the remaining plies and ultimately leading to the loss of integrity of the whole specimen.
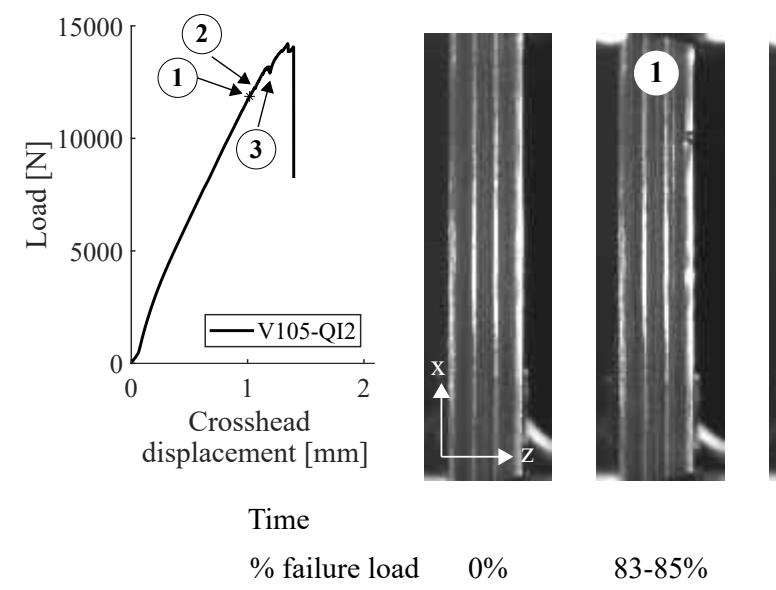

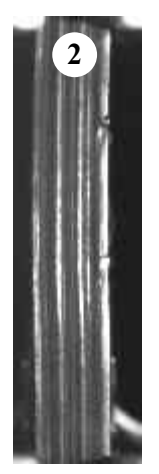

$86-87 \%$

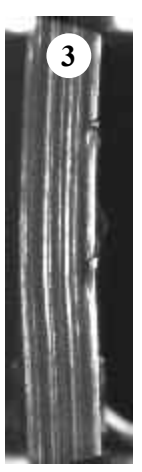

$<-3991 \mathrm{~ms}$

$90-93 \%$

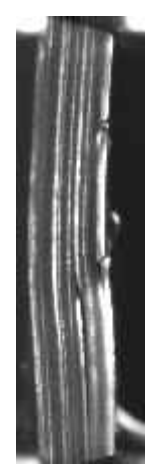

$-77650 \mu \mathrm{s}$

$99.9 \%$

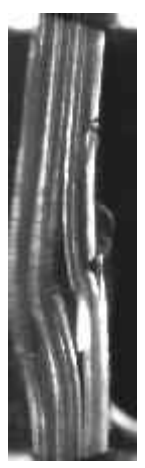

$-77630 \mu \mathrm{s}$

$99.9 \%$

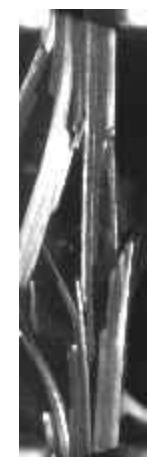

$0 \mu \mathrm{s}$

$100 \%$

Figure 3.11 High-speed camera footages of the side of the QI2 specimen with waviness.

Typical HSC images of the QI3 specimen with waviness are given in Figure 3.13. The fracture behavior, in terms of the damage sequence as observed by the HSC, was similar for all QI3 samples with waviness (V90-QI3, V105-QI3, and V120-QI3). The initial damage was seen in the wavy $0^{\circ}$ plies, which all seem to fail simultaneously. The load drop associated with this fracture event is also larger than that observed in the QI1 and QI2 samples with waviness. The ultimate fracture followed soon after the failure of the wavy plies and may be attributed to the absence of inner $0^{\circ}$ plies in this sample. 


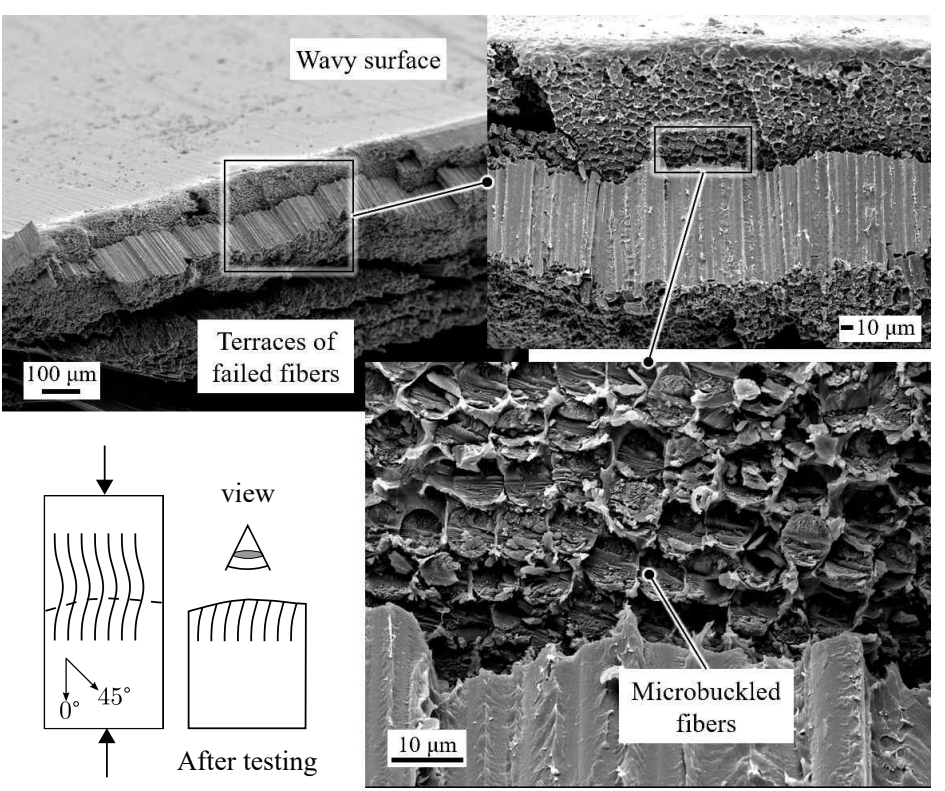

(a)

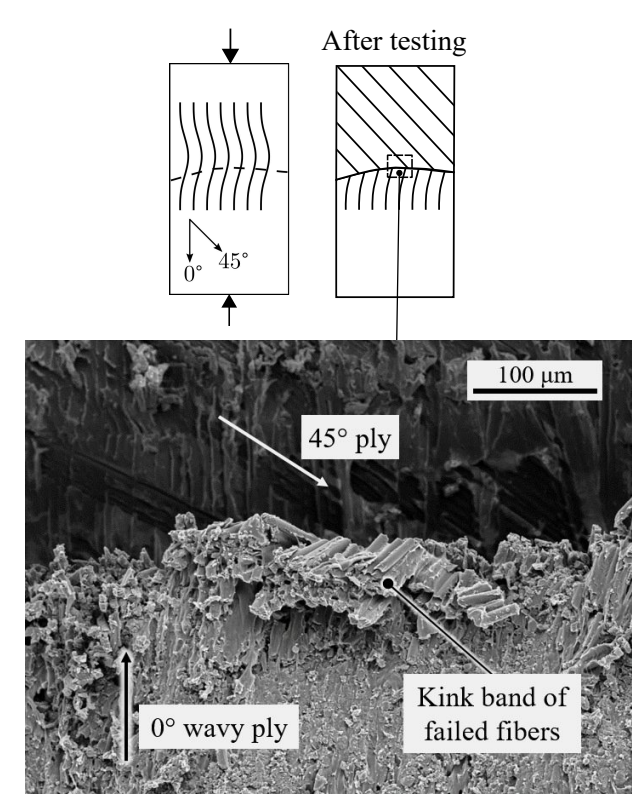

(b)

Figure 3.12 SEM images of (a) QI2 specimen with waviness, showing terraces of failed fibers, and (b) QI3 specimen with waviness, showing a remnant of a kink band. The images were taken at the wavy regions where damage initiated.

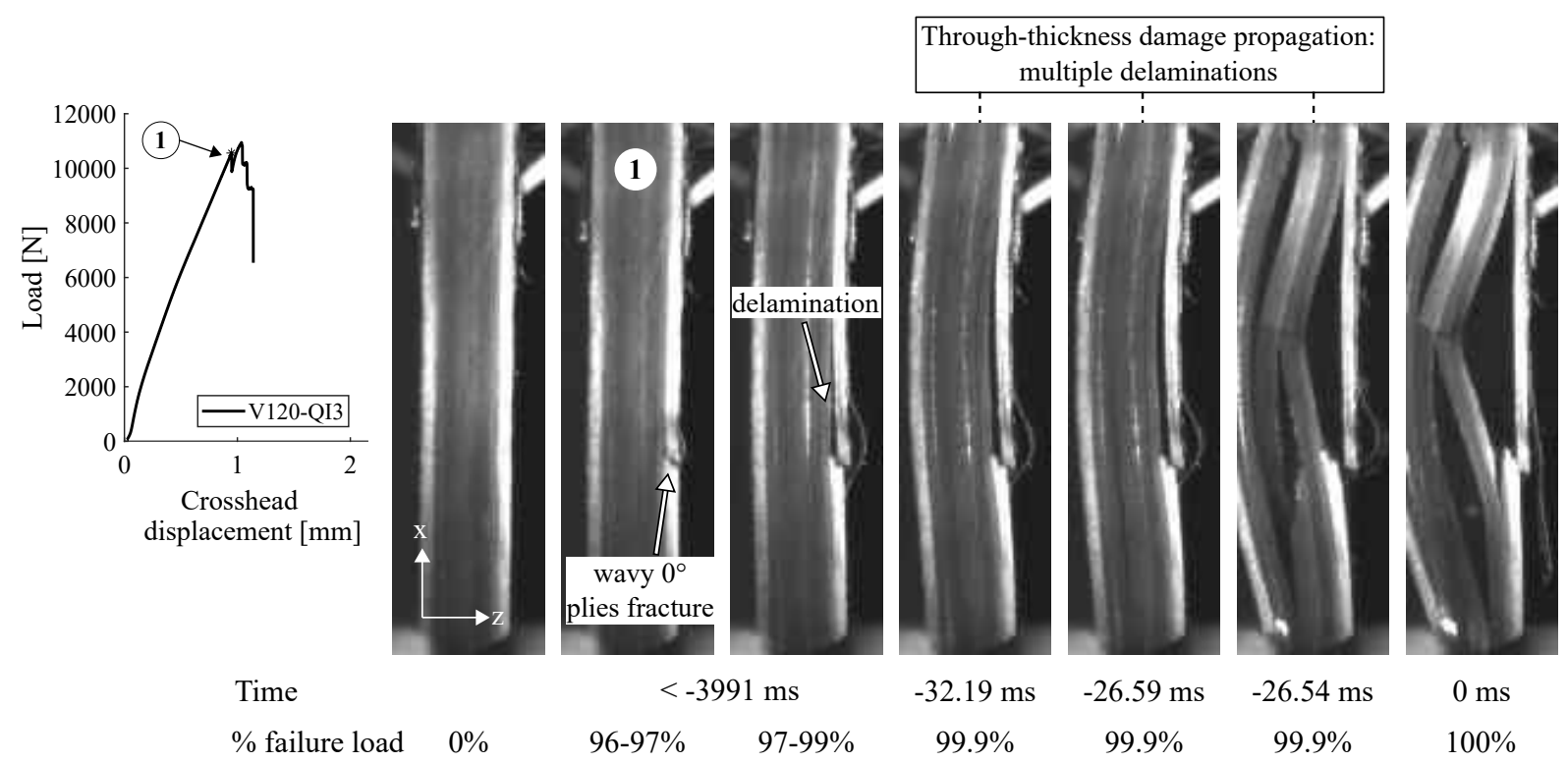

Figure 3.13 High-speed camera footages of the side of the QI3 specimen with waviness.

After testing until the ultimate failure, two specimens from the V90-QI3 sample showed no fracture at the wavy regions with the largest $\theta_{\max }$, i.e. $54^{\circ}$ and $56^{\circ}$. For one of these specimens, a remnant of a kink band that was still attached to the test coupon (Figure 3.12b) was clearly observed at the wavy region with the smaller $\theta_{\max }$ 
$\left(35^{\circ}\right)$, while no fracture was visible at the other wavy region with $\theta_{\max }$ of $54^{\circ}$. This may be related to the in-plane shear stress which is at the maximum when the fibers are oriented at a $45^{\circ}$ angle. As will be shown later, a further increase of the rotation angle above $45^{\circ}$ does not lead to a decrease in the ply compressive strength. The other specimens from the same sample set (V90-QI3) with similar severity showed fiber fractures at all wavy regions. Unfortunately, the failure sequences between the wavy regions could not be determined solely from the HSC images and the fractured surface after the final failure. There is also a possibility that the fiber fracture seen at the wavy region with large $\theta_{\max }$ occurred only much later in the failure process and is a secondary fracture as the consequence of the release of energy from the preceding failure. Further work is needed to evaluate the failure initiation in the wavy ply, particularly the one with such large $\theta_{\max }$.

In general, the HSC footages and the fractography analysis showed that the initiation of failure in the wavy $0^{\circ}$ plies was predominantly due to the formation of kink bands at the wavy region, as observed in about $75 \%$ of the tested specimens. It appears that the specimens predominantly failed by fiber failure due to the kinking mechanism in the wavy $0^{\circ}$ plies before delamination occurred. This indicates that the fiber kinking mechanism is the dominant damage mechanism for the failure initiation at the wavy region, particularly for the waviness with $\theta_{\max }$ smaller than approximately $40^{\circ}$. The results shown here also suggest that further work focusing on the damage initiation in the wavy ply is needed in order to identify the failure mechanism of the more severe waviness, i.e. with larger $\theta_{\max }$.

The difference between the samples with and without waviness (baseline), regardless of the layup, is mainly the location and load level of the initiation of damage in the axial ply, and the damage propagation. The damage initiation in the samples with waviness was always localized at the wavy region in the outermost $0^{\circ}$ ply. However, for the baseline samples, there was no preferable location for the initial damage, since it was found to initiate on either side of the outermost $0^{\circ}$ ply. Furthermore, the development of damage in the samples with waviness is much more gradual than in the baseline samples.

\subsubsection{Effect of fiber waviness on strength}

The results of the CLC tests are summarized in Table 3.1. In the following sections, to exclude the influence from the difference in the layup, all of the strengths of the specimens with waviness are compared to each of their own reference, i.e. average strength from the baseline sample with an identical layup.

The experimental data in Table 3.1 shows a considerable reduction of the ultimate strength of the samples with waviness for all layups with respect to each of their baseline. This is related to the noticeable difference in the failure process between the samples with and without waviness. As described earlier, the samples with waviness 
exhibit an early failure at a significantly lower stress level due to the presence of wavy fibers. The wavy ply failed much earlier than the rest of the axial plies within the laminate, hence there were fewer plies that effectively contribute to the loadcarrying capability of the laminate. Further analysis of the influence of the waviness parameters on the compressive strength is presented in the following sections.

Table 3.1 Summary of compressive tests results. $n$ is the number of specimens tested. $\theta_{\max }$ is the largest (global) maximum waviness angle from each specimen. The values given within parentheses represent the standard deviations.

\begin{tabular}{ccccccc}
\hline Sample & $\boldsymbol{n}$ & $\begin{array}{c}\text { Mean } \\
\theta_{\max }\left[{ }^{\circ}\right]\end{array}$ & $\begin{array}{c}\text { Min. } \\
\theta_{\max }\left[{ }^{\circ}\right]\end{array}$ & $\begin{array}{c}\text { Max. } \\
\theta_{\max }\left[{ }^{\circ}\right]\end{array}$ & $\begin{array}{c}\text { Elastic } \\
\text { modulus [GPa] }\end{array}$ & $\begin{array}{c}\text { Max. stress } \\
{[\mathrm{MPa}]}\end{array}$ \\
\hline Baseline-QI1 & 8 & $\mathrm{~N} / \mathrm{A}$ & $\mathrm{N} / \mathrm{A}$ & $\mathrm{N} / \mathrm{A}$ & $47.7(2.4)$ & $601(43)$ \\
V90-QI1 & 5 & $49(3)$ & 46 & 54 & $45.6(1.6)$ & $502(22)$ \\
V105-QI1 & 5 & $34(5)$ & 27 & 42 & $44.0(1.1)$ & $510(19)$ \\
V120-QI1 & 5 & $33(2)$ & 31 & 37 & $45.7(0.5)$ & $508(18)$ \\
\hline Baseline-QI2 & 7 & $\mathrm{~N} / \mathrm{A}$ & $\mathrm{N} / \mathrm{A}$ & $\mathrm{N} / \mathrm{A}$ & $44.6(1.3)$ & $566(48)$ \\
V90-QI2 & 5 & $58(2)$ & 55 & 60 & $45.6(0.8)$ & $375(11)$ \\
V105-QI2 & 5 & $35(4)$ & 29 & 40 & $45.6(1.2)$ & $370(9)$ \\
V120-QI2 & 5 & $28(4)$ & 23 & 33 & $44.5(0.6)$ & $354(16)$ \\
\hline Baseline-QI3 & 6 & $\mathrm{~N} / \mathrm{A}$ & $\mathrm{N} / \mathrm{A}$ & $\mathrm{N} / \mathrm{A}$ & $44.2(1.4)$ & $580(49)$ \\
V90-QI3 & 5 & $50(5)$ & 45 & 56 & $42.3(0.2)$ & $296(14)$ \\
V105-QI3 & 5 & $40(4)$ & 35 & 44 & $46.3(0.5)$ & $294(16)$ \\
V120-QI3 & 5 & $45(5)$ & 40 & 52 & $43.9(1.2)$ & $274(7)$ \\
\hline
\end{tabular}

QI1 layup: $[0 / 45 / 90 /-45]_{3 s}$

QI2 layup: $\left[0_{2} / 45_{2} / 90_{2} /-45_{2} / 0 / 45 / 90 /-45\right]_{\text {s }}$

QI3 layup: $\left[0_{3} / 45_{3} / 90_{3} /-45_{3}\right]_{\mathrm{s}}$

\section{Effect of maximum waviness angle on compressive strength}

The measured ultimate strength values are presented as a function of the maximum waviness angle in Figure 4.18 for the three types of layup considered. The results from the baseline samples are represented as horizontal lines with their respective standard deviations. Although the specimens evaluated cover a broad range of waviness severity, no obvious trend is observed for the specimens with waviness with respect to the $\theta_{\max }$, irrespective of the layup. As opposed to the results from the studies described in the introduction, all specimens having waviness and with the same layup have a similar strength. The range of $\theta_{\max }$ emerging in TPCs during stamp forming in the present study was between $23^{\circ}$ to $60^{\circ}$, whereas the past studies in the literature have only investigated the influence of less severe waviness at the lower end of $\theta_{\max }$. The $\theta_{\max }$ values in the studies on uniform through-thickness waviness in UD composites were up to $30^{\circ}[11,27]$. Similarly, the studies on partial 
waviness in multidirectional composites have a comparable upper bound of $\theta_{\max }$ value $[17,18]$.
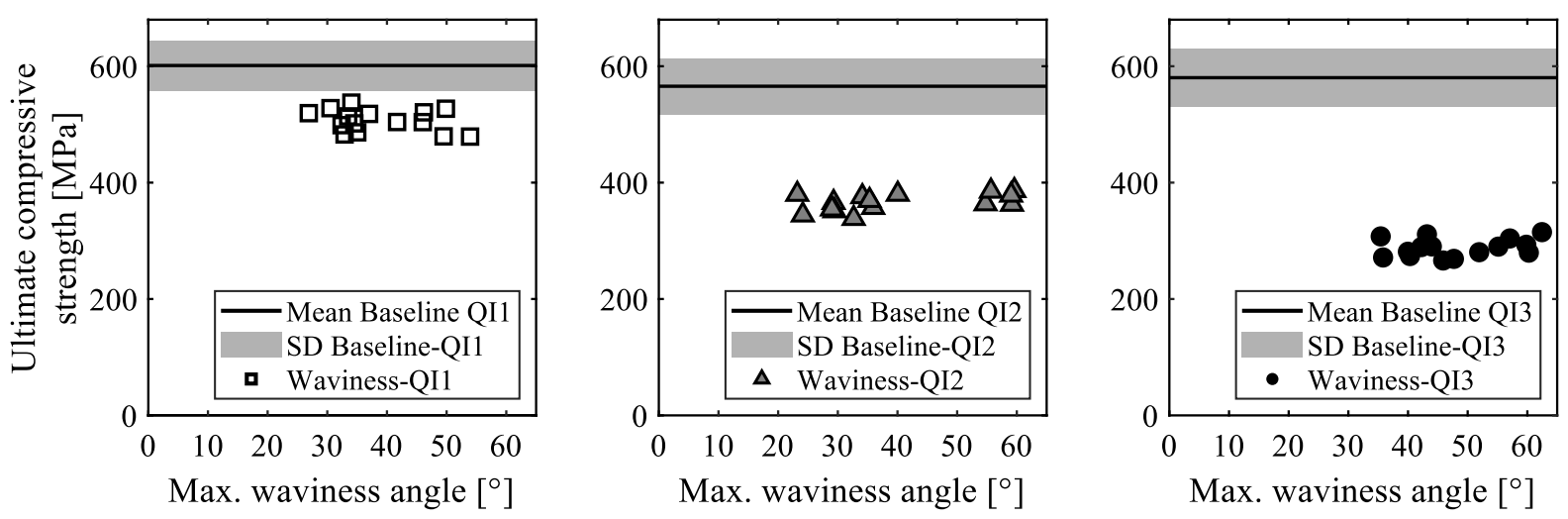

Figure 3.14 Effect of maximum waviness angle on compressive strength. SD indicates the standard deviation of the baseline strength.

The waviness in this study is considered as mesoscale fiber misalignment, characterized by $\theta_{\max }$ which is the deviation from the nominal ply orientation. The deviation of the fiber angle from the loading direction locally causes a combined compressiveshear loading in the wavy region, as will be shown later in the FE analysis results. Thus, the change in the stress state due to the fiber rotation influences the failure load. Such influence of the fiber angle rotation on the apparent compressive strength can be described by using the maximum stress criterion. According to this criterion, the apparent compressive strength $\sigma_{c}$ of a ply rotated by an angle $\theta$ can be expressed as:

$$
\sigma_{c}=\min \left\{\frac{S_{c 1}}{\cos ^{2} \theta}, \frac{S_{s 12}}{\cos \theta \sin \theta}, \frac{S_{c 2}}{\sin ^{2} \theta}\right\}
$$

where $S_{c 1}$ and $S_{c 2}$ are the compressive strengths in the fiber and transverse directions, respectively, and $S_{s 12}$ is the in-plane shear strength of the ply in the principal material coordinate system [28]. The strength parameters values used were obtained from the literature for AS4/PEEK material, with $S_{c 1}=1300 \mathrm{MPa}$ [21] and $S_{c 2}=176 \mathrm{MPa}$ [29]. Figure 3.15 shows that the resulting apparent compressive strength from Equation 3.1 is sensitive to the shear strength parameter, particularly at the larger values of fiber angle. The lower bound of shear strength $S_{s 12}$ was obtained from a series of six uniaxial tensile tests on $\pm 45^{\circ}$ laminated specimens using the same material as in this study [30]. The shear strength from this test was determined at 5\% shear strain, resulting in $S_{s 12}=76 \mathrm{MPa}$, following the guidelines in the ASTM standard [31], i.e. at the strain level where fiber rotation due to progressive damage is small. The upper bound of shear strength was obtained from the literature for similar material measured by the Iosipescu test, with $S_{s 12}=113 \mathrm{MPa}$ taken from the peak shear stress [32]. 


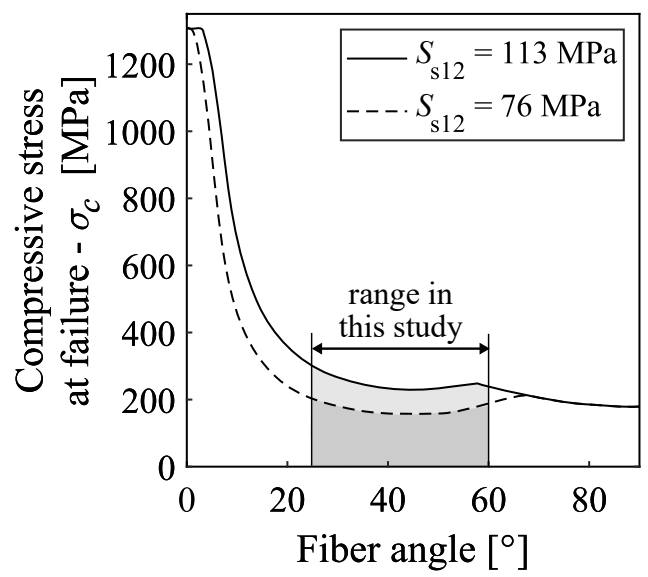

Figure 3.15 Apparent compressive strength for various fiber angles according to the maximum stress criterion for UD AS4/PEEK composite.

The analytical prediction presented in Figure 3.15 shows that the ply compressive strength does not significantly change with increasing $\theta_{\max }$ in the range between $23^{\circ}$ to $60^{\circ}$, for both the lower and upper estimates. This suggests that the failure of all the wavy plies within this study occurs at around the same stress level, with the failure being governed by the shear strength limit. Since the strength of the wavy ply is similar for all cases, then the ultimate strength of the laminates with waviness is also expected to be similar, which agrees with the similar performance observed for all samples with waviness in this study. It is worth mentioning that the kinking model proposed by Budiansky [33] also explains a similar dependency of compressive strength on fiber misalignment angle. This model, however, is particularly suited for small angles.

\section{Effect of number of wavy plies on compressive strength}

The influence of both the number of wavy plies and the maximum waviness angle on the reduction of the compressive strength is presented in Figure 3.16a as the normalized strength, i.e. ratio of the strength of the specimen with waviness to its baseline strength. It is evident from Figure 3.16a that the number of wavy plies has a larger influence on the ultimate strength than the maximum waviness angle.

Figure 3.16b illustrates the dependence of the compressive strength reduction on the number of wavy $0^{\circ}$ plies within the 24-ply QI laminates. Since there appears to be no significant influence of the maximum waviness angle, the normalized compressive strength was averaged. A strong negative linear correlation between the normalized ultimate compressive strength and the number of wavy $0^{\circ}$ plies was found. The largest reduction found was up to $50 \%$ for the QI3 sample where half of the $0^{\circ}$ plies, i.e. 3 out of 6 plies, were wavy. This shows that the ultimate compressive strength decreases proportionally to the fraction of the wavy axial plies. This finding 
is in agreement with the results from an earlier study on multiple-layer (out-ofplane) waviness which shows that under limited conditions, compression strength reductions may be estimated by the percentage of the $0^{\circ}$ plies containing waviness [15]. The simplest explanation for this observation is that only the intact $0^{\circ}$ plies contribute to the strength which works surprisingly well for the results found in our study (Figure 3.16b). As was shown earlier, the waviness in this study causes a significant reduction of the ply compressive strength, thereby diminishing the load bearing capacity.

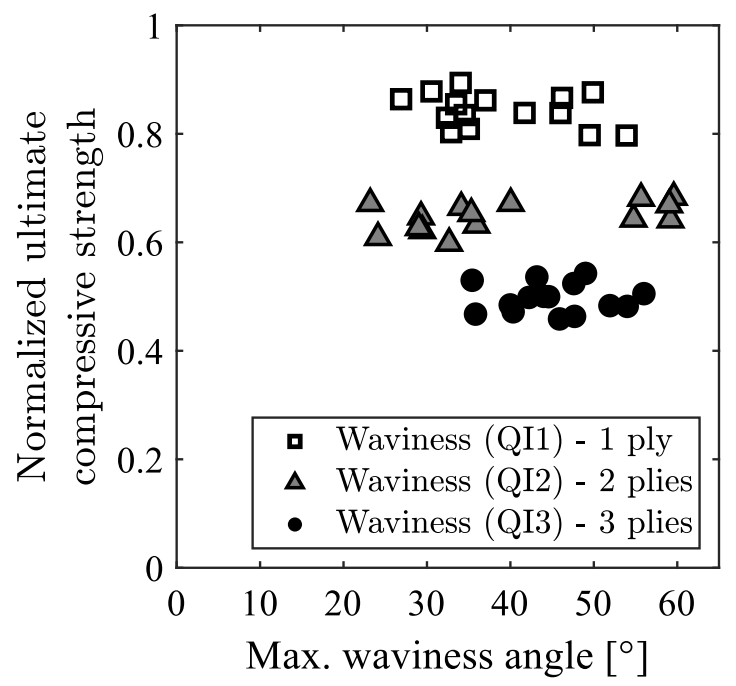

(a)

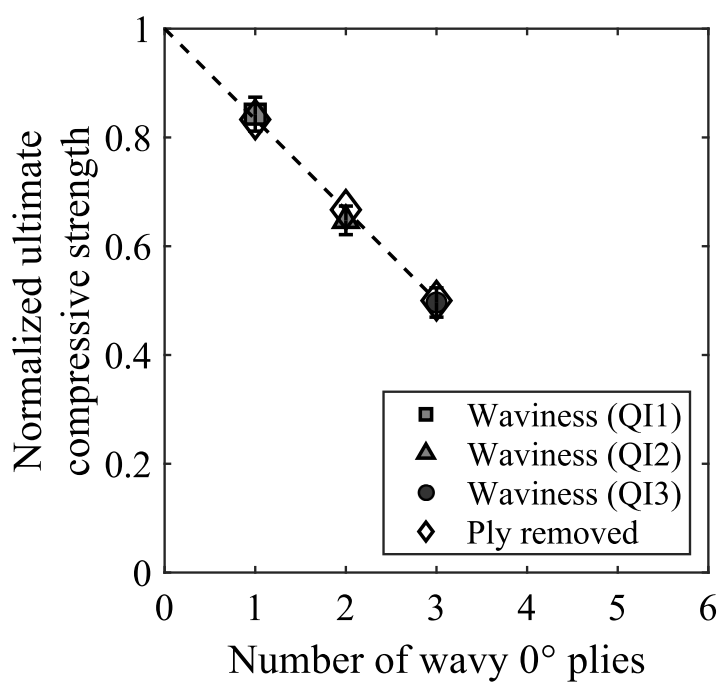

(b)

Figure 3.16 Normalized ultimate compressive strength with respect to the corresponding baseline for each layup: (a) correlated with the maximum waviness angle, $(b)$ represented as the average strength for each layup correlated with the number of wavy $0^{\circ}$ plies in a 24-ply QI laminate (the standard deviations are represented by the error bars).

\section{FE analysis of the composites with waviness}

An FE analysis was performed to evaluate the dominant stress component that causes initiation of failure in the wavy ply. A three-dimensional linear elastic analysis of the laminate modeled at the ply-level (mesoscale) was carried out to simulate the compression test by using a commercial FE software package Abaqus (Figure 3.17). 8-node linear brick elements (C3D8) were used to model the gage section of the CLC test coupon, with a dimension of $20 \mathrm{~mm} \times 12 \mathrm{~mm} \times 3.36 \mathrm{~mm}$. The thickness of each element is the thickness of each ply $(0.14 \mathrm{~mm})$. The elements have inplane dimensions of $0.075 \mathrm{~mm} \times 0.075 \mathrm{~mm}$. The waviness in this study was not modeled geometrically but by varying the local material orientation of the wavy ply. This was achieved by mapping the experimentally measured fiber angles to each individual element of the wavy ply, i.e. by defining a discrete field for the material orientation (Figure 3.17). The boundary conditions are schematically illustrated in 
Figure 3.17. A compressive load was introduced by a prescribed displacement of 0.04 $\mathrm{mm}$ (equivalent to a longitudinal strain of $0.2 \%$ ) in the $\mathrm{x}$-direction at the upper side of the model, with unconstrained $y$ and $z$-displacements, while the opposite face at the bottom side of the model was fixed in the x-direction. To prevent rigid body motion, one corner node at the bottom face was also fixed in the $y$ and $z$-directions.
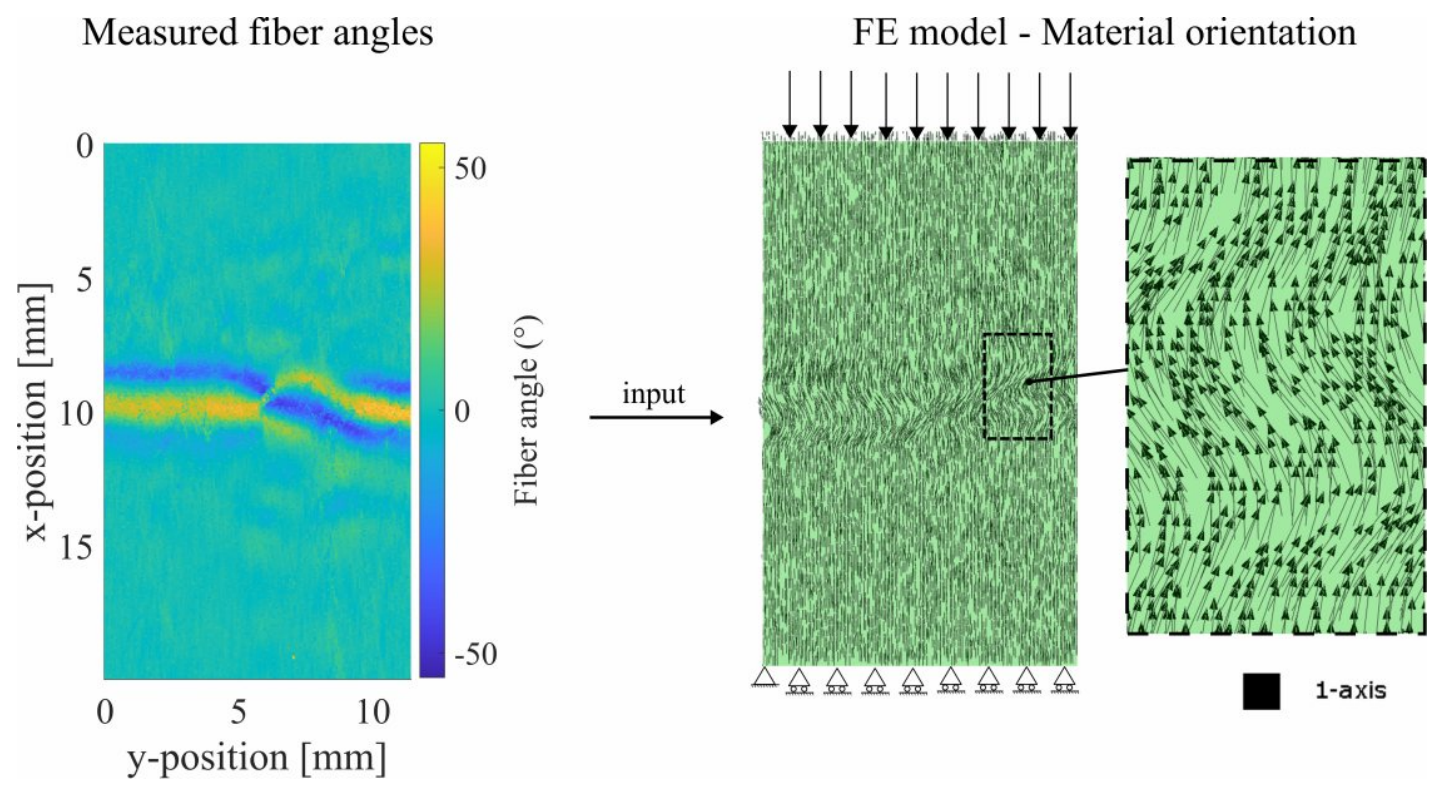

Figure 3.17 Input for the FE model: measured fiber angles (left) as the input of the material orientations of the wavy ply (right), and the $2 D$ representation of the applied boundary conditions at both ends of the test coupon's gage section (right).

The elastic properties of the C/PEEK prepreg material used as the input for the FE model are given in Table 5.1. Most of these elastic properties were obtained directly from material supplier datasheet [21], while few other properties that were absent $\left(v_{23}, G_{23}\right)$ were calculated with the help of the Chamis model [34] using the fiber and matrix material properties from the manufacturer. In-plane shear properties were determined experimentally by means of a uniaxial tensile test of a $\pm 45^{\circ}$ laminate, as was elaborated earlier.

Table 3.2 Elastic properties of the AS4/PEEK material used in the FE model.

\begin{tabular}{ccccccccc}
\hline $\begin{array}{c}E_{11} \\
{[\mathrm{GPa}]}\end{array}$ & $\begin{array}{c}E_{22} \\
{[\mathrm{GPa}]}\end{array}$ & $\begin{array}{c}E_{33} \\
{[\mathrm{GPa}]}\end{array}$ & $\begin{array}{c}v_{12} \\
-\end{array}$ & $\begin{array}{c}v_{13} \\
-\end{array}$ & $\begin{array}{c}v_{23} \\
-\end{array}$ & $\begin{array}{c}\mathrm{G}_{12} \\
{[\mathrm{GPa}]}\end{array}$ & $\begin{array}{c}\mathrm{G}_{13} \\
{[\mathrm{GPa}]}\end{array}$ & $\begin{array}{c}G_{23} \\
{[\mathrm{GPa}]}\end{array}$ \\
\hline 124 & 10 & 10 & 0.33 & 0.33 & 0.43 & 4.2 & 4.2 & 4.1 \\
\hline
\end{tabular}

The strain fields from the FE model were validated using the results from Digital Image Correlation (DIC) experiments. Figure 3.18 shows that the result from the FE analysis (FEA) compared well with DIC strain contour. The model was able to 
capture the strain inhomogeneity seen in the waviness region. It was confirmed that the model can predict the compressive response of composite with waviness by including the experimentally measured local fiber orientation in the analysis.
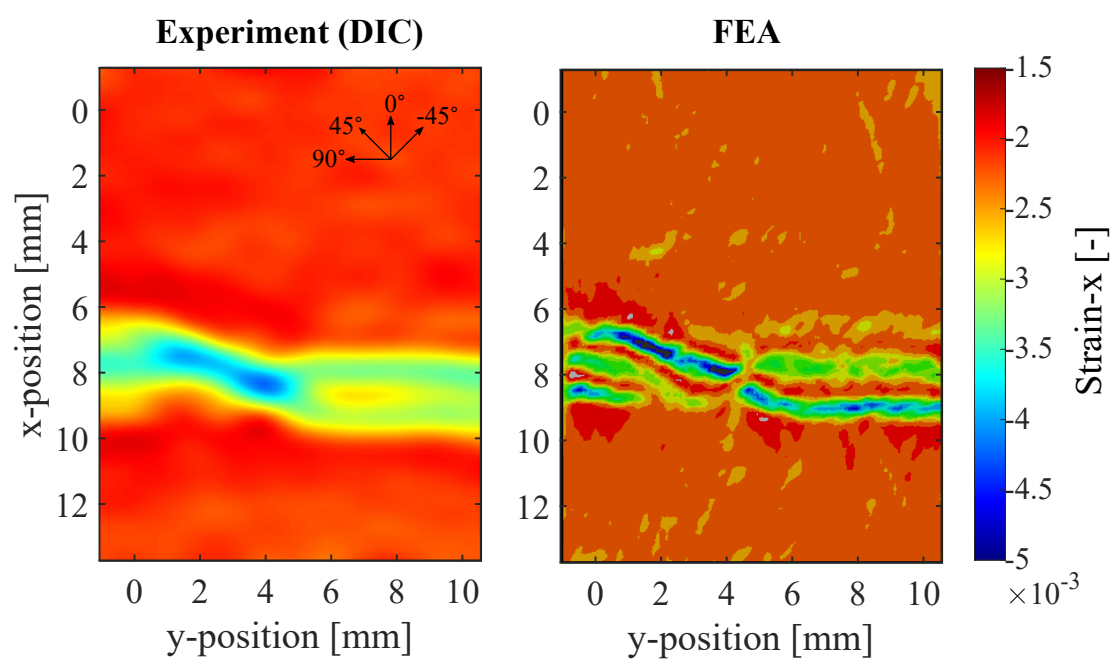

Figure 3.18 Comparison of the strain fields from DIC measurements (left) and FEA (right).

Figure 3.19 shows an example of the simulated stress fields for the V120-QI1 specimen with waviness at the same applied displacement as from the compression test. The longitudinal $\left(\sigma_{11}\right)$ and the in-plane shear $\left(\tau_{12}\right)$ stress fields of the wavy ply in the principal material coordinate system are presented in Figure 3.19a. It is apparent that the presence of waviness significantly alters the stress fields surrounding the defective region. Shear stresses are also developed in the $0^{\circ}$ ply around the wavy fibers. This can be explained by the change in local fiber orientation which causes the change in local stiffness, hence the local stress state.

The critical regions indicated by the location with large in-plane shear stresses $\left(\tau_{12}\right)$, i.e. larger than the shear strength of the material of $76 \mathrm{MPa}$ (lower bound), are compared with the surface fractography of the tested specimen shown in Figure 3.19b. Multiple kink bands at the waviness region with a large maximum waviness angle were observed from the micrographs shown in Figure 3.19c. It appears that the locations with large in-plane shear stresses coincide well with the location of the kink bands. These results thus confirm the expected mechanism in which the shear stress that develops because of the misalignment of the fibers is the dominant stress component that triggers the failure. This also explains the early failure because of the kinking mechanism observed in the majority of the specimens with waviness, which ultimately leads to strength reduction. 

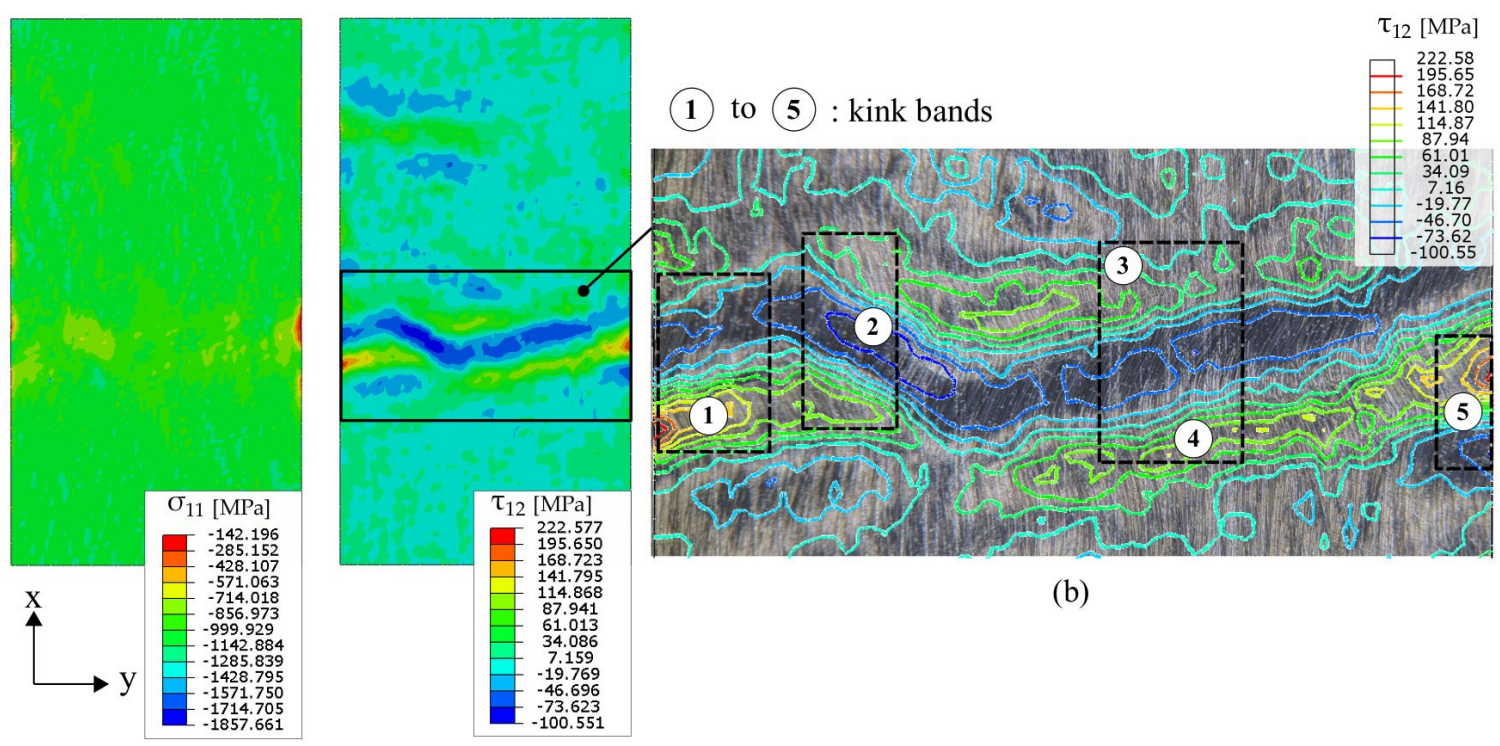

(b)

(a)
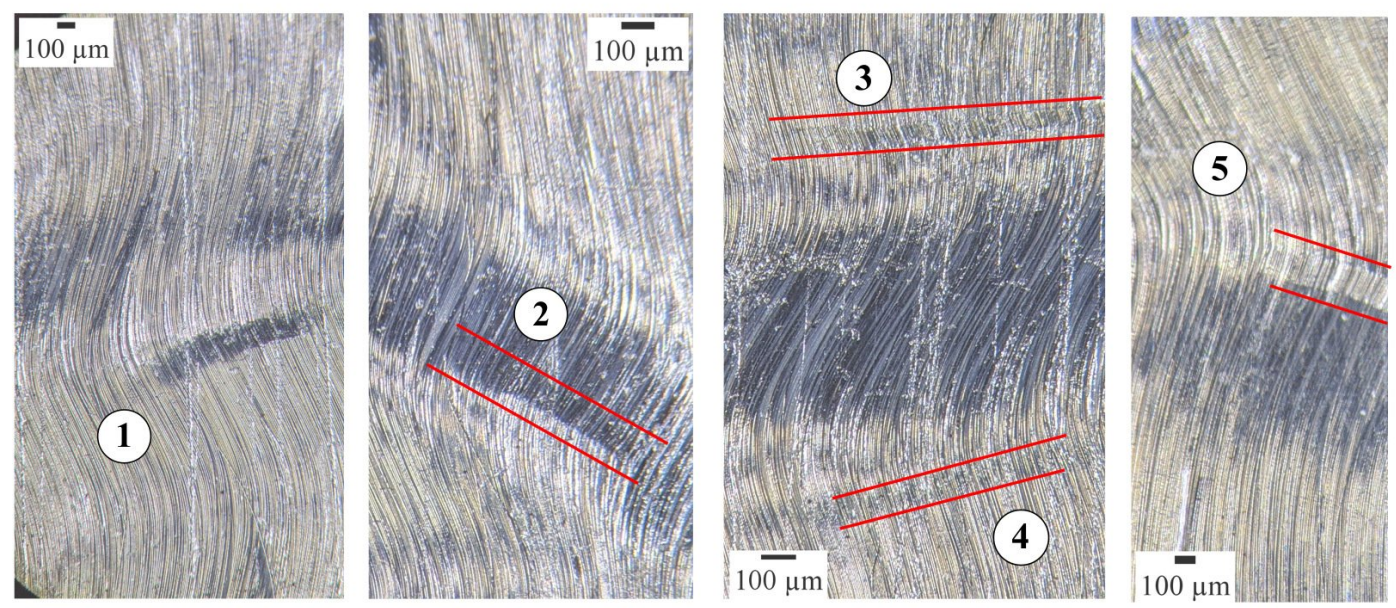

(c)

Figure 3.19 (a) Stress fields of the V120-QI1 specimen at the level of the applied displacement in which the first damage in the wavy ply was observed during the compression test experiment. The stresses were computed at the local material coordinate system for each element: $\sigma_{11}$ represents the longitudinal stress and $\tau_{12}$ represents the in-plane shear stress, both in the principal material directions. (b) Surface fractography at the wavy region with large $\theta_{\max }$, superimposed with the line contour of $\tau_{12}$. (c) Zoomed-in fracture surfaces from figure $b$, highlighted with several red lines just outside of the kink band boundaries for clarity.

\subsection{Conclusions}

The effects of in-plane waviness defects on the compressive properties of QI C/PEEK laminates have been studied in this chapter. Wavy 24-ply QI laminates with three different stacking sequences were manufactured using a stamp forming process and have been tested using the CLC test method. The waviness formed was only visible 
on one surface of the test coupon and localized in the gage section. The wavy plies, ranging from one to three wavy $0^{\circ}$ plies, were located only at the outermost layers of the stack. The compression test results showed no significant influence of waviness on the global laminate stiffness. As expected, the strength of the samples with waviness was significantly reduced with respect to the baseline, non-defective, samples. Highspeed camera monitoring during the compression test confirmed that the waviness defects act as a trigger for early failure. Fractography analysis has shown that the initiation of failure in the wavy region was predominantly due to the formation of kink bands. Moreover, it was found that the locations of the kink bands coincide with the regions that have high shear stress as identified from the FE model. This confirms the expected mechanism in which the matrix shear failure triggers the kink band formation.

The influence of the waviness parameters, characterized by means of microscopy analysis, on the compressive strength has been investigated in this chapter. The strength was not significantly affected by the change in the maximum waviness angle within the range studied in this work, which was between $23^{\circ}$ and $60^{\circ}$. However, a negative linear dependency was observed between the ultimate compressive strength and the number of wavy $0^{\circ}$ plies. A significant reduction of the strength of up to $50 \%$ was found for the QI3 laminates, which have the largest number of wavy plies within this study, i.e. three wavy plies out of a total of six $0^{\circ}$ plies. Disregarding the loadbearing capacity of the wavy ply appears to provide a good estimation of the reduced ultimate strength of the laminate. In general, it was found that local waviness has a negligible effect on the global laminate stiffness, but that the severity of waviness was such that the compressive strength of the QI laminate drops proportionally to the percentage of plies oriented in the loading direction that is wavy.

\section{References}

[1] M. R Piggott. The effect of fibre waviness on the mechanical properties of unidirectional fibre composites: a review. Composites science and technology, 53(2):201-205, 1995.

[2] M. R. Wisnom and J. W. Atkinson. Compressive failure due to shear instability: Experimental investigation of waviness and correlation with analysis. Journal of Reinforced Plastics and Composites, 15(4):420-439, 1996.

[3] P. J. Joyce and T. J. Moon. Compression Strength Reduction in Composites with inPlane Fiber Waviness, pages 76-96. ASTM International, West Conshohocken, PA, 1998.

[4] D. Wilhelmsson, R. Gutkin, F. Edgren, and L. E. Asp. An experimental study of fibre waviness and its effects on compressive properties of unidirectional NCF composites. Composites Part A: Applied Science and Manufacturing, 107:665-674, 2018. 
[5] R. D. R. Sitohang, W. J. B. Grouve, L. L. Warnet, S. Koussios, and R. Akkerman. An experimental approach to reproduce in-plane fiber waviness in thermoplastic composites test coupons using a reverse forming method. Journal of Composite Materials, July 2021.

[6] C. T. Sun and A. Wanki Jun. Compressive strength of unidirectional fiber composites with matrix non-linearity. Composites Science and Technology, 52(4):577-587, 1994.

[7] B. Budiansky and N. A. Fleck. Compressive failure of fibre composites. Journal of the Mechanics and Physics of Solids, 41(1):183-211, 1993.

[8] H. M. Hsiao and I. M. Daniel. Effect of fiber waviness on stiffness and strength reduction of unidirectional composites under compressive loading. Composites science and technology, 56(5):581-593, 1996.

[9] Q. Sun, H. Guo, G. Zhou, Z. Meng, Z. Chen, H. Kang, S. Keten, and $X$. Su. Experimental and computational analysis of failure mechanisms in unidirectional carbon fiber reinforced polymer laminates under longitudinal compression loading. Composite Structures, 203:335-348, 2018.

[10] P. Y. Mechin, V. Keryvin, J. C. Grandidier, and D. Glehen. An experimental protocol to measure the parameters affecting the compressive strength of cfrp with a fibre micro-buckling failure criterion. Composite Structures, 211:154-162, 2019.

[11] S. N. Nair, A. Dasari, C. Y. Yue, and S. Narasimalu. Failure behavior of unidirectional composites under compression loading: Effect of fiber waviness. Materials (Basel, Switzerland), 10(8):909, 2017.

[12] D. Wilhelmsson, R. Talreja, R. Gutkin, and L. Asp. Compressive strength assessment of fibre composites based on a defect severity model. Composites Science and Technology, 181:107685, 2019.

[13] T. Yokozeki, H. Takemura, and T. Aoki. Numerical analysis on the flexural strength of unidirectional cfrtp composites with in-plane fiber bundle waviness. Advanced Composite Materials, 29(1):89-100, 2020.

[14] N. Ichihara, M. Ueda, Y. Urushiyama, A. Todoroki, R. Matsuzaki, and H. Hirano. Progressive damage simulation for a 3d-printed curvilinear continuous carbon fiber-reinforced thermoplastic based on continuum damage mechanics. Advanced Composite Materials, 29(5):459-474, 2020.

[15] D. O. Adams and S. J. Bell. Compression strength reductions in composite laminates due to multiple-layer waviness. Composites Science and Technology, 53(2):207-212, 1995.

[16] S. Mukhopadhyay, M. I. Jones, and S. R. Hallett. Compressive failure of laminates containing an embedded wrinkle; experimental and numerical study. Composites Part A: Applied Science and Manufacturing, 73:132-142, 2015.

[17] B. Khan, K. D. Potter, and M. R. Wisnom. Simulation of process induced defects in resin transfer moulded woven carbon fibre laminates and their effect on mechanical behaviour. In The 8th International Conference on Flow Processes in 
Composite Materials (FPCM8), 2006.

[18] J. F. Mandell, D. D. Samborsky, and L. Wang. Effects of fiber waviness on composites for wind turbine blades. In 48th International SAMPE symposium, volume 48, 2003.

[19] A. Shipsha, S. Hallström, and M. Burman. Effect of stacking sequence and bundle waviness in quasi-isotropic NCF composites subjected to compression. Composites Part B: Engineering, 178:107423, 2019.

[20] M. R. Wisnom and J. W. Atkinson. Fibre waviness generation and measurement and its effect on compressive strength. Journal of Reinforced Plastics and Composites, 19(2):96-110, 2000.

[21] Toray Advanced Composites. Cetex TC1200 PEEK - Technical Data Sheet, 2019.

[22] ASTM. ASTM D6641 - Standard Test Method for Compressive Properties of Polymer Matrix Composite Materials Using a Combined Loading Compression (CLC) Test Fixture, 2001.

[23] D. Wilhelmsson and L. Asp. A high resolution method for characterisation of fibre misalignment angles in composites. Composites Science and Technology, 165, 2018.

[24] E. Greenhalgh. Failure analysis and fractography of polymer composites. Elsevier, 2009.

[25] K. Goto, M. Arai, Y. Kano, E. Hara, and T. Ishikawa. Compressive fracture aspect of thick quasi-isotropic carbon fiber reinforced plastic laminates. Composites Science and Technology, 181:107706, 2019.

[26] J. Lee and C. Soutis. Thickness effect on the compressive strength of T800/924C carbon fibre-epoxy laminates. Composites Part A: Applied Science and Manufacturing, 36(2 SPEC. ISS.):213-227, 2005.

[27] S. N. Nair. Effect of in-plane fiber waviness on the failure of fiber reinforced polymer composites. Ph.D. Thesis, 2018.

[28] R. F. Gibson. Principles of composite material mechanics. CRC press, 2016.

[29] H. Liu, J. Liu, Y. Ding, J. Zhou, X. Kong, L. T. Harper, B. R. K. Blackman, B. G. Falzon, and J. P. Dear. Modelling damage in fibre-reinforced thermoplastic composite laminates subjected to three-point bend loading. Composite Structures, 236:111889, 2020.

[30] M. van der Werff and M. Bouwman. TPRC internal report 2018: Long term exposure of thermoplastic composites. Report, TPRC, 2018.

[31] ASTM. ASTM D3518 - Standard Test Method for In-Plane Shear Response of Polymer Matrix Composite Materials by Tensile Test of a $\pm 45^{\circ}$ Laminate, 2007.

[32] S. L. Coguill and D. F. Adams. Mechanical properties of several neat polymer matrix materials and unidirectional carbon fiber-reinforced composites. Report, 1989.

[33] B. Budiansky. Micromechanics. Computers \& Structures, 16(1):3-12, 1983.

[34] C. C. Chamis. Mechanics of composite materials: past, present, and future. Journal of Composites, Technology and Research, 11(1):3-14, 1989. 


\title{
CHAPTER 4
}

\section{The relation between in-plane fiber waviness severity and first ply failure*}

\begin{abstract}
The influence of in-plane fiber waviness on the first ply failure of quasi-isotropic thermoplastic composite laminates was investigated. $\mathrm{C} /$ PEEK bending specimens with multiple wavy regions and with maximum waviness angles $\left(\theta_{\max }\right)$ ranging between $3^{\circ}$ to $64^{\circ}$ were produced. The failure mode and stress at first failure were studied by using a four-point bending test and an end-loaded bending test. The experiments demonstrated that waviness severity affects stress at first failure and compressive damage development. The stress at first failure initially decreases with increasing maximum waviness angle and levels off as the angle starts exceeding $20^{\circ}$. These results reinforce the hypothesis from previous research which suggests that wavy ply compressive strength is less sensitive to changes in severity at larger angles. Furthermore, it was found that kinking failure was the dominant failure mode for maximum waviness angle up to about $45^{\circ}$. No kink band was observed in wavy regions with $\theta_{\max }$ above $45^{\circ}$ when there was another wavy region with a lower angle in the same specimen. This means that the highest maximum waviness angle of a specimen does not necessarily cause the first failure.
\end{abstract}

${ }^{*}$ Reproduced from Sitohang, R.D.R., Grouve, W.J.B., Warnet, L.L., Wijskamp, S., Akkerman, R., The relation between in-plane fiber waviness severity and first ply failure in thermoplastic composite laminates, submitted to Composite Structures, 2021. 


\subsection{Introduction}

\subsubsection{Background}

The demand for lighter aircraft structures to reduce carbon emissions is growing. One effective way to reduce the mass of aircraft is to use composite materials. Thermoplastic composites (TPCs) are ideal for this application, thanks to their high stiffness and strength-to-weight ratio, and particularly because of the possibility for process automation resulting from their melt-processable matrix. These advantages have been recognized by the aerospace industry and, as a result, the application of TPCs in commercial aircraft has been steadily growing over the past decades. Despite the gains made in manufacturing technologies, surface defects such as inplane fiber waviness may still occur during parts manufacturing, i.e. during the consolidation or the forming process. These defects can cause uncertainty of the mechanical properties, particularly the compressive strength. This may then cause an unnecessarily high safety factor in the design of the aircraft structure, and consequently an increase of the structure's weight. Hence, efficient use of TPCs requires a proper understanding of the failure mechanisms and the mechanical properties of the composites with waviness defects.

Compressive strength is often a limiting design factor of composite materials for aircraft structures. The presence of waviness serves as a trigger to early compressive failure, as was observed in unidirectional (UD) [1-9] and multidirectional (MD) composites [10-14]. The kinking failure mechanism has been shown to be the dominant failure mode in UD composites and in some MD composites, depending on the severity of the defect and the stacking sequence [12-14]. This kinking mechanism is governed by the local shearing of the matrix due to the misalignment of fiber [15].

A previous study by the author on quasi-isotropic (QI) laminates subjected to uniaxial compression showed that waviness in the ply oriented in loading direction caused early kink band formation in the wavy region, resulting in early failure of the laminate and significantly lower ultimate strength [14]. The studied waviness was found in one to three plies in 24-ply QI laminates with a maximum waviness angle $\left(\theta_{\max }\right)$ between $23^{\circ}$ to $60^{\circ}$, relevant to the defects from a stamp forming process. Similarly to earlier studies [10, 11], the waviness caused a significant reduction of ultimate compressive strength. However, contrary to earlier work, the compressive strength of the specimens with waviness did not significantly depend on the maximum waviness angle for the range studied. Based on the maximum stress failure criterion, it can be shown that the compressive strength of a ply changes rapidly for small angles and then levels off as the angle further increases. This suggests that the first failure in the wavy ply occurs at about the same stress level for the range of angles studied. To confirm whether this translates to the compressive strength of MD TPC laminates, further research focusing on the first ply failure of 
laminate with waviness is required.

Most published studies have used compression tests to evaluate the effect of waviness defects, which can lead to a sudden fracture [2, 12, 16]; this makes it difficult to monitor the initiation of damage and the failure mechanisms. Such sudden failure behavior was also found in the author's previous study, which investigated waviness in laminates tested by using the combined loading compression (CLC) test method [14]. High-speed camera monitoring during the compression test used in that study confirmed that the first ply to fail was the wavy ply. However, for some of the specimens the damage initiation mechanism of the wavy ply is not yet clear, as it cannot be established solely from the fractography analysis of these specimens after testing. The initiated damage grows within a few milliseconds into full fracture, making it impossible to stop the test in time. In contrast with the compression test, the damage progression of composites under flexural loading is more gradual. It is thereby easier to monitor the damage evolution and to isolate the failure initiation by using a bending test.

\subsubsection{Objective}

This chapter aims to investigate the influence of in-plane fiber waviness with a wide range of severities on the first ply failure of quasi-isotropic thermoplastic composite laminates. More specifically, it focuses on determining the ply compressive stress at which the first failure occurs when the laminate is subjected to bending, and identifying the mechanisms causing this failure.

\subsubsection{Approach}

Various test methodologies have been developed to measure the bending strength of composites. The generally accepted and standardized test methods are the threepoint bending (3PB) and the four-point bending (4PB) test. The $4 \mathrm{~PB}$ test is more suitable for the study of waviness defects due to the constant bending moment between the two loading cylinders. Although the $4 \mathrm{~PB}$ test is commonly used to evaluate the bending strength of composites, it has the limitation of suffering from stress concentrations under the loading points which often causes premature failure of the specimen [17].

An alternative test method to overcome undesirable premature failure due to load introduction was developed by Fukuda et al. [17-19]. This test is in principle based on an eccentric compression loading condition. The term end-loaded bending (ELB) test is used in this chapter to describe the compression bending test, to avoid confusion with the compression test. The previously developed method only measured the deflection at the mid-span of the specimen, and the authors did not report the failure 
location [17-20]. The bending moment with the ELB test method is not constant over the specimen length, with the maximum at the mid-span. Due to the presence of defects, the failure may not be located exactly in the mid-span. In such a case, the bending moment at the point of failure could not be determined solely from the midspan deflection. To overcome this, a new measurement method by means of image analysis technique was implemented in this work to directly measure the curvature over the whole specimen length. The failure mode and the stress at first failure of several baseline (non-defective) samples obtained from the ELB and the 4PB tests were compared with the motivation to validate the use of the ELB test method.

One important aspect for an effect-of-defect study is to investigate the severity that is representative of the defects in actual parts. To this end, the specimenmanufacturing methods that directly mimic the mechanisms by which waviness is formed during TPC manufacturing processes were applied in this work. Two manufacturing procedures, i.e. press consolidation [21] and reverse forming method [22], were used to produce specimens whose waviness has a broad range of maximum waviness angles. The waviness investigated in this study is in the ply oriented in the loading direction. The stress at first failure of the specimens with waviness was subsequently assessed by using mainly the ELB test method. A limited number of specimens with waviness were also tested using the $4 \mathrm{~PB}$ test method as a comparison. In both cases, the tests were stopped when the first failure was detected, to identify the damage mechanisms causing this failure. The failure mode was identified by fractography analysis using optical microscopy and scanning electron microscopy (SEM).

\subsection{Experimental work}

\subsubsection{Material and specimens}

Quasi-isotropic (QI) laminates were prepared from unidirectional carbon polyetherether-ketone (PEEK) tapes known as Cetex ${ }^{\circledR}$ TC1200 from Toray Advanced Composites. A total of 24 plies were stacked in a [0/45/90/-45] 3 s layup to produce laminates with a nominal thickness of $3.4 \mathrm{~mm}$. The UD tapes contain AS4 fibers with a fiber volume fraction of 59\% [23]. As mentioned earlier, two manufacturing procedures were used to produce specimens with different levels of severity. The first was a press consolidation process which was performed using a well-chosen combination of tool material and release media, based on the findings from a study of the formation of fiber waviness during consolidation [21]. The second procedure was based on a stamp forming process, i.e. by a reverse forming method [22]. These two manufacturing procedures are described in more detail in the subsequent sections. 


\section{Press-consolidated specimens}

UD tapes with the size of $300 \mathrm{~mm} \times 300 \mathrm{~mm}$ were stacked in a picture frame mold between a combination of tool plates with release media. Two different materials were used as tool plates. The steel tool plates with the combination of Upilex $25 \mathrm{~S}$ release films and Frekote 700-NC release agent were used to manufacture the baseline (non-defective) laminates, while the aluminum plates with Upilex $25 S$ release films, but without any release agent, were used for the laminates with waviness (as listed in Table 4.1). The combination of a high coefficient of thermal expansion of the tool material and a high tool-ply coefficient of friction was found in an earlier study to promote the formation of fiber waviness during C/PEEK consolidation [21]. The UD tapes stack was then press-consolidated under 20 bar pressure with 20 minutes dwell time at $385^{\circ} \mathrm{C}$, and a cooling rate of $5^{\circ} \mathrm{C} / \mathrm{min}$. Two laminates were produced for each of the settings.

Bending test coupons, $13 \mathrm{~mm}$ wide and $150 \mathrm{~mm}$ long, were cut from the manufactured laminates using a CNC milling machine. The test coupons were oriented parallel to the fiber direction of the surface ply. The specimen length was chosen such that a span-to-thickness ratio of 32:1 can be used for the 4PB test, according to the ASTM D7264 standard [24]. The specimen size was kept the same for both bending tests, $4 \mathrm{~PB}$ and ELB tests.

\section{Reverse-formed specimens}

UD tapes were press-consolidated in the same way as the baseline laminate described in section 4.2.1. The produced laminates were then cut using a water-cooled diamond-coated saw to obtain two $300 \mathrm{~mm} \times 150 \mathrm{~mm}$ blanks for the subsequent stamp forming steps. These blanks were free of waviness prior to stamp forming.

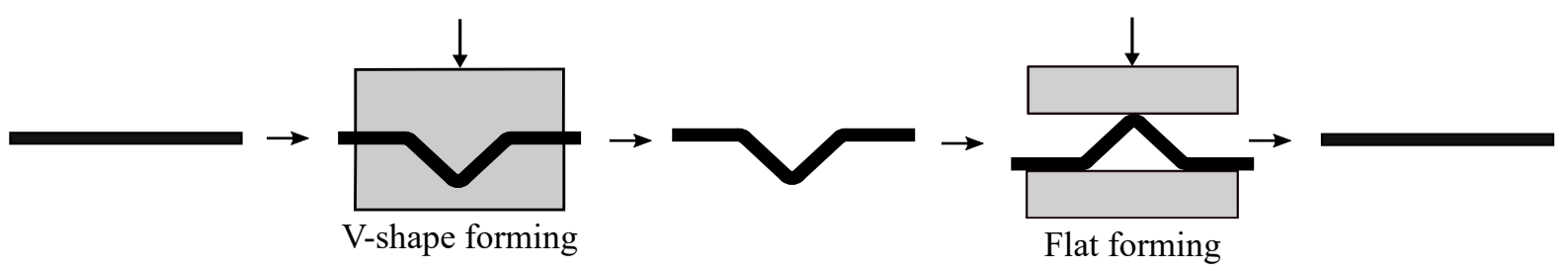

Figure 4.1 Reverse forming steps to form in-plane waviness defects in a flat laminate. Reproduced from [14].

Laminates with waviness were manufactured using a reverse forming method consisting of two stamp forming cycles (Figure 4.1). Prior to the stamp forming process, the blanks were preheated in the IR oven at $465^{\circ} \mathrm{C}$ for 300 seconds, to reach a midplane temperature of $390^{\circ} \mathrm{C}$. Three V-shaped matched metal toolings, as listed in Table 4.1, with different combinations of bend angles and inner radii were used in 
Table 4.1 Sample manufacturing methods. $P C=$ press consolidation, $R F=$ reverse forming. Release media: $U=$ Upilex 25S, $F=$ Frekote 700-NC, $M=$ Marbocote 227CEE.

\begin{tabular}{ccccc}
\hline Sample & Processing method & Tool & Release & Tool geometry \\
\hline Baseline-PC & Press consolidation & Steel & U + F & Flat \\
\hline Waviness-PC & Press consolidation & Aluminum & U & Flat \\
\hline Baseline-RF & Flat forming & Aluminum & $\mathrm{M}$ & Flat \\
\hline \multirow{3}{*}{ Waviness-RF } & \multirow{2}{*}{ Reverse forming } & Steel & $\mathrm{M}$ & V-shape $90^{\circ}$ bend \\
& & Aluminum & $\mathrm{M}$ & V-shape $105^{\circ}$ bend \\
& & Aluminum & $\mathrm{M}$ & V-shape $120^{\circ}$ bend \\
\hline
\end{tabular}

the first stamp forming step in order to vary the waviness severity induced. All of the toolings were coated using the Marbocote 227CEE release agent. The V-shaped geometries used had a bend angle of $90^{\circ}, 105^{\circ}$, and $120^{\circ}$ with an inner radius of 6.4 $\mathrm{mm}, 8 \mathrm{~mm}$ and $10 \mathrm{~mm}$, respectively. The V-shaped parts were formed by applying a nominal 40 bar consolidation pressure for 60 seconds while the part was cooled down to the tool temperature of $240^{\circ} \mathrm{C}$. The V-shaped parts were then reheated again in the IR oven for the subsequent flat forming step, with the same settings as before. The same forming parameters, except for pressure, were used for flattening the V-shaped parts to induce waviness. This second forming step was carried out by applying 100 bar consolidation pressure for 60 seconds. Two laminates were produced with the $90^{\circ}$-bend angle, one for each bending test method, and one laminate each for the other V-bend angles (the $105^{\circ}$ and the $120^{\circ}$-bend). Finally, bending test coupons were cut from these laminates to the specimen dimension described earlier using a $\mathrm{CNC}$ milling machine. Seven specimens per laminate with waviness were prepared for the bending tests. Nevertheless, several issues were encountered during testing due to the rather complex measurement steps, reducing the number of specimens kept for the analysis. Only the valid test results, which amounted to at least five specimens per sample for each type of bending test, were reported in this chapter.

Baseline laminates, as the non-defective reference, were manufactured using flat aluminum tools (Table 4.1) by following the same two stamp forming process cycles as previously described for the reverse forming procedure. These laminates therefore have the same pressure and thermal history as the ones with fiber waviness. Two laminates were produced, one for each bending test method. Finally, bending test coupons were cut from the baseline laminates to the specimen dimension described earlier.

\subsubsection{Characterization of waviness parameters}

Surface micrographs of each test coupon were taken with a Keyence VHX-5000 digital microscope with a resolution of $1.5 \mu \mathrm{m}$ per pixel in order to quantify the waviness 
severity. Before image acquisition, the surface was prepared by applying a thin layer of sunflower oil on the surface to enhance the visibility of the fibers. Each test coupon typically had multiple wavy regions scattered across the surface. Separate micrographs were taken from each wavy region. The micrographs were processed with the high resolution misalignment analysis (HRMA) method developed by Wilhemsson et al. to trace the fibers [25]. A block size of 50 pixels $\times 50$ pixels $(75 \mu \mathrm{m} \times 75 \mu \mathrm{m})$ was used in this study. The maximum waviness angle $\left(\theta_{\max }\right)$ and the wavelength $(\lambda)$ were then measured for each wavy region. The largest $\theta_{\max }$ from a given test coupon is defined as the overall $\theta_{\max }$. For example, the overall $\theta_{\max }$ of the reverse-formed test coupon presented later in Figure 4.5 is equal to $40^{\circ}$.

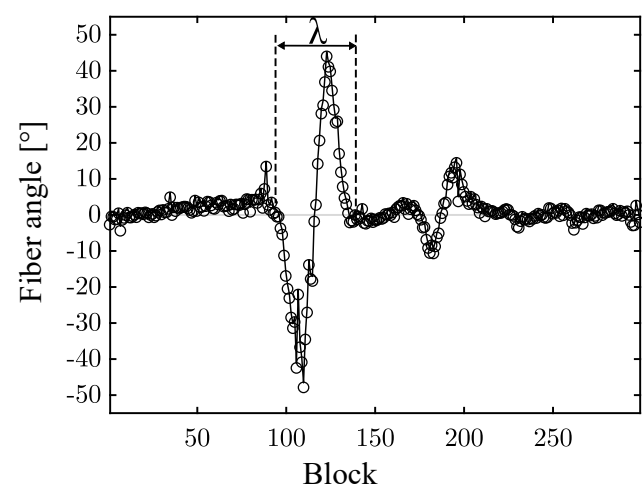

(a)

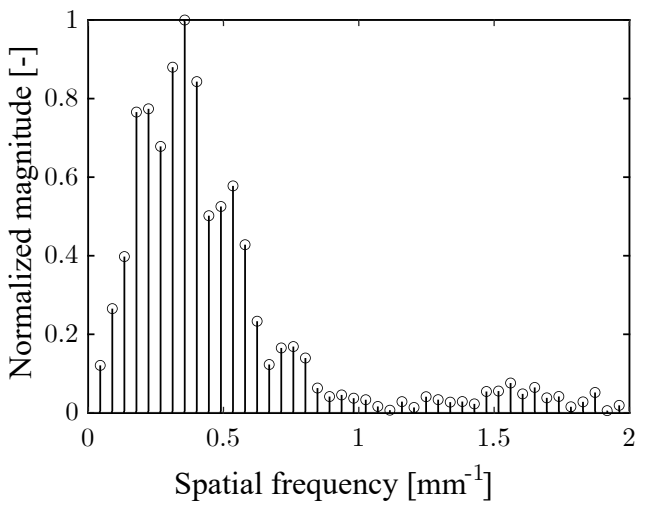

(b)

Figure 4.2 Representation of the procedure to measure the wavelength. (a) Fiber angles displayed as a function of the number of blocks from a micrograph along the direction parallel to the nominal surface ply orientation. (b) The spatial frequencies from the fiber angles data in Figure a. The wavelength $(\lambda)$ is calculated from the spatial frequency at the highest peak, where the wavelength equals $1 /$ spatial frequency.

The wavelength was determined by performing a spectral analysis individually for each wavy region. The method proposed here utilizes Fourier transform to identify the spatial frequencies that can be found in the signal. This is done by transforming the result from the spatial domain, i.e. the fiber angle data along the horizontal direction, parallel to the $0^{\circ}$ fiber orientation (Figure 4.2a) to its frequency domain $X(k)$. The fiber angle, represented as $x(n)$ with a total of $N$ number of blocks, is transformed to its frequency domain according to:

$$
X(k)=\sum_{n=0}^{N-1} x(n) \exp \left(\frac{-2 \pi j}{N} k n\right) \quad \text { for } k=0,1,2, \ldots, N-1
$$

The spatial frequency is $k f_{s} / N$, where the sampling frequency $f_{s}$ equals the inverse of the spatial resolution, i.e. the block length of $75 \mu \mathrm{m}$. The wavelength is determined from the inverse of the dominant spatial frequency, i.e. the frequency at the largest magnitude, normalized to its maximum magnitude value. This can be visualized by 
determining the corresponding spatial frequency at the highest peak (Figure 4.2b). The wavelength reported in this chapter is the mean wavelength from each row of a given micrograph, which represents the dimension of the waviness in the fiber direction.

\subsubsection{Mechanical testing procedure}

\section{Four-point bending test}

The failure stress of the specimens was measured by means of four-point bending tests according to ASTM D 7264 [24]. The fiber direction of the surface ply $\left(0^{\circ}\right.$ ply) was along the length of the specimen, as the strength reduction due to fiber waviness is expected to be maximum for this loading direction. The wavy surface of the specimens was placed on the compression side. The support span length was set to $108 \mathrm{~mm}$, resulting in a span-to-thickness ratio of 32:1. The loading cylinders were positioned equidistantly from the adjacent support, with the load span length equaling half of the support span length. The test was performed using an Instron 5982 universal testing machine equipped with a $10 \mathrm{kN}$ load cell. It was carried out at a constant crosshead speed of $1 \mathrm{~mm} / \mathrm{min}$, which corresponds to the maximum strain rate of $2.1 \cdot 10^{-5} \mathrm{~s}^{-1}$ occurring at the outer surface and the mid-span length of the specimen. The test was stopped when the first failure was detected. The longitudinal stress $\sigma_{11}$ in the top outermost $0^{\circ}$ ply for a pure bending state was calculated according to:

$$
\sigma_{11}=Q_{11} z \kappa_{x}
$$

where $z$ is the ply out-of-plane coordinate with respect to the laminate midplane, $Q_{11}$ is the 11 element of the lamina stiffness matrix, and $\kappa_{x}$ is the curvature along the $x$-axis (specimen length direction) [26]. The UD tape material properties in Table 4.2 were used to determine the theoretical $Q_{11}(125 \mathrm{GPa})$. The ply stress was calculated assuming the nominal fiber orientation of the ply. The curvature $\kappa_{x}$ can be obtained from the following relation:

$$
\kappa_{x}=d_{11} M_{x}
$$

where $M_{x}$ is the bending moment per unit width and $d_{11}$ belongs to the laminate bending compliance matrix, calculated by $d_{11}=12 /\left(h^{3} E_{f}\right)$, and where $h$ is the specimen thickness and $E_{f}$ is the measured flexural modulus [26]. The bending moment per unit width between the two loading noses is defined as $M_{x}=P L / 8 b$, calculated using the measured force $P$, the support span length $L$, and the specimen width $b$. The flexural secant modulus, i.e. the ratio of stress to corresponding strain 
at the strain of 0.003 [24], was determined from the test, according to:

$$
E_{f}=\frac{0.17 L^{3} m}{b h^{3}}
$$

where $m$ is the slope of the secant of the force-deflection curve. The deflection of the specimen was measured at the mid-span using a deflectometer.

Table 4.2 Material properties of AS4/PEEK UD tape for the ply stress calculation [14, 23].

\begin{tabular}{cccc}
\hline $\begin{array}{c}E_{11} \\
{[\mathrm{GPa}]}\end{array}$ & $\begin{array}{c}E_{22} \\
{[\mathrm{GPa}]}\end{array}$ & $\begin{array}{c}v_{12} \\
{[-]}\end{array}$ & $\begin{array}{c}G_{12} \\
{[\mathrm{GPa}]}\end{array}$ \\
\hline 124 & 10 & 0.33 & 4.2 \\
\hline
\end{tabular}

\section{End-loaded bending test}

The second test method used to measure the failure stress was the end-loaded bending test using the setup shown in Figure 4.3. The fiber direction of the outermost ply $\left(0^{\circ}\right.$ ply) was oriented along the length of the specimen. The test coupon was clamped at both ends in fixtures that are fitted to ball bearings which then permit rotation of the test coupon ends. To facilitate predetermined direction of the deflection, the test coupon slots were positioned eccentrically such that there is an initial offset which is equal to half of the specimen thickness $h$ (see Figure 4.3) between the specimen's neutral axis and the axis of rotation of the bearing. In this way, similarly to the $4 \mathrm{~PB}$ test method, the tension and compression sides can be predetermined. This ensures that the wavy surface is loaded primarily under compression during the test.

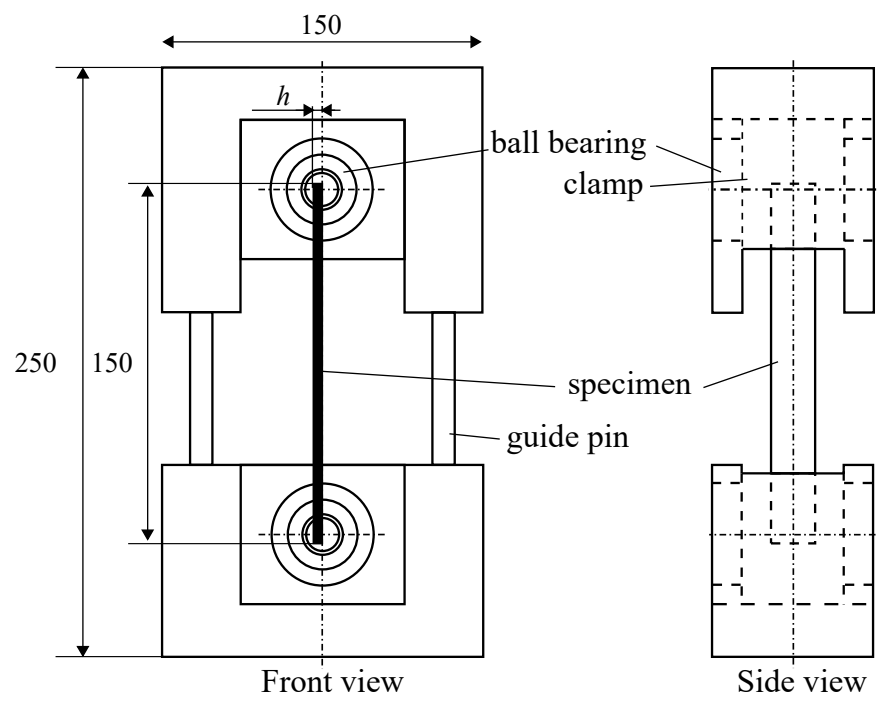

Figure 4.3 Schematic of the end-loaded bending test setup. $h$ is the specimen thickness. All dimensions are in $\mathrm{mm}$. 
The test was carried out using an Instron 5982 universal testing machine equipped with a $10 \mathrm{kN}$ load cell, at a constant crosshead speed of $1 \mathrm{~mm} / \mathrm{min}$ until the first failure was detected. The maximum strain rate was $2.2 \cdot 10^{-5} \mathrm{~s}^{-1}$, occurring at the outer surface and the mid-span length of the specimen. The specimen edge was monitored throughout the test by using a camera set viewing the specimen side (see Figure 4.4). This camera was intended to evaluate the specimen curvature. It recorded videos at 2 frames per second (fps). Another camera was also used simultaneously monitoring the compression side at $240 \mathrm{fps}$ during testing to observe the failure occurring. In addition, a limited number of tests was performed by using a highspeed camera (HSC) to monitor the damage sequence at a higher frame rate of 25,000 fps. The lighting for the HSC monitoring was too bright for the camera used to measure the curvature during the ELB test and disrupted the measurement.
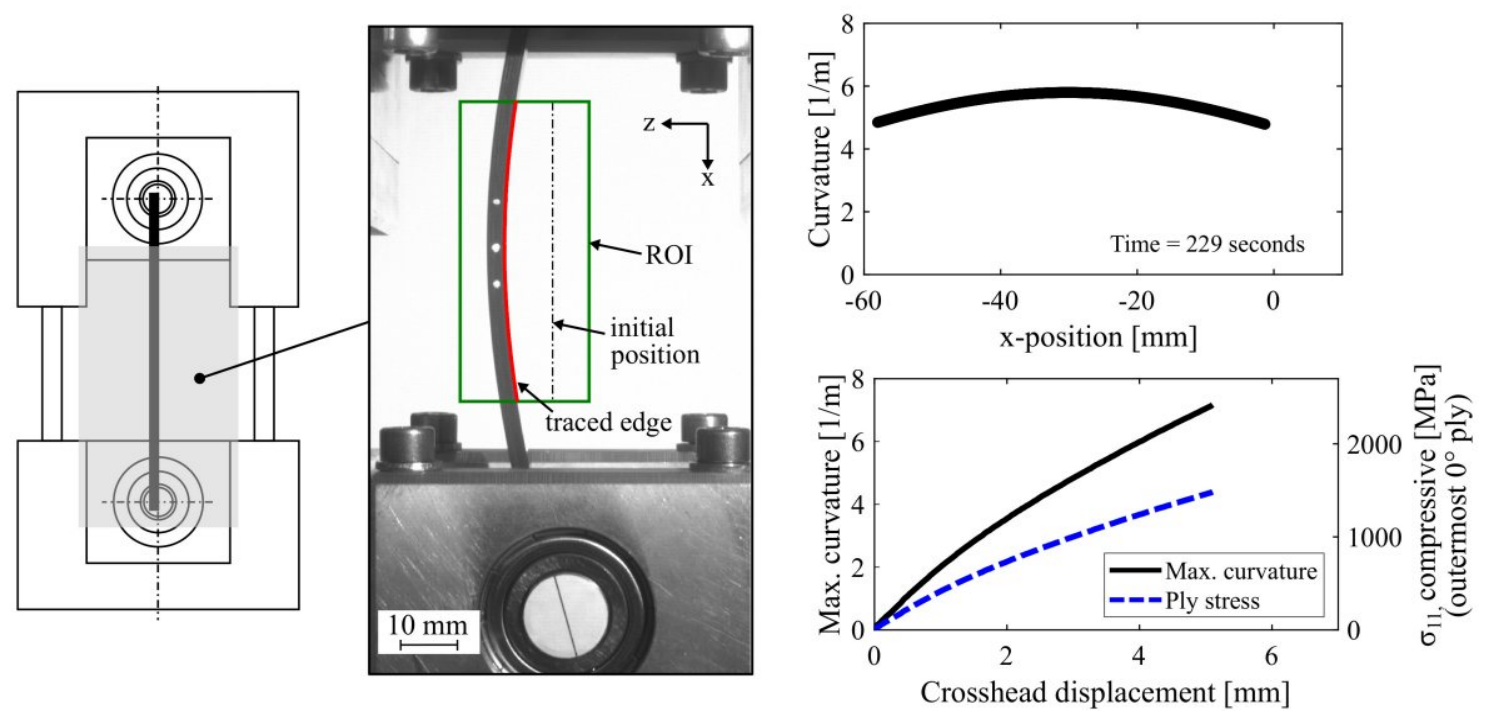

Figure 4.4 Optical measurement of curvature from an image of the specimen side during ELB testing. The measured curvature along the specimen length is shown at the top right. The output from the image analysis is given on the bottom right, showing the maximum curvature and the outermost $0^{\circ}$ ply longitudinal compressive stress $\left(\sigma_{11}\right)$ from the whole test duration.

Scoping experiments have indicated that the stress derived from deflection largely depends on the assumed initial position of the specimen's neutral axis, and the eccentricity, which also depends on the end rotation angle. Hence, the ply stress was calculated by using the directly measured curvature to avoid having to evaluate these end rotation angles. The curvature along the specimen length was automatically measured from the videos of the specimen side by image analysis. This works by tracing the edge of the specimen side, shown as the red line, at the region of interest (ROI) within the green rectangle in Figure 4.4. The coordinates of the traced edge points in the $z$-direction (the horizontal coordinate in the image of the specimen side in Figure 4.4) are expressed similarly to the general solution for eccentrically-loaded 
column buckling as:

$$
z=A \sin \left(\sqrt{P d_{11} / b} x\right)+B \cos \left(\sqrt{P d_{11} / b} x\right)-C,
$$

where $x$ represents the coordinates along the specimen length, $P$ is the measured force, $d_{11}$ is the bending compliance of the laminate, and $b$ is the specimen width. The three unknown coefficients $A, B$, and $C$ are estimated by fitting the coordinates of the traced edge points to Equation 4.5. The curvature along the specimen length $\kappa_{x}$ (Figure 4.4 top right) is then calculated according to:

$$
\kappa_{x}=\frac{\left|z^{\prime \prime}\right|}{\left(1+\left(z^{\prime}\right)^{2}\right)^{3 / 2}} .
$$

The measured curvature was validated by comparing it to the curvature determined by using strain gages. Two strain gages were bonded at the mid-span on both surfaces of a baseline (non-defective) specimen to determine the curvature. The difference between the optical and the strain gages measurements was within $1 \%$.

The longitudinal stress $\left(\sigma_{11}\right)$ of the outermost $0^{\circ}$ ply in the principal material axes was calculated according to Equation 4.2, assuming a negligible mid-plane strain from the axial compressive load. The influence of the compressive axial strain generated from the compressive force in the vertical direction, which was up to about 1000 $\mathrm{N}$, was on average about $4 \%$ of the strain from the maximum curvature of each specimen. The ply stress was calculated assuming the nominal fiber orientation of the ply. The bending moment is not constant along the length of the specimen, leading to a non-constant curvature (as shown in Figure 4.4). The position dependency of the curvature was taken into account when calculating the ply stress by considering the failure location.

\section{Fractography}

A number of specimens were selected for a closer post-failure analysis following the bending tests. The fractured surface was evaluated by means of optical microscopy using a Leica M125 microscope, and scanning electron microscopy with a JEOL JSM7200F SEM.

\subsection{Results and discussion}

The characterization results of the waviness parameters are given first. The bending test results for the baseline samples and those with waviness are described next in separate sections, with both the 4PB and ELB test results given jointly for each type of sample. Lastly, the relation between waviness parameters and stress at first failure and the corresponding failure modes is discussed. 


\subsubsection{Waviness characterization results.}

All press-consolidated (Waviness-PC) test coupons have wavy regions scattered throughout both the top and the bottom surfaces. Two to eight wavy regions (indicated by the ellipses in the micrograph in Figure 4.5a) were observed to be scattered across the specimen length. Cross-sectional microscopy in Figure 4.6a shows that the wavy fibers appear as ellipses with a small aspect ratio, i.e. majoraxis-length over minor-axis-length in both outer $0^{\circ}$ plies. The figure shows that the waviness extended through the entire thickness of the outer $0^{\circ}$ plies, but did not propagate to the internal plies. For the bending test, the surface with the most pronounced waviness was placed on the compression side. Only the measured waviness parameters of this surface were reported here, as the failure is expected to occur on this side. Figure 4.7 shows that the Waviness-PC sample represents the lower end of waviness severity, with the maximum waviness angle ranging between $3^{\circ}$ to $13^{\circ}$. The wavy regions from the Waviness-PC sample have a mean wavelength of $3.3 \mathrm{~mm}$.

\section{Press consolidation}

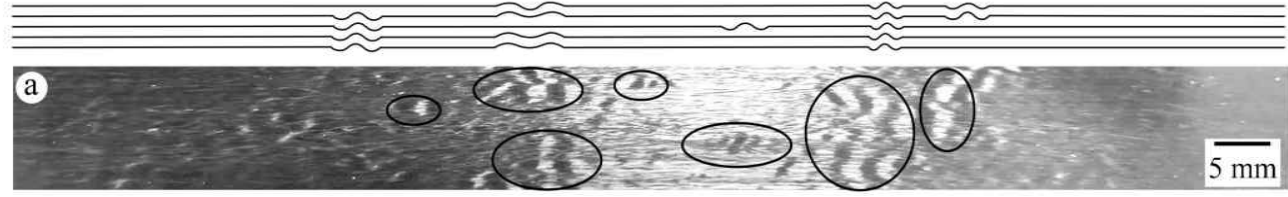

\section{Reverse forming}
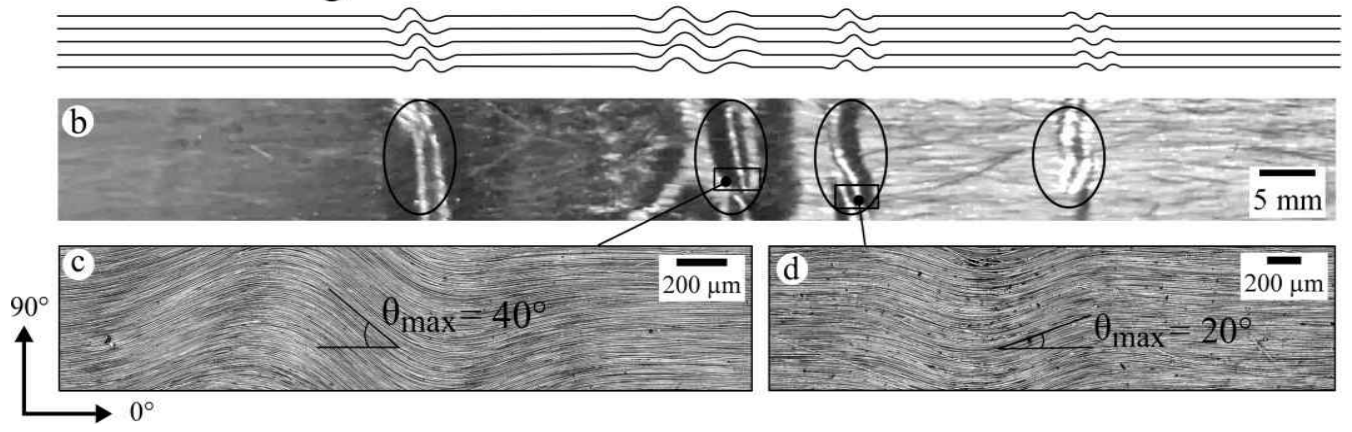

Figure 4.5 Schematics of the in-plane waviness on the surface based on the typical surface micrographs of the test coupons manufactured by: (a) press consolidation and (b) reverse forming procedures. The surface micrographs (c) and (d) show examples of two wavy regions from the reverseformed test coupon, with the maximum waviness angle $\left(\theta_{\max }\right)$ shown at each wavy region.

The reverse-formed test coupons produced in this work have from one up to six wavy regions along their length (see Figure 4.5b). These wavy regions were only observed on one surface. In this case, as illustrated in Figure $4.6 \mathrm{~b}$, the waviness was only formed on the surface from the convex side of the V-shaped part [22]. Microscopy of the cross-section revealed no waviness in the internal plies. Figure 4.8 shows the fiber angle distribution of the Waviness-RF specimens. Note the different scales between the vertical axes in Figure 4.8 and in Figure 4.7 for the press-consolidated sample 
discussed earlier. Figure 4.8 shows that the Waviness-RF sample has a much wider range of maximum waviness angle $\left(\theta_{\max }\right)$ than the Waviness-PC sample, i.e. between $14^{\circ}$ to $64^{\circ}$. The wavy regions from the Waviness-RF sample have a mean wavelength of $2.3 \mathrm{~mm}$.

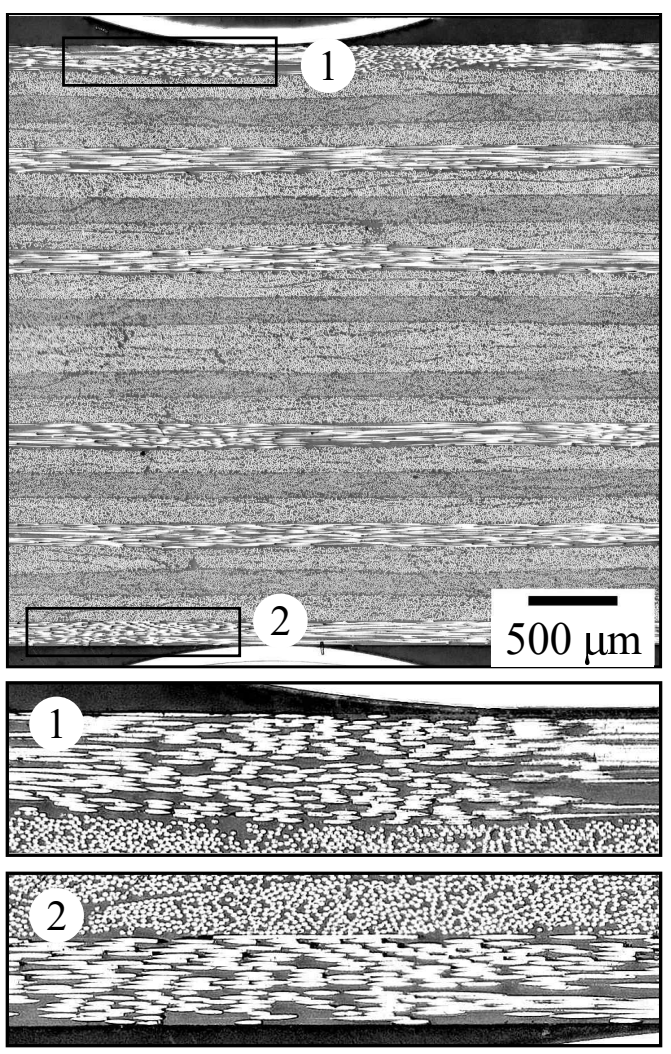

(a)
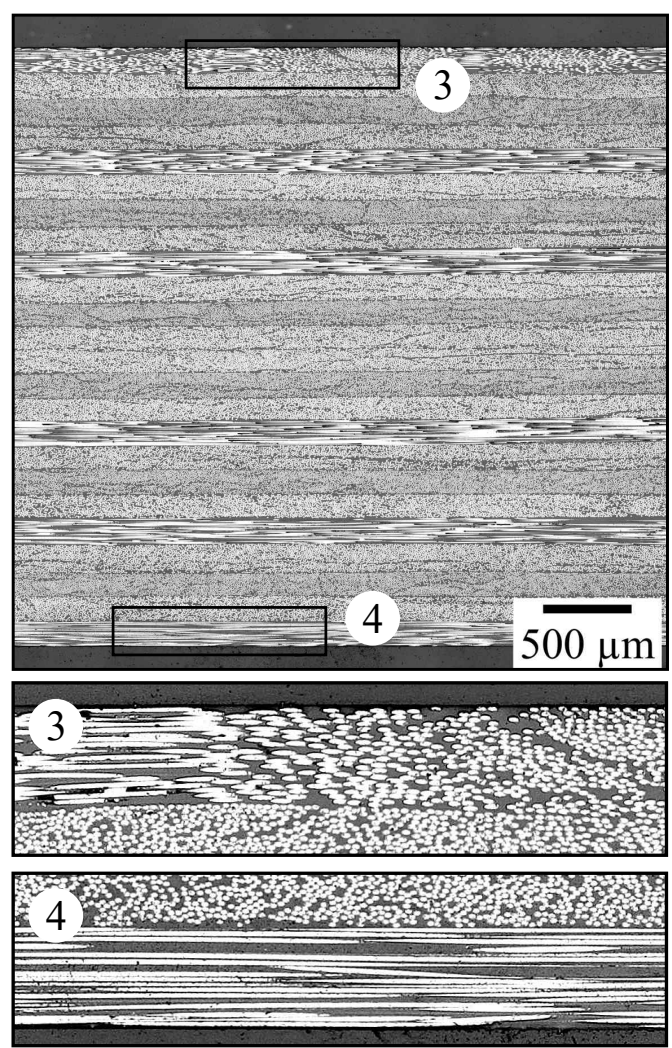

(b)

Figure 4.6 Typical cross-sectional micrographs taken parallel to the fiber direction of the $0^{\circ}$ ply from (a) the press consolidated and (b) the reverse-formed specimen with waviness. The numbers 1 and 3 indicate the micrographs from the top outermost $0^{\circ}$ ply, and the numbers 2 and 4 indicate the bottom outermost $0^{\circ}$ ply.

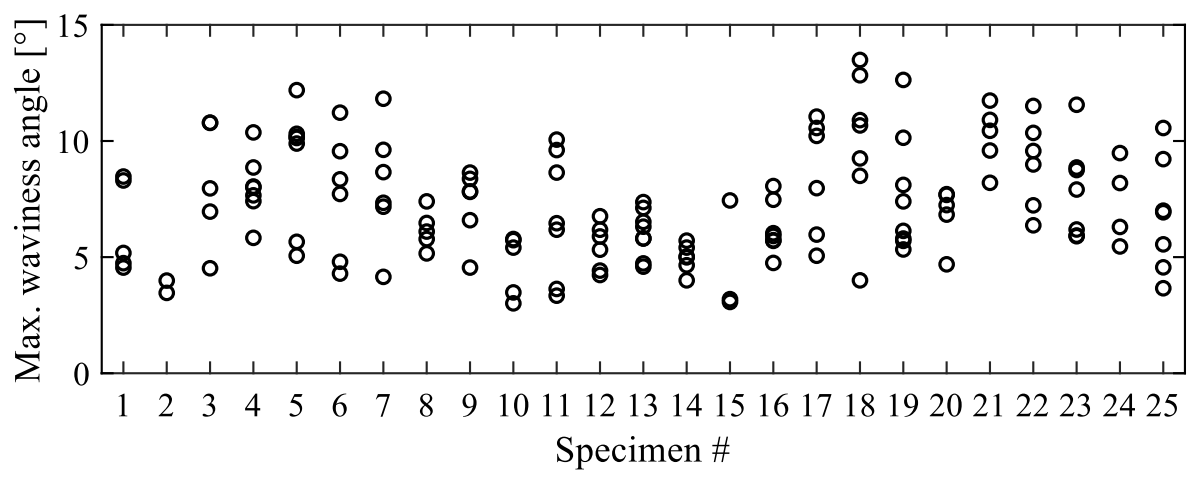

Figure 4.7 Maximum waviness angles of the wavy regions in the Waviness-PC specimens. Each symbol represents a wavy region. 


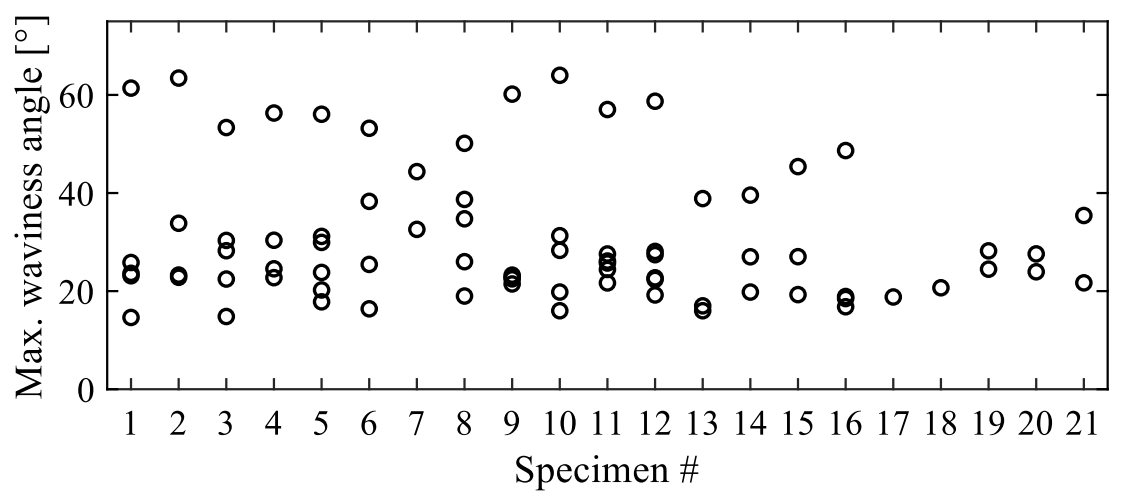

Figure 4.8 Maximum waviness angles of the wavy regions in the Waviness-RF specimens. Each symbol represents a wavy region.

The baseline test coupons did not have any wavy regions, therefore no waviness parameters characterization was performed on these test coupons.

\subsubsection{Bending test results of baseline samples}

The typical force-versus-displacement curves obtained during 4PB and ELB testing are shown in Figure 4.9a and b respectively. These tests were stopped when the first failure was detected, to inspect the specimen and identify the failure mechanisms. The ELB specimens showed a force-displacement behavior similar to that of an eccentrically-loaded column buckling response, where the force initially increases quickly with increasing displacement until a certain critical load and then levels off to a near-plateau (see Figure $4.9 \mathrm{~b}$ ). The tested baseline samples have on average a flexural modulus of approximately $58.5 \mathrm{GPa}$. The difference between the moduli of the baseline samples manufactured by press consolidation and reverse forming processes was not significant. Moreover, the measured flexural modulus was fairly similar to the theoretical bending stiffness of $57.8 \mathrm{GPa}$, calculated using the classical laminate theory (CLT), assuming the elastic constants given earlier in Table 4.2.

The 4PB specimens showed two types of failure depending on the failure location, i.e. at the loading nose or in the loading span. As can be seen in Table 4.3, the majority of these $4 \mathrm{~PB}$ specimens showed compression failure at the loading nose; these are not considered as valid test results for failure stress measurement, as the stress state under the loading cylinder is unknown. The values shown in Table 4.3 for these specimens are thus not indicative of the strength of the material tested. For the Baseline-RF sample, in particular, all specimens failed at the loading nose, therefore no valid failure stress was determined from the $4 \mathrm{~PB}$ test. In contrast to the specimens tested using the $4 \mathrm{~PB}$ test, all baseline specimens tested using the ELB test showed failure in the loading span. These results confirm that no undesirable stress concentration due to load introduction occurred in the ELB test, thereby supporting the use of the ELB test as an alternative method to measure the stress at failure. 

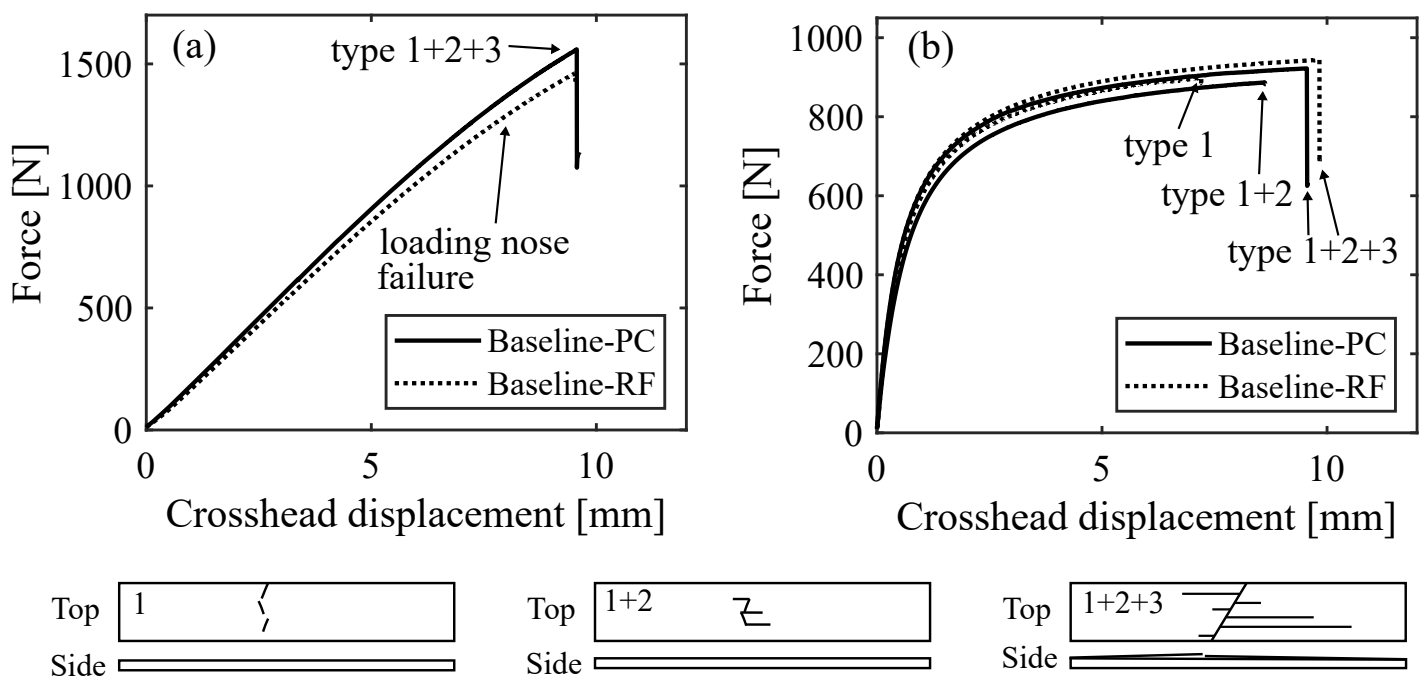

Figure 4.9 Typical force-displacement curves from (a) $4 P B$ and (b) ELB tests, performed until the first failure of the baseline specimens for each type of compression failure: kinking failure (type 1), ply splitting (type 2), and delamination (type 3).

Table 4.3 Summary of failure type and ply compressive stress at first failure for the baseline samples. $n=$ number of tested specimens.

\begin{tabular}{ccccc}
\hline Sample & Test method & Failure type* $^{*}$ & $\boldsymbol{n}$ & $\begin{array}{c}\text { Stress at first failure } \\
\text { [MPa] (SD) }\end{array}$ \\
\hline Baseline-PC & 4PB & Type 1+2+3 & 3 & $1591(69)$ \\
Loading nose & 4 & $1594(160)$ \\
Baseline-PC & ELB & Type 1+2 & 2 & $2223(283)$ \\
& & Type 1+2+3 & 5 & $2089(285)$ \\
Baseline-RF & 4PB & Loading nose & 6 & $1676(118)$ \\
Baseline-RF & ELB & Type 1 & 2 & $1598(123)$ \\
& & Type 1+2+3 & 7 & $2267(212)$ \\
\hline
\end{tabular}

*Loading span failure: type 1 = kinking, type 2 = ply splitting, type 3 = delamination

All tested baseline specimens that failed in the loading span, both the $4 \mathrm{~PB}$ and the ELB specimens, showed failure on the compression side. As shown in Figure 4.10, the failure can be distinguished into three types: kinking, which (in most cases) extends over the full width of the specimen (indicated with 1a), ply splitting (indicated with 2 ), and delamination (indicated with 3). The summary of the observed types of failure and the corresponding stress at first failure is presented in Table 4.3. The average ply compressive stresses at first failure for all the ELB baseline specimens, regardless of failure type, were $2127 \mathrm{MPa}$ for the press-consolidated specimens and $2119 \mathrm{MPa}$ for the reverse-formed specimens. The similar failure stress indicates that there is no significant influence of the different manufacturing processes on the ply failure stress. These values are significantly higher than the UD tape compressive strength obtained 
from the material datasheet (1300 MPa) [23]. The discrepancy can be explained by the difference in the type of tests used. The strength from the datasheet was measured by compression tests on UD composites, while the strength in this chapter came from bending tests. As explained by Wisnom and Atkinson [27], a very high value of compressive strength can be reached in a bending test due to the presence of a through-the-thickness stress gradient.
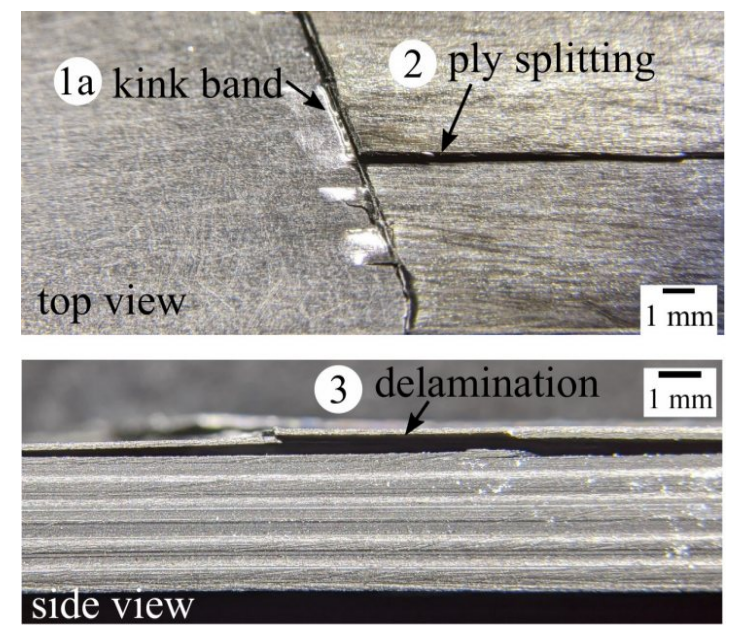

Figure 4.10 Compressive failure modes of the baseline specimens.

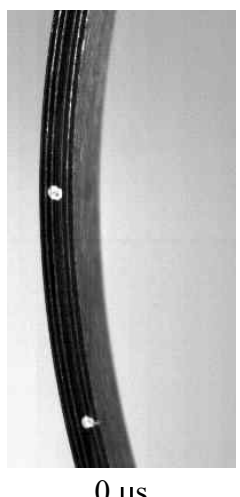

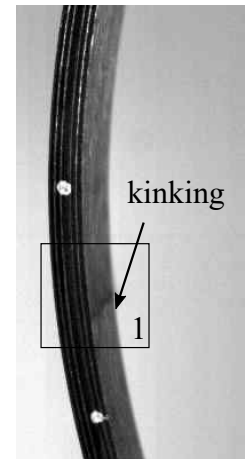

$40 \mu \mathrm{s}$

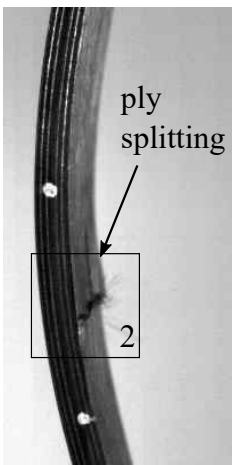

$80 \mu \mathrm{s}$

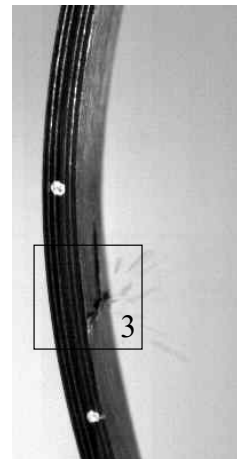

$120 \mu \mathrm{s}$

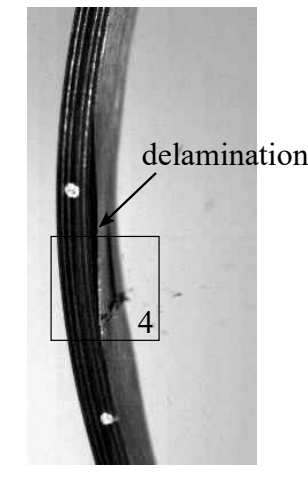

$360 \mu \mathrm{s}$
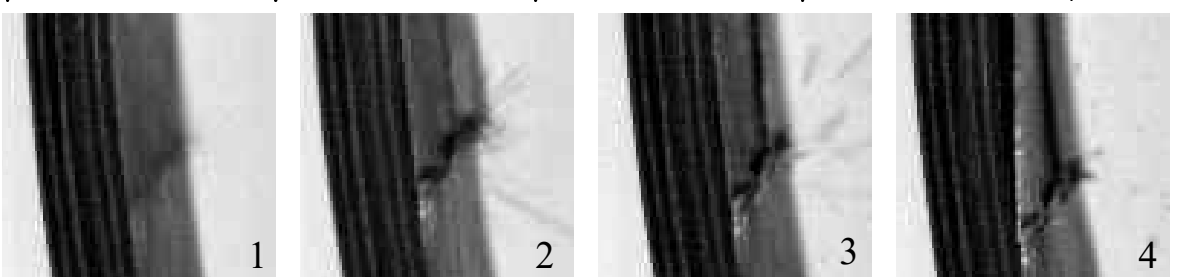

Figure 4.11 High-speed camera images showing the damage sequence of a Baseline-RF specimen from the ELB test, with the close-up images at the bottom (numbers 1-4). The top white marker on the side of the specimen indicates the mid-span.

Most specimens that failed in the loading span during 4PB and ELB testing showed a large load drop at the end of the test, but no complete through-thickness fracture 
(see Figure 4.9). These specimens showed mixed types of failure (see Figure 4.10), i.e. kinking (type 1), ply splitting (type 2) and delamination (type 3). The summary of the number of specimens for each corresponding failure type is given later in Table 4.4. The HSC footages in Figure 4.11 show that the kinking failure preceded the ply splitting and the delamination. Therefore, ply splitting and delamination are considered as secondary mechanisms. A few baseline specimens showed a minor load drop, as shown in Figure 4.9b. This behavior is associated with the specimens which failed only by kinking (type 1) or a combination of kinking and ply splitting (type 1+2). No delamination occurred in these cases.

\subsubsection{Bending test results of samples with waviness}

The typical force-versus-displacement curves obtained during 4PB and ELB testing of the specimens with waviness are presented in Figure 4.12. Similarly to the tests of the baseline specimens, these tests were stopped when the first failure was detected. This is why in some cases only a very minor load drop can be seen at the end of the curves in Figure 4.12. These results show a similar trend to that of the curves shown earlier for the baseline specimens. The tested samples with waviness have an average flexural modulus of approximately 57.6 GPa. The difference between the moduli of the wavy samples manufactured by press consolidation and reverse forming processes was (as expected) not significant. Compared to that of the baseline samples, it appears that the flexural modulus is not significantly influenced by the presence of waviness.
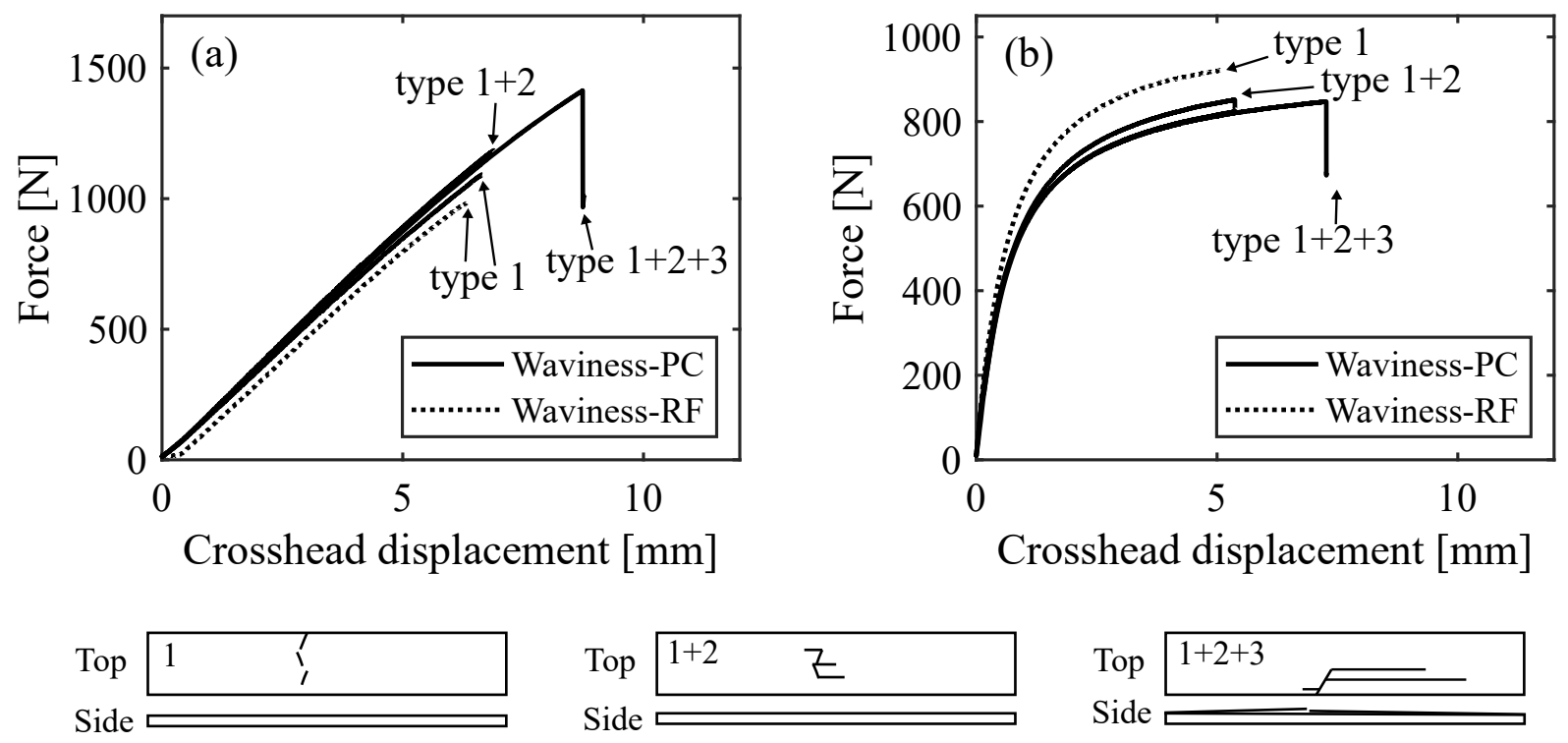

Figure 4.12 Typical force-displacement curves from (a) $4 P B$ and (b) ELB tests, performed until the first failure of the specimens with waviness for each type of compression failure: kinking failure (type 1), ply splitting (type 2) and delamination (type 3) 
Table 4.4 Summary of failure types. $n=$ number of tested specimens.

\begin{tabular}{ccccccc}
\hline Sample & $\begin{array}{c}\text { Test } \\
\text { method }\end{array}$ & $\boldsymbol{n}$ & Type 1* & Type 1+2* & Type 1+2+3* & $\begin{array}{c}\text { Loading nose } \\
\text { failure }\end{array}$ \\
\hline Baseline-PC & 4PB & 7 & 0 & 0 & 3 & 4 \\
Baseline-PC & ELB & 7 & 0 & 2 & 5 & 0 \\
Baseline-RF & 4PB & 6 & 0 & 0 & 0 & 6 \\
Baseline-RF & ELB & 9 & 2 & 0 & 7 & 0 \\
Waviness-PC & 4PB & 14 & 2 & 2 & 5 & 5 \\
Waviness-PC & ELB & 11 & 2 & 4 & 5 & 0 \\
Waviness-RF & 4PB & 5 & 5 & 0 & 0 & 0 \\
Waviness-RF & ELB & 16 & 16 & 0 & 0 & 0 \\
\hline
\end{tabular}

*Type 1 = kinking, type 2 = ply splitting, type 3 = delamination

Table 4.4 shows that about one-third of the press-consolidated specimens with waviness from the $4 \mathrm{~PB}$ tests failed under the loading nose. These specimens were excluded from the following discussion. By contrast, all the ELB specimens with waviness showed failure in the loading span, which again confirms the advantage of using the ELB test.

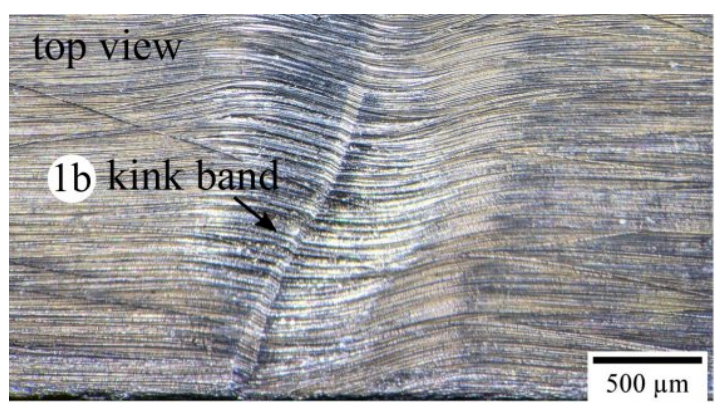

(a)

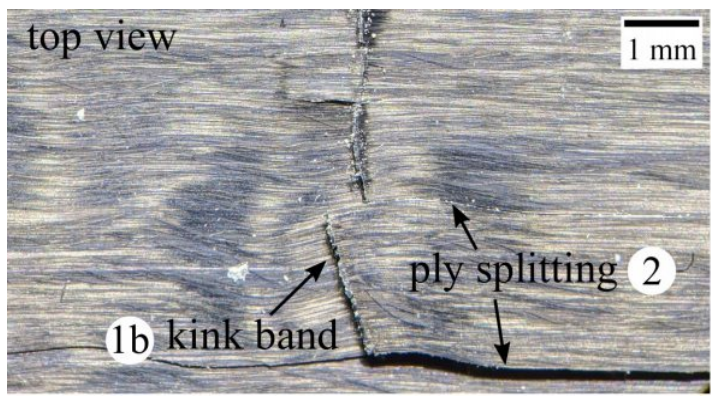

(b)

Figure 4.13 Compressive failure modes of the specimens with waviness: (a) reverse-formed specimen, showing only kinking failure and (b) press-consolidated specimen, showing mixed types of failure: kinking and ply splitting.

Similarly to the baseline specimens, the majority of the press-consolidated specimens with waviness showed mixed types of compression failure (as listed in Table 4.4), i.e. kinking, ply splitting (Figure 4.13b), and delamination, with the failure localized at a single wavy region within a specimen. However, unlike the baseline specimens, in most cases, the kink bands did not extend over the full width of the specimen. A large load drop was observed at the end of the test of the specimen that failed by kinking and immediately followed by ply splitting and delamination (indicated as type $1+2+3$ in Figure 4.12 ). In this case, at the boundary of the kink band shown in Figure $4.13 \mathrm{~b}$, the fiber fracture has propagated through the thickness of the wavy ply, 
indicating delamination. By contrast, only a minor load drop (Figure 4.12b) was seen at the end of the test for the specimens that failed by either combined kinking and ply splitting (type 1+2), or only kinking (type 1). This indicates that delamination causes a significant loss of the load-bearing capability of the specimen.

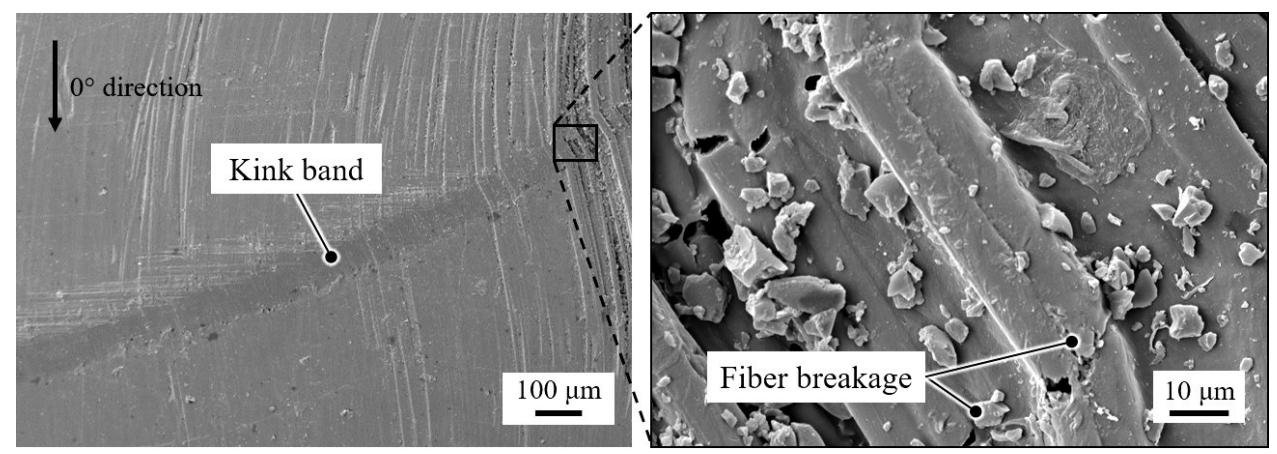

Figure 4.14 SEM surface micrographs showing a kink band in the failed specimen that has waviness.

Unlike the Waviness-PC specimens, all Waviness-RF specimens showed only kinking failure (see Figure 4.13a), with fiber breakage visible at the boundary of the kink bands (see Figure 4.14). These kink bands were observed in most cases at multiple wavy regions in a single specimen, although they did not grow into ply fracture and delamination. This also means that most Waviness-RF specimens showed failure in multiple locations. In contrast to the kinking failure observed in the baseline specimens, no kink bands (indicated as 1b in Figure 4.13a) in the Waviness-RF specimens propagated across the entire width of the specimen. The sequence of the formation of kink bands between these wavy regions, however, was unknown since it was indistinguishable from the recorded images which have low magnification. Moreover, the failure was often barely audible and was accompanied by an indiscernible load drop. Testing by using a camera at higher magnification focusing on the wavy regions or having a specimen with less scattered wavy regions would help to better observe the failure mechanisms.

\subsubsection{The relation between waviness parameters, stress at first failure, and failure mechanisms}

The current section combines the characterization results from subsection 4.3.1 and the results obtained from the bending experiments presented in subsection 4.3.2 and subsection 4.3 .3 to discuss the effect of waviness. 


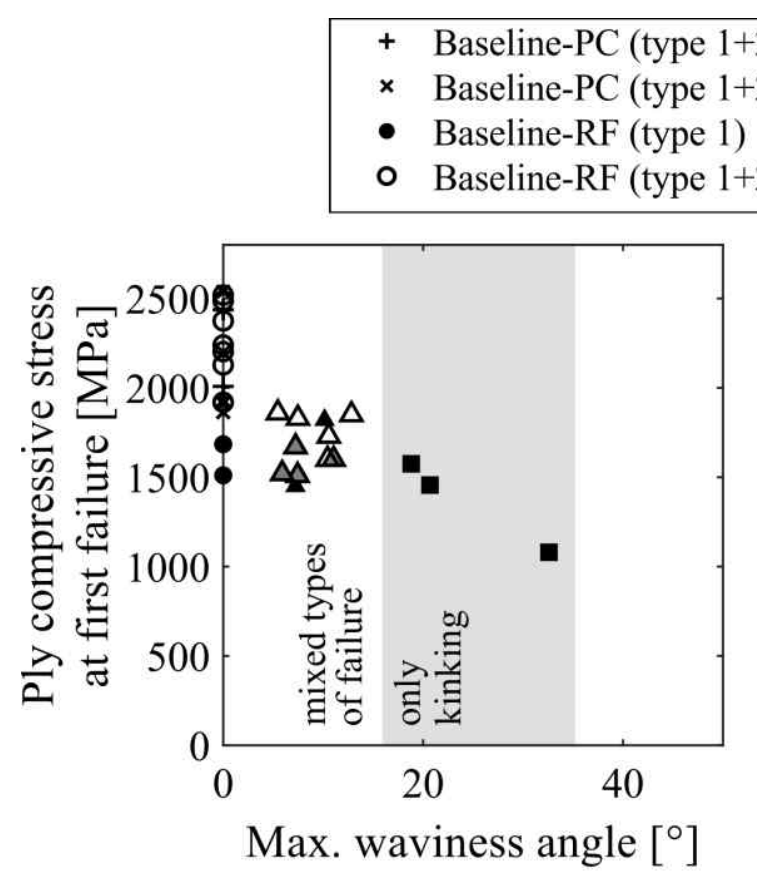

(a) End-loaded bending
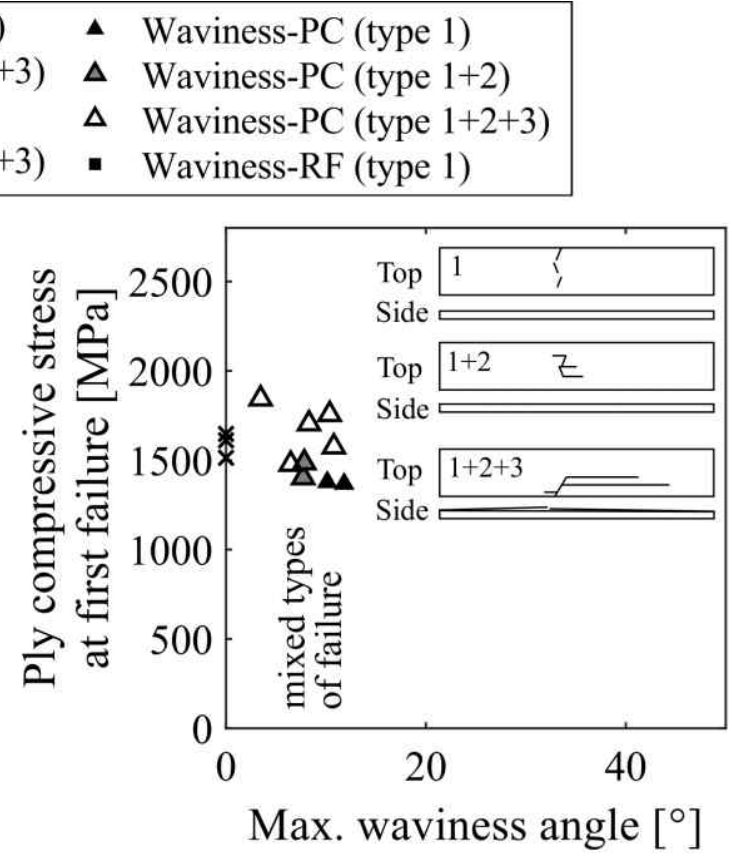

(b) Four-point bending

Figure 4.15 Effect of waviness on ply compressive stress at first failure for the specimens which showed failure in a single location, as measured by: (a) ELB and (b) $4 P B$ tests.

As mentioned earlier, several kink bands were found at multiple wavy regions within a specimen for the Waviness-RF sample. However, the sequence of failure between the multiple wavy regions within a specimen cannot be identified from the recorded images. Only few specimens showed failure in a single wavy region. As such, only selected test results from the specimens for which the first wavy region to fail can be identified are given in Figure 4.15. The graph shows the influence of the maximum waviness angle $\left(\theta_{\max }\right)$ on the ply compressive stress at first failure and the associated failure types. It is evident from Figure 4.15 that waviness severity affects compressive damage development: the three mixed types of failure were observed for the lower $\theta_{\max }$, and only kinking failure was observed for the higher $\theta_{\max }$. This change in damage development seems to correspond with the difference in failure stress. The secondary failure mechanisms (ply splitting and delamination) occurring immediately after kinking were observed in the majority of the specimens that failed at a higher stress. These specimens failed at a larger compressive strain, as also reflected in the force-displacement curves presented earlier in Figure 4.12; they possibly released more energy during failure, hence may have triggered the secondary damage mechanisms. 


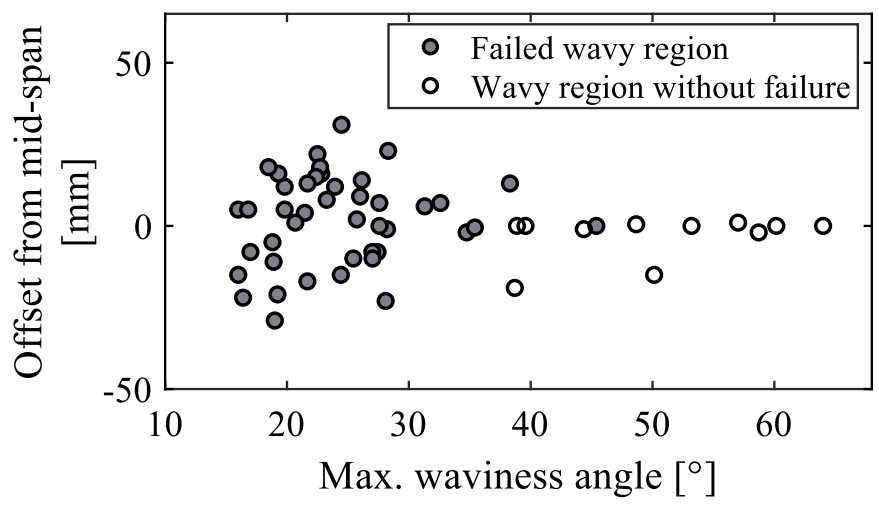

Figure 4.16 Visual representation of the wavy region locations in the ELB test specimens from the Waviness-RF sample vs the maximum waviness angle $\left(\theta_{\max }\right)$. For the sake of clarity, only the wavy regions with the largest $\theta_{\max }$ and those closer to the mid-span (relative to the wavy region with the overall $\theta_{\max }$ within the corresponding specimen) are shown here.

For the ELB test method, the bending moment-hence the compressive stress-varies along the specimen length. For this reason, the location of each wavy region was also taken into account in the analysis, as represented in Figure 4.16 as the offset distance from the mid-span. Note that the results shown in Figure 4.16 were from all the Waviness-RF specimens, including those displaying multiple failure locations within a single specimen. It is evident from Figure 4.16 that no kink band was observed at the wavy regions that have a maximum waviness angle larger than $45^{\circ}$, even when those wavy regions are located at the mid-span of the specimen. In such cases, the first failure was instead seen on the wavy region with a smaller $\theta_{\max }$ that was further away from the mid-span than the wavy region with the largest $\theta_{\max }$ in the same specimen. In addition, specimens with large overall $\theta_{\max }$ values, i.e. between $53^{\circ}$ to $63^{\circ}$, were also tested using the $4 \mathrm{~PB}$ test to exclude dependency of the location of the wavy region. For the sake of brevity, the $4 \mathrm{~PB}$ results are not presented in detail here as the same phenomenon was also observed, i.e. none of the Waviness-RF specimens showed failure at the wavy region with the largest $\theta_{\max }$. The $4 \mathrm{~PB}$ results confirm that this observation was not influenced by the test method used, but rather the material behavior.

In conclusion, these results imply that the largest $\theta_{\max }$ of a specimen above a certain threshold value does not necessarily cause the first failure when the laminate is subjected to bending. Instead, the first failure occurred in the other neighboring wavy regions that have smaller $\theta_{\max }$ values. There are a few possible explanations for this phenomenon:

1. Failure is not governed by the maximum waviness angle in a region, but by some other waviness parameters.

2. Wavy regions with large fiber angles act as compliant regions, reducing local normal and shear stress. 
Regarding the first point, Figure 4.17 shows the influence of both wavelength and maximum waviness angle of each wavy region in Waviness-RF ELB specimens on the occurrence of compressive failure. Again, these results included those showing failure in multiple wavy regions within a single specimen. No obvious correlation between wavelength and the occurrence of failure can be established from the results shown here. The same conclusion was found from the analysis of the influence of the wavy region area. Hence for the sake of brevity, the characterization result of the other waviness parameter is not given here. In summary, these results do not support the first hypothesis.

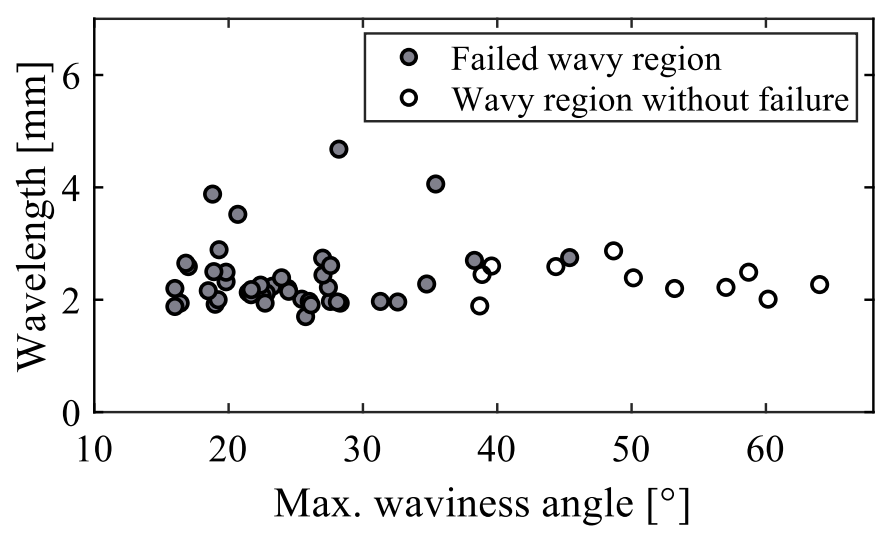

Figure 4.17 Influence of wavelength and maximum waviness angle on compressive failure in WavinessRF ELB specimens. Each symbol represents a single wavy region.

Regarding the second point, in-plane waviness is known to give rise to an inhomogeneous stress distribution in the wavy region [14, 28]. The inhomogeneity is due to the change in local fiber orientation, which causes a change in local stiffness. The region with a large fiber angle within the wavy region is locally more compliant than the surrounding material. This compliant region may cause a reduction of the stresses in the wavy region. A preliminary finite element (FE) analysis, using the modeling approach from the author's previous work on compression testing [14], was performed to evaluate the stress distribution in an idealized sinusoidal wavy region. This FE modeling approach has been previously validated by comparing the simulated and the measured strain fields from digital image correlation (DIC) experiments (see Chapter 3). The FE simulation results will be presented in detail later in Chapter 5. Those results show that for the same level of applied displacement, the maximum in-plane shear stress generated in the wavy region with a large maximum waviness angle (above approximately $40^{\circ}$ ) can be less than that of the wavy region with a lower maximum waviness angle (see section 5.3). Further research is required to gain more insight into the failure of such waviness. This can be performed, for example, by testing a specimen that has only one single wavy region with a large maximum waviness angle, in combination with a more detailed stress analysis by means of FE simulation. 

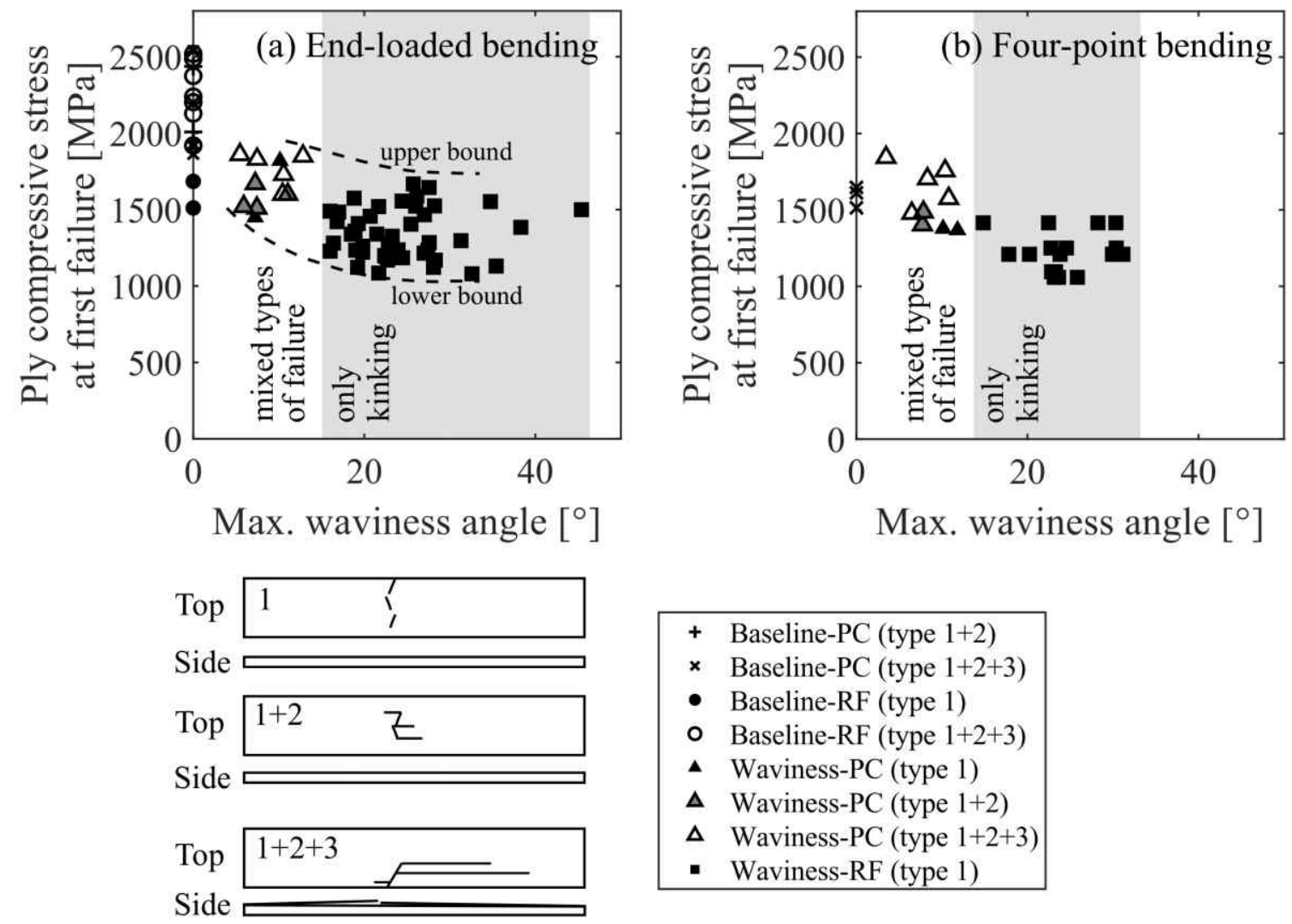

+ Baseline-PC (type $1+2)$

$\times$ Baseline-PC (type 1+2+3)

- Baseline-RF (type 1)

- Baseline-RF (type $1+2+3$ )

- Waviness-PC (type 1)

$\Delta$ Waviness-PC (type 1+2)

$\Delta$ Waviness-PC (type $1+2+3$ )

- Waviness-RF (type 1)

(c) Compression failure types

Figure 4.18 Effect of waviness on ply compressive stress at first failure measured by: (a) ELB and (b) $4 P B$ tests, and $(c)$ the corresponding failure types. Note that there are multiple data points for the Waviness-RF specimens that were generated from the failure observed in multiple wavy regions from a single specimen.

As mentioned earlier, the sequence of failure between the multiple wavy regions within a single Waviness-RF specimen could not be identified. Nevertheless, the test results from these specimens may provide insight into the general trend of the influence of waviness parameters on the stress at first failure. The stresses at first failure for all the failed wavy regions within a single specimen are reported separately in Figure 4.18 according to the local $\theta_{\max }$ measured from the corresponding wavy region. Figure 4.18 shows the influence of $\theta_{\max }$ on ply compressive stress at first failure and the associated failure types from all tested specimens. The dashed lines in Figure 4.18 indicate the lower and upper bounds of the ply compressive stress at failure at the region with large scatter. These data were generated under the assumptions that these failures occurred at the same force level and that the failure of a wavy region does not influence the stress state of the neighboring wavy region. The results presented in Figure 4.18 show similar behavior regarding the influence of waviness severity on compressive failure types as that presented earlier from the specimens with a single failure location (Figure 4.15). 


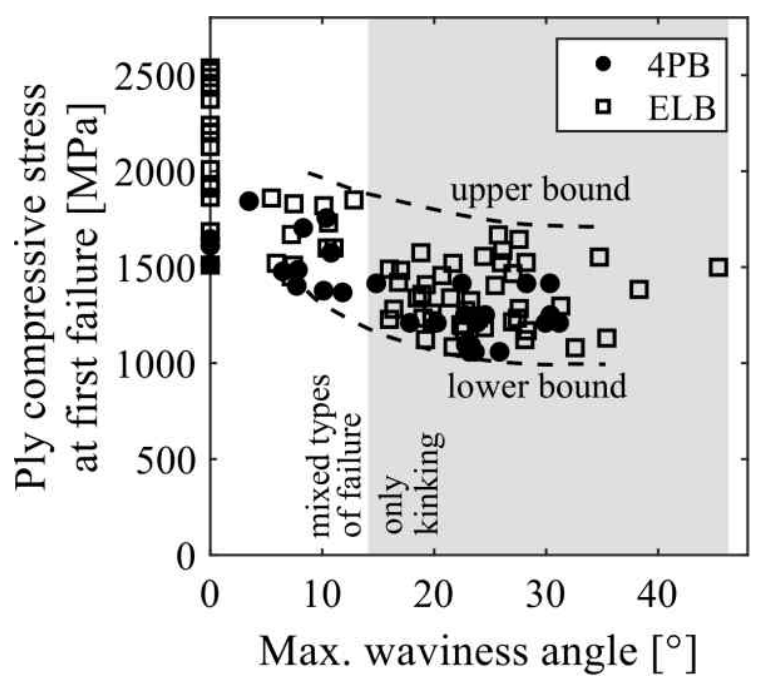

Figure 4.19 Summary of the obtained experimental results from the four-point bending (4PB) and endloaded bending (ELB) tests.

The results from both the $4 \mathrm{~PB}$ and ELB tests for the baseline specimens and those with waviness, including the specimens with multiple failed wavy regions, are combined in Figure 4.19. The measured ply stress at first failure showed a large scatter, especially at the range of $\theta_{\max }$ values between $7^{\circ}$ to $32^{\circ}$, as indicated by the upper and lower bounds in Figure 4.19. In general, as expected, the failure stress appears to decrease with increasing $\theta_{\max }$, with the largest reduction of failure stress up to about $50 \%$ with respect to the average baseline failure stress. The waviness with $\theta_{\max }$ up to approximately $45^{\circ}$ triggers an early failure initiation by kinking, thus lowering the failure stress. Despite the large scatter seen in Figure 4.19, it seems that the stress at first failure initially decreases with increasing maximum waviness angle, then levels off as the angle starts exceeding $20^{\circ}$. A similar conclusion was found from the previous work on uniaxial compression testing, where similar ultimate strengths were found for the specimens with $\theta_{\max }$ between $23^{\circ}$ to $60^{\circ}$ [14]. These bending test results thus reinforce the hypothesis from our previous work: ply compressive strength is less sensitive to changes in severity at larger angles.

\subsection{Conclusions}

The influence of in-plane waviness defects in the ply oriented in loading direction on the first ply failure of quasi-isotropic C/PEEK laminates was investigated experimentally. The representative waviness defects were manufactured by a press consolidation process for low maximum waviness angles and a reverse forming method for the higher angles. The maximum waviness angles studied were between $3^{\circ}$ to $64^{\circ}$. The wavy regions extended through the whole thickness of the surface $0^{\circ}$ ply. 
Ply compressive stress at failure was measured by using the end-loaded bending (ELB) and the four-point bending (4PB) test methods such that the first ply failure can be isolated. The experimental results showed an influence of waviness severity on compressive damage development, i.e. kinking failure immediately followed by ply splitting and delamination for the smaller maximum waviness angles, and only kinking failure for the larger angles. Kinking failure was shown to be the dominant failure mode for maximum waviness angle up to about $45^{\circ}$, with fiber breakage observed at the boundary of the kink bands. No kink band was observed in the more severe wavy regions above $45^{\circ}$ when there was another wavy region with a lower angle in the same specimen. This means that the wavy region with the largest $\theta_{\max }$ in a specimen does not necessarily cause the first failure.

The specimens that showed kinking, ply splitting, and delamination failed at higher stresses than those that only exhibited kinking failure. Although the bending test results show a large scatter, the stress at first failure appeared to initially decrease with increasing maximum waviness angle but did not significantly change at the larger angles approximately above $20^{\circ}$. These results reinforce the hypothesis from previous research, which suggests that wavy ply compressive strength is less sensitive to changes in severity at the large angles.

\section{References}

[1] A. L. Highsmith, J. J. Davis, and K. L. E. Helms. The influence of fiber waviness on the compressive behavior of unidirectional continuous fiber composites. ASTM International, 1992.

[2] P. J. Joyce and T. J. Moon. Compression Strength Reduction in Composites with inPlane Fiber Waviness, pages 76-96. ASTM International, West Conshohocken, PA, 1998.

[3] M. R. Wisnom and J. W. Atkinson. Fibre waviness generation and measurement and its effect on compressive strength. Journal of Reinforced Plastics and Composites, 19(2):96-110, 2000.

[4] T. Yokozeki, K. Akakabe, T. Aoki, and A. Kobiki. Effects of process-induced fiber bundle waviness on the mechanical properties of carbon fiber reinforced thermoplastic composites. In ECCM 2016 - Proceeding of the 17th European Conference on Composite Materials.

[5] S. N. Nair, A. Dasari, C. Y. Yue, and S. Narasimalu. Failure behavior of unidirectional composites under compression loading: Effect of fiber waviness. Materials (Basel, Switzerland), 10(8):909, 2017.

[6] D. Wilhelmsson, R. Gutkin, F. Edgren, and L. E. Asp. An experimental study of fibre waviness and its effects on compressive properties of unidirectional NCF composites. Composites Part A: Applied Science and Manufacturing, 107:665-674, 2018. 
[7] Q. Sun, H. Guo, G. Zhou, Z. Meng, Z. Chen, H. Kang, S. Keten, and X. Su. Experimental and computational analysis of failure mechanisms in unidirectional carbon fiber reinforced polymer laminates under longitudinal compression loading. Composite Structures, 203:335-348, 2018.

[8] P. Y. Mechin, V. Keryvin, J. C. Grandidier, and D. Glehen. An experimental protocol to measure the parameters affecting the compressive strength of CFRP with a fibre micro-buckling failure criterion. Composite Structures, 211:154-162, 2019.

[9] T. Yokozeki, H. Takemura, and T. Aoki. Numerical analysis on the flexural strength of unidirectional CFRTP composites with in-plane fiber bundle waviness. Advanced Composite Materials, 29(1):89-100, 2020.

[10] J. F. Mandell, D. D. Samborsky, and L. Wang. Effects of fiber waviness on composites for wind turbine blades. In 48th International SAMPE symposium, volume 48.

[11] B. Khan, K. D. Potter, and M. R. Wisnom. Simulation of process induced defects in resin transfer moulded woven carbon fibre laminates and their effect on mechanical behaviour. In The 8th International Conference on Flow Processes in Composite Materials (FPCM8), 2006.

[12] S. Mukhopadhyay, M. I. Jones, and S. R. Hallett. Compressive failure of laminates containing an embedded wrinkle; experimental and numerical study. Composites Part A: Applied Science and Manufacturing, 73:132-142, 2015.

[13] A. Shipsha, S. Hallström, and M. Burman. Effect of stacking sequence and bundle waviness in quasi-isotropic NCF composites subjected to compression. Composites Part B: Engineering, 178:107423, 2019.

[14] R. D. R. Sitohang, W. J. B. Grouve, L. L. Warnet, and R. Akkerman. Effect of in-plane fiber waviness defects on the compressive properties of quasi-isotropic thermoplastic composites. Composite Structures, 272:114166, 2021.

[15] B. Budiansky and N. A. Fleck. Compressive failure of fibre composites. Journal of the Mechanics and Physics of Solids, 41(1):183-211, 1993.

[16] C. Wu, Y. Gu, L. Luo, P. Xu, S. Wang, M. Li, and Z. Zhang. Influences of inplane and out-of-plane fiber waviness on mechanical properties of carbon fiber composite laminate. Journal of Reinforced Plastics and Composites, 37(13):877-891, 2018.

[17] H. Fukuda. A new bending test method of advanced composites. Experimental Mechanics, 29(3):330-335, 1989.

[18] H. Fukuda, H. Katoh, and H. Uesugi. A modified procedure to measure bending strength and modulus of advanced composites by means of compression bending. Journal of composite materials, 29(2):195-207, 1995.

[19] H. Fukuda and M. Itabashi. Simplified compression bending test method for advanced composites. Composites Part A: Applied Science and Manufacturing, 30(3):249-256, 1999.

[20] H. Fukuda, M. Itabashi, and A. Wada. Development of Compression Bending Test 
Method for Advanced Composites - A Review, volume 11. 2004.

[21] E. T. M. Krämer, W. J. B. Grouve, L. L. Warnet, S. Koussios, and R. Akkerman. Tool-ply interaction in the formation of waviness during C/PEEK consolidation. Composites Part A: Applied Science and Manufacturing, 2021.

[22] R. D. R. Sitohang, W. J. B. Grouve, L. L. Warnet, S. Koussios, and R. Akkerman. An experimental approach to reproduce in-plane fiber waviness in thermoplastic composites test coupons using a reverse forming method. Journal of Composite Materials, July 2021.

[23] Toray Advanced Composites. Cetex TC1200 PEEK - Technical Data Sheet, 2019.

[24] ASTM. ASTM D7264 - Standard Test Method for Flexural Properties of Polymer Matrix Composite Materials, 2007.

[25] D. Wilhelmsson and L. Asp. A high resolution method for characterisation of fibre misalignment angles in composites. Composites Science and Technology, 165, 2018.

[26] R. F. Gibson. Principles of composite material mechanics. CRC press, 2016.

[27] M. R. Wisnom and J. W. Atkinson. Constrained buckling tests show increasing compressive strain to failure with increasing strain gradient. Composites Part A: Applied Science and Manufacturing, 28(11):959-964, 1997.

[28] T. Miyake and M. Futamura. Experimental investigation of fiber stress distribution in CFRP with in-plane fiber waviness. In P. Maimi \& M. Fagerström A. Turon, editor, 7th Eccomas Thematic Conference On The Mechanical Response Of Composites, pages 83-91. 



\title{
CHAPTER 5
}

\section{A theoretical analysis of the influence of waviness severity on compressive failure of laminate}

\begin{abstract}
In-plane fiber waviness defects can decrease the compressive strength of a laminate as they can act as a trigger for an early kinking failure. This chapter presents a theoretical analysis of the influence of the waviness severity on the compressive failure of a quasi-isotropic laminate. A finite element analysis (FEA) was performed to confirm the failure behavior observed from the experimental results. A parametric study on the maximum waviness angle was carried out by using finite element models of laminates consisting of idealized sinusoid waves. The FEA results highlight that the waviness with the largest maximum angle does not necessarily cause the first failure in a specimen with multiple wavy regions of varying levels of severity. Furthermore, an analytical approach employing the classical laminate theory (CLT) was presented as a tool for quick and simple analysis of waviness effects aimed to provide a first approximation of the first failure stress and the ultimate strength of laminates with in-plane waviness.
\end{abstract}




\subsection{Introduction}

In-plane fiber waviness defects may be induced during part manufacturing of thermoplastic composites (TPCs). As discussed earlier in Chapters 3 and 4, these defects can decrease the laminate's compressive strength. The experimental observations of the damage development of TPC laminates, with and without waviness, subjected to uniaxial compression in Chapter 3 has shown that in either case, failure is governed by intralaminar failure of the ply oriented in the loading direction. For the laminates with waviness, it was found that the first ply to fail was the wavy ply. The damage initiates in the wavy region in the surface ply. The specimens with waviness, particularly those with smaller maximum waviness angles, predominantly failed by fiber breakage due to kinking before delamination occurred. The same failure initiation mechanism was also observed in the bending experiments described in Chapter 4. Other past studies in the literature have shown the same failure mechanism as the dominant mechanism causing compressive failure in most unidirectional (UD) composites [1-6] and some multidirectional (MD) composites $[7,8]$.

Generally, the misalignment of the fibers in composites having waviness triggers kinking failure, and, hence, reduces the compressive strength. Chapter 4 describes the relation between the maximum waviness angle and the first ply failure as evaluated by bending experiments. The bending test method was used in Chapter 4 to characterize the first ply failure as damage progression of composites under flexural loading is more gradual than experienced in compression tests. The test results have shown that the strength initially decreases with increasing maximum waviness angle and levels off as the angle further increases above approximately $20^{\circ}$. As a consequence, the ultimate compressive strength is less sensitive to the change in severity at the large angles, as was shown from the uniaxial compression tests described in Chapter 3. Furthermore, the bending test results in Chapter 4 show that no failure was observed at the wavy region with the maximum waviness angle larger than $45^{\circ}$ if there is another wavy region with a lower angle in the same specimen. The wavy region with a large angle appears to behave differently and further stress analysis is needed to better understand this failure behavior. Therefore, this chapter provides a theoretical analysis of the influence of waviness on the compressive failure of laminates. The purpose of this theoretical analysis is twofold. The first is to develop an understanding of the influence of the waviness severity (maximum waviness angle) on compressive failure of a laminate and the second is to develop a tool for quick and simple analysis of waviness effects.

This chapter is broadly divided into two parts: the first part describes the influence of waviness severity on the laminate compressive failure by using finite element analysis (FEA); the second part describes the analytical approach to be used as a tool for quick and simple analysis of waviness effects. FEA has been used by other researchers to 
study the compressive failure of laminates with waviness [7-9]. The waviness was modeled by varying either the material's local coordinate system for each element $[8,9]$ or the mesh geometry following the variation of the ply angle (for out-of-plane waviness) [7]. The current work follows the former approach to model the waviness. The FE model is used for a parametric study in order to identify the influence of the maximum waviness angle on the stress state and failure of the wavy ply. The FEA results are used to identify the critical waviness severity which may cause the first failure if there are multiple wavy regions within a specimen (as the waviness studied in Chapter 4).

The second part of this chapter presents a simplified analytical approach to evaluate the waviness effects on compressive strength. One of the earliest analytical models of fiber kinking has considered the fiber misalignment angle and the non-linear shear behavior in the matrix [1]. This model, however, is suited for small fiber misalignment angles. The in-plane waviness considered in this study instead has a maximum angle that can be up to $64^{\circ}$ (see Chapter 4). Other researchers have developed analytical models employing the classical laminate theory (CLT) to determine the stress state of off-axis compression-loaded MD composites that have wavy fiber tows $[10,11]$. The waviness was represented in the model as a homogenized lamina material assuming straight fibers with reduced longitudinal modulus [10]. The lamina strength in their study was derived from compression test experiments in the $0^{\circ}$ direction of the same laminates with waviness. Another approach is to assume the fiber bundle waviness orientation at its most misaligned cross-section (considering both the in-plane and the out-of-plane misalignment angles) with reduced longitudinal modulus [11]. The current work follows a similar approach of assuming the wavy lamina to have a uniform off-axis orientation rotated according to the maximum waviness angle and employs the CLT for the stress-strain analysis. The relations between the maximum waviness angle and the compressive strengths, i.e. both the first ply failure stress and the ultimate strength, are established and compared with the strengths from the experimental work in Chapters 3 and 4.

\subsection{Finite element model description}

An FEA was performed to evaluate the stress distribution in the wavy ply under compression loading. The model was made according to the experimental work described in the previous chapters and thus only considered a single ply having in-plane waviness within a quasi-isotropic $\left([0 / 45 / 90 /-45]_{3 s}\right)$ laminate. The waviness was only present in a single outermost $0^{\circ}$ ply. The analysis was carried out to simulate the compression test described in Chapter 3 by using the commercial FE software package Abaqus.

A parametric study was carried out to investigate the effect of maximum waviness 
angle on the local stress state in the wavy ply and the compressive failure initiation. The waviness here was assumed as an idealized sinusoidal wave and was included in the model following the same approach as earlier studies [8, 9]. This approach has been validated in Chapter 3 for the waviness considered in this thesis, i.e. the waviness was not modeled geometrically but by changing the local material orientation of the wavy ply. This was achieved by mapping the local fiber angle to each individual element of the wavy ply, i.e. by defining a discrete field for the material orientation (Figure 5.1). In Chapter 3, the strain fields from the FE model were validated using the results from digital image correlation (DIC) experiments. A good agreement was obtained between the DIC measured and the predicted strain distributions. The model was able to capture the strain inhomogeneity seen in the waviness region. Those results confirmed that the model can predict the compressive response of wavy composites by including the local fiber orientation in the analysis.

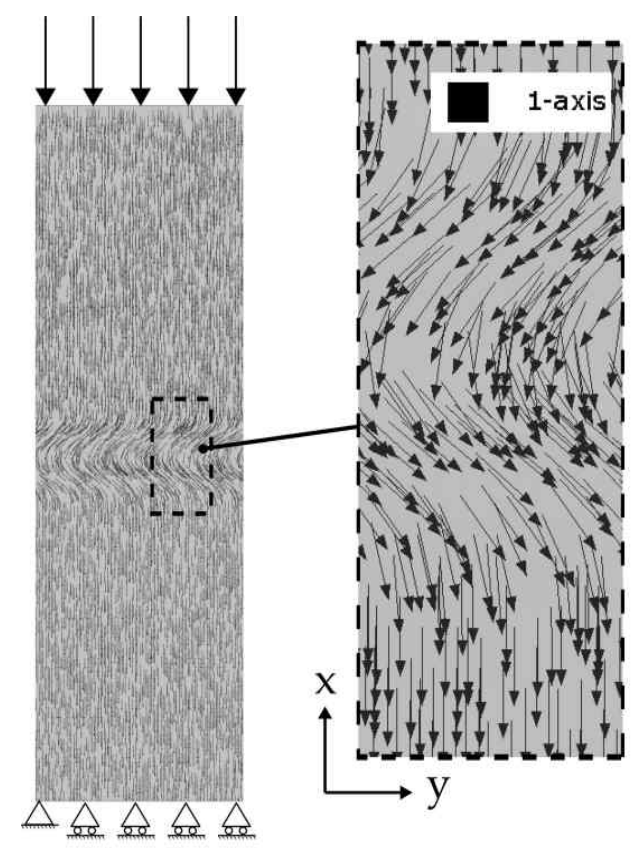

Figure 5.1 FE model input: fiber angles in the wavy ply and the $2 D$ representation of the boundary conditions at both ends of the test coupon's gage section.

The model was set up to represent the gage section of the compression test coupon (Figure 5.1). The dimensions of the FE model were $20 \mathrm{~mm} \times 6 \mathrm{~mm} \times 3.36 \mathrm{~mm}$. This model size was small enough for reduced computation costs and large enough to represent the stresses as obtained from the full model of the specimen. The laminate was modeled at the ply-level (mesoscale) using the 8-node linear brick elements (C3D8). The thickness of each element is the thickness of each ply $(0.14$ $\mathrm{mm}$ ). No further through-thickness mesh convergence study was carried out as a good agreement with the optical strain measurement result shown in Chapter 3 was obtained with the currently chosen dimension. The elements have in-plane 
dimensions of $0.1 \mathrm{~mm} \times 0.1 \mathrm{~mm}$. The mesh size was refined such that a sufficiently fine mesh was able to resolve the sinusoidal wave. Based on the mesh refinement analysis presented in Appendix 5.A, an element length of $0.1 \mathrm{~mm}$ was considered sufficient since smaller elements produced a similar result.
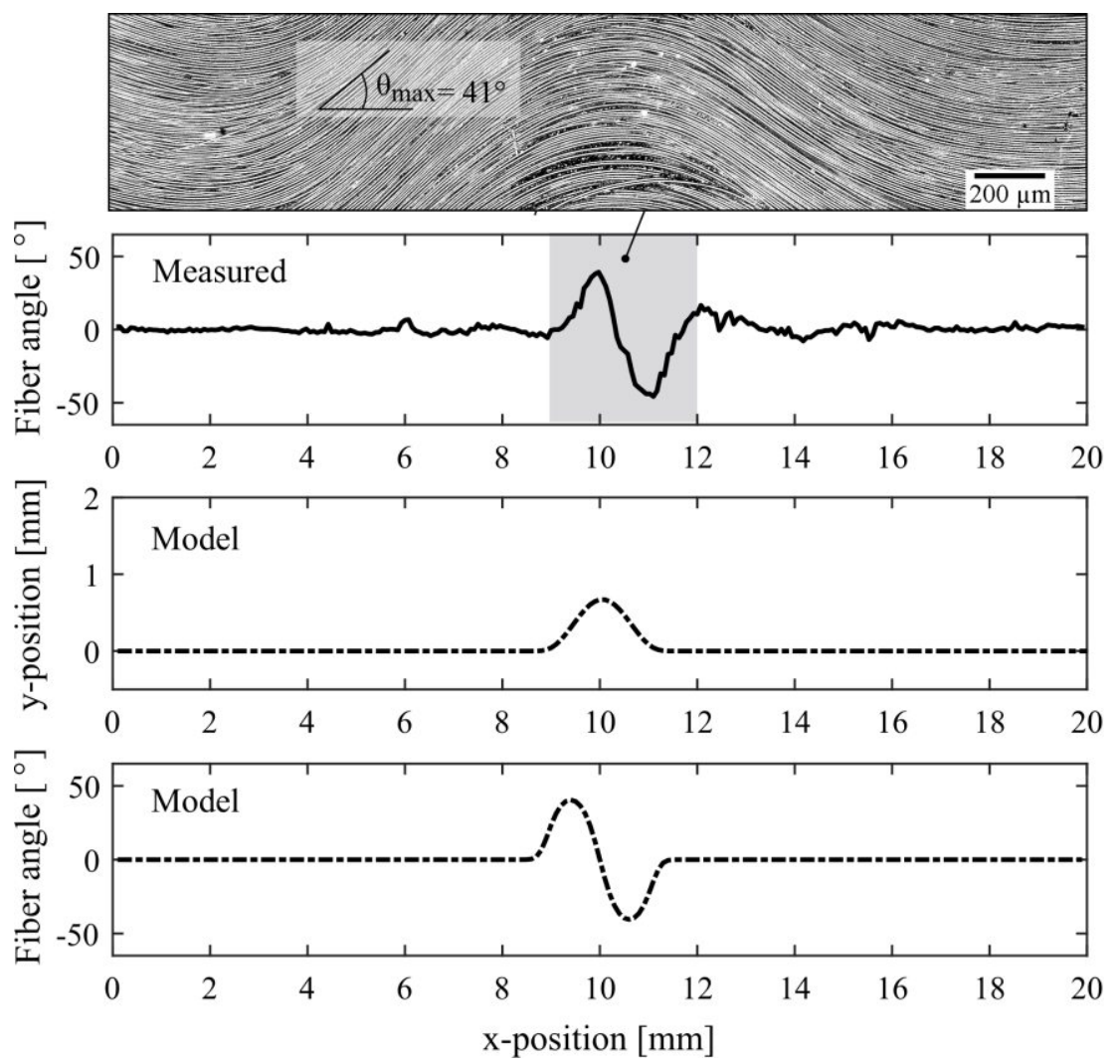

Figure 5.2 Measured fiber angles from the surface micrograph (top) and idealized sinusoidal waveform for the FE model input (bottom).

The idealized wave has a fiber angle distribution as shown in Figure 5.2. The distribution was chosen according to the experimentally measured fiber angle distribution along the specimen length (see the top image in Figure 5.2). The waveform was defined according to:

$$
y=\frac{A}{2} \sin \left(\frac{2 \pi x}{\lambda}-\frac{\pi}{2}\right)
$$

where $x$ and $y$ represent the coordinates of the points according the coordinate system shown in Figure 5.1, and the wave parameters are represented as the amplitude $A$ and the wavelength $\lambda$. All waves have a constant wavelength of $2.5 \mathrm{~mm}$, according to the mean wavelength of the waviness from the reverse-formed specimens described in Chapter 4. The wavy region lies at the midlength and extends across the full width of the model Figure 5.1. A Gaussian filter was applied to the waveform to 
smoothen it and eliminate the discontinuity between the wave from Equation 5.1 and the region without waviness. The fiber angle at each $x$-position was derived from the smoothened complete waveform (with the region without waviness), according to the arctangent of the smoothen waveform's slope. The fiber angle distribution input for the FE model was varied by changing the amplitude of the wave. In total, $13 \mathrm{FE}$ models with the maximum angles ranging from $5^{\circ}$ to $65^{\circ}$ with the interval of $5^{\circ}$ were evaluated in the present study.

The boundary conditions are schematically illustrated in Figure 5.1. A compressive load was introduced by prescribed displacements of $0.1 \mathrm{~mm}$ in the x-direction at the upper face of the model, with unconstrained $y$ and z-displacements, while the opposite face at the bottom side of the model was fixed in the x-direction. The vertical faces in Figure 5.1 are free. To prevent rigid body motion, a corner node at the bottom face was fixed in the $y$ and z-directions, and another corner node at the same face was also fixed in the $\mathrm{z}$-direction.

Table 5.1 Elastic properties of the AS4/PEEK material used in the FE model.

\begin{tabular}{ccccccccc}
\hline$E_{11}$ & $E_{22}$ & $E_{33}$ & $v_{12}$ & $v_{13}$ & $v_{23}$ & $G_{12}$ & $G_{13}$ & $G_{23}$ \\
{$[\mathrm{GPa}]$} & {$[\mathrm{GPa}]$} & {$[\mathrm{GPa}]$} & - & - & - & {$[\mathrm{GPa}]$} & {$[\mathrm{GPa}]$} & {$[\mathrm{GPa}]$} \\
\hline 124 & 10 & 10 & 0.33 & 0.33 & 0.43 & 4.2 & 4.2 & 4.1 \\
\hline
\end{tabular}

Table 5.1 shows the elastic properties of the C/PEEK UD tape material used as the input for the FE model. Most of these elastic properties were obtained directly from the material supplier's datasheet [12]. Two missing properties $\left(v_{23}, G_{23}\right)$ were calculated with the help of the Chamis model [13] using the fiber and matrix material properties from the manufacturer. In-plane shear properties were determined experimentally by means of a uniaxial tensile test of a $\pm 45^{\circ}$ laminate [14], as was elaborated earlier in Chapter 3.

In order to study the critical waviness severity which may cause the first failure, the Tsai-Wu failure criterion was used to evaluate the occurrence of damage initiation [15]. The aim here is to use the failure index for comparative purposes. This failure criterion showed a good agreement with the experimentally measured apparent compressive strength of UD composites under off-axis loading [16] and the failure of off-axis UD composites under bending [17]. According to the Tsai-Wu failure criterion, for a state of plane stress, failure occurs when:

$$
\begin{aligned}
& \left(\frac{1}{S_{t 1}}-\frac{1}{S_{c 1}}\right) \sigma_{11}+\left(\frac{1}{S_{t 2}}-\frac{1}{S_{c 2}}\right) \sigma_{22}+\frac{1}{S_{t 1} S_{c 1}} \sigma_{11}^{2}+\frac{1}{S_{t 2} S_{c 2}} \sigma_{22}^{2} \\
& +\left(\frac{\tau_{12}}{S_{s 12}}\right)^{2}+2 F_{12} \sigma_{11} \sigma_{22} \geq 1
\end{aligned}
$$

where $\sigma_{11}, \sigma_{22}$ and $\tau_{12}$ are the stress components, and $S_{t 1}, S_{c 1}, S_{t 2}, S_{c 2}$ are the 
tensile and compressive strengths in the fiber and transverse directions, respectively, and $S_{s 12}$ is the in-plane shear strength. The interaction coefficient $F_{12}$ is set to zero following the recommendation in Ref. [18]. The strength parameters here are taken as the absolute values for Equation 5.2, and were obtained from the literature and the experimental work in Chapter 3 as listed in Table 5.2. An offaxis compression loading at the range of angles studied here predominantly causes a combined compressive-shear loading. As such, the predicted apparent compressive strength of a rotated ply in the range of angles studied is sensitive to both the material's compressive and in-plane shear strengths. Therefore, experimentally measured values for the two strength parameters $S_{c 1}$ and $S_{s 12}$ were used in the failure analysis. As elaborated in Chapter 3, the in-plane shear properties of the material were measured experimentally. The $S_{s 12}$ value was taken as the shear stress at $5 \%$ shear strain, following the guidelines in the ASTM standard [19]. The lamina compressive strength $S_{c 1}$ used was the mean "backed out" strength determined from the CLC tests of the baseline (non-defective) laminates. It was determined by using the CLT to back-calculate the maximum stress developed in the $0^{\circ}$ ply within the laminate, assuming the same elastic properties as given in Table 5.1. This strength value was used as the compressive lamina strength in a (multidirectional) laminate can differ considerably from that obtained from a unidirectional composite. This difference is attributed to the inherent problem with unidirectional test coupons which often cause premature failure [20].

Table 5.2 Strength parameters of AS4/PEEK UD tape.

\begin{tabular}{cccccc}
\hline & $S_{t 1}$ & $S_{c 1}$ & $S_{t 2}$ & $S_{c 2}$ & $S_{s 12}$ \\
\hline Strength [MPa] & 2280 & 1500 & 86 & 176 & 76 \\
Reference & {$[12]$} & Ch. 3 & {$[12]$} & {$[21]$} & Ch. 3 \\
\hline
\end{tabular}

\subsection{FE analysis results and discussion}

\subsubsection{Local stress state in the wavy ply}

Figure 5.3 shows an example of the simulation result for the laminate with a maximum waviness angle of $30^{\circ}$. The longitudinal strain distribution in the wavy ply is shown in the left of Figure 5.3. As expected, similar to the observation in Chapter 3, there is strain inhomogeneity, particularly at the waviness region. The longitudinal stress distribution in the principal material coordinate system given in the right of Figure 5.3 is also not uniform particularly at the waviness region. 

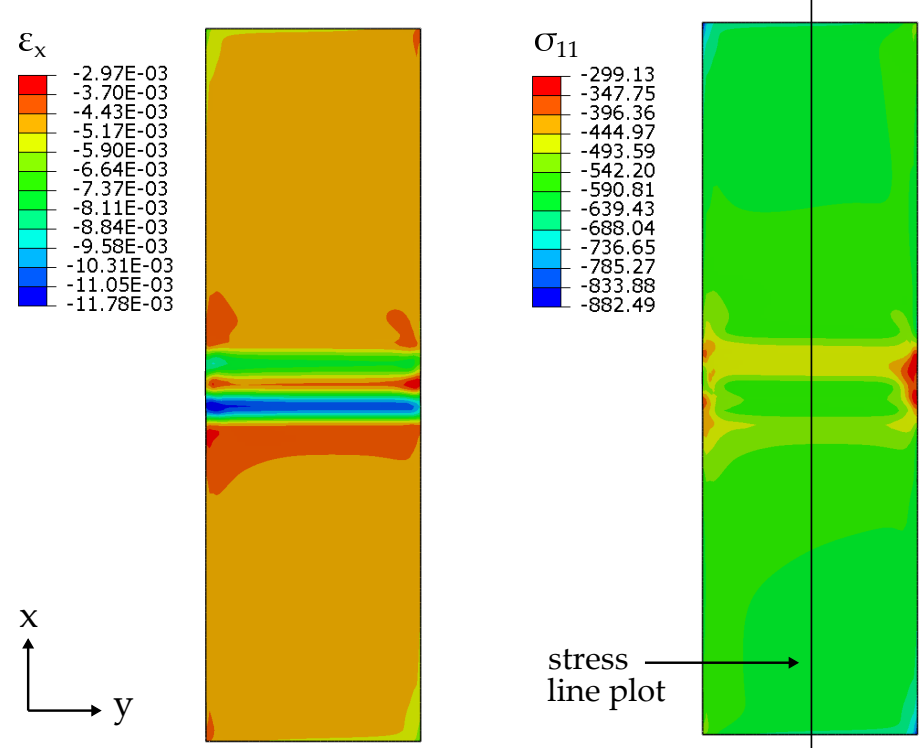

Figure 5.3 Longitudinal strain $\left(\varepsilon_{x}\right)$ field in global coordinate system (CS) and longitudinal stress $\left(\sigma_{11}\right)$ field in the principal material CS of the wavy ply for the laminate with a maximum waviness angle of $30^{\circ}$.
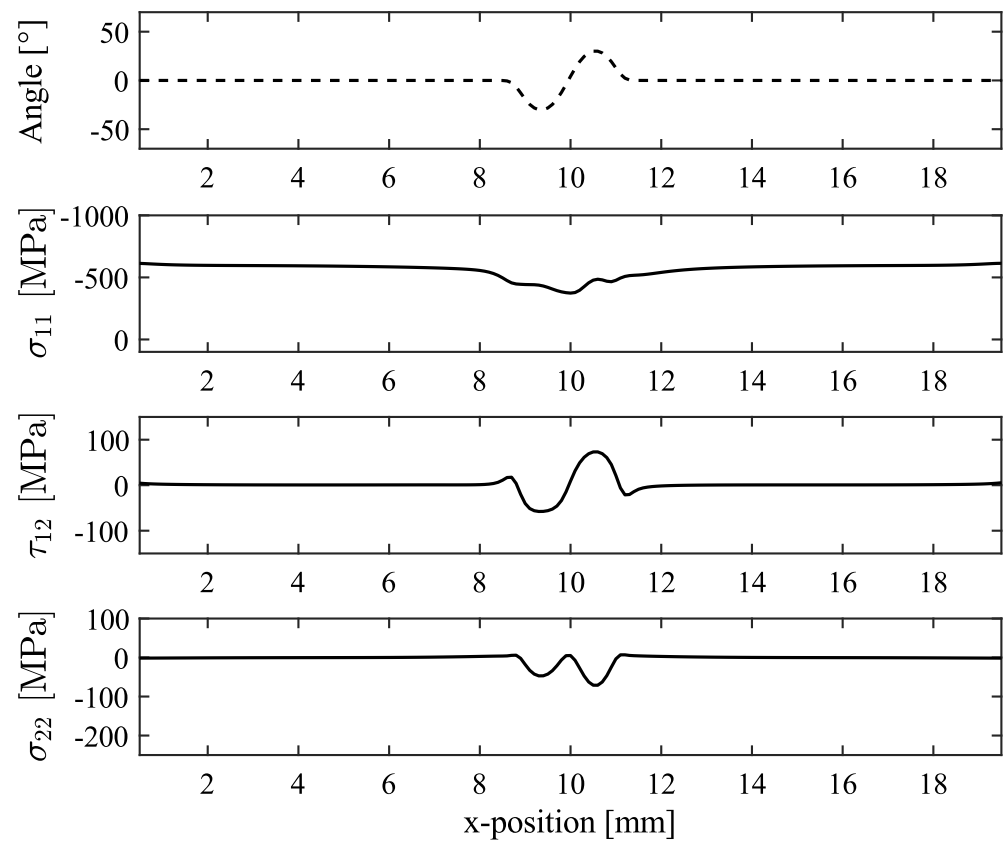

Figure 5.4 Fiber angle distribution and stresses in the principal material CS in the wavy ply for the laminate with a maximum waviness angle of $30^{\circ}$.

In the following discussion, all in-plane stress components are given with respect to the principal material CS. As indicated by the vertical black line in Figure 5.3, all stresses shown in Figure 5.4 are from the wavy ply along the length and at the midwidth of the model away from the free edge. The FEA results in Figure 5.4 show 
a local stress perturbation at the wavy region which is caused by the change in the local stiffness. At the wavy region, the compressive stress $\sigma_{11}$ is locally reduced compared to that of the surrounding region with straight fibers. Equilibrium of stresses implies that a gradient in uniaxial compression will lead to a gradient in shear and transverse stresses in off-axis planes. Any waviness in the $0^{\circ}$ plies will hence induce shear and transverse stresses in the principal material coordinates, as demonstrated in Figure 5.4. The longitudinal and transverse stresses in Figure 5.4 between the wavy region's two halves, i.e. between the x-position of 8.75 to $10 \mathrm{~mm}$ and 10 to $11.25 \mathrm{~mm}$, are not symmetric. This is caused by the constraints from the $45^{\circ}$ layer underneath the wavy ply.
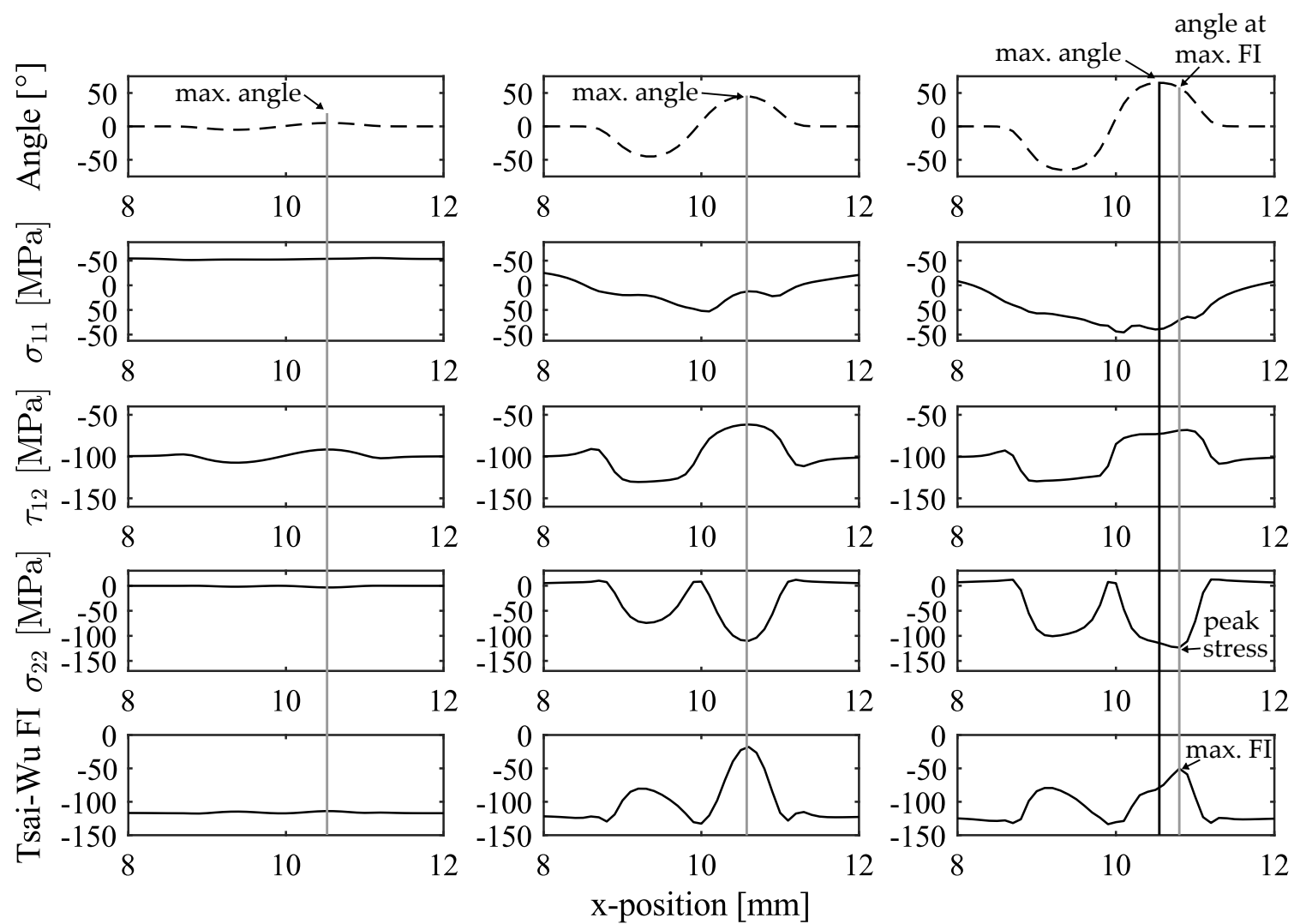

Figure 5.5 Fiber angle distribution and stresses in the wavy ply in the principal material CS at the wavy region with the maximum waviness angle of: $5^{\circ}$ (left), $45^{\circ}$ (middle), $65^{\circ}$ (right).

The FEA results for an arbitrary displacement $(0.1 \mathrm{~mm}$ over the gage length of $20 \mathrm{~mm})$ applied to laminates with three levels of waviness severity are shown in Figure 5.5. It shows that increasing maximum waviness angle causes a decrease of the longitudinal compressive stress $\left(\sigma_{11}\right)$, and an increase of the shear $\left(\tau_{12}\right)$ and transverse compressive stresses $\left(\sigma_{22}\right)$ locally at the maximum angle location with respect to the surrounding non-wavy region. However, for the waviness with a large maximum angle (the right graphs in Figure 5.5), there is a reduction of $\sigma_{11}$ and $\tau_{12}$, and an increase of $\sigma_{22}$ locally around the peak angle of the waviness with respect to its surrounding wavy region. 

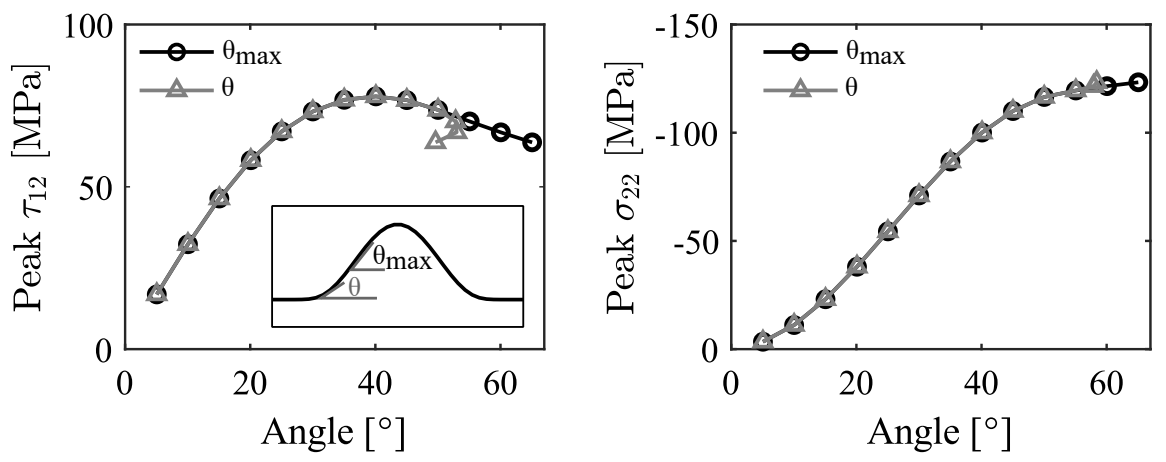

Figure 5.6 Peak in-plane shear stress $\tau_{12}$ (left) and transverse compressive stress $\sigma_{22}$ (right) in the laminates with various severities of waviness under the same applied displacement. The peak stresses are plotted against the maximum waviness angle $\left(\theta_{\max }\right)$ and the angle at which the peak stress is found $(\theta)$.

The peak shear and transverse stresses for all laminates with waviness are shown in Figure 5.6. The black line shows the peak stress plotted against the maximum waviness angle (illustrated by the vertical black line in Figure 5.5), while the gray line shows the peak stress plotted against the local angle at the location of this peak stress (from the vertical gray line in Figure 5.5). The black line shows that for the same level of applied displacement, the peak shear stress $\tau_{12}$ initially increases with increasing maximum angle and then decreases as the maximum angle becomes larger than $40^{\circ}$, while the peak transverse stress $\sigma_{22}$ increases with increasing maximum angle and tends to level off for angles larger than approximately $50^{\circ}$. Furthermore, Figure 5.6 shows that there is a deviation between the black and gray lines. This means that there is a shift in the peak shear and transverse stresses from the maximum angle of the waviness to a lower angle within the wavy region for the waviness with a maximum angle above $50^{\circ}$.

\subsubsection{Failure analysis}

The Tsai-Wu failure index (FI) was used to indicate the occurrence of damage initiation in the wavy ply for all laminates with waviness. The maximum Tsai-Wu FI from the model with a single wavy region at various maximum angles is shown in Figure 5.7. These values were determined from the stresses computed earlier in Figure 5.5, with the same arbitrary displacement of $0.1 \mathrm{~mm}$ applied in the model. The failure sequence between the different waviness with varying severity can be interpreted by comparing the FI values. Under incremental compression loading, the higher the FI, the earlier failure occurs at the corresponding wavy region. Figure 5.7 shows that, for the range of waviness severity considered in this chapter, the highest maximum FI was found in the wavy region with the maximum angle of $45^{\circ}$ (shown by the black line in Figure 5.7). Therefore, the wavy region with the maximum angle of $45^{\circ}$ is expected to fail first for the range of waviness severity considered here.

The interpretation of the dominant failure mode which causes damage initiation 
was made on the basis of the ratio between the stress component and the material strength, e.g. $\sigma_{11} / S_{c 1}$ and $\tau_{12} / S_{s 12}$. It was found that the dominant stress component which causes failure to initiate for the waviness with small maximum angles below $10^{\circ}$ is the compressive stress $\sigma_{11}$. For the larger angles, the dominant stress component is the in-plane shear stress $\tau_{12}$. This observation is also reflected in the trend between the influence of the maximum waviness angle on the maximum Tsai$\mathrm{Wu}$ FI in Figure 5.7 that is similar to its influence on the peak in-plane shear stress $\tau_{12}$ in Figure 5.6.

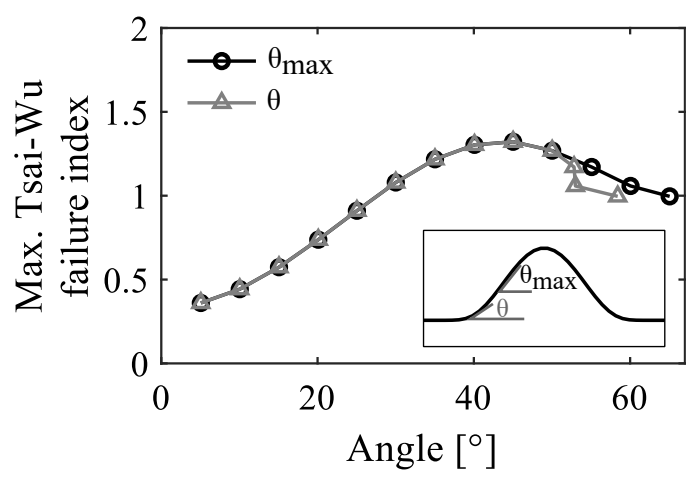

Figure 5.7 Maximum Tsai-Wu failure index (FI) for various waviness angles from the FE model of a single wavy region in a 24-ply QI laminate. The failure index is plotted against the maximum waviness angle $\left(\theta_{\max }\right)$ and the angle at which the peak stress is found $(\theta)$.

The sequence of failure between multiple wavy regions with different severity within a single specimen was studied by comparing the Tsai-Wu failure index (FI) of each wavy region. The analysis result from the FE model with two wavy regions which are one wavelength apart and have maximum angles of $35^{\circ}$ and $65^{\circ}$ is shown in Figure 5.8. Such wavy regions were chosen to represent the variation in severities within a specimen that was studied in Chapter 4 . The maximum FI of the wavy region with the maximum angle of $35^{\circ}$ is higher than the one with $65^{\circ}$, which again confirms that the critical waviness is not necessarily the waviness with the largest maximum angle. Although the exact FI value is not the same, a similar trend between the maximum Tsai-Wu FI from each waviness severity was found from the model with a single isolated wavy region and the one which includes multiple wavy regions. This suggests that the sequence of failure can be predicted by evaluating the wavy region in isolation as a single wavy region provided that they are sufficiently far apart (such as the analysis given earlier in Figure 5.7) and the remaining undamaged plies have sufficient load bearing capacity.

Figure 5.7 suggests that the critical waviness which will cause the first failure for a specimen with multiple wavy regions is the one with a maximum angle of $45^{\circ}$, as opposed to the largest maximum angle which can be up to $64^{\circ}$. Please note that this observation is only applicable for the set of material property data used in this study. The reader is reminded again that a sinusoidal wave consists of fiber angles spanning 
from $0^{\circ}$ to the maximum angle back to $0^{\circ}$ (see Figure 5.2). As an example, the waviness with the maximum angle of $55^{\circ}$ passes through all smaller angles, including $40^{\circ}$. When there are two wavy regions with the maximum angles of $40^{\circ}$ and $55^{\circ}$ in a single specimen, one might expect that for the wavy region with a maximum angle of $55^{\circ}$, failure occurs at the $45^{\circ}$ location within that wavy region or at the same time as the wavy region with a maximum angle of $40^{\circ}$. However, the experiments in Chapter 4 showed that this was not the case. The previous stress analysis result presented in Figure 5.6 indicates that for the same level of applied displacement, the peak in-plane shear stress $\tau_{12}$ generated in the wavy region with a maximum angle of $55^{\circ}$ is still less than that in the wavy region with a maximum angle of $40^{\circ}$, even though the wavy region with a maximum angle of $55^{\circ}$ also contains $40^{\circ}$ angles. In other words, the local in-plane shear stresses $\tau_{12}$ at the $40^{\circ}$ angle location in the two wavy regions are not equal, i.e. the stress $\tau_{12}$ is lower in the wavy region with a maximum angle of $55^{\circ}$. The FEA results thus confirm and explain the experimental observations in Chapter 4 , in which no failure was found in the wavy region that has a maximum angle above $45^{\circ}$ when there was another wavy region with a lower maximum angle in the same specimen. This may be explained by the presence of a wavy region with a large angle which may act as a compliant region, reducing the local normal and shear stresses around the peak angle of a wavy region that has a large maximum angle.
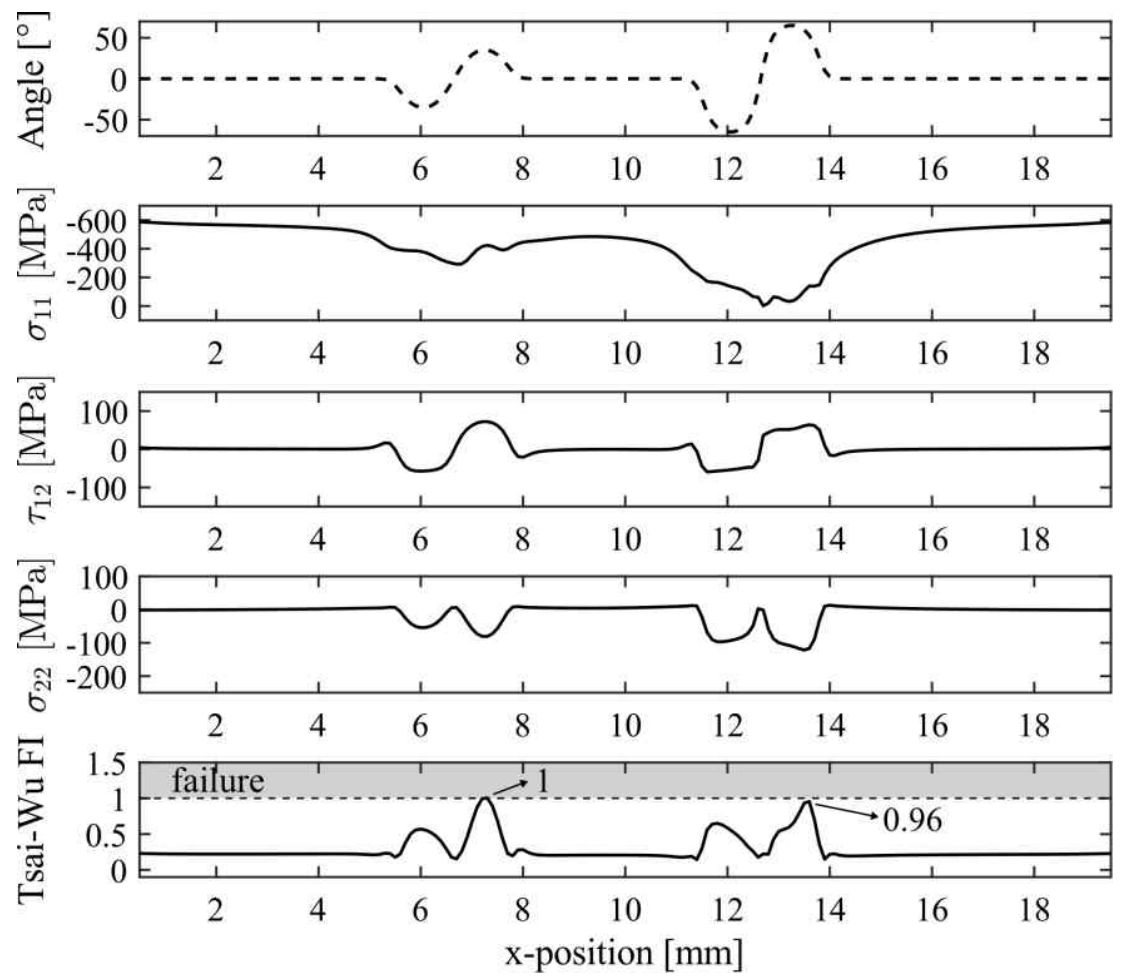

Figure 5.8 Stresses of the wavy ply in the principal material CS, the resulting Tsai-Wu failure index (FI) and fiber angle distribution from the FE model with two wavy regions: maximum of $35^{\circ}$ on the left and $65^{\circ}$ on the right. 
As presented earlier in Figure 5.6, the peak shear and transverse compressive stresses were not always at the maximum angle within a wavy region, especially for the waviness with a large maximum angle. As a consequence, there is also a shift of the maximum FI to the lower angle for such waviness. This is indicated by the deviation between the black and gray lines in Figure 5.7. Same as before, the black line represents the maximum Tsai-Wu FI plotted against the maximum waviness angle (from the vertical black line in Figure 5.5), while the gray line shows the same value of maximum Tsai-Wu FI plotted against the local angle at the location of the maximum Tsai-Wu FI (from the vertical gray line in Figure 5.5). This failure analysis thus indicates that for waviness with the maximum waviness angle up to $50^{\circ}$, failure will initiate at the maximum angle within the wavy region. As expected, the fibers that are the most misaligned act as the weakest link and will lead to failure. This suggests that a simplification by only evaluating the failure initiation at the maximum angle for the range of waviness severity up to $50^{\circ}$ seems to be a reasonable assumption for the following analytical model. However, for the waviness with a larger maximum angle, such assumption does not hold anymore as the highest FI was found at the lower angle. As such, the analysis of the full wavy region is required for the waviness with a larger maximum angle.

\subsection{Analytical model description}

This section describes the analytical modeling approach that is meant to be used as a tool for quick and simple analysis of waviness effects. The models for first ply failure and ultimate failure are validated by comparing the predicted strengths with the experimental results in Chapter 3 (uniaxial compression) and Chapter 4 (bending).

The analytical model is formulated with the simplifying assumption based on the previous findings from the FEA. The failure in this case is assumed to initiate at the maximum angle within a wavy region and that the stress state of the wavy region is not influenced by the neighboring wavy region. Stress-strain analysis of the laminate is performed using the CLT. As mentioned previously, the waviness in this study has a relatively large maximum angle and thus, the compression loading on the wavy ply is comparable to an off-axis compression loading. As such, a similar modeling approach as earlier studies for off-axis compression-loaded laminates with waviness $[10,11]$ is used in this work. The wavy lamina here is assumed to have a uniform off-axis orientation rotated according to the maximum waviness angle, but it has the same elastic material properties as the lamina without waviness (Table 5.1). This approach essentially changes the effective stiffness of the wavy ply. A quasiisotropic (QI) $[0 / 45 / 90 /-45]_{3 \text { s }}$ laminate with a maximum waviness angle (only in the top outermost ply) increasing up to $50^{\circ}$ - covering all the applicable range as described earlier in section 5.2 - was evaluated here. Same as before, only a single wavy ply is considered in this model, i.e. the top outermost ply (ply 24). 


\subsubsection{First ply failure}

Ply failure was evaluated sequentially with incremental loading until the first failure of the wavy lamina is detected. The analysis was performed for a laminate subjected to bending, based on the experimental work in Chapter 4. As described earlier in section 5.2, the initiation of failure in this study was determined according to the Tsai-Wu failure criterion, assuming the material strength given in Table 5.2. The accuracy of the predicted strength with this failure criterion is limited by the accuracy of the lamina strength input. It is known that a very high failure compressive stress can be reached in a bending test due to the presence of the stress gradient throughthe-thickness [22], and hence it is expected that the input derived from a uniaxial compression test may not be sufficient. Therefore, instead of the $S_{c 1}$ value used earlier for the FEM, a different experimentally derived "backed out" lamina strength was used for this failure analysis. The value was determined from the bending tests of the baseline (non-defective) laminate with the same material and layup used as the model input. The maximum ply stress developed in the $0^{\circ}$ ply within the laminate at failure was back-calculated by using the CLT, resulting in a compression strength value $S_{c 1}$ of $2119 \mathrm{MPa}$.

For comparison with the first ply failure determined from the experimental work in Chapter 4, a bending moment was applied parallel to the ideal fiber direction of the outermost ply in the failure analysis. The stress state of each ply at each load increment was determined by using the lamina properties listed in Table 5.1. The bending moment at which the first failure in the wavy (rotated) lamina occurs was used to determine the ply stress at first failure in the global coordinate system.

\subsubsection{Ultimate failure}

The ultimate failure analysis was performed for a laminate subjected to uniaxial compression, based on the experimental work in Chapter 3. The analysis was first performed by using the same approach as described earlier, i.e. the wavy lamina was assumed to be rotated according to the maximum waviness angle. In addition, the simplest approach by removing the contribution of the wavy plies on the ultimate strength was also evaluated. For this approach, the stiffness of the wavy ply was assumed to be close to zero.

The compression load was applied parallel to the fiber direction of the outermost ply. The ply failure was evaluated sequentially with incremental loading, as illustrated in Figure 5.9. The model uses the ply-discount method [23, 24]. It evaluates the load which results in the first failure of one or more plies, then updates the stiffness matrix of the failed plies according to the degradation rule shown in Figure 5.9, and again increases the load until it finds failure in the next ply. Same as before, the initiation of failure was determined according to the Tsai-Wu failure criterion, assuming the same 
material strength given earlier in Table 5.2 with $S_{c 1}$ of $1500 \mathrm{MPa}$. The degradation rule is based on the stiffness reduction model, in which the corresponding elastic constant is reduced according to an arbitrary degradation factor if failure is found, i.e. $1 \%$ of the initial value. For transverse or shear failure (in the off-axis plies), the reduction in matrix modulus was considered to only affect the transverse modulus $E_{2}$, shear modulus $G_{12}$, and Poisson's ratio $v_{12}$. For the compression load case, the whole procedure is repeated until longitudinal (fiber) failure in any of the nondefective plies oriented in the loading direction (any $0^{\circ}$ ply) is found or until any of the elastic constants become singular, which is regarded as the ultimate failure. This stop criterion was set according to the identified failure process in Chapter 3 , where the failure of any of the non-defective $0^{\circ}$ plies immediately caused the damage to propagate through the thickness leading to the final fracture. This damage development occurred in a very short time period at the peak load.

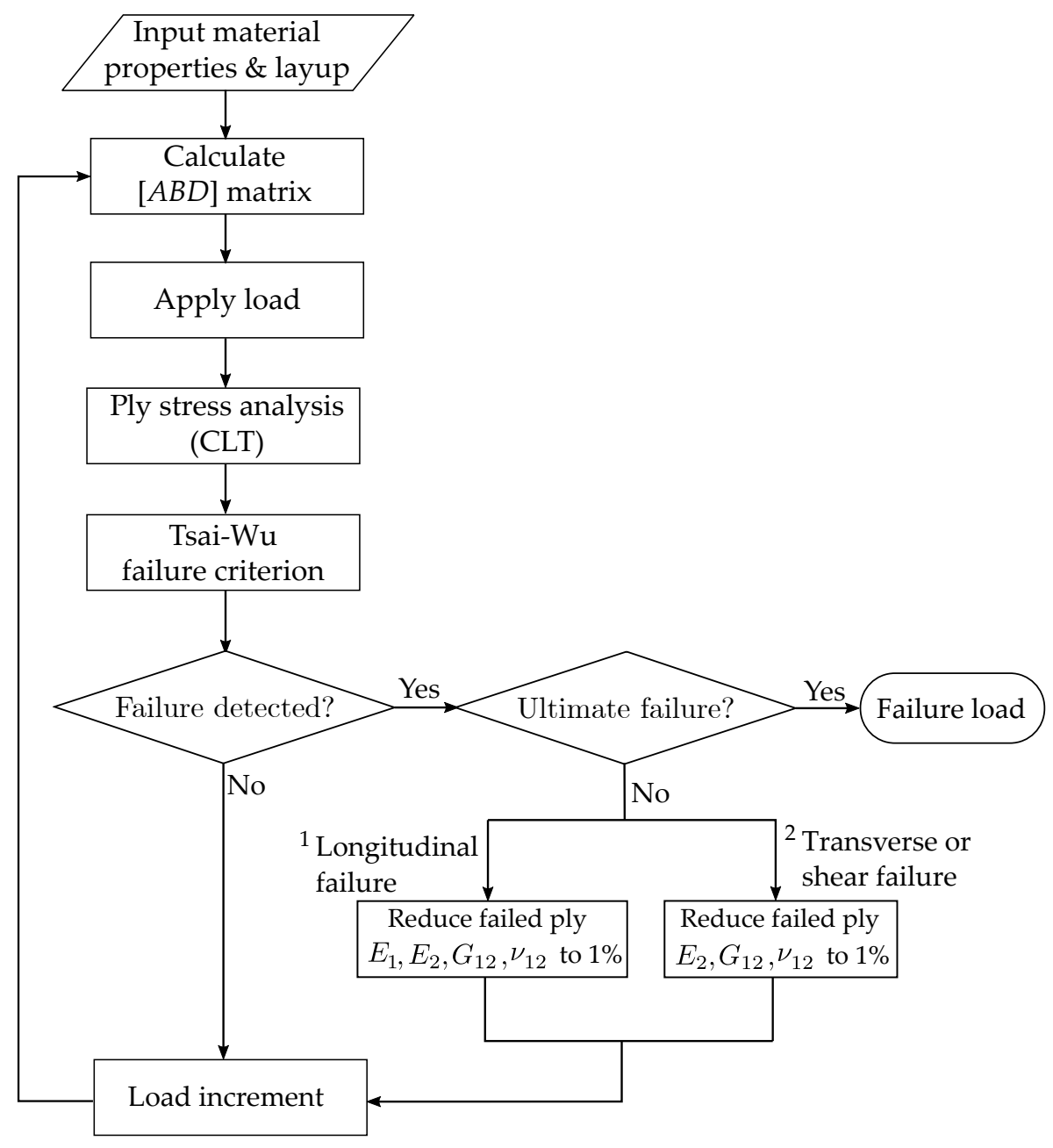

Figure 5.9 CLT failure analysis flowchart.

The simplifying assumption used in this analytical approach, i.e. rotating the 
wavy lamina according to the maximum angle, essentially causes the layup to be asymmetric. As a consequence, the laminate's bending-extension coupling matrix is non-zero. This first case will be referred to as the unconstrained condition. Actually, the bending-free assumption may give a more realistic estimate than the unconstrained condition to compare with the experimental results from the Combined Loading Compression (CLC) tests given in Chapter 3. The waviness in reality is very localized, while in this model the whole ply was assumed to be rotated. In addition, the test fixture used in the experiment also constrained bending. This means that the curvature in the model as-is will not be the same as that from the experiments in Chapter 3. Therefore, a zero curvature and non-zero moment are imposed for the bending-free condition, which leads to the following moments:

$$
\{M\}=[d]^{-1}[b]\{N\}
$$

in which $[b]$ and $[d]$ are the laminate compliance matrices and $\{\mathrm{N}\}$ is the in-plane forces. This condition will be referred to as the constrained condition. Lower and upper bound estimates will be given based on those two conditions, i.e. the unconstrained and constrained conditions.

\subsection{Analytical modeling results and discussion}

\subsubsection{Local stress state of the rotated wavy ply}
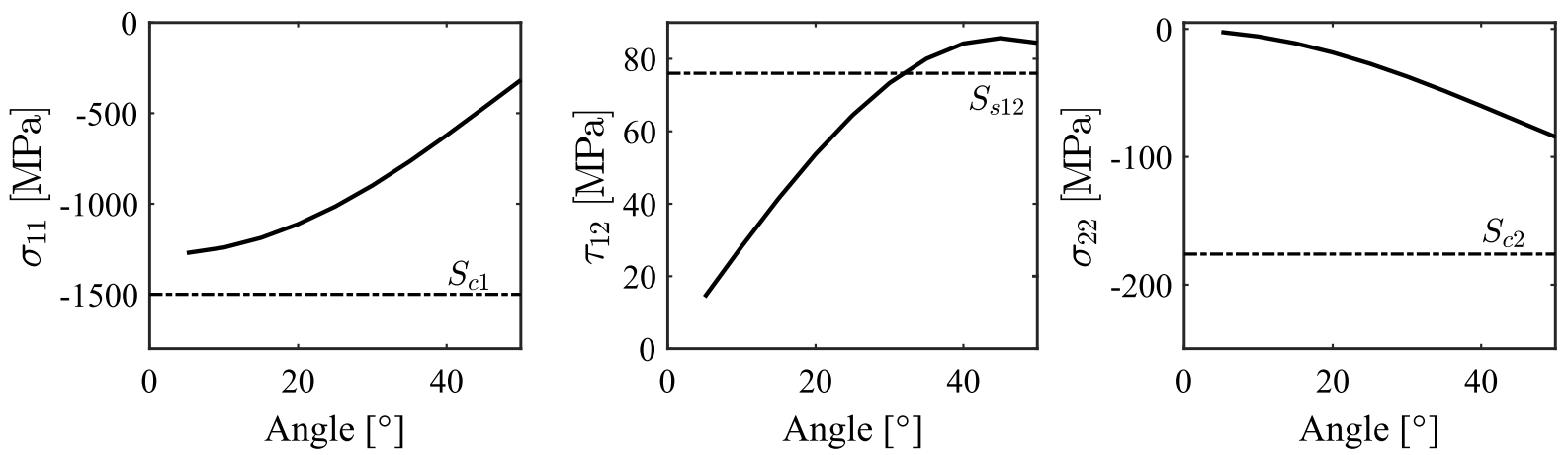

Figure 5.10 Stresses in the principal material coordinate system as a function of the rotation angle from CLT at an arbitrary compression load: longitudinal $\left(\sigma_{11}\right)$, shear $\left(\tau_{12}\right)$, and transverse $\left(\sigma_{22}\right)$ stress. The horizontal dashed lines indicate the material strength.

Figure 5.10 shows the stresses of the rotated wavy ply as a function of the rotation angle, as determined by the CLT. The stresses presented in Figure 5.10 are the three in-plane stresses in the principal material coordinate system from the top (wavy) ply. These stresses were determined for laminates subjected to an arbitrary compression load of $10,000 \mathrm{~N}$. As expected, the waviness which was represented as the rotated top 
ply induces not only longitudinal compressive stress but also shear and transverse compressive stresses in the principal material coordinates.

\subsubsection{First-ply failure stress}

The compressive ply stresses at first failure determined from the bending tests, i.e. the end-loaded bending (ELB) and the four-point bending (4PB) tests, presented in Chapter 4 are compared in this section with the analytical modeling results. The bending tests of the $[0 / 45 / 90 /-45]_{3 s}$ laminates showed that the first ply to fail was the outermost $0^{\circ}$ ply for the baseline laminate and the outermost $0^{\circ}$ wavy ply for the laminate with waviness. The ply failure stress appeared to initially decrease with increasing maximum waviness angle, but did not significantly change at the larger angles above $20^{\circ}$.

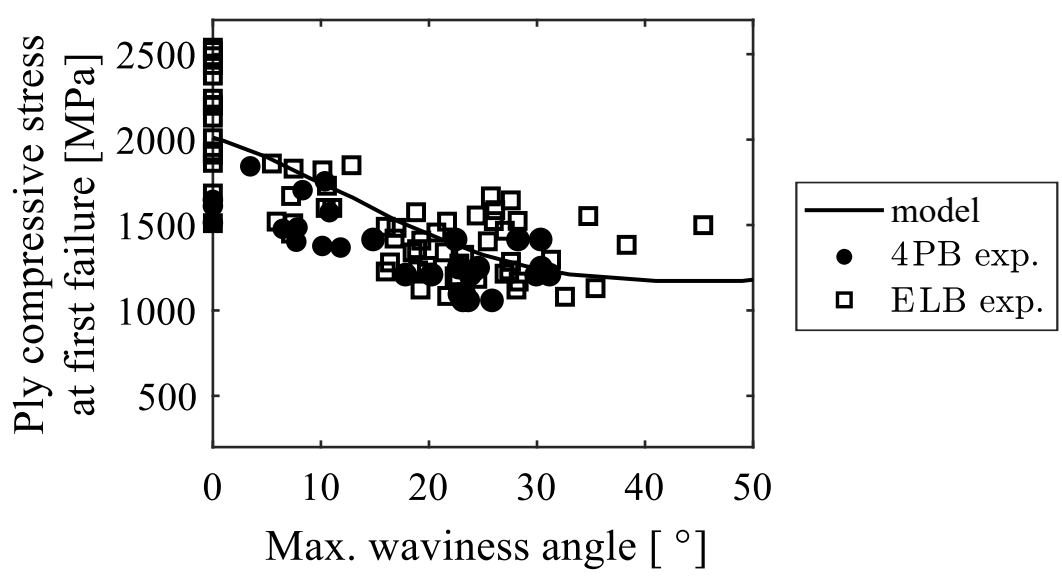

Figure 5.11 Predicted (line) and measured (dots) ply compressive stress at first failure in the global coordinate system.

Figure 5.11 shows the predicted compressive stress at first failure of the wavy ply as a function of the maximum waviness angle. Despite its simplicity, the analytical model with the "backed out" compressive strength appears to be able to capture the trend seen from the experiments in Chapter 4 . The ratio between the stresses and the corresponding material strengths (shown as the dashed horizontal line in Figure 5.10) indicates that at lower angles (below $10^{\circ}$ ), the longitudinal compressive stress dominates the failure initiation. At higher angles, the in-plane shear stress appears to be the dominating stress component.

These results demonstrate that the simplifying assumption of representing the waviness in the model as an off-axis lamina rotated according to the maximum waviness angle seems to be suitable for the localized waviness studied in this work. This also supports the view that the reduction of laminate strength due to in-plane waviness is mainly caused by the misorientation of the fibers. However, please 
note that the simplifying assumptions used here are only confirmed for the material system and the type of waviness studied in this work, by using the experimentallyderived material strength specific to the laminates studied. The approach still needs to be validated for other materials.

\subsubsection{Ultimate strength}

The ultimate strengths measured from the CLC tests presented in Chapter 3 are used for comparison with the modeling results. The experimental results show that the ultimate strength reduction levels off as the maximum waviness angle increases. It was found that the change of maximum waviness angles within the range between $26^{\circ}$ to $50^{\circ}$ for the laminates with the $[0 / 45 / 90 /-45]_{3 s}$ layup (QI1 sample in Chapter 3) did not significantly affect the ultimate strength.

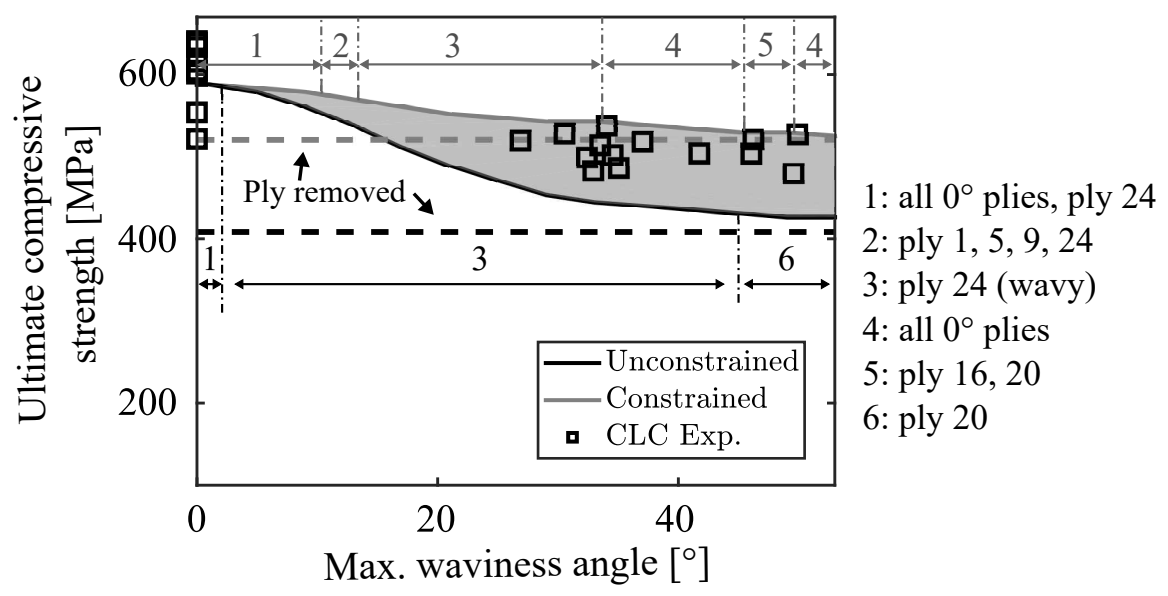

Figure 5.12 Measured (dots) and predicted (shaded region) ultimate strengths for laminates with $[0 / 45 / 90 /-45]_{3 s}$ stacking sequence. Two horizontal dashed lines (denoted as ply removed) indicate the prediction by disregarding the contribution of the wavy plies on the ultimate strength. The numbers 1 to 6 indicate the first ply/plies to fail within the denoted range of maximum waviness angle.

Figure 5.12 shows the ultimate failure analysis results from both the unconstrained and constrained conditions. The complete progressive failure analysis results are not shown here for brevity, but instead, only the details for the first ply/plies to fail and the final failure results are presented in Figure 5.12. The black line in Figure 5.12 shows the predicted ultimate strength from the unconstrained condition. It shows that the first plies to fail for the low waviness angle up to $5^{\circ}$ are all of the $0^{\circ}$ plies and wavy ply. For the angles above this value, the first ply to fail is the wavy ply, i.e. according to the experimental observations in Chapter 3 . Above the angle of $45^{\circ}$, the first ply to fail is the first inner $0^{\circ}$ ply from the top (ply 20). In this case, the axial stress generated in the first inner $0^{\circ}$ ply from the top is the highest as the laminate is asymmetric, and hence a uniaxial compression load leads to bending of the laminate. 
Such failure sequence, however, was not observed in the experiments described in Chapter 3.

The influence of bending-free assumption (constrained condition) on the predicted ultimate strength is also illustrated in Figure 5.12. It shows that the imposed bending constraint significantly increases the predicted ultimate strength (the gray line in Figure 5.12) and alters the sequence of the first ply to fail. It can be seen in Figure 5.12 that the model with the constrained condition serves as the upper bound estimate. It appears that the experimental data lie in between the unconstrained and constrained conditions, which is in good agreement with the experiments in reality, i.e. the specimens were partially constrained. As such, the results from both models are shown as a band (shaded region) in Figure 5.12, with the lower and upper bounds given from the unconstrained and the constrained condition, respectively. Similarly to the previous results from the unconstrained condition, the first plies to fail for the model with large maximum angles (see the numbers 4 and 5 in Figure 5.12) for the constrained condition are also the non-defective $0^{\circ}$ plies. This is again caused by the rotation of the wavy ply which creates an asymmetric laminate.

The results computed by disregarding the contribution of the wavy plies on the ultimate strength are shown in Figure 5.12 as the two dashed lines, marked as "ply removed". In this case, the influence of the imposed bending constraint is also evaluated for the "ply removed" analysis. It can be seen that, in all cases, as the maximum waviness angle increases, the predicted strength by rotation of the wavy ply (the two solid lines) approaches the two "ply removed" dashed lines. This means that disregarding the contribution of the wavy ply on the ultimate strength in the unconstrained condition serves as the lower bound estimate. However, note that this approach is only validated for the number of wavy plies investigated in this work. An earlier study on out-of-plane waviness shows a similar conclusion that such approach is applicable under a limited condition up to a certain wavy $0^{\circ}$ ply fraction beyond which the strength does not decrease any further [25].

The results from the ultimate failure analysis (Figure 5.12) show that although the identified first ply to fail was not always the wavy ply, as that was observed from the experiments in Chapter 3, the model captures the trend of the ultimate strength reduction which levels off as the maximum waviness angle increases. Moreover, the simplest approach by removing the contribution of the wavy ply on the ultimate strength can be used to give the most conservative of the ultimate strength for the severity considered in this study. The simplest explanation for this observation is that the ultimate strength is primarily governed by the strength of the non-defective $0^{\circ}$ plies. In summary, these results demonstrate that the current simplified modeling approach with the backed out lamina compressive strength input can provide a reasonable first approximation of the effect of waviness on the compressive strength. 


\subsection{Conclusions}

A theoretical analysis of the influence of the waviness severity on the compressive failure of quasi-isotropic laminates has been presented in this chapter. Finite element models were used to perform a parametric study to investigate the effect of maximum waviness angle on the local stress state in the wavy ply and the compressive failure initiation. The FEA results support the experimental observations from the bending tests described in Chapter 4. Both the model and the experiments show that the waviness with the largest maximum angle in a specimen that has multiple wavy regions with varying levels of severity does not necessarily cause the first failure. The parametric study revealed that the critical wavy region that causes the first failure is not simply the one with the largest maximum angle when one of the wavy regions has a maximum angle larger than $45^{\circ}$.

This chapter has presented an analytical model to be used as a tool for quick and simple analysis of the waviness effect on the compressive strength. The analytical approach employing the classical laminate theory was proposed with the simplifying assumption that the maximum angle acts as the weakest link from which failure will initiate. Despite the simplicity of the model, this study has demonstrated that the current modeling approach can provide a reasonable first approximation of the first failure stress and the ultimate strength of laminates with in-plane waviness. Furthermore, the most conservative estimate of the ultimate compressive strength for the severity considered in this study can be obtained by simply disregarding the contribution of the wavy ply on the strength. These modeling approaches, however, only work by using the experimentally measured "backed out" strength as the model input calibrated specifically for the laminates studied in this work.

\section{References}

[1] B. Budiansky and N. A. Fleck. Compressive failure of fibre composites. Journal of the Mechanics and Physics of Solids, 41(1):183-211, 1993.

[2] A. L. Highsmith, J. J. Davis, and K. L. E. Helms. The influence of fiber waviness on the compressive behavior of unidirectional continuous fiber composites. ASTM International, 1992.

[3] M. R. Piggott. The effect of fibre waviness on the mechanical properties of unidirectional fibre composites: a review. Composites science and technology, 53(2):201-205, 1995.

[4] P. J. Joyce and T. J. Moon. Compression Strength Reduction in Composites with InPlane Fiber Waviness, pages 76-96. ASTM International, West Conshohocken, PA, 1998.

[5] Q. Sun, H. Guo, G. Zhou, Z. Meng, Z. Chen, H. Kang, S. Keten, and X. Su. Experimental and computational analysis of failure mechanisms in 
unidirectional carbon fiber reinforced polymer laminates under longitudinal compression loading. Composite Structures, 203:335-348, 2018.

[6] P. Y. Mechin, V. Keryvin, J. C. Grandidier, and D. Glehen. An experimental protocol to measure the parameters affecting the compressive strength of cfrp with a fibre micro-buckling failure criterion. Composite Structures, 211:154-162, 2019.

[7] S. Mukhopadhyay, M. I. Jones, and S. R. Hallett. Compressive failure of laminates containing an embedded wrinkle; experimental and numerical study. Composites Part A: Applied Science and Manufacturing, 73:132-142, 2015.

[8] A. Shipsha, S. Hallström, and M. Burman. Effect of stacking sequence and bundle waviness in quasi-isotropic NCF composites subjected to compression. Composites Part B: Engineering, 178:107423, 2019.

[9] D. Wilhelmsson, R. Talreja, R. Gutkin, and L. Asp. Compressive strength assessment of fibre composites based on a defect severity model. Composites Science and Technology, 181:107685, 2019.

[10] F. Edgren, L. E. Asp, and R. Joffe. Failure of NCF composites subjected to combined compression and shear loading. Composites Science and Technology, 66(15):2865-2877, 2006.

[11] A. Shipsha, M. Burman, and J. Ekh. Failure of cross-ply NCF composites under off-axis compressive loads - An experimental study and a new strength prediction model including fibre bundle waviness. Composites Part B: Engineering, 153:49-56, 2018.

[12] Toray Advanced Composites. Cetex TC1200 PEEK - Technical Data Sheet, 2019.

[13] C. C. Chamis. Mechanics of composite materials: past, present, and future. Journal of Composites, Technology and Research, 11(1):3-14, 1989.

[14] M. van der Werff and M. Bouwman. TPRC internal report 2018: Long term exposure of thermoplastic composites. Report, TPRC, 2018.

[15] S. W. Tsai and E. M. Wu. A general theory of strength for anisotropic materials. Journal of Composite Materials, 5(1):58-80, 1971.

[16] M. Kawai and S. Saito. Off-axis strength differential effects in unidirectional carbon/epoxy laminates at different strain rates and predictions of associated failure envelopes. Composites Part A: Applied Science and Manufacturing, 40(10):1632-1649, 2009.

[17] M. Koc, F. O. Sonmez, N. Ersoy, and K. Cinar. Failure behavior of composite laminates under four-point bending. Journal of Composite Materials, 50(26):3679_ 3697, 2016.

[18] R. Narayanaswami and H. M. Adelman. Evaluation of the Tensor Polynomial and Hoffman Strength Theories for Composite Materials. Journal of Composite Materials, 11(4):366-377, 1977.

[19] ASTM. ASTM D3518 - Standard Test Method for In-Plane Shear Response of Polymer Matrix Composite Materials by Tensile Test of a $\pm 45^{\circ}$ Laminate, 2007.

[20] L. J. Hart-Smith. 5.07 - Backing-out Composite Lamina Strengths from Cross- 
Ply Testing, Comprehensive Composite Materials, Volume 5, pages 149-161. Pergamon, Oxford, 2000.

[21] H. Liu, J. Liu, Y. Ding, J. Zhou, X. Kong, L. T. Harper, B. R. K. Blackman, B. G. Falzon, and J. P. Dear. Modelling damage in fibre-reinforced thermoplastic composite laminates subjected to three-point bend loading. Composite Structures, 236:111889, 2020.

[22] M. R. Wisnom and J. W. Atkinson. Constrained buckling tests show increasing compressive strain to failure with increasing strain gradient. Composites Part A: Applied Science and Manufacturing, 28(11):959-964, 1997.

[23] Composite Materials Handbook (CMH-17-3G), Volume 3-Polymer Matrix Composites Materials Usage, Design, and Analysis. SAE International, 2012.

[24] K. S. Liu and S. W. Tsai. A progressive quadratic failure criterion for a laminate. Composites Science and Technology, 58(7):1023-1032, 1998.

[25] D. O. Adams and S. J. Bell. Compression strength reductions in composite laminates due to multiple-layer waviness. Composites Science and Technology, 53(2):207-212, 1995. 


\section{A Mesh refinement analysis}

A mesh refinement study was carried out to select the appropriate mesh size that is fine enough to resolve the sinusoidal wave. Figure 5.13 shows the in-plane stresses of the wavy ply in the principal material coordinate system for several elements lengths, i.e. from $0.05 \mathrm{~mm}$ up to $0.2 \mathrm{~mm}$. Only the model with $0.2 \mathrm{~mm}$ element length did not capture the stresses in the zoomed-in view in the right graph in Figure 5.13 (see the black lines). This means that an element length of $0.1 \mathrm{~mm}$ is sufficient since the models with smaller element lengths produced similar results.
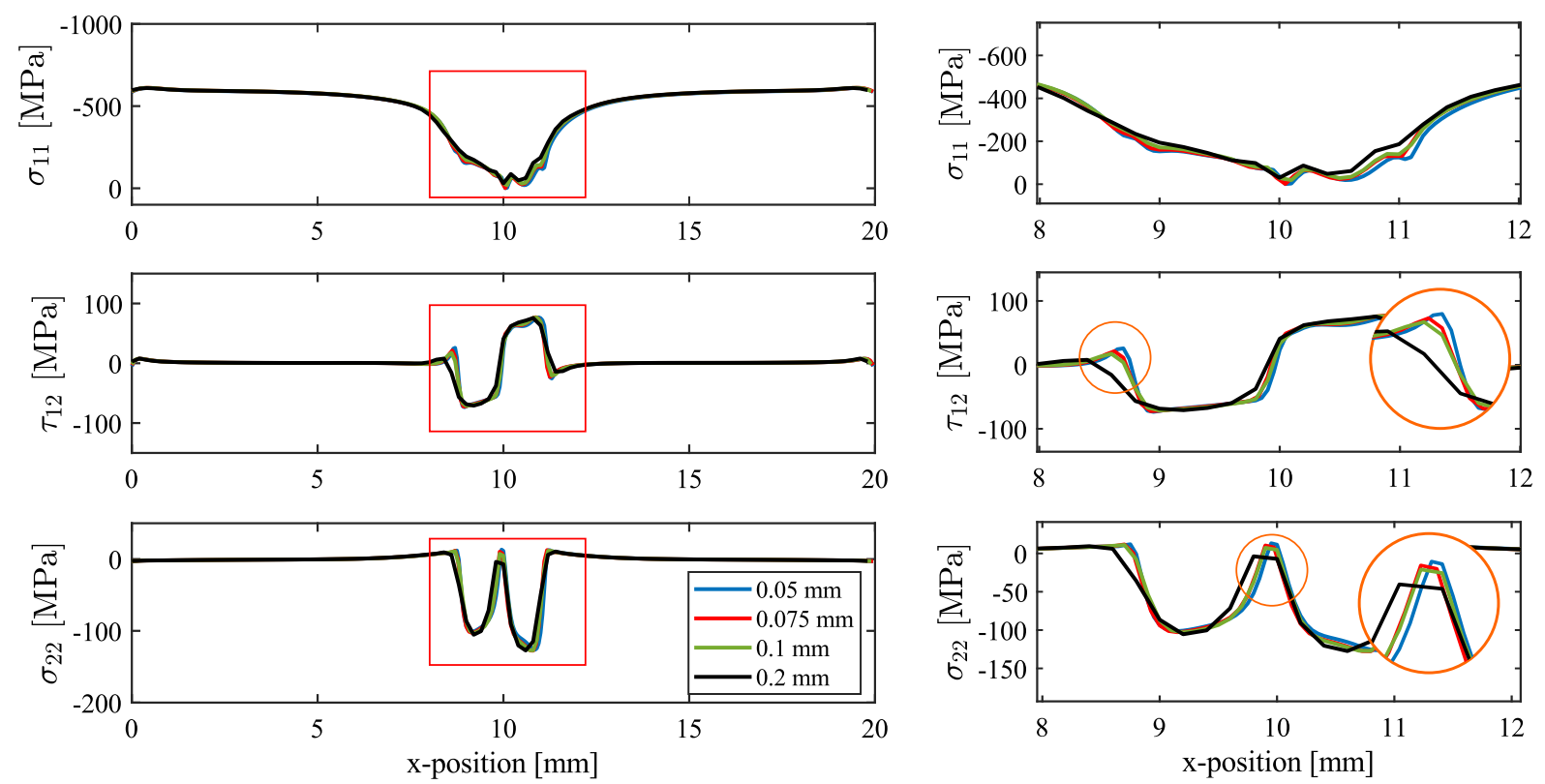

Figure 5.13 In-plane stresses in the principal material coordinate system for several element lengths (left) and the detailed view at the wavy region (right). These stresses are from the wavy ply along the length and at the mid-width of the model. 



\section{CHAPTER 6}

\section{Discussion}

The mechanical performance of composite parts has to meet design requirements set corresponding to the loading condition that the parts would experience during service. The mechanical performance may be reduced due to the presence of defects in the parts and, thus, any possible effects of those defects have to be taken into account during the design phase. Firstly, this chapter reviews the defect assessment approach in terms of its general applicability for other defects, loading conditions and material systems. This is then followed by a discussion on the methodology specific for the measurement of waviness effects. Subsequently, the effects of in-plane fiber waviness defects on the compressive failure process and the compressive strength of thermoplastic composite laminates are discussed based on the results from previous chapters. Lastly, this chapter broadens the discussion on the implication of waviness defects on the design of aircraft structures.

\subsection{Defect assessment}

Generally, the effects of defects on the mechanical properties of composites can be evaluated according to the approach presented in Figure 6.1. A defect found in a produced part has to be identified and characterized to establish a defect metric as a measure for the severity. The defect metric can be defined in several ways. For example, as was done in this work, based on the defect geometry. The metric has to be chosen such that it can define the influence of the defect on the mechanical performance of the composites part. After determining the defect metrics, mechanical test coupons can be made directly from the actual parts, provided that they are suitable for the test methods considered. This approach, however, is limited by the part size and the defect distribution. It may not always be possible to extract a sufficient number of coupons from actual parts and often replicates are not available to establish statistically-based mechanical properties. Another alternative is to reproduce the defects, either artificially by directly manipulating the material to mimic the appearance of the defect, or by replicating the defect formation 
mechanisms. The latter can produce desirable specimens with representative defects but may not always allow for full control of the level of severity. The former provides more freedom in controlling the defect severity but may not always be feasible, and may not always successfully yield the same defect metrics and distribution as that from the actual parts. Subsequently, mechanical testing of the produced specimens can be performed to determine the mechanical behavior such as the stress-strain response and the failure mechanisms, and the mechanical properties that are relevant for the parts loading condition in service. Finally, the experimental results can be used to determine design allowable which accounts for the presence of defects.

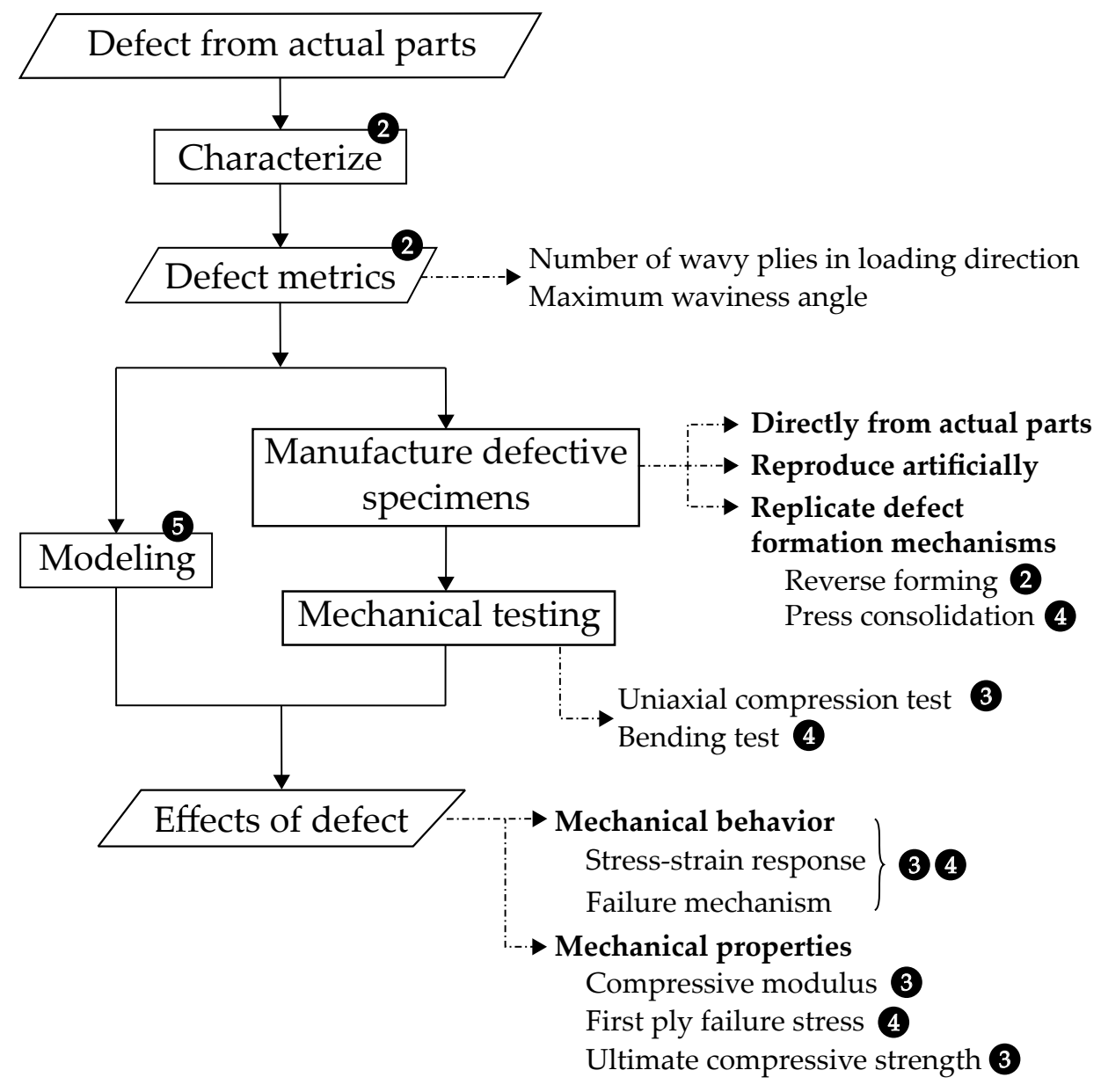

Figure 6.1 Methodology for evaluation of the effects of in-plane fiber waviness defects on laminate compressive properties. The numbers indicate the chapters that provide more detailed information on the specific subjects.

Experimental investigation for determining the effects of defects can be costly and time-consuming. Moreover, evaluation of the full strain or stress fields may be difficult from experiments. Such analysis may be required to support the description of the mechanisms leading to failure. An optional route other than the experimental approach is, therefore, proposed in Figure 6.1. In this case, the established defect 
metrics can be used as input for a model used for structural analysis. Such a modeling approach may aid in supporting the observation from experiments or used solely for virtual testing which can be verified with a limited number of experimental tests. However, to date, the latter approach is not yet a standard practice as none of the proposed failure criteria and damage models are able to capture the composite material behavior for all loading conditions.

\subsection{Waviness effects measurement methodology}

This work has developed an approach specifically to measure the effects of in-plane waviness defects on the compressive properties of laminates, by using primarily test evidence (experiments in Chapters 2-4) supported by theoretical analysis (Chapter 5). This work followed the defective specimens manufacturing approach by replicating the waviness formation mechanisms (see Figure 6.1) to obtain test coupons meant for compressive and bending testing (Chapters 2 and 4). More details on the waviness effects measurement methodology are presented in the following sections.

\subsubsection{Severity characterization}

This thesis has shown that the laminate compressive strength is affected by the presence of waviness which is induced during laminate and stamp-formed product processing. Chapters 3 and 4 highlight that the most influential parameters on the compressive strength, in the order of importance, are the number of wavy plies that are oriented in the loading direction and the maximum waviness angle. Therefore, these waviness parameters should be measured as part of the laminate quality inspection and should be used as the defect metrics in a structural analysis.

Non-destructive characterization of the maximum waviness angle can be performed on the laminate surface, as Chapters 2 and 4 have shown that the in-plane waviness defects from the press-consolidation and the stamp forming process in TPC laminates are always visible on the surface. No isolated waviness was observed in the internal plies of the studied laminates. Furthermore, the number of wavy plies can be characterized by using, for example, X-Ray computed tomography (CT), eddy current imaging method, or cross-sectional micrography analysis (although destructive) to evaluate the state of the internal plies. The recently developed eddy current imaging method was able to visualize the subsurface waviness in the internal plies, although it is only limited for conductive composite materials such as CFRP [1]. Ultrasonic C-scan inspection may not always detect the presence of small in-plane waviness defects. 


\subsubsection{Method to reproduce representative test coupons}

As stated in the guideline given in Ref. [2], it is generally advised that effects-ofdefects testing is performed on standard test specimens to obtain design allowables. Chapters 2 and 4 described two methods to reproduce standard test coupons with representative in-plane fiber waviness defects which are suited for the typical mechanical tests that are performed to generate design values. The two evaluated procedures are the reverse forming method and press consolidation with a wellchosen combination of tool material and release media. The proposed methods can be extended to reproduce waviness in other types of laminates as well, i.e. for other layups and TPC materials.

As mentioned earlier, in order of importance, the ultimate compressive strength is influenced by the number of wavy plies that are oriented in the loading direction and the maximum waviness angle. Full control of the number of wavy plies, however, is not possible with the test coupon manufacturing methods used in this work. Chapter 2 showed that with the reverse forming method of the V-shape parts, the number of wavy plies was controlled by the layup. For the press consolidation method used in Chapter 4, the waviness was isolated in the surface ply and was not transferred through the thickness when the ply underneath has a different fiber orientation. However as mentioned in Chapter 1, in some cases, the waviness can extend to several plies deep. Therefore, additional research on a manufacturing method that would induce waviness to the inner plies in a laminate with dispersed stacking sequence is still required.

\subsubsection{Mechanical testing}

This thesis mainly focused on the compressive properties of laminates as those are particularly sensitive to waviness defects. In addition, the compressive properties of composites often determine the design of the aircraft structure. Apart from the compressive properties, earlier studies on the effect of waviness on longitudinal tensile properties showed a reduction of tensile strength and modulus. Such degrading effects were found in UD composites for both in-plane and out-of-plane waviness [3-8], and in MD composites with out-of-plane waviness [9, 10]. The longitudinal tensile properties of MD composites are also expected to be prone to in-plane waviness defects, although the sensitivity is expected to be less than the longitudinal compressive strength. Similar to the effect on static compressive strength, past studies on the influence of waviness under cyclic compressive loading showed that waviness can decrease the fatigue life of MD composites [11-13]. A separate study also showed a similar reduction of fatigue life for specimens with waviness under tension-tension cyclic loading condition [14]. Additional research to quantify the influence of in-plane waviness in MD TPC on fatigue response appears to be relevant. 
As described in the guidelines for property testing of composites in the Composite Materials Handbook [15], those mechanical properties, i.e. tensile properties and fatigue resistance, are a few of the other properties that need to be characterized. In principle, the experimental methods described in Chapters 2 and 4 enable the study of the influence of waviness on these other mechanical properties, as the laminates produced were generic flat laminates from which standard specimens can be produced. In particular, studies on cyclic/fatigue loading conditions should be the focus for future work since the alternating straightening and relaxing of wavy fibers under cyclic loading conditions may cause damage in the matrix surrounding these fibers eventually causing fatigue failure [16]. The work in Chapter 4 demonstrates that waviness can cause early damage onset. Repeated loading on such specimens is expected to induce growth of existing damage.

In addition to the standard mechanical test procedure, in-situ observation by using, for example, a high-speed camera with high magnification, acoustic emission, or an accelerometer detecting a dynamic response from damage events during loading, would help for further understanding of the sequence of failure leading to the final fracture. As an example, such monitoring may aid to capture the onset of failure preceding fiber breakage during kinking failure for the purpose of validating compressive damage initiation criteria.

\subsubsection{Modeling approach}

Accurate prediction of the mechanical performance of composites with waviness defects firstly requires an adequate representation of its geometry such that their effects on the local stress perturbation are properly represented. The DIC experiments and the FEA results in Chapter 3 demonstrated that the elastic strain response of the laminates with waviness can be simulated fairly accurately through mapping of the experimentally measured fiber angles to each individual element which represents the wavy lamina. Such an approach effectively alters the local stiffness. A detailed characterization of the waviness geometry, including the waviness in the inner plies, if any, needs to be performed for such a modeling approach. This approach allows for the evaluation of the stress distribution at every location that would otherwise be difficult to obtain solely from experiments.

The compressive failure models in Chapter 5 are not yet predictive at this stage, but they can help in understanding the failure process observed from experiments. The models can also provide a qualitative assessment of failure for the first approximation of the strength of laminates with waviness. This modeling approach may pave the way for more realistic simulations of complex laminated structures used in the industry and a step forward towards virtual testing. Future research is still required to develop a predictive model which can potentially enable virtual testing. Prediction of failure of multidirectional laminates involves several challenges in determining the 
failure criteria (damage initiation) and damage evolution model. These are currently still active research topics even for laminates without defects. Another challenge is determining the correct material strength. There are differences in the strength of a lamina embedded in a multidirectional laminate and the lamina strength determined directly by UD coupon tests. The constraint from the adjacent ply in the laminate can especially affect the matrix-dominated material strength, known as the "in-situ effect" $[17,18]$. Moreover, the heterogeneity of in-plane fiber waviness defects complicates generating a representative volume element (RVE) for simplification of the model for a detailed micro-mechanical FEA.

\subsection{Effect of waviness on compressive failure}

In Chapters 3 and 4, the influence of waviness defects on compressive properties was investigated. The local waviness defects appear to have a negligible effect on the coupon stiffness, i.e. the compressive modulus determined at low strains. However, the DIC experiments and FEA described in Chapter 3 showed that stresses and strains locally at the waviness region can be much higher than the surrounding region with straight fibers. It consequently leads to a considerable detrimental effect on the laminate strength. Therefore, the following sections only discuss the waviness effects related to the compressive failure.

\subsubsection{On the damage development}

Chapter 3 studied the damage evolution of C/PEEK QI laminates with and without waviness loaded under compression. The observed damage development process is schematically illustrated in Figure 6.2. The experimental method used in this work is only limited to monitoring intralaminar failure in the ply oriented in the loading direction and delamination. Therefore, no detail in the failure occurring in the offaxis plies is depicted in Figure 6.2.

As illustrated in sequence 2a in Figure 6.2, the damage was always found to initiate in the wavy ply which was oriented in the loading direction. Post-failure analysis revealed the presence of kink bands that initiate at the waviness region. The same failure initiation mechanism was also observed from bending tests (Chapter 4), thus confirming that waviness defects act as a trigger for kinking failure and highlighting the crucial role of waviness in determining the location of the compressive failure initiation. Furthermore, it was found that the compressive failure of the laminates without waviness is also dominated by intralaminar failure of the ply oriented in the loading direction $\left(0^{\circ}\right.$ ply). Post-failure analysis again revealed characteristics of kinking failure in the $0^{\circ}$ ply. Compared with the baseline laminates, the damage was initiated earlier in the wavy ply for the laminates with waviness. 


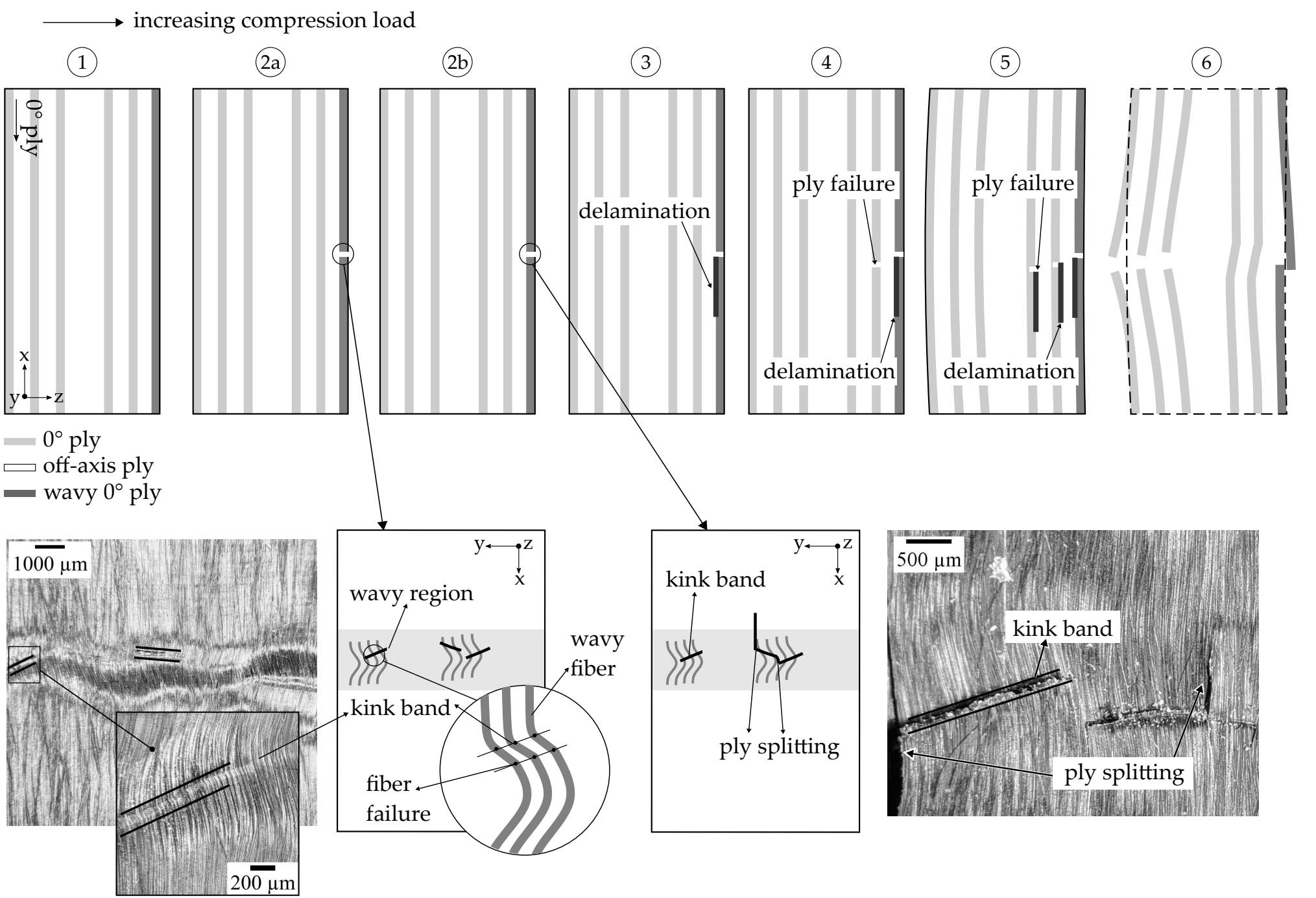

Figure 6.2 Schematic overview of the damage evolution of a specimen with waviness loaded under longitudinal compression. 
Chapter 4 showed that the maximum waviness angle affects the compressive damage development process. For waviness with smaller angles, extensive ply splitting ( $2 \mathrm{~b}$ in Figure 6.2), that can propagate into the region with straight fibers, and delamination (3) immediately followed the kinking failure (2a). For waviness with larger angles, such extensive ply splitting did not always occur in the vicinity of the kink band (2a). Soon after the failure of the wavy $0^{\circ}$ failure, local delamination occurred between this layer and the off-axis ply underneath (3). Eventually, the failure propagated to the next inner $0^{\circ}$ ply on the same side of the specimen (4). This immediately led to failure propagation through the thickness, as seen by the failure of the next inner $0^{\circ}$ ply and numerous delaminations (5) which ultimately caused the total collapse of the specimen (6).

Both the compression and bending tests described in Chapters 3 and 4 highlighted that fiber breakage due to kinking in the wavy ply occurred before delamination (see Figure 6.2). Kinking failure was found to be the governing damage initiation mechanism for all quasi-isotropic C/PEEK laminates with the maximum waviness angle up to $45^{\circ}$ (Chapter 4). Similar to these experimental observations, kinking failure is known to be one of the most dominant failure mechanisms of UD composites under longitudinal compression [19-23], which is particularly sensitive to fiber misalignment. This was found earlier for both thermoplastic [20] and thermoset-based composites [21-23]. Kinking failure in UD composites with small fiber misalignment typically propagates rapidly leading to catastrophic failure, and thus determines the ultimate strength. However, contrary to the failure of UD composites, in most cases, once kinking failure occurs at the wavy region in MD composites, it does not immediately propagate through the thickness as there are intact off-axis plies in the laminates (see Chapter 3).

Earlier studies on compressive failure of multidirectional (MD) thermoset-based composites showed that there is no single dominant failure mechanism for laminates with waviness. These studies showed that the dominant mechanism which initiates the fracture can be either kinking or delamination. The occurrence appears to be dependent on the type of material, the stacking sequence, and the waviness type (inplane or out-of-plane) and the severity [12,24-26]. As mentioned earlier, in this study kinking failure was identified as the dominant mechanism responsible for failure initiation. This may be partly due to the inherent toughness of the thermoplastic material which inhibits delamination. This is not yet confirmed for other TPC materials. An earlier study on MD TPC laminates made of carbon/polysulfone composites did not report the detailed failure sequence as the specimen failure was sudden and any visual observation of the damage sequence was not feasible to confirm our hypothesis [27]. For other TPC material such as UD C/PPS, the dominant failure initiation mechanism may not be the same, since it typically has a lower interlaminar fracture toughness than the UD C/PEEK material used in this study $[28,29]$. 


\subsubsection{On the compressive strength}

The influence of waviness defects on the compressive strength of quasi-isotropic laminates was quantified in Chapters 3 and 4 . The results showed that the compressive strength of laminates is susceptible to reduction in the presence of waviness defects. The experimental results in Chapter 4 showed that the compressive strength of a ply decreases with increasing maximum waviness angle, especially at small angles, and becomes less sensitive to changes in severity as the angle further increases. Consequently, the ultimate compressive strength of the laminates with large maximum waviness angles described in Chapter 3 also shows a similar dependency on the maximum waviness angle. Furthermore, Chapter 3 shows that the ultimate strength reduction is proportional to the increase in the fraction of wavy plies oriented in the loading direction. The largest reduction was up to $50 \%$ when half of the $0^{\circ}$ plies in the laminate were wavy. This indicates that the intact $0^{\circ}$ plies governed the ultimate strength, as was also observed in the theoretical analysis results in Chapter 5.

A similar dependency on the maximum waviness angle and the number of plies that are wavy has also been reported in the literature. There are only a few previous studies on the influence of in-plane waviness on the compressive strength, while the influence of out-of-plane waviness is well reported in the open literature. In general, the literature shows that a higher degree of waviness severity in either form for both UD and MD composites is associated with a lower compressive strength $[5,12,20,23-27,30-32]$. Few earlier studies which have investigated the influence of waviness over a quite wide range of maximum angles, up to the angle of $30^{\circ}$, indicate that the strength dependency on the maximum waviness angle is not linear $[5,12,30]$. It appears that the change of maximum waviness angle at the larger values has little influence on the compressive strength. The current work extended the observation over a greater range of waviness severity, up to the angle of $64^{\circ}$. It was experimentally demonstrated in this work that the compressive strength initially decreases with increasing maximum waviness angle and tends to level off for angles larger than $20^{\circ}$.

Earlier theoretical studies have shown that the wavy region position relative to the edge of the laminate affects the strength reduction of laminates under compression $[32,33]$. The specimen with a wavy region in the edge of the plate has a slightly lower compressive strength than that in the middle of the plate. This can be explained by the surrounding straight fibers that can provide transverse support to the wavy region and delay the onset of kinking failure when the wavy region is in the middle of the plate [33]. Similarly to that, the position of the wavy ply within the laminate stack also affects the reduction in compressive strength. The wavy ply in the outer layer is considered more critical as it is not supported with other plies [34]. This work has only studied waviness which extended through the entire width of the specimen and was found in the surface ply. Moreover, the wavy ply was oriented 
in the loading direction. As such, the effect of in-plane waviness on the compressive strength described in this thesis can be considered as the worst-case scenario for a given combination of maximum waviness angle and number of wavy plies. In practice, however, this is rarely the case. In-plane fiber waviness defects can often be found spread in the middle of a part and do not extend to the edge of the part. Moreover, the typical laminate design practice for structural parts is to use plies oriented in the least critical directions as the surface plies, i.e. generally at $+45^{\circ}$ or $45^{\circ}$ with respect to the loading direction [35]. An earlier study on compression testing of $\pm 45^{\circ}$ laminates with in-plane waviness showed similar, if not higher, compressive strength compared to the control specimens [36]. These results suggest that in-plane waviness defects in the surface plies that are in $+45^{\circ}$ or $-45^{\circ}$ from the loading direction have a less detrimental effect than that in the ply oriented in the loading direction. Nevertheless, the effects of waviness in such configurations should be quantified as well to establish a database relevant for industrial practice. This can be done by using the waviness effects measurement methodology developed in this work.

\subsection{The implication on design of aircraft structures}

Most structural aerospace applications are designed using notched data, as composites are notch sensitive [2]. Furthermore, as stated in the Composite Materials Handbook: "open-hole allowable values are commonly used as reference strengths for the effects of manufacturing anomalies and impact damage on laminate strength" [15]. The defects may act as stress concentrators comparable to the influence of holes in laminates. Therefore, if the strength retention from the sample with waviness is higher than the existing value, then the existing allowable strength can be used for design [2], although perhaps over-conservative.

As mentioned earlier, the waviness studied in this work was present in the surface ply that was oriented at the loading direction and extended throughout the entire width, and hence this study provides conservative results. The static compressive strength reduction due to in-plane fiber waviness defects established in Chapter 3 is discussed next with respect to the existing allowable values. Figure 6.3 compares the ultimate unnotched compressive (UNC) strength retention (strength of laminate with defect/baseline strength) of laminates with waviness and open-hole compressive $(\mathrm{OHC})$ strength retention. There were three different types of quasi-isotropic layups evaluated in this work. All of them have a similar range of maximum waviness angle, i.e. at the large angles, and thus, the (unnotched) ultimate strengths were similar for the laminates with the same layup. The notched compressive strengths were measured by open-hole compression tests according to the standard ASTM D6484. The OHC strength was determined from a sample with the typical QI stacking sequence at the most favorable configuration according to the typical laminate design 
practice, i.e. dispersed layup with $45^{\circ}$ layers as the surface plies. Figure 6.3 shows that the open-hole compressive strength retention is lower than the strength retention of QI1 and QI2 laminates with waviness and similar to that of the QI3 laminate with waviness, which is the lowest value obtained in the current work. This implies that in terms of the static compressive strength, if the most conservative approach is to be followed, no change to the design allowable value is needed for the material system and the whole range of waviness severity studied in this thesis. The existing allowable derived from the open-hole strength still accommodates the reduction found for the cases considered in the current work. From another point of view, Figure 6.3 also implies that further optimization towards a less conservative design is possible by still ensuring the required compressive performance with minimum weight penalty even in the presence of in-plane fiber waviness defects in the laminates. However, this would require additional work to quantify the compressive strength retention for laminates having waviness with configurations that are relevant for practical applications, in terms of the size and location as mentioned in subsection 6.3.2.

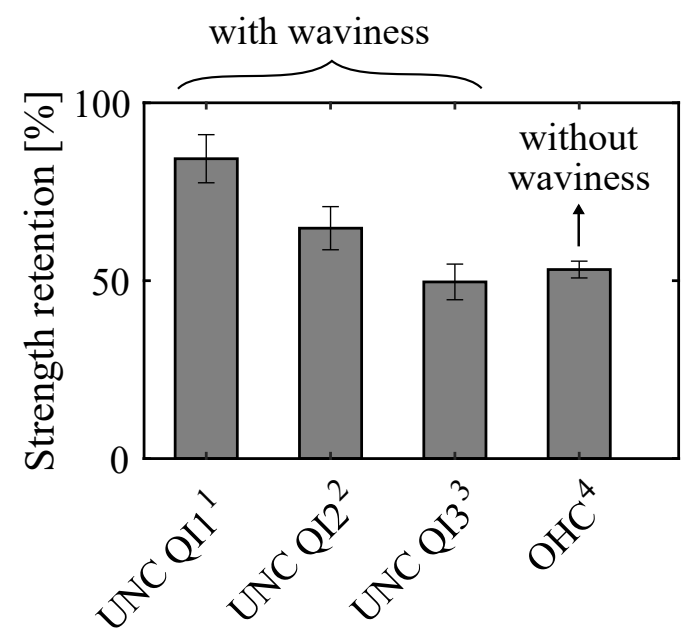

Figure 6.3 Mean compression strength retention of various unnotched laminates (UNC) with waviness and laminates with open hole (OHC) made of AS4/PEEK material. Layup 1: [0/45/90/-45] 3 , layup 2: $\left[0_{2} / 45_{2} / 90_{2} /-45_{2} / 0 / 45 / 90 /-45\right]_{S}$ (clustered), layup 3: $\left[0_{3} / 45_{3} / 90_{3} /-45_{3}\right]_{s}$ (clustered), and layup 4: $[45 / 90 /-45 / 0]_{3 s}$. Error bars show the standard deviations.

The standard laminate design practice is to maintain dispersed stacking sequence or if plies must be grouped, limit the number of adjacent plies with the same orientation [35, 37]. This work confirms that the use of laminates with dispersed stacking sequence is favored compared to those that are clustered (Figure 6.3). The sample with three clustered plies (QI3) studied in this work had the lowest ultimate compressive strength. This sample has similar strength retention as those with openhole. Once damage initiates in one of the plies within a cluster, it can easily propagate across the entire block [38]. 


\subsection{Concluding remarks}

The influence of waviness on compressive performance was studied for multidirectional TPC laminates with waviness oriented in the loading direction. The work presented in this thesis showed that the presence of in-plane waviness defects triggers early kinking failure in the wavy region and ultimately causes a reduction in compressive strength. This failure mechanism was found to be the governing damage initiation mechanism for the laminates with waviness. The most influential parameters on the compressive strength, in the order of significance, are the number of wavy plies that are oriented in the loading direction and the maximum waviness angle.

This chapter translates the results from the previous chapters in a wider perspective towards the implication on the design of aircraft structures. The strengths were quantified in the worst-case scenario for a given waviness severity and therefore this work provides conservative results. Although a considerable reduction of the ultimate compressive strength was found due to waviness, this work showed that the ultimate strength retention of the laminate with waviness is higher than, if not similar to, the open-hole strength retention. This suggests that no change to the relevant design allowable value is needed for the material system and the waviness severity studied in this thesis if the most conservative approach is to be followed. This also means that there is still room for optimization towards less conservative design even for laminates with in-plane fiber waviness defects. However, this would require further study for quantification of the effects of waviness in other configurations that are relevant for practical applications.

\section{References}

[1] K. Mizukami, Y. Mizutani, K. Kimura, A. Sato, A. Todoroki, and Y. Suzuki. Detection of in-plane fiber waviness in cross-ply CFRP laminates using layer selectable eddy current method. Composites Part A: Applied Science and Manufacturing, 82:108-118, 2016.

[2] R. Elhajjar, P.N. Grant, and C. Ashforth. Composite Structures: Effects of Defects. Wiley, 2018.

[3] C. Zhao, J. Xiao, Y. Li, Q. Chu, T. Xu, and B. Wang. An experimental study of the influence of in-plane fiber waviness on unidirectional laminates tensile properties. Applied Composite Materials, pages 1-17, 2017.

[4] J. Galos. Novel method of producing in-plane fibre waviness defects in composite test coupons. Composites Communications, 17:1-4, 2020.

[5] T. W. Riddle, J. W. Nelson, D. S. Cairns, and J. E. Workman. Effects of Defects : Part A -Development of a Protocol for Defect Risk Management \& Improved 
Reliability of Composite Structures. 53nd AIAA/ASME/ASCE/AHS/ASC Structures, Structural Dynamics and Materials Conference, 2012.

[6] L. D. Bloom, J. Wang, and K. D. Potter. Damage progression and defect sensitivity: An experimental study of representative wrinkles in tension. Composites Part B: Engineering, 45(1):449-458, 2013.

[7] C. Wu, Y. Gu, L. Luo, P. Xu, S. Wang, M. Li, and Z. Zhang. Influences of inplane and out-of-plane fiber waviness on mechanical properties of carbon fiber composite laminate. Journal of Reinforced Plastics and Composites, 37(13):877-891, 2018.

[8] M. Thor, U. Mandel, M. Nagler, F. Maier, J. Tauchner, M. G. R. Sause, and R. M. Hinterhölzl. Numerical and experimental investigation of out-of-plane fiber waviness on the mechanical properties of composite materials. International Journal of Material Forming, 14(1):19-37, 2021.

[9] S. Mukhopadhyay, M. I. Jones, and S. R. Hallett. Tensile failure of laminates containing an embedded wrinkle; numerical and experimental study. Composites Part a-Applied Science and Manufacturing, 77:219-228, 2015.

[10] R. F. El-Hajjar and D. R. Petersen. Gaussian function characterization of unnotched tension behavior in a carbon/epoxy composite containing localized fiber waviness. Composite Structures, 93(9):2400-2408, 2011.

[11] D. O. Adams and M. W. Hyert. Effects of layer waviness on the compression fatigue performance of thermoplastic composite laminates. International Journal of Fatigue, 16(6):385-391, 1994.

[12] J. F. Mandell, D. D. Samborsky, and L. Wang. Effects of fiber waviness on composites for wind turbine blades. In 48th International SAMPE symposium, volume 48, 2003.

[13] L. Wang. Effects of in-plane fiber waviness on the static and fatigue strength of fiberglass, 2001.

[14] S. Mukhopadhyay, O. J. Nixon-Pearson, and S. R. Hallett. An experimental and numerical study on fatigue damage development in laminates containing embedded wrinkle defects. International Journal of Fatigue, 107:1-12, 2018.

[15] Composite Materials Handbook (CMH-17-1G), Volume 1. Polymer Matrix Composites Guidelines for Characterization of Structural Materials. SAE International, 2012.

[16] M. R. Piggott. The effect of fibre waviness on the mechanical properties of unidirectional fibre composites: a review. Composites science and technology, 53(2):201-205, 1995.

[17] C. T. Sun. 1.20 - Strength Analysis of Unidirectional Composites and Laminates, pages 641-666. Pergamon, Oxford, 2000.

[18] P. P. Camanho, C. G. Dávila, S. T. Pinho, L. Iannucci, and P. Robinson. Prediction of in situ strengths and matrix cracking in composites under transverse tension and in-plane shear. Composites Part A: Applied Science and Manufacturing, 37(2):165-176, 2006.

[19] B. Budiansky and N. A. Fleck. Compressive failure of fibre composites. Journal 
of the Mechanics and Physics of Solids, 41(1):183-211, 1993.

[20] P. J. Joyce and T. J. Moon. Compression Strength Reduction in Composites with inPlane Fiber Waviness, pages 76-96. ASTM International, West Conshohocken, PA, 1998.

[21] S. N. Nair, A. Dasari, C. Y. Yue, and S. Narasimalu. Failure behavior of unidirectional composites under compression loading: Effect of fiber waviness. Materials (Basel, Switzerland), 10(8):909, 2017.

[22] Q. Sun, H. Guo, G. Zhou, Z. Meng, Z. Chen, H. Kang, S. Keten, and $X$. Su. Experimental and computational analysis of failure mechanisms in unidirectional carbon fiber reinforced polymer laminates under longitudinal compression loading. Composite Structures, 203:335-348, 2018.

[23] D. Wilhelmsson, R. Gutkin, F. Edgren, and L. E. Asp. An experimental study of fibre waviness and its effects on compressive properties of unidirectional NCF composites. Composites Part A: Applied Science and Manufacturing, 107:665-674, 2018.

[24] B. Khan, K. D. Potter, and M. R. Wisnom. Simulation of process induced defects in resin transfer moulded woven carbon fibre laminates and their effect on mechanical behaviour. In The 8th International Conference on Flow Processes in Composite Materials (FPCM8), 2006.

[25] S. Mukhopadhyay, M. I. Jones, and S. R. Hallett. Compressive failure of laminates containing an embedded wrinkle; experimental and numerical study. Composites Part A: Applied Science and Manufacturing, 73:132-142, 2015.

[26] A. Shipsha, S. Hallström, and M. Burman. Effect of stacking sequence and bundle waviness in quasi-isotropic NCF composites subjected to compression. Composites Part B: Engineering, 178:107423, 2019.

[27] D. O. Adams and M. W. Hyer. Effects of layer waviness on the compression strength of thermoplastic composite laminates. Journal of Reinforced Plastics and Composites, 12(4):414-429, 1993.

[28] F. Sacchetti, W. J. B. Grouve, L. L. Warnet, and I. F. Villegas. Effect of cooling rate on the interlaminar fracture toughness of unidirectional carbon/pps laminates. Engineering Fracture Mechanics, 203:126-136, 2018.

[29] Toray Advanced Composites. Cetex TC1200 PEEK - Technical Data Sheet, 2019.

[30] S. N. Nair. Effect of in-plane fiber waviness on the failure of fiber reinforced polymer composites. Ph.D. Thesis, 2018.

[31] D. O. Adams and S. J. Bell. Compression strength reductions in composite laminates due to multiple-layer waviness. Composites Science and Technology, 53(2):207-212, 1995.

[32] T. Yokozeki, H. Takemura, and T. Aoki. Numerical analysis on the flexural strength of unidirectional cfrtp composites with in-plane fiber bundle waviness. Advanced Composite Materials, 29(1):89-100, 2020.

[33] S. L. Lemanski and M. P. F. Sutcliffe. Compressive failure of finite size unidirectional composite laminates with a region of fibre waviness. Composites 
Part A: Applied Science and Manufacturing, 43(3):435-444, 2012.

[34] A. Caiazzo, M. Orlet, H. McShane, L. Strait, and C. Rachau. The Effects of Marcel Defects on Composite Structural Properties, pages 158-187. ASTM International, West Conshohocken, PA, 2001.

[35] Composite Materials Handbook (CMH-17-3G), Volume 3-Polymer Matrix Composites Materials Usage, Design, and Analysis. SAE International, 2012.

[36] J. W. Nelson, T. W. Riddle, and D. S. Cairns. Effects of defects in composite wind turbine blades - part 1: Characterization and mechanical testing. Wind Energ. Sci., 2(2):641-652, 2017.

[37] F. C. Campbell. Structural Composite Materials. ASM International, 2010.

[38] J. Lee and C. Soutis. Thickness effect on the compressive strength of T800/924C carbon fibre-epoxy laminates. Composites Part A: Applied Science and Manufacturing, 36(2):213-227, 2005. 



\section{CHAPTER 7}

\section{Conclusions and recommendations}

\subsection{Conclusions}

This thesis focused on in-plane fiber waviness defects that can be expected from manufacturing of UD tape-based thermoplastic composite products. The objectives of this work were $i$. to develop a methodology to measure the effects of waviness on the mechanical performance, with a focus on the development of specimen manufacturing techniques that allow reproduction of representative waviness defects in test coupons, as well as on the mechanical test methods; $i$. to identify the mechanisms leading to failure in order to understand the effect of waviness defects on the laminate compressive strength; and iii. to quantify the effect of waviness defects on the compressive strength of thermoplastic composite laminates. This section summarizes the major conclusions obtained from the results of this work.

\section{Waviness effects measurement methodology}

The number of wavy plies in the loading direction and the maximum waviness angle were found to be the important characteristics that influence the compressive strength of multidirectional thermoplastic composite laminates with in-plane waviness defects, with the former being the most influential parameter. Consequently, these two parameters should be used as the defect metrics for waviness.

Mechanical test coupons with representative in-plane waviness defects are required for an experimental study of the effect of waviness. Such waviness defects can be reproduced by using reverse forming and press consolidation with a well-chosen combination of tool material and release media. These two methods allow for manufacturing of test coupons with a wide range of waviness severity comparable to the defect metrics found in TPC parts.

A bending test, which could either be a four-point bending test or an end-loaded bending test, was found to be a valuable tool for characterizing compressive failure initiation in the wavy ply. This test allows for more gradual damage progression 
compared to that in a uniaxial compression test. A uniaxial compression test in combination with a bending test, and supported by finite element analysis, was found to be an informative tool to analyze the effect of waviness defects on the compressive damage development and to quantify the effect of waviness on compressive properties.

\section{Effect of waviness on compressive failure}

The influence of in-plane fiber waviness defects, with a wide range of severities, on the compressive failure of quasi-isotropic C/PEEK laminates has been investigated in this work. These defects can cause early damage, which consequently leads to a pronounced adverse effect on the compressive strength. The compressive failure initiation mechanism was dominated by fiber kinking in the wavy ply oriented in the loading direction. Damage in the form of kink bands was found to initiate earlier compared to that in the non-defective case because the waviness caused an increase in the in-plane shear stress in the material coordinate system. The in-plane shear stress was the primary stress component that triggered the failure. Furthermore, it was found that the waviness with the largest maximum angle was not always the critical defect that caused failure to initiate when multiple wavy regions with varying levels of severity were present in a specimen.

The study on the first ply failure of the wavy ply, by means of bending tests, showed that the maximum waviness angle affects the compressive damage development. For smaller angles, the first ply failure was governed by kinking failure in conjunction with ply splitting and delamination which occurred immediately after the kink band formation. For larger angles, only kinking failure was observed in the wavy ply.

The experimental data showed that the compressive ply stress at first failure initially decreased with increasing maximum waviness angle and tended to level off for angles larger than $20^{\circ}$. Consequently, the ultimate compressive strength of the laminates with large maximum waviness angles also showed a similar dependency on the maximum waviness angle. A quantitative description of the influence of the maximum waviness angle and the number of wavy plies on the compressive strength has been obtained for 24-ply QI C/PEEK laminates. For laminates with one wavy axial ply, the compressive ply stress at first failure was reduced by about $50 \%$ in the worst case, for the material system and the range of severity studied in this work. For clustered wavy plies with large maximum waviness angles, the reduction of ultimate compressive strength was linearly proportional to the fraction of wavy plies oriented in the loading direction, at least up to the fraction of 0.5 . This suggests that the ultimate strength is primarily governed by the strength of the intact ply in the loading direction, as was also found from the analytical modeling results by disregarding the contribution of the wavy plies. 
The ultimate strength retention of the laminates with waviness was found to be higher than, if not similar to, the reference open-hole compressive strength retention of QI laminate made of the same material. This was verified for the three types of QI laminates with various ply grouping considered in this work. These experimental results suggest that, for the material system and the severity studied in this thesis, the existing design value derived from open-hole strength can accommodate the reduction due to waviness. These results also suggest that there is still potential for further optimization towards a less conservative design even in the presence of waviness.

\subsection{Recommendations}

This thesis focused on the effect of in-plane fiber waviness defects on the compressive failure of quasi-isotropic thermoplastic laminates. The failure mechanism was identified and the effect of waviness on the compressive strength was quantified for a wide range of waviness severities. Although this work presents an important step forward towards understanding failure in multidirectional laminates that are particularly relevant for the industrial application of TPC parts and structures, further research is still required to extend the current understanding for other conditions. The following recommendations are formulated as future research topics.

The influence of multiple wavy plies that are not clustered was not studied in this thesis. The number of wavy plies produced by the reverse forming method used in this work was controlled by the layup. In some cases, the waviness can extend to several plies deep. Future research should, therefore, comprise a study on a coupon manufacturing method tailored to induce waviness that can extend to the inner plies in a laminate with dispersed stacking sequence.

A first step was made to study the effect of in-plane waviness in C/PEEK QI laminates under compression loading. This study should be extended further for other layups and general loading scenarios that are relevant for applications. The effect of waviness under cyclic/fatigue loading conditions is of particular interest as this work showed an early damage initiation in the wavy ply. Repeated loading may cause further growth of such existing damage that was initiated in the wavy region. Future research can be done by extending the waviness effects measurement methodology presented in this work to other relevant types of mechanical testing.

This thesis has shown that full control in creating a particular waviness severity is not always possible through experiments. For the purpose of defining defect acceptability limits, a complete database of the effect of waviness is desirable for various combinations of severities and layups. Therefore, this exercise requires a combination of experimental and virtual testing. The feasibility of using simulations to evaluate the stress and strain of laminates with arbitrary waviness was studied 
in this thesis. It was found that modeling using the local stiffness values by incorporating the local fiber orientation can provide an adequate representation of the waviness. Although this approach seems to be promising, at least to predict the deformational response of the laminates with waviness prior to the initiation of failure mechanisms, further work is required to accurately predict the first ply failure. Such a predictive tool can eventually aid in accelerating the product development process of thermoplastic composites for structural applications. 


\section{Acknowledgements}

Welcome to the most read part of this thesis. Without the support of many people, this book would have never seen the light of the day. Now, it can finally be a nice decoration for your bookshelf. Here I would like to acknowledge all those people.

First of all, I would like to express my gratitude to my promotor, Remko Akkerman. Thank you for giving me this opportunity, your guidance and constructive feedback during our progress meetings and the writing process. I really appreciate your efforts in reviewing this thesis, especially in the last few months.

I would like to thank my supervisors Laurent Warnet, Wouter Grouve, Sebastiaan Wijskamp and Sotiris Koussios. These people are the ones who have a very important role in my research. Thank you for your constant support and encouragement during all these years. Especially, the weekly progress meetings in which there were not only serious discussions but a ton of bad jokes as well. This happened more often when Sebastiaan joined the meeting. Thanks Sebastiaan for your sharp eye in assessing my work, your humor and outstanding rapping skills which you presented when we went to JEC in Paris. I would like to extend my gratitude to Erik Krämer for working alongside me in this project and for nicely introducing our PhD topics during TAB meetings. I would also like to thank all of them for being members of my reading committee. Your critical feedback has helped me to improve my writing. Looking back to the very beginning, I still remember the interview with Laurent and Wouter - the two 'OG' that have been there since the start. Thank you for giving me this opportunity and having the confidence in me to actually finish this thesis. Laurent, thank you for the out-of-the-box ideas for the experiments, and your nudge (which was necessary at times) about the A4 which was still not a one-pager for me, even until this thesis is finished. Nevertheless, the process of making that A4 was helpful for me to see the big picture. Wouter, thanks for your encouragement to keep making cool stuff. Thanks for always having a seemingly open agenda - I know it is not true, but you always make the time for discussion and to answer all my doubts.

I would like to thank Harald Heerink and all the TPRC members for making this research possible and for letting me work at the 'cool side' of TPRC. I also thank the members of the Technical Advisory Board for their input, especially at the beginning of the project, which helped me to find the direction of the research.

The next part is for the lab technicians; thank you Edwar Boer, Gert-Jan Navenzel, Bert Vos, Nick Helthuis, Ivo Vrooijink for helping with my experiments both at the 
TPRC and PT-labs. Special thanks to Edwar for helping me with the many forming experiments until we got the 'perfect' defects and for introducing the road bode lunch on Thursdays. Thank you to GeeJee for designing the mold for forming. Thanks Nick for helping in making beautiful micrographs. I would also like to thank Nico van Vliet, Sikander Naseem, Nachiket Deshmane and Ozan Erartsin for their support for the DIC measurements. Further, I would like to thank Axel Lok as well for the support in Abaqus software.

Some of the experimental studies in this work were conducted with the help of BSc and MSc students that I have supervised. I appreciate the contributions from Camilla Piazzi, Emiel van de Wetering, Kiran Krishnappa and Sylvio van Ditzhuijzen, although not all of their results ended up in this thesis.

During my PhD, I have had the opportunity to work with two groups of colleagues. I will start with my colleagues at the University of Twente. Martina Tjapkes, Debbie Zimmerman van Woesik and Belinda Bruinink, thank you for your support with all kinds of administrative business so that I could focus on my research. Thank you Debbie for your help, particularly when I first settled in Enschede, and for your tips for living in the Netherlands. I want to thank my former and current colleagues and friends from the PT group, and from our neighboring group: Waqas Ali, Arka Bhakta, Amin Zaami, Mohammad Hosseini, Sybren Jansma, Yibo Su, Ton Bor, Martin van Drongelen, Ismet Baran, Martin Luckabauer, Leon Govaert, Jamal Zanjani, Liangyong Chu, Logendra Dilli, Senem Aktas, Onur Yuksel, Imrah Yusof, Ning Han, Yash Guha, Iqbal Rasheed, Lily Shaojie Liu, Ngoc Vu, Nick Hoksbergen, Ozan Erartsin, Bharath Kumar, Sam Benou. Thank you for the discussions and the many cakes during the Monday morning meetings. Special thanks to Onur and Senem for your patience and help in Abaqus-related problems.

In the beginning of my PhD, I got assigned a desk at the UT and got to meet my first office mates. Those people, especially Lily and Ozan, have helped me to adapt quickly to the group. Special thanks to Lily for quite the welcome at that time, for introducing me to the real chinese dumplings (especially the right wonton), and for always being available to help me out in all sorts of things. Then, I finally switched spots with Iqbal Rasheed and moved office to TPRC. Iqbal, thanks for being the go-to person for any doubts, answering my many small questions about the research and many other random topics that always ended up being a long discussion.

This part goes to my colleagues at the TPRC. I will start with my office mates in the $\mathrm{PhD}$ room, and the Compete scientist over the years. Thank you Francisco Sacchetti, Thijs Kok, Tjitse Slange, Guillaume Vincent, Jeroen Houwers, Thijs Donderwinkel, Erik Krämer, Coen Hartjes, Jagadeesh Swamy, Vanessa Marinosci, Marten van der Werff, Sebastiaan van den Berg, Rick Schrijver, Andres Garcia, Thibault Hernandez, Emiel van de Wetering, Lars Niens, Yannick Buser, Linda Grafen, Rens Pierik, Tom Asijee, Dennis Brands, Liran Kratz. The non-sense talk at the 'cool side' coffee corner was a good stress-reliever. The Moka pot was a nice addition and became a good 
excuse to extend our lunch break and continue our 'serious' discussion. It was even more fun particularly on Fridays, as they were completed by the bombastic party music from the old technician office. I am definitely missing that vibe ever since the technician office moved downstairs. Thank you Selma Kalee for sharing your fun music and always bringing a happy mood with your particular laughter. I also really appreciate your outstanding procurement skills in getting all of my fast order requests for strain gages and all sorts of glues. Next, I would like to thank Guillaume for his Matlab magic. Thanks to Ricky Rick for his CLT made easy tool, the abdcomposites.com. Also special thanks to Thijs-tje 'Thundershop' for helping me in setting up the Abaqus model and translating the Dutch summary. Thanks to Wouter as well for finalizing the Dutch summary. I also owe thanks to Sebastiaan 'from the mountain' for his input on the model and Jeroen for his help with the milling machine. Another one is dedicated to Coen 'small heart', thanks for helping with any struggle I had with Instron. I am also thankful for my other colleagues: Ulrich Sachs, Simon Veenstra, Reinier Jansen, Thomas de Bruijn, Mark Bouwman, Matthijs van der Velden, Simone Schapink, Esther van der Veen, Renata Heerink, Iris de Klerk, Nick van der Vall, Evi Nijhof, Sanne Bruggink, Freya Nordmann, Magnus Gurian, Allard Braakhuis, Martin Hartman, Mayke Klumper, Barry Holt, Elianne Hopman, Hilda Hoekstra, and extending to our office neighbor (some years ago) from Aniform: René ten Thije, Sebastiaan Haanappel, Stephan Christian, Peter Sloetjes. It has been a pleasure working with you all.

This part is special for my two paranymphs Jagadeesh 'the very long secret $\mathrm{K}^{\prime}$ Narayana Swamy and Vanessa Marinosci. You two have given me moral support, not only for the defense but also through the ups and downs all these years. Thank you for our 'scientific' discussions and the many many dinners we have shared together after work, for enduring my constant complaints about food, and teaching me how to correctly hold a pizza. To Jaga, the meme whisperer, thank you for your wisdom and enlightenment that you often showcased through very thoughtful memes, and for the free astronomy lessons. To Vane, thank you for the unlimited access (although without consent) to your backpack full of chocolates, bird food, and tarallini stock that kept me going during the writing period, and for hanging out with me outside of the office, especially in the sports center (perhaps too much until we got labeled as work wives), and even inviting to Puglia. You should definitely consider being the ambassador to promote tourism to Puglia, among the other career alternatives that I have suggested.

Thank you to my Indonesian friends in Enschede: Linda, Dwi, Suyanti, Farah and extended to all DBL household members. Thank you for helping me to settle in Enschede when I first moved here, and when I again moved to 'the future'. We had great fun traveling together and during the game nights. I am especially thankful for all of our Indonesian-themed lunches and dinners, terutama gorengannya, that made it feel a bit like home. I owe thanks to the bootycamp buddies Henrieke Meijer and 
Sanne van der Poel-Slot for helping me to balance out that food intake. Thank you for inviting me to exercise together during the lockdown, both outdoor and virtually. Those exercises helped me to avoid becoming a couch potato during that time.

I want to thank my friends in Indonesia, especially to Aurora, si anak murah, for dragging me to Iceland and risking traveling from Jakarta at the very beginning of the pandemic. Our very risky trip ended up giving me the cover page inspiration. Somehow the combo with you (thinking of our trip to Cambodia as well) often results into a trip that is full of drama and definitely becomes one of those stories to tell when you become a grandma. Finally, I would like to thank my family for their support, especially to my sisters Naomi and Stacia, and to my brother Nuel. Special thanks to my brother for making the illustration for the cover page. At last, I will end this with thank you in my language: terima kasih!

Ramona Sitohang

December 2021 


\section{Publications}

1. Sitohang, R.D.R., Grouve, W.J.B., Warnet, L.L., Koussios, S., Akkerman, R., An experimental approach to reproduce in-plane fiber waviness in thermoplastic composites test coupons using a reverse forming method. Journal of Composite Materials, July 2021. https://doi.org/10.1177/00219983211026734. (Chapter 2 of this thesis).

2. Sitohang, R.D.R., Grouve, W.J.B., Warnet, L.L., Akkerman, R., Effect of inplane fiber waviness defects on the compressive properties of quasi-isotropic thermoplastic composites, Composite Structures 272 114166, 2021. (Chapter 3 of this thesis).

3. Sitohang, R.D.R., Grouve, W.J.B., Warnet, L.L., Wijskamp, S., Akkerman, R., The relation between in-plane fiber waviness severity and first ply failure in thermoplastic composite laminates, submitted to Composite Structures, 2021. (Chapter 4 of this thesis). 